\title{
MARITIME ORGANIC MODERATED AND COOLED REACTOR
}

UNIVERSITY OF Documents Collection.

SEP 171959

May 27, 1959

North American Aviation, Inc. Atomics International Division Canoga Park, California

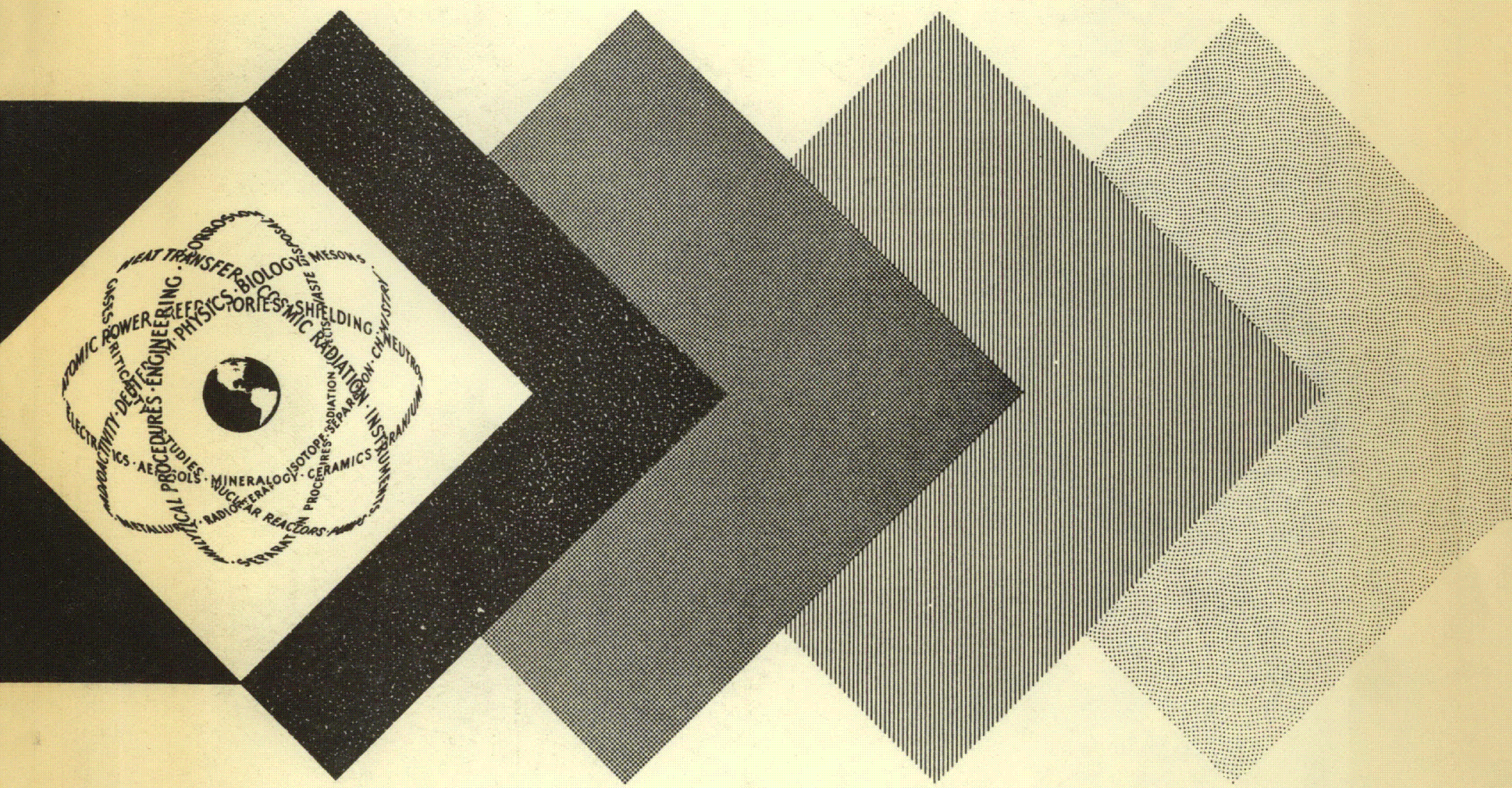

UNITED STATES ATOMIC ENERGY COMMISSION

Technical Information Service 


\section{LEGAL NOTICE}

This report was prepared as an account of Goverament sponsored work. Nelther the United States, nor the Commission, nor any person acting on behalf of the Commission:

A. Makes any warranty or representation, expressed or implied, with respect to the accuracy, completeness, or usefulness of the information contained in this report, or that the use of any information, apparatus, method, or process disclosed in this report may not infringe privately owned rights; or

B. Assumes any liabilities with respect to the use of, or for damages resulting from the use of any information, apparatus, method, or process disclosed in this report.

As used in the above, "person acting on behalf of the Commission" includes any employee or contractor of the Commission, or employee of such contractor, to the extent that such employee or contractor of the Commission, or employee of such contractor prepares, disseminates, or provides access to, any information pursuant to his employment or contract with the Commission, or his employment with such contractor.

This report has been reproduced directly from the best available copy.

Printed in USA. Price $\$ 3.50$. Avallable from the Office of Technical Services, Department of Commerce, Washington 25, D. C.

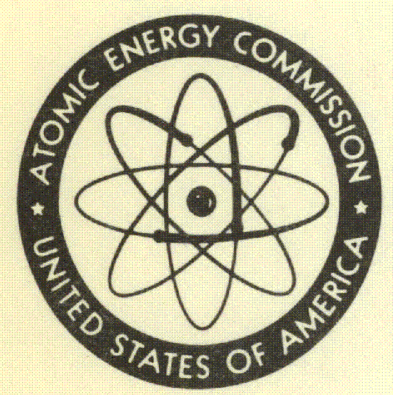


MARITIME ORGANIC MODERATED

AND COOLED REACTOR

NAA-SR-3859

\section{ATOMICS INTERNATIONAL}

A DIVISION OF NORTH AMERICAN AVIATION, INC.

P.O. BOX 309 CANOGA PARK, CALIFORNIA

CONTRACT: AT(11-1)-GEN-8

ISSUED: MAY 27, 1959 



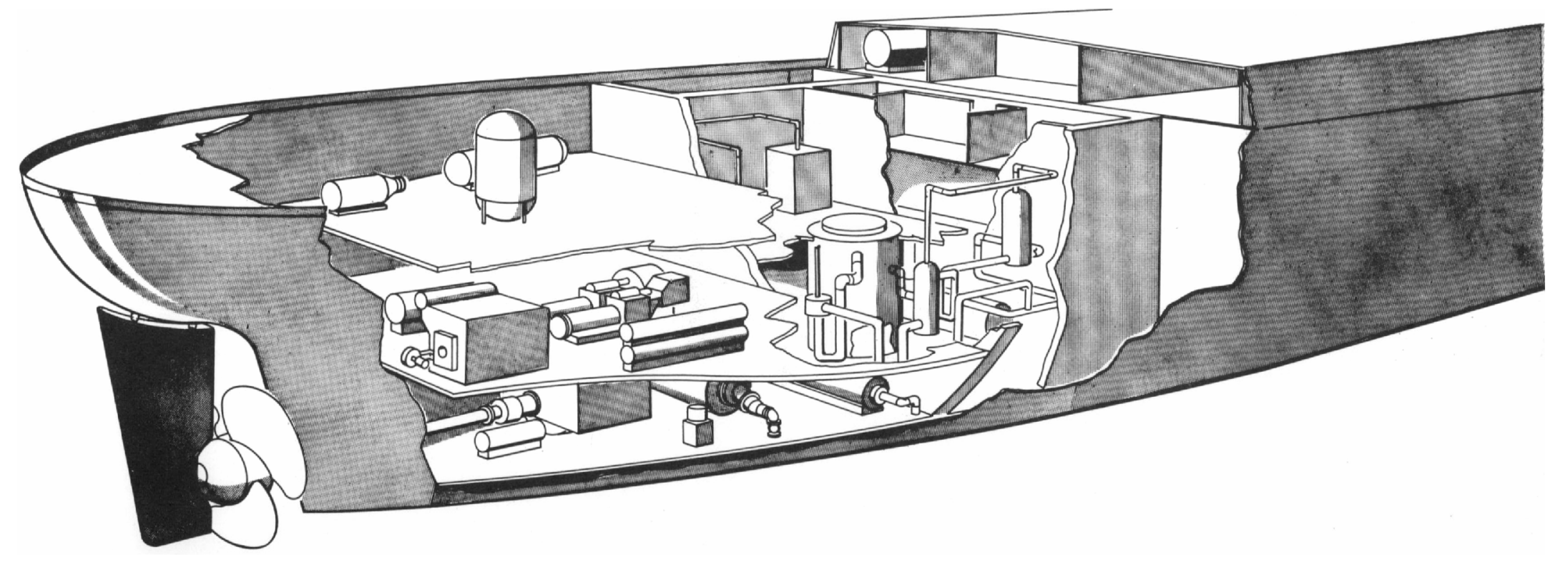





\section{CONTENTS}

Page No.

Introduction

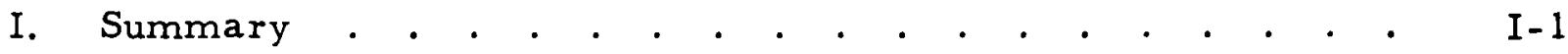

A. Conclusions . . . . . . . . . . . . . . . . I-1

B. Ship Design Specifications . . . . . . . . . . . I I

C. Plant Description . . . . . . . . . . . . . . . I-7

D. Dock Side Facilities . . . . . . . . . . . . . I-14

II. Reactor Selection . . . . . . . . . . . . . . . . . . . II-1

A. Coolant.$\cdot$. . . . . . . . . . . . . . . II-1

B. Fuel . . . . . . . . . . . . . . . . . . II-13

C. Cladding . . . . . . . . . . . . . . . . . II-15

D. Structural Material . . . . . . . . . . . . II-20

III. Reactor and Primary Loop . • . . . . . . . . . . III-1

A. Reactor Vessel . . . . . . . . . . . . . III-1

B. Fuel Elements . . . . . . . . . . . . . . III-6

C. Control Rods and Drives . . . . . . . . . . . III-7

D. Heat Transfer Loop . . . . . . . . . . . . . III-10

IV. Reactor Auxiliary Systems . . . . . . . . . . . . IV -1

A. Purification System . . . . . . . . . . . . IV -1

B. Degasification and Pressurization . . . . . . . . IV -2

C. Decay Heat Removal System . . . . . . . . . . IV -4

D. Coolant Drain, Vent and Fills . . . . . . . . . IV -6

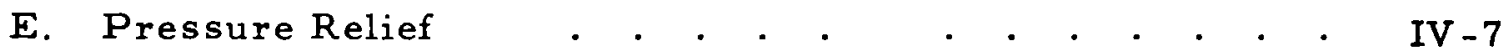

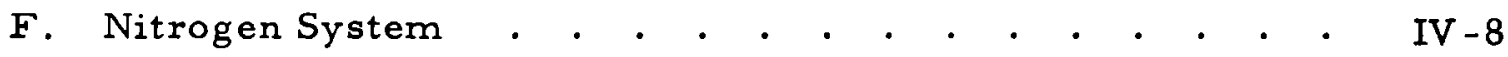

G. New Coolant Storage and Handling . . . . . . . . IV -8

H. Preheating System . . . . . . . . . . . . . IV -8

I. Biological Shield Cooling System . . . . . . . . IV -9

J. Waste Gas Handling . . . . . . . . . . . . . IV -9

K. Liquid Organic Waste Handling . . . . . . . . . IV-10

L. Aqueous Waste Disposal . . . . . . . . . . . IV-11

M. Solid Waste Disposal . . . . . . . . . . . . . IV-11

N. Decontamination Facilities . . . . . . . . . . IV -11 


\section{CONTENTS (Continued)}

Page No.

V. Turbine Plant

$\begin{array}{lll}\text { A. General Description of Power Plant . . . . . . } & & \text { V }-1 \\ \text { B. Description of Main Turbines and Reduction Gears . } & \cdot & \text { V }-2 \\ \text { C. Description of Auxiliary Turbine Generators . . . . } & \text { V-6 }\end{array}$

VI. Reactor Design . . . . . . . . . . . . . . . VI-1

A. Core Physics . . . . . . . . . . . . .

B. Core Heat Transfer and Fluid Flow . . . . . . VI-19

C. Shielding . . . . . . . . . . . . . . . VI-25

VII. Plant Operation . . . . . . . . . . . . . . . VII-1

A. Instruments and Controls . . . . . . . . . VII-1

B. Reactor Operation . . . . . . . . . . . . VII-25

C. Steady State and Transient Operation . . . . . . VII-30

D. Auxiliary Power . . . . . . . . . . . . . VII-31

E. Refueling . . . . . . . . . . . . . . . VII -36

F. Operating Personnel . . . . . . . . . . VII-38

VIII. Safety and Containment . . . . . . . . . . . VIII-1

A. Introduction and Summary . . . . . . . . . . VIII-1

B. Radiation Monitoring . . . . . . . . . . . VIII-1

C. Shielding . . . . . . . . . . . . . . . . VIII-2

D. Containment . . . . . . . . . . . . . VIII-2

E. Nuclear Incidents . . . . . . . . . . . . . VHI-3

F. Incidents Resulting from Failures in the Primary Systems and Auxiliary Systems . . . . . . . . VIII-7

G. Collisions, Groundings and Sinkings . . . . . . VIII-11

H. Radiological Hazards . . . . . . . . . . . VIII-14

IX. Research and Development . . . . . . . . . . IX-1

A. Introduction . . . . . . . . . . . . . . . IX-1

B. OMCR Development Projects . . . . . . . . . IX-1

C. Estimate of Funding Requirements for OMCR 


\section{CONTENTS (Continued)}

Page No.

$\mathrm{X}$. Economics . . . . . . . . . . . . . . . . . $\mathrm{X}-1$

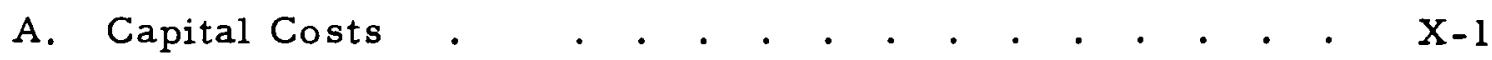

B. Fuel Costs . . . . . . . . . . . . . . . $\mathrm{X}-2$

C. Operating Costs . . . . . . . . . . . . . . . $\mathrm{X}-5$

XI. Equipment Lists and Weights . . . . . . . . . . . XI-1

A. Reactor System . . . . . . . . . . . . . . $\mathrm{XI}-1$

B. Turbine System . . . . . . . . . . . . . . XI-9

C. Barge Refueling Equipment . . . . . . . . . . XI-15

D. Summary Table of Weights . . . . . . . . XI-16

XII. Engineering Drawings . . . . . . . . . . . . . XII-1 


\section{TABLES}

Page No.

I. Flammability and Explosibility Properties of Polyphenyls . . II-12

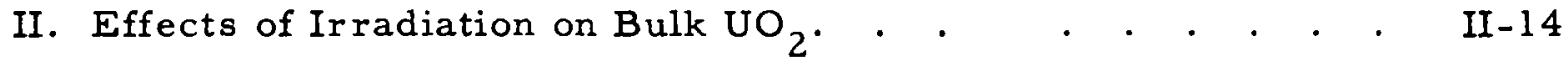

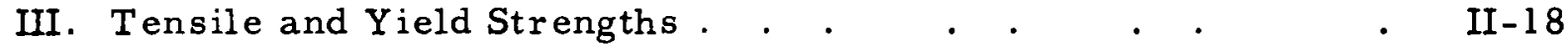

IV. Irradiation Stability of M257.

V. Design Features of Reactor Vessel and Structure. . . . III-2

VI. Microscopic Thermal Cross Sections. . . . . . . . VI-2

VII. Reactor Constants • . • . . . . . . . . . . . VI-6

VIII. Cross Sectional Areas and Volume Fractions . . . . . VI-7

IX. Two-Group Constants . . . . . . . . . . . . . . VI-8

X. Neutron Economy (Percent Efficient Neutrons) . . . V VI-9

XI. Thermal and Flow Data for Core . . . . . . . . . . VI-22

XII. Hot Channel Factors Used for Organic Moderated and

Cooled Core with Subcooled Boiling . . . . . . . . . VI-25

XIII. Dose Rates 1 Foot Away from the Primary Coolant

Equipment in the Reactor Compartment . . . . . . . VI-28

XIV. Summary of the Radiation Levels in the Reactor

Compartment. . . . . . . . . . . . . . . . VI-30

XV. Shielding Requirements for Hot Storage and Waste Area . VI-31

XVI. Electrical Load Analysis. . . . . . . . . . . . VII-35

XVII. Ships Complement . . . . . . . . . . . . . . . VII-38

XVIII. Organization Chart for an OMCR Shipboard Propulsion

System Engine Department . . . . . . . . . . . VII-4I

XIX. Schedule and Funding - OMCR R\&D . • • . . . . . . IX-5

XX. Capital Cost Summary. . . . . . . . . . . . . . . X-2

XXI. Steady State Fuel Cycle Costs . . . . . . . . . . . . X-5

XXII. Cargo Capacity Comparison OMCR and Conventional Tanker (Long Tons) . . . . . . . . . . . . . . . . . .

XXIII. Capital Cost Summary OMCR Tanker. $\quad$. . . . $\quad$ X-7

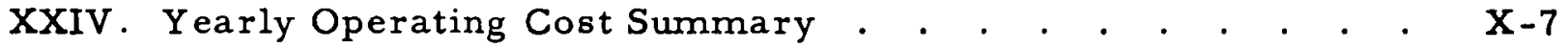




\section{FIGURES}

Page No.

1. Pyrolysis of Santowax $R$ versus Temperature . II-3

2. Radiolytic Decomposition Rate of Santowax R . . . II 4

3. Estimated Vapor Pressure of Irradiated Santowax R. . . . II-5

4. Thermal Conductivity of Unirradiated Santowax R . . . . . II-6

5. Specific Heat of Unirradiated and Irradiated Santowax R . . II-7

6. Viscosity of Irradiated Santowax R . . . . II-8

7. Density of Irradiated Santowax R . . . . . . . . . . II-9

8. Solubility of Nitrogen in Unirradiated Santowax R. . . . . . II-10

9. Finned APM Tube . . . . . . . . . . . . II-2l

10. APM End Cap Weld. . . . . . . . II-22

11. Fuel Element. . . . . . . . . . . . . . . III-8

12. Circulating Pump . . . . . . . . . . . . . . . . III-12

13. Main Circulating Pump Performance Characteristics . . III-13

14. Steam Generator and Superheater. . . III-15

15. Decay Heat Generation . . . . . . . . . . . . IV -5

16. Thermal Flux Distribution Around a Single Fuel Rod . . . . VI-10

17. Power Distribution in a Fuel Element . . . . . . . . . VI-11

18. Power Distribution in a Fuel Element Adjacent to a Control

Rod . . . . . . . . . . . . . . VI 12

19. Radial Flux Distribution in Initial Clean Core . . . VI-13

20. Heavy Isotope Buildup During Burnup. . . . . VI-16

21. Reactivity Lifetime of Initial Core. . . . . . . . . . . VI-17

22. Temperature Distribution for Hottest Fuel Pin with Hot

Channel Factors. . . . . . . . . . . . . . VI-23

23. Temperature Distribution for Hottest Fuel Pin without Hot

Channel Factors. . . . . . . . . . VI-24

24. Part Load Temperatures. . . . . . . . VI-26

25. Reactor Plant Control System . . . . . . VII-4

26. Nuclear Instrumentation . . . . . . . . VII-8

27. Core Power Mapping System . . . . . . . . VII-12 


\section{FIGURES (Continued)}

Page No.

28. Fuel Element Failure Detection and Location System

. . VII-16

29. Reactor Plant Protective System . VII -22

30. Radiation Monitoring System . . . . . . . . . V VII -23

31. Steam and Organic Coolant Flow Program . . VII-31

32. Steam and Organic Temperature Program . . . . . . . . VII-32

33. Plant Response to Load Increase . . . . VII-33 


\section{INTRODUCTION}

This document describes the results of a six-week conceptual design study of an organic moderated and cooled reactor (OMCR) power plant adapted to a Class T-7 tanker. It has been prepared for the Maritime Reactors Branch of the Atomic Energy Commission by Atomics International, a division of North American Aviation, Inc.

The conceptual design study encompassed the ship's power plant including the reactor, primary loops, reactor auxiliary equipment, turbine system, and standby power equipment. The purpose of the study was to develop preliminary design data in sufficient detail to estimate:

1. Ship's reactor machinery space and weight requirements

2. Plant operating characteristics

3. Preliminary hazards review

4. Preliminary capital costs

5. Preliminary operating costs

The study was directed at achieving an advanced organic moderated and cooled reactor conceptual design which would yield the lowest ship operating costs based upon currently available reactor technology and upon a construction schedule of 48 months. The most recent design information which has been developed on similar organic moderated reactor projects, together with information contained in a previous maritime OMCR design, has been utilized in the study and incorporated into the conceptual design. The 48 month construction schedule permits a reactor development program which could extend over a two-year period prior to the actual construction of the reactor equipment. The report also includes an outline of the recommended development program and its estimated cost.

The De Laval Steam Turbine Company was retained by Atomics International to prepare preliminary design information and quotations on the steam turbine plant and auxiliary power equipment. The six-week design schedule dictated the use of standard steam plant equipment throughout the ship. Other work at Atomics International indicates that somewhat higher steam pressures would result in a more economical plant. 



\section{SUMMARY}

\section{A. CONCLUSIONS}

The results of this design study indicate that a 60,000 DWT tanker, propelled by a 30,000 SHP Organic Moderated and Cooled Reactor (OMCR), can be built and operated at a cost which is only slightly higher than a conventional tanker.

The capital cost of an OMCR power plant, including the main turbine, reduction gear, turbine-generators and heat transfer equipment is approximately $\$ 14,182,800$. This cost includes engineering design, startup and pre-operational testing, equipment F.O.B. Philadelphia, Pa., installation, and escalation consistent with a four year construction schedule. The cost of the first core loading, including spares, is approximately $\$ 905,600$. This amount is not capitalized as part of the construction cost.

It is estimated that the total capital cost of the first OMCR tanker is approximately $\$ 28,502,400$. Also the cost of operating this tanker, hauling oil from Kuwait to Philadelphia and returning under ballast, is approximately $\$ 11.30$ per long ton of cargo. This operating cost is estimated to be approximately $18.4 \%$ greater than a conventional tanker for the same service which consumes fuel oil worth $\$ 2.70$ per barrel.

The reactor design is predicated on a four year construction schedule with preliminary engineering starting July 1, 1959. This construction schedule was set by the Atomic Energy Commission to permit a two year research and development program prior to the construction of the ship. The actual construction schedule for the OMCR design could probably be shortened.

Several research and development (R\&D) programs are required specifically for the OMCR plant in addition to the Advanced Organic Moderated Reactor program now being conducted under sponsorship of the AEC. No R\&D costs have been included in the capital cost of the plant. The additional funding required is approximately $\$ 1,645,000$ for fiscal year 1960 and $\$ 950,000$ for fiscal year 1961 . This funding will cover development work for the OMCR tanker design and includes (a) fuel element development and evaluations, (b) fuel element heat transfer and 
hydraulic studies, (c) fission product removal, (d) development of absolute seals, (e) power mapping system, (f) fuel element failure detection system, (g) control rod development, and (h) organic fire control and containment evaluation.

In addition to these specific development programs, a full scale critical experiment is recommended in order to develop necessary physics data so that the reactor plant can go into full operation as soon after core loading as possible. The critical experiment is estimated to cost $\$ 1,070,000$; of this $\$ 275,000$ is for pelletizing uranium oxide which can serve as fuel for the first core loading, and is therefore recoverable. The net cost in addition to existing programs for all research and development chargeable to the OMCR tanker project is therefore $\$ 3,390,000$.

The reactor is fueled with uranium dioxide enriched to $3.7 \%$. The core is a right circular cylinder approximately 5 feet in diameter and 5 feet high. There are 100 fuel pins in each of 88 fuel elements in the core. Each fuel pin is clad with extended surface tubing fabricated from an aluminum alloy. Santowax $R$ is used for the reactor coolant and heat is removed from the reactor by forced convection cooling and nucleate boiling (subcooled boiling).

The steam generated by the OMCR power plant is at a pressure and temperature fairly close to the steam conditions normally used in maritime practice. Therefore, off-the-shelf steam propulsion equipment was incorporated in the plant design. The reactor system is designed to produce steam at a rate of $300,000 \mathrm{lb} / \mathrm{hr}$ at $450 \mathrm{psig}$ and $650^{\circ} \mathrm{F}$. The propulsion system heat balance at nominal power $(27,250 \mathrm{SHP})$ is illustrated in Plate I.

Reactor process systems provide continuous control over the high boiler content (HBC) and the contained gases in the primary coolant. These processing operations also remove soluble and insoluble radioactive material from the primary coolant. It is considered that OMCR reactors, with low inherent levels of induced activity in the coolant, are in an excellent position to benefit from further experience and increased confidence in high integrity fuel element design and fully proven fabrication and quality control techniques. If fission products can thereby be confined to the fuel elements, coolant purification 
and waste disposal costs should be reduced, loop accessibility greatly facilitated, and plant design criteria significantly eased with a resultant saving in operating cost, as well as cost of future units, without any loss in plant availability.

The design and evaluation presented in this report is for the first OMCR tanker. It illustrates the inherent safety, confidence and future potential of this type of nuclear power plant for maritime application. Many cost savings can be anticipated for future OMCR tankers based upon the experience gained from the construction of the first OMCR system. For example, it is estimated that the second OMCR tanker should be approximately $\$ 5,000,000$ cheaper than the first. Much of this cost reduction is due to the significant reduction in engineering charges for the second ship. Also, the cost of fuel element fabrication should reduce $40 \%$. This reduction should reduce fuel costs from about $3.57 \mathrm{mill} / \mathrm{sHP}$ hr to 3.07 mills/SHP-hr. The reduced fuel cost, combined with the lower capital cost, should reduce the cost of hauling cargo in the second OMCR tanker to $\$ 10.00$ per ton. This operating cost is equivalent to the operating cost of a conventional tanker consuming fuel oil worth about $\$ 3.20$ per barrel. Therefore, the OMCR tanker has an excellent probability of becoming competitive with conventional tankers in the near future. 


\section{B. DESIGN SPECIFICATIONS}

The conceptual design of the 30,000 SHP organic moderated reactor propulsion system has been prepared for application in a Class T-7 tanker. Since this ship was designed specifically for a nuclear application, the space set aside for the reactor and propulsion machinery was held essentially constant and the organic moderated reactor propulsion system was located within these spaces. No attempt was made to review the location of the reactor compartment in areas other than those originally set aside for this purpose. Also, no attempt was made to evaluate the center of gravity, weight distribution, or the stability of the ship. The equipment was arranged within the reactor compartment and machinery spaces to satisfy the functional requirements of the components, minimize shielding weights, minimize capital costs and provide sufficient accessibility for maintenance operations. The arrangement of the ship is illustrated in Plate II.

The T-7 tanker has been designed to carry oil from Kuwait to Philadelphia via the Cape of Good Hope and return to Kuwait under ballast through the Suez Canal. The round trip covers 21,350 miles. The principal design features of the nuclear ship are as follows:

1. Length between perpendiculars

2. Beam

3. Draft

4. Displacements

5. Dead weight

6. Lightship

7. Maximum power

8. Normal power

9. Propeller shaft speed at 30,000 SHP

10. Propeller shaft speed at 27,250 SHP
$770 \mathrm{ft}$

$104 \mathrm{ft}$

$43 \mathrm{ft}$

77,100 tons

60,840 tons

16,260 tons

30, 000 SHP

27, 250 SHP

$113 \mathrm{rpm}$

$109 \mathrm{rpm}$ 
11. Condenser cooling water temperature

12. Design ship speed at $27,250 \mathrm{SHP}$

13. Design ship speed at 30,000 SHP $75^{\circ} \mathrm{F}$

17.7 knots

18.2 knots

The annual operating schedule for the T-7 tanker is:

1. Operating days per year

2. Sea days per trip

50

3. Port days per trip

4. Canal days per trip

1

5. Total days per trip

6. Round trips per year

6.48

Of this time, approximately $1-1 / 2$ days is required to load the ship in Kuwait and 18 hours is required to discharge the cargo in Philadelphia. This operating schedule represents about an 80 to $85 \%$ plant utilization factor. The ship should be in drydock for about 4 to 5 days per year. This time is designated for normal ship maintenance and not for refueling.

The organic moderated reactor propulsion system has been designed to meet the following operating conditions:

1. Permanent list $15^{\circ}$

2. Temporary roll $45^{\circ}$

3. Pitch $10^{\circ}$

4. Transverse shock loading $1.1 \mathrm{G}$

5. Perpendicular shock loading

2. $0 \mathrm{G}$

6. Longitudinal shock loading

$0.2 \mathrm{G}$

A single organic moderated reactor has been employed as the source of power to furnish steam to drive the propeller, furnish the ship's electrical loads and heating loads. The reactor has been designed to follow the load demand in accordance with normal ship's practice. The reactor can follow a load swing from 
20 to $80 \%$ of nominal power in 10 seconds due to the inherent characteristics of the organic moderated reactor. Also, the load on the reactor system can be dropped from full load to $20 \%$ of full load instantaneously and not adversely affect the ship's machinery or reactor system.

The main turbine is divided into a high and low pressure section. Each section is capable of driving the propeller shaft independently of the other section. In the event of reactor failure while the ship is at sea, take-home power has been provided by installing a boiler which can supply steam to the main turbine at a sufficient rate to provide 3000 SHP and drives the ship at about 8.5 knots. The steam from the auxiliary boiler can be used to drive either section of the main turbine.

Adequate shielding has been provided to limit the annual dose received by the crew to $5 \mathrm{R}$. Also, the shielding has been designed so that the ship's structure and the cargo do not become radioactive by neutron capture. During normal operating conditions, no radioactivity is released to the sea water. Radioactivity is vented to the atmosphere when the ship is at sea. However, when the ship is at dockside, all radioactive gases from the process systems are held up.

The organic moderated reactor vessel, heat exchangers, and auxiliary reactor equipment are located within a reactor compartment. This reactor compartment is surrounded by a cofferdam to separate the cargo from the reactor machinery. The inner walls of this cofferdam are used to comprise a containment structure surrounding the reactor system. In the event of a ship collision, this containment structure is protected by a barricade constructed of large structural steel stringers between the ship's hull and the cofferdam. It has been assumed that the integrity of this containment structure is not violated in the event of a ship collision, though the equipment inside the containment structure may be dearranged during any collision condition due to the shifting of the equipment's foundations.

During emergency conditions all vital electrical loads are carried by a topside mounted diesel generator unit. Necessary heating loads are accommodated by the auxiliary boiler when the reactor is shut down. 
The vessel is sub-divided by watertight and oil-tight transverse and longitudinal bulkheads to form cargo tanks for the purpose of carrying petroleum products. All the ship's superstructure, including the crew's quarters, are located amidships above the cargo tanks. The machinery spaces are located aft and the reactor compartment is located at the forward end of the machinery space. The equipment within the reactor compartment is heavily shielded and the whole structure is supported by a system of floors and girders on the double bottom underneath. A cofferdam space is arranged around the sides and ends of the reactor compartment. The cofferdam space between the reactor compartment and the machinery space is intended to store oil for the auxiliary take-home boiler. The other cofferdam spaces are ordinarily maintained empty when the ship is loaded with cargo but they can be filled with sea water to provide shielding in the unloaded condition if it is needed. Cargo tanks are provided outboard of the reactor compartment. During the loaded condition, the cargo in these spaces acts as shielding material. The main cargo pump room is located forward of the reactor compartment and is separated from the reactor compartment by cargo tanks.

\section{PLANT DESCRIPTION}

\section{Reactor Compartment}

The arrangement of the equipment within the reactor compartment is illustrated in Plate III. The compartment is divided by a transverse bulkhead separating the compartment into two almost equally large sections. The aft section encloses the reactor and primary loops while the forward section encloses the reactor auxiliary and process equipment.

The reactor vessel is centrally located within the reactor room and on the centerline of the ship. The reactor vessel is surrounded by a primary biological shield consisting of iron, lead and borated water to attenuate and capture neutrons escaping from the reactor core. The shield also reduces the gamma radiation emitted from the core to a level corresponding to the radiation emitted from the core to a level corresponding to the radiation emitted from other primary loop components external to the core. 
The reactor is fueled with uranium oxide enriched to $3.7 \% \mathrm{U}-235$. The fuel is contained within extended surface tubes fabricated from an aluminum power metal. There are 88 fuel elements in the core and each element consists of 100 fuel pins. Twenty-one cruciform control rods are employed to control the reactor. These control rods are actuated by control rod drive mechanisms located in a sub-pile room beneath the reactor. The upper reactor vessel head is designed specifically for refueling.

Two heat transfer loops are employed to remove heat from the reactor. Each loop consists of a circulating pump, superheater and a steam generator. These loops are located symmetrically about the centerline of the ship and are of opposite hand. Hot organic fluid circulates from the reactor core to a superheater where some of its heat is given up to superheating steam which has been generated in the steam generator. The organic material then circulates to the steam generator where the bulk of its heat is transferred to boiling water. Finally, the cool organic liquid from the steam generator circulates back to the reactor core. The steam conditions at the superheater outlet are $450 \mathrm{psig}$ and $650^{\circ} \mathrm{F}$. Constant steam pressure is maintained at varying reactor loads by bypassing some of the hot organic steam around the superheater and steam generator. Each loop can be isolated from the reactor by isolation valves.

A surge tank is located within the reactor compartment and is connected to the primary system. A liquid level is maintained within the surge tank and the atmosphere above the organic coolant is provided by nitrogen gas. The surge tank acts as a cushion to damper minor pressure surges in the heat transfer loop.

The steam generators are located above the reactor core. This arrangement provides natural circulation of the coolant to remove decay heat from the reactor core in the event of complete power failure. The steam generator in each loop is located forward and outboard of the reactor core. They are so arranged to provide decay heat removal by natural circulation in either loop at a 15 degree permanent list. A third smaller loop for decay heat removal is also located in the reactor compartment. The decay heat removal loop is provided with a circulating pump to remove heat to a small steam boiler. The steam generated in this boiler circulates by natural convection to an air condenser located on the 
main deck. The condensate drips back into the decay heat boiler. This boiler is also located above the core to provide natural circulation of the organic coolant. The boiler is located on the ship's centerline and aft of the reactor vessel. The incorporation of a decay heat removal system permits reactor plant operation with one primary heat transfer loop shut down. During this operating condition, it provides a means to remove decay heat from the reactor core if the second heat transfer loop fails.

The reactor core is suitably instrumented with neutron monitoring equipment to record the flux level and power level of the core during reactor operating conditions. A core power mapping system is provided to record flux levels at various points within the reactor core. Boron thermopiles are strategically located to give the reactor operator an indication of relative flux distributions. This information will assist him in locating the optimum control rod positions. This information can also be recorded and used to determine integrated fuel burnup at various positions in the core during its lifetime.

A failed fuel element detection and location system is provided in the reactor structure. Provisions have been made to remove samples of coolant from the discharge of each fuel element. If the gross activity level in the primary circulating system exceeds a predetermined level, the failed fuel element detection and location system can be employed to locate the specific element or elements causing the high radiation levels. The refueling operation is scheduled to take place at the ship's home port and in conjunction with dockside facilities and a refueling barge.

The reactor drain tank is located at the bottom of the reactor room. It is designed to contain the contents of both of the heat transfer loops. In the event of excessively high pressure in the heat transfer loops, pressure relief valves are provided to protect the equipment. These valves release the over-pressure to the drain tank.

Suitable cooling and ventilation is provided within the reactor compartment to maintain normal room temperatures and an environment free of radioactivity. For design purposes, the activity level in the primary coolant was established at $10 \mu \mathrm{c} / \mathrm{cc}$ although the expected activity level is $1.8 \mu \mathrm{c} / \mathrm{cc}$. The 
activity level within the reactor room during normal operating conditions limits accessibility to short periods of time. The shielding provided around the reactor compartment is designed to reduce the activity level to tolerance values in areas accessible by the ship's crew.

A shielding deck is located just below the main deck and above the reactor and heat transfer equipment. The space provided above this deck is designed for full accessibility by the ship's crew. The main organic coolant circulating pump motor-drives are located on this deck. Also, remotely operated hand valves and equipment are operated from this elevation. Facilities for remote viewing of the reactor room are provided. The refueling operation is conducted after a shield plug is removed from this deck.

The forward portion of the reactor compartment is divided into two elevations. The high boiler compound (HBC) storage tank, waste gas storage equipment, HBC pumps, and the relief condenser are located on the lower elevation. Radioactive materials which are removed from the primary circulating system are stored in this area. The process rooms located on the elevation above the hot storage area include the organic purification system, the degasification equipment, and the aqueous waste handling equipment.

Purification of the organic coolant is accomplished by vacuum distillation. The higher boiling compounds are concentrated in the distillation unit and are collected in the HBC storage tank. The distillate is returned to the reactor system. A filter and a centrifuge are provided in the degasifier circuit for the removal of particulate matter. Stored HBC can be burned at sea if the activity level is sufficiently low.

Organic coolant from the primary system is circulated to the degasification system to remove contained water vapor, nitrogen and any other gaseous materials. The degasifier strips the gaseous materials from the coolant at a reduced pressure. The degassed organic coolant is circulated back to the primary system and any radioactive gases are held up for a suitable decay period before venting to the atmosphere.

A decontamination room, hot storage room, and auxiliary process equipment are also located on this elevation. 
The entire reactor compartment is enclosed within a vapor tight containment structure. The sides of this structure comprise the walls of the cofferdam surrounding the reactor compartment. The double bottom constitutes the floor, and the upper shielding deck forms the top of the compartment. Access is obtained to the reactor compartment through airlocks. The reactor compartment is designed to contain an internal pressure of about $15 \mathrm{psig}$ which corresponds to the maximum pressure which is anticipated during a complete failure of the reactor system and the steam generators. Water, which is normally used for primary and secondary shielding, is utilized during the maximum credible accident situation to condense steam and limit pressure buildup in the reactor compartment.

\section{Turbine Compartment}

The turbine compartment is located in the stern of the ship and it is separated from the reactor compartment by a cofferdam. All the conventional propulsion machinery and the auxiliary power equipment is located in this area. The turbine equipment arrangement is illustrated in Plate IV.

The turbine compartment is arranged in three elevations. The main condenser, auxiliary condensers, reduction gear, main feed pumps, air ejectors and selected small components are located on double bottom which constitutes the lowest elevation.

The equipment on the deck above the double bottom includes: high and low pressure turbine, turbo-generators, auxiliary steam generator, fresh water storage and selected small components. The switchgear, evaporator, direct contact heater, storage batteries, heating and ventilating equipment and smaller items are located on the deck immediately below the main deck.

Conventional equipment and design philosophy have been used in the selection and placement of the main propulsion and auxiliary power equipment. Boiler oil is stored in the cofferdam separating the reactor and turbine compartments.

\section{Service Facilities}

The area immediately below the main deck and forward of the reactor room is set aside for the reactor control room, health physics storage room, 
locker and change room and air conditioning equipment. The deck plan of the area is illustrated in Plate $\mathrm{V}$.

Airlocks to the reactor compartment are located conveniently near the control room to furnish easy access to the control areas and provide positive control of all personnel entering or leaving potentially hazardous areas. The areas above the reactor compartment are designed for full accessibility by ship's personnel under normal operating conditions.

The fire protection system is designed in accordance with the requirements of the National Board of Fire Underwriters, and the applicable portion of the AEC Manual, Volume 6000. A diesel engine driven fire pump is provided in the system as a standby to maintain system pressure under peak fire flow conditions. Pressure is maintained in the fire lines at all times by a jockey pump and accumulator tank supplied frum the water storage tank. Fire hydrants and hose houses are provided for fire protection for the outside plant area.

Automatic, dry pipe, pre-action sprinkler systems with fog type heads are provided for the areas within the reactor compartment. A separate pressurized carbon dioxide fire extinguishing system is provided for the control room, cable spreading room, coolant storage and melt station, lube oil storage room, and the main generator. Hand-operated $\mathrm{CO}_{2}$ extinguishers are also provided.

A central fire detection and coded alarm system of the positive succession, non-interfering type is provided for all process areas. The reactor control room is air-conditioned. The reactor and steam plant machinery spaces are ventilated in a conventional manner. The ventilation equipment is designed to protect operating and maintenance personnel from airborne radioactive contaminants and excessive temperature conditions. Air circulating within the reactor room and the reactor auxiliary areas moves in a general direction from areas of lesser to areas of greater contamination potential with final exhaust and dispersion to the atmosphere through the ventilation stack. Activity released from the ventilating stack is below the levels established for radiological safety during normal operating conditions. All air exhausted to the atmosphere is filtered to remove particulate matter. 
Heating and ventilating ductwork having contamination potential is fabricated of welded and flanged steel sheets or schedule 10 steel pipe with a corrosion protection coating. Heating and ventilating ductwork without contamination potential is fabricated of aluminum sheets. Ventilation ducts to areas subject to radiation level increase due to minor spills or a rise in pressure above a set point are supplied with two quick-closing, tight-sealing valves in series at the point where they enter and leave the enclosure. In the event of an increase in level or pressure, these valves are automatically closed and maintained tight.

The reactor room is supplied with filtered ventilation air by a supply fan and ductwork. Ventilation air quantities are such that the cooling requirements for this area are provided by the ventilation air. Ventilation air is exhausted from the reactor and primary loop area by a fan and ductwork through filters to the ventilation stack. Negative pressure within the room is controlled by regulating the flow of air into and out of the room. Supply and exhaust fans for the reactor and primary loop area are provided with $100 \%$ capacity standby. Ventilation air quantities for the reactor and primary loop area are based on a minimum of two room volume air changes per hour. During periods of occupancy, both the main and the standby supply and exhaust fans can be operated to provide a minimum of six room volume air changes per hour for the room and to maintain room temperature at a maximum of about $105^{\circ} \mathrm{F}$.

Filtered ventilation air for the operating floor, access galleries and other process equipment rooms is provided by a supply fan and ductwork terminating in the area above the operating floor. Ventilation air is drawn from the operating floor and access galleries through openings into the process equipment rooms by a central exhaust fan and ductwork system connected to each room and exhausted through filters to the ventilation stack. Negative pressures within the spaces are maintained by regulating the flow of air into and out of the rooms. Ventilation air quantities for the equipment rooms are such that the cooling requirements are provided by the ventilation air. Fan and coil type cooling and heating units are located on the operating floor and in the access galleries to provide for cooling and heating of these areas. Ventilation air quantities for the equipment rooms are based on a minimum of two room volume air changes per hour. During periods of occupancy of any one equipment room, a minimum of ten room volume air 
changes are provided for increased ventilation and cooling by closing the normal exhaust from the operating floor and exhausting this air through the equipment room. This increased quantity of ventilation air maintains room temperatures at a maximum of about $105^{\circ} \mathrm{F}$. The supply and exhaust fans are provided with $100 \%$ capacity standby.

The heating and ventilating, maintenance, chemistry lab, and locker rooms are also supplied with filtered ventilation air by a central fan and ductwork system. Ventilation air is exhausted through filters to the ventilation stack. The nitrogen storage, new coolant storage and turbine area rooms are provided with heating and ventilating units within the rooms to maintain design room temperatures. Water chilling units and pumps are provided to supply the cooling coils in the reactor room with chilled water. The heating coils are provided with steam from the auxiliary boilers.

The control room is air conditioned by remote equipment located adjacent to the control room. System controls maintain design temperatures within close tolerances. The air conditioning unit consists of fan, filters, direct expansion cooling coil and steam heating coil, all mounted in a unit cabinet. For cooling, a freon compressor with water cooled condenser is provided.

\section{DOCK-SIDE AND BARGE FACILITIES}

The fuel handling and waste disposal operations have been predicated upon the use of a refueling barge. It has been assumed that this barge will be built for another nuclear application and it will be made available to service the OMCR tanker. The aqueous waste handling facilities, ventilation facilities and spent fuel storage provided on the barge are assumed adequate for the OMCR. Also, the barge can be used in conjunction with a 60 to 70 ton dockside crane. The major additional facilities which are peculiar to the OMR system and must be provided are as follows:

1. Provisions for fuel washing must be provided. Before the fuel element is drawn into the fuel transfer cask, coolant is drawn into the cask to provide adequate cooling during the transfer operation. The cask is provided with solvent connection nozzles to facilitate cleaning the 
element within the transfer cask. After sufficient solvent has been circulated, the fuel element is discharged to the spent fuel storage pool. This procedure requires a solvent circulating system, including a solvent tank, pump and lines, located on the barge. Solvent, which has contaminated the spent fuel storage pit water, can be separated from the water with a centrifuge. This requires a system for circulating water from the pool, including a pump, centrifuge and lines. Also, facilities for reprocessing the solvent are required, including a storage tank, pump, and distillation unit.

2. New coolant receipts will be provided in bulk molten form wherever possible. Therefore, the barge should be equipped with a heated and insulated storage tank, suitably sized to fill the tanker's new coolant storage tank (18,000 gallons) and equipped with a transfer pump, loading and unloading lines, and venting facilities.

3. Any high boiler compound ( $\mathrm{HBC}$ ) collected during the tanker round trip may have considerable activity. Therefore, the barge should be equipped with a 15,000 gallon tank to permit the safe transfer of HBC from the tanker to the barge. The barge must also have a transfer pump, to enable pumping the HBC from the barge mounted tank to shore tankage for proper decay and subsequent disposal. Ultimate disposal of decayed HBC can be accomplished by burning in a small incinerator, and the heat of combustion utilized to produce steam for other shore requirements. 



\section{REACTOR SELECTION}

\section{A. COOLANT-MODERATOR}

Atomics International has operated the Organic Moderated Reactor Experiment (OMRE) for the Atomic Energy Commission since 1957. The OMRE, located at the

National Reactor Test Station, Idaho, has logged over 22 million tkw hours of operation and has demonstrated the technical feasibility of utilizing an organic material as the moderator and coolant for a nuclear reactor. The use of organic material as the moderator and coolant for power reactor application has the following attractive features:

1. Low pressures in the primary system for temperatures in the range of $600-800^{\circ} \mathrm{F}$.

2. Compact core.

3. Good neutron economy.

4. No hazardous chemical reactions with coolant, uranium fuel, or water.

5. Negligible corrosion rates.

6. Standard materials and components for construction (aluminum alloys for fuel cladding and low carbon steel for structural components).

7. Low induced activity in coolant.

8. Fluid moderator - coolant gives large negative temperature coefficient of reactivity.

9. Relatively high inherent safety.

Special design features which are characteristic of reactor concepts employing organic material as coolant and moderator are:

1. A purification system and makeup supply is provided because organic coolant slowly decomposes at operating temperatures and under nuclear irradiation. 
2. A high surface-to-volume fuel element design (compared to water and liquid metal concepts).

3. Preheating for the primary system (most organics of interest are solid at room temperature).

The coolant selected for this reactor is a mixture of terphenyls $\left(\mathrm{C}_{18} \mathrm{H}_{14}\right)$ commercially available as Santowax-R. This coolant was chosen primarily because of its low vapor pressure at operating temperatures and the attendant increase in safety. Santowax-R is composed of approximately $10 \%$ ortho-terphenyl, $60 \%$ meta-terphenyl, and $30 \%$ para-terphenyl. This material is available as a by-product of diphenyl manufacture and is marketed at a competitive price, on the order of $17 \notin$ per pound in spite of its limited production and market. In addition to low cost considerations, the physical properties of Santowax-R make it attractive as a coolant. The hydrogen density is suitable for moderating requirements, it has a relatively low vapor pressure over the operating temperature range, it has good thermal conductivity, relatively high flash and fire points, and it undergoes only moderate radiolytic decomposition and negligible pyrolytic decomposition. Figures 1 through 8 illustrate the physical properties of Santowax-R.

The toxicology of diphenyl $\left(\mathrm{C}_{12} \mathrm{H}_{10}\right)$, which is chemically similar to Santowax-R, has been studied extensively by the Mine Safety Appliance Company. This work indicates that diphenyl is no more toxic than Dowtherm-A, which is used extensively as a heat transfer medium, and is probably less toxic on the basis of ingestion, contact, and inhalation. Diphenyl is pharmacalogically inert.

Inhalation of large amounts of vapor is difficult because of the low vapor pressure of Santowax-R. The maximum safe concentration of diphenyl in air for prolonged exposure is 50 ppm for rabbits, $1-6$ ppm for rats, 1 ppm for mice. * As a basis for design, the maximum safe concentration for prolonged human exposure has been set at $1 \mathrm{ppm}$, an easily detectable concentration by odor.

Tests by the Bureau of Mines on Santowax-R indicate that dust clouds containing 0.035 ounces per cubic foot can be ignited by a hot surface, an open flame, and a high voltage electrical discharge. It should be noted that the ignition temperature

*"Diphenyl and W-3 Ammino and Nitro derivatives", Industrial Toxicology 


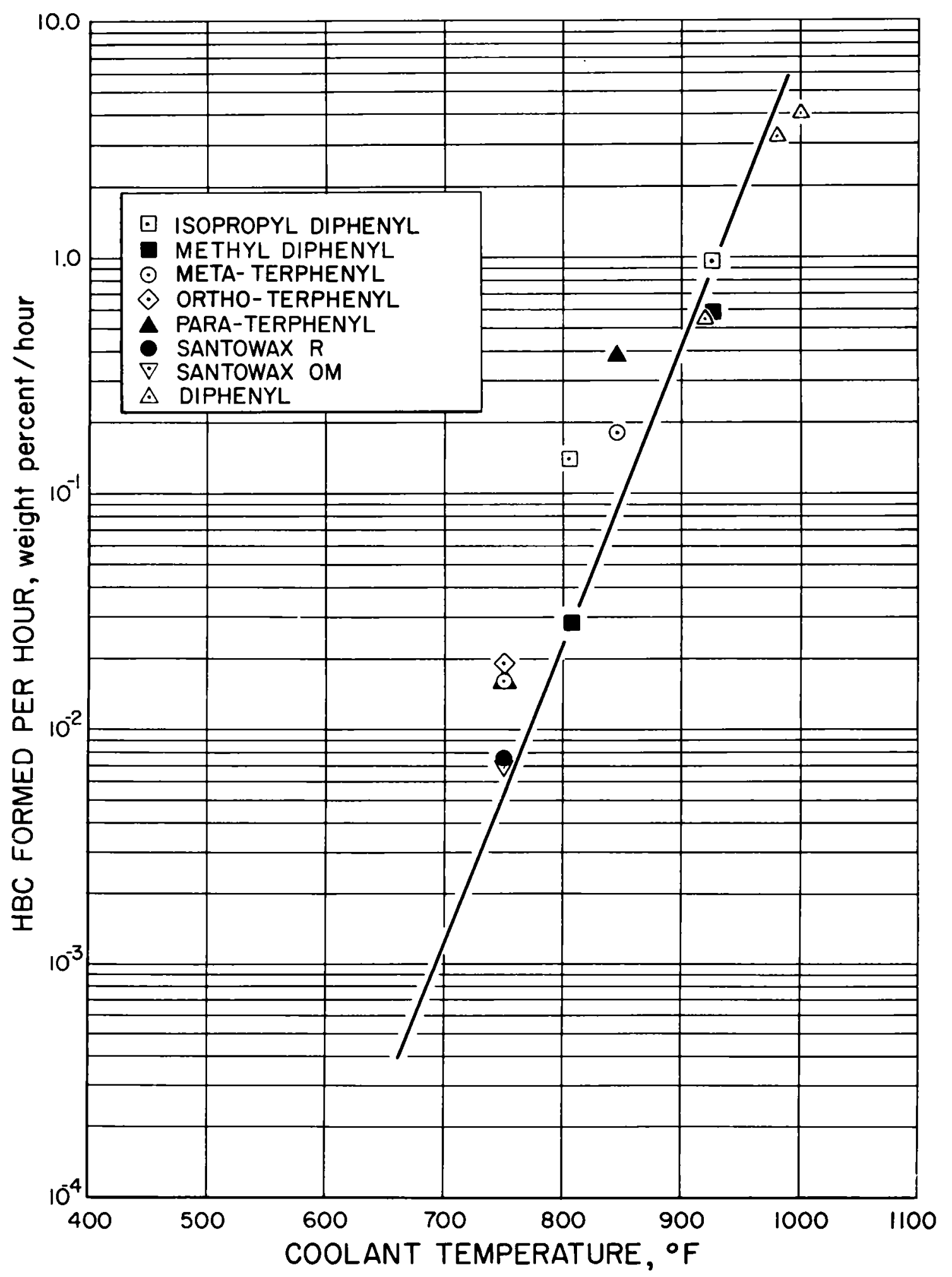

Figure 1. Pyrolysis of Santowax R versus Temperature 


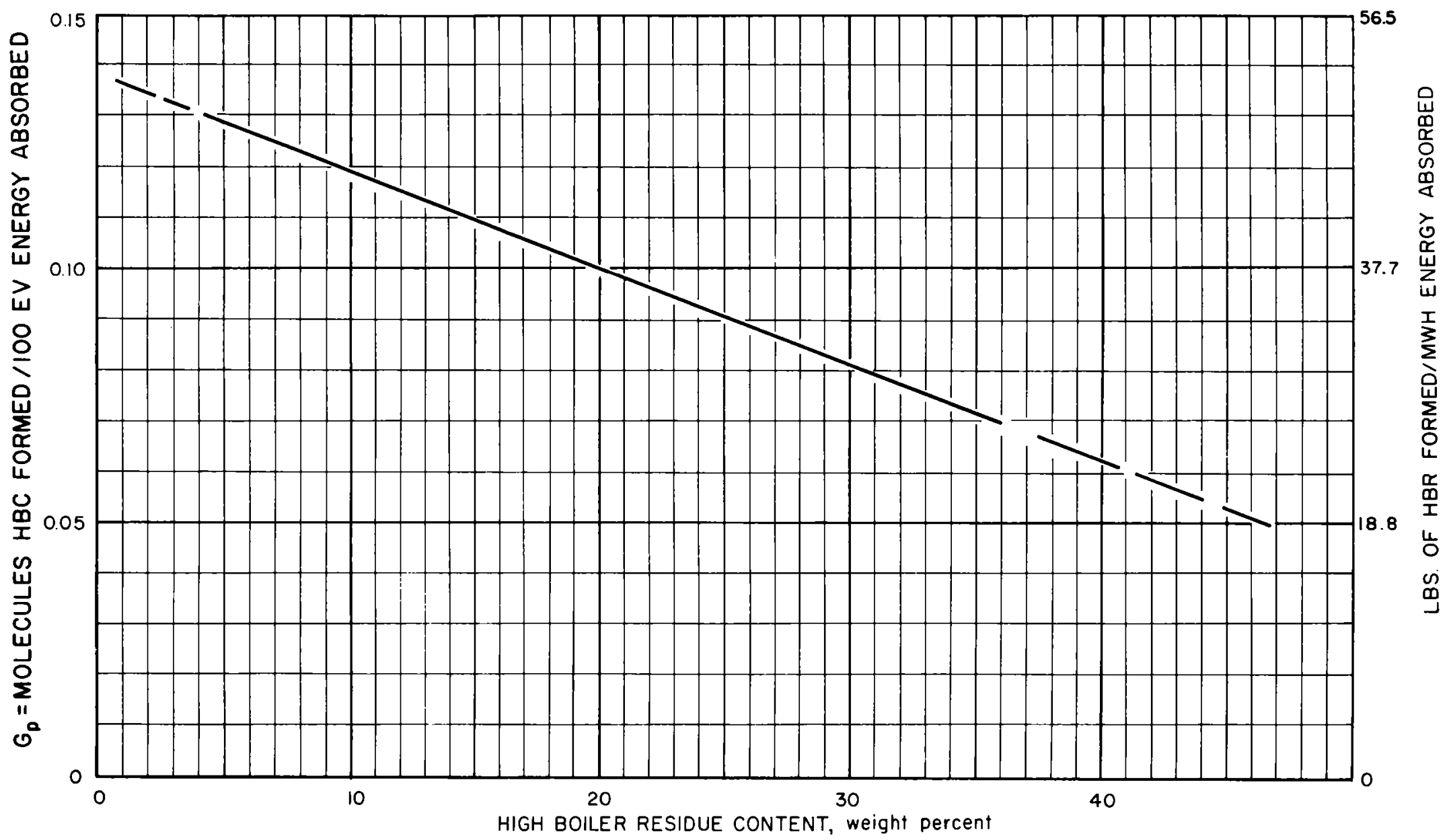

Figure 2. Radiolytic Decomposition Rate of Santowax R 


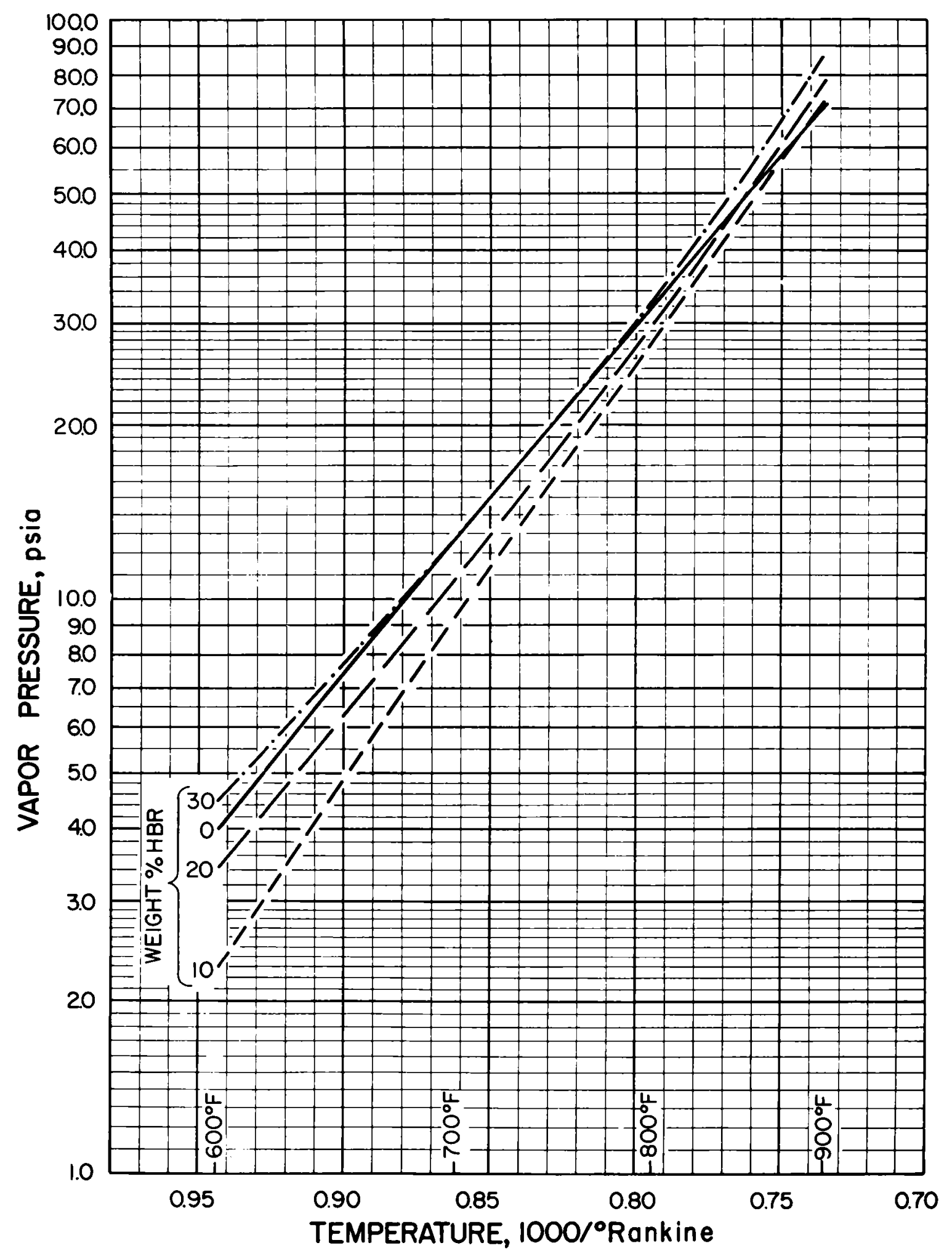

Figure 3. Estimated Vapor Pressure of Irradiated Santowax R 
早

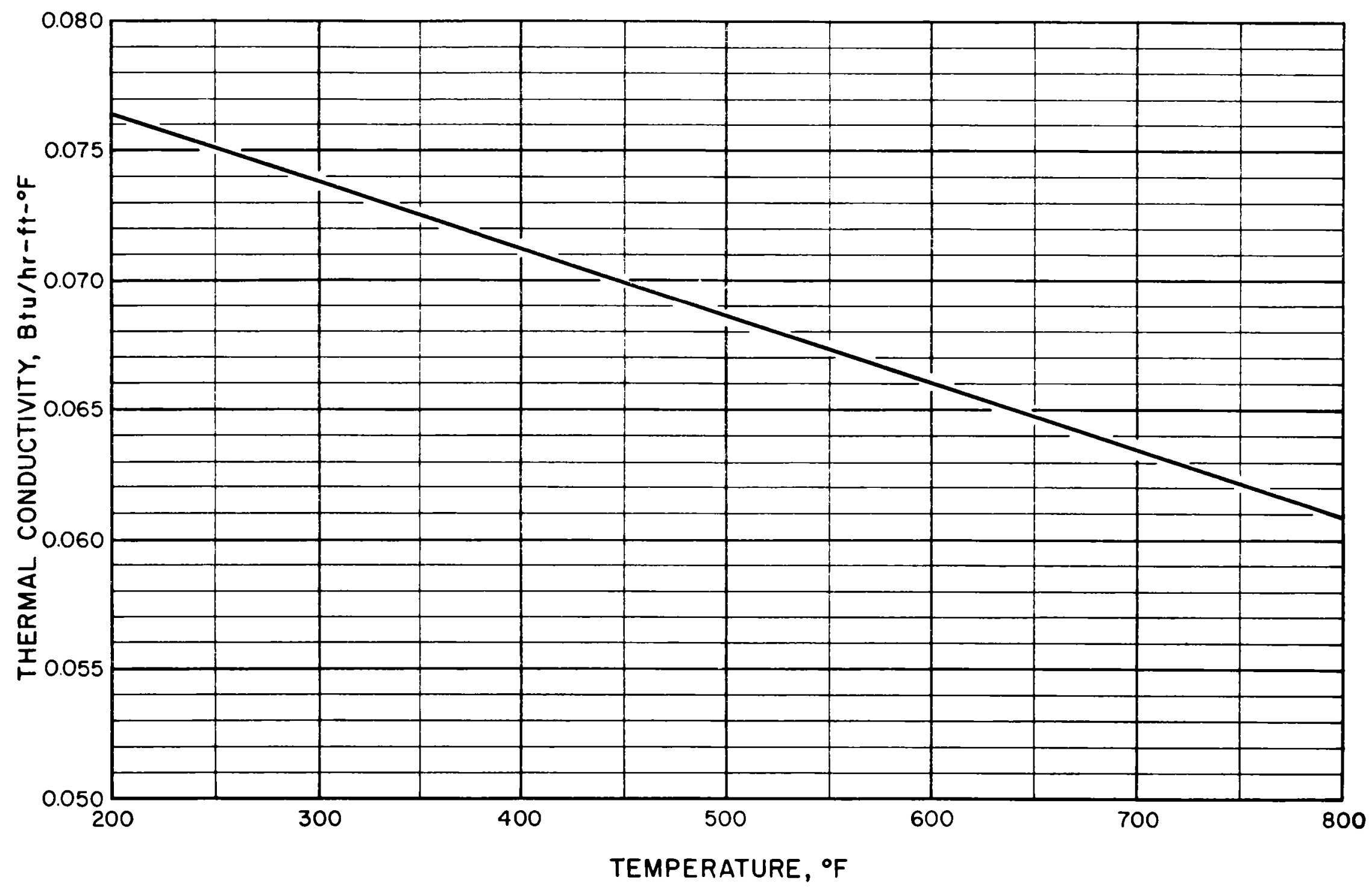

Figure 4. Thermal Conductivity of Unirradiated Santowax R 


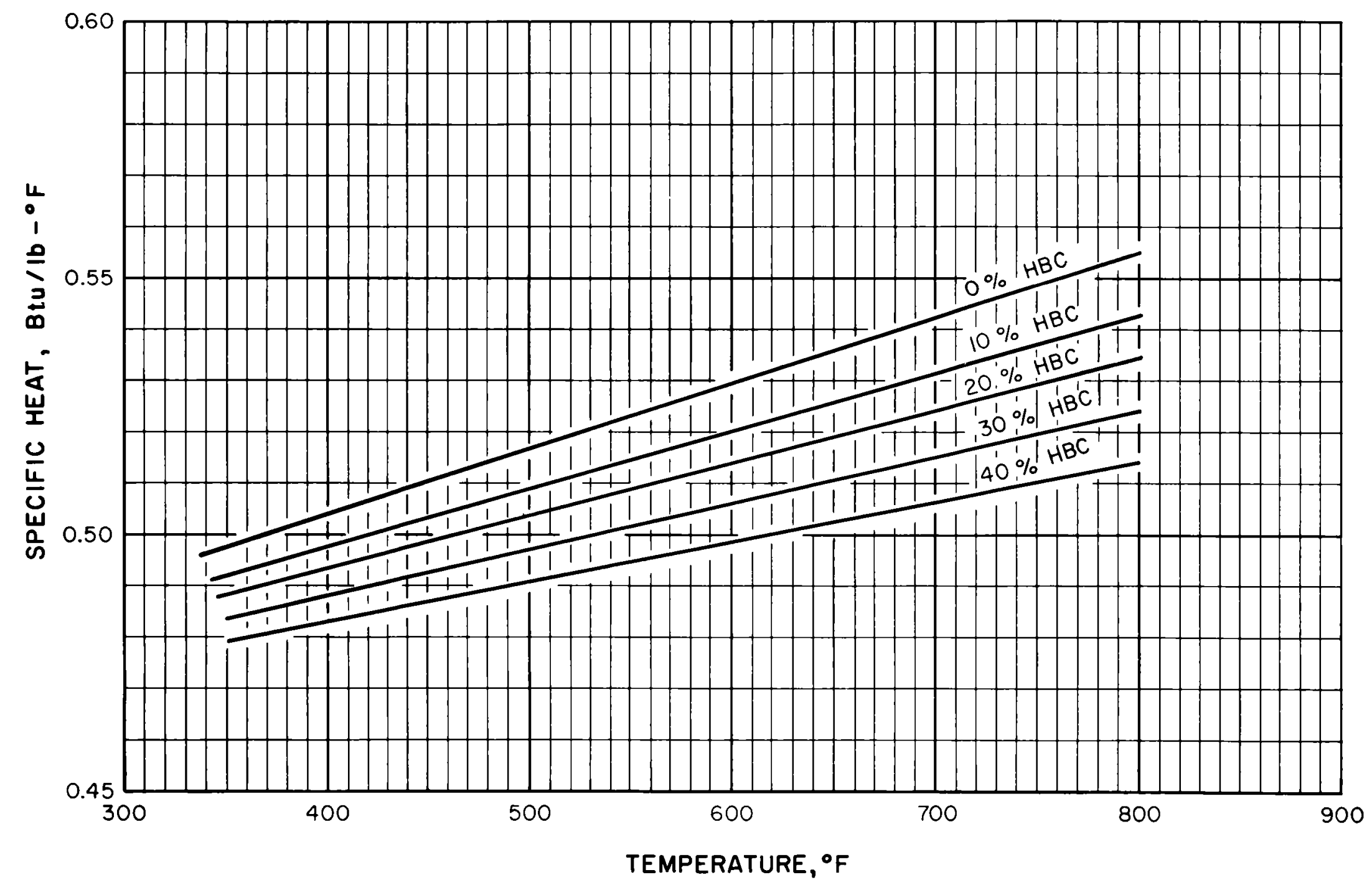




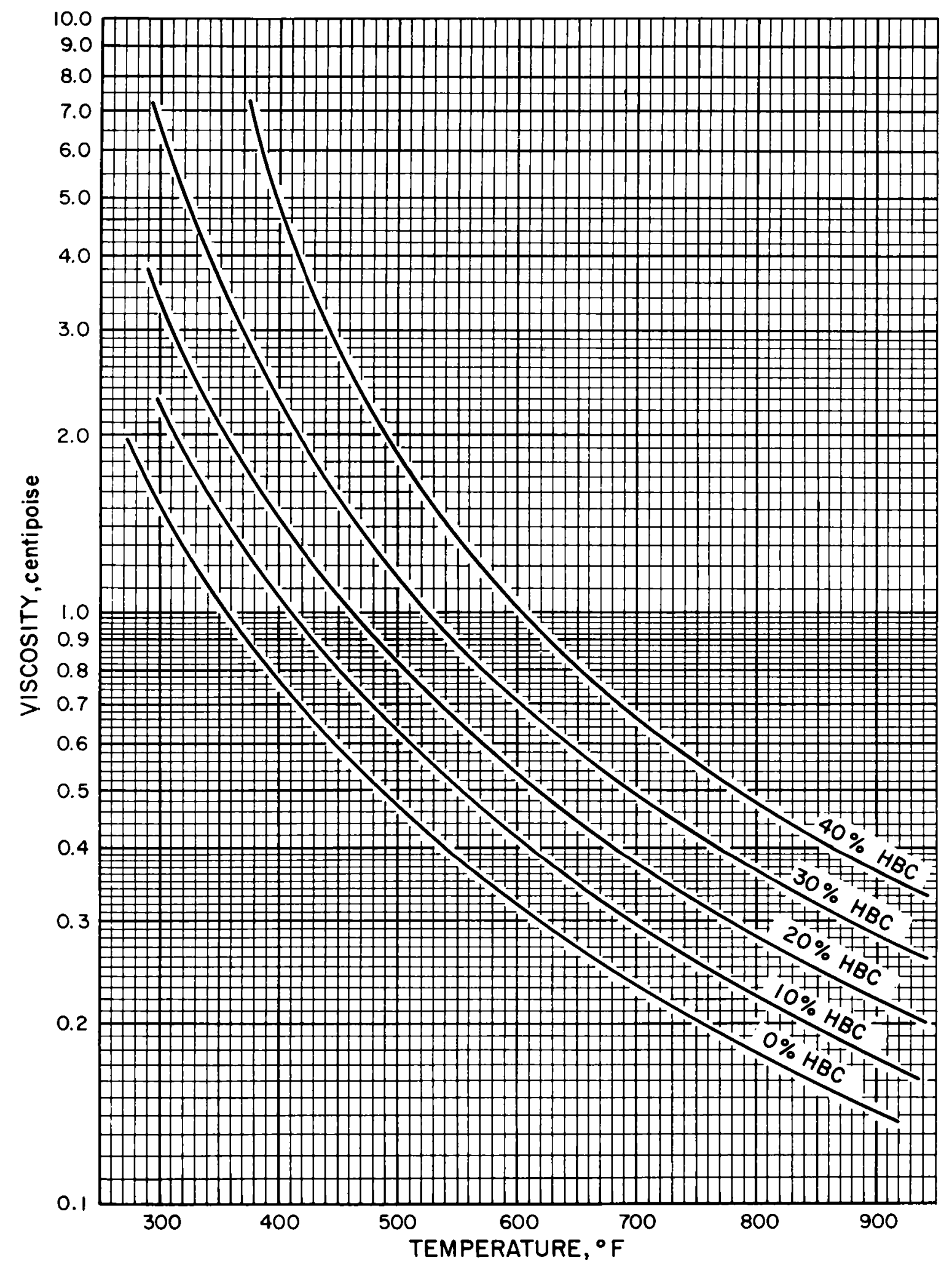

Figure 6. Viscosity of Irradiated Santowax R 


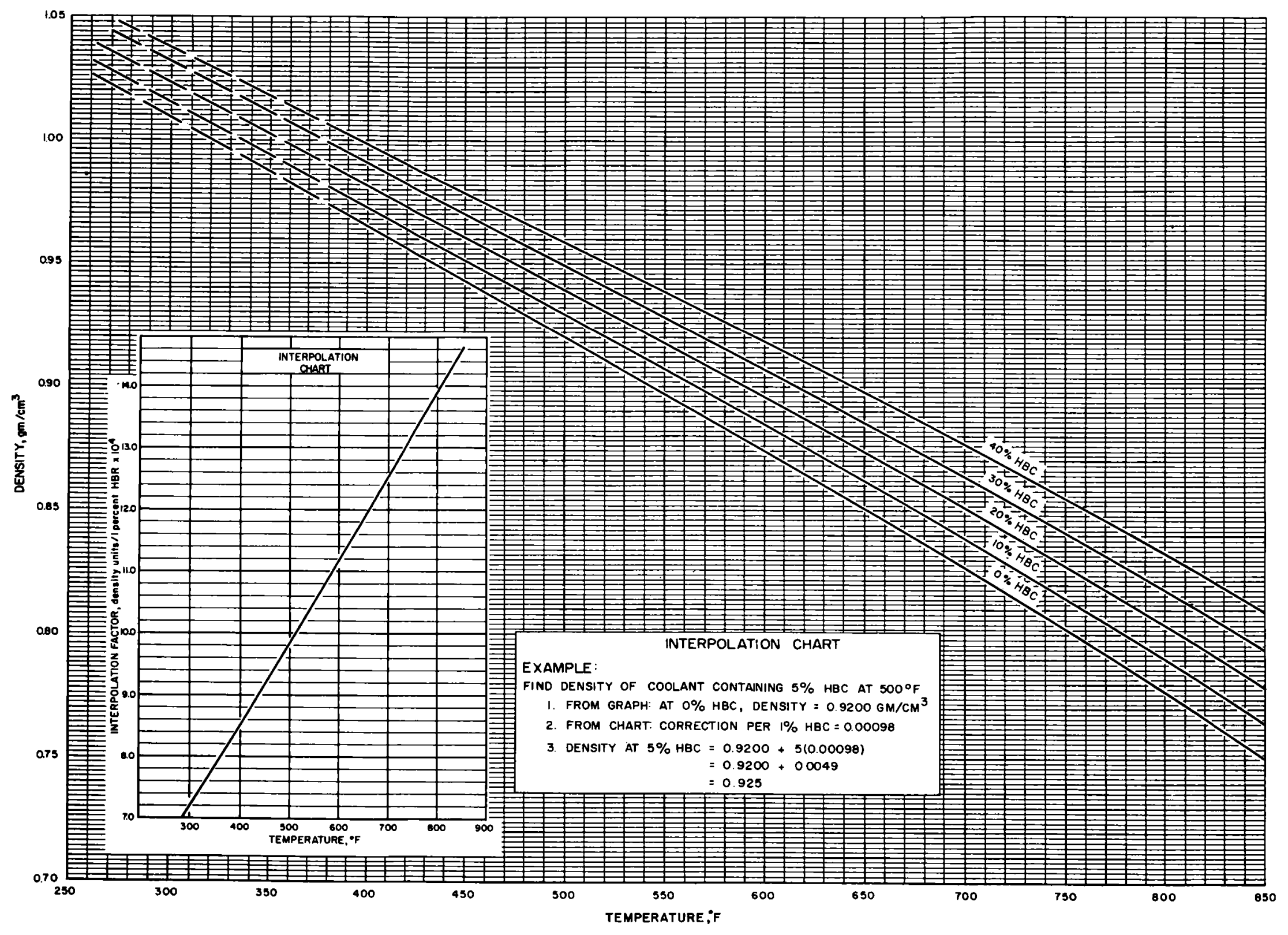


$\stackrel{⿱ 中}{\vdots}$

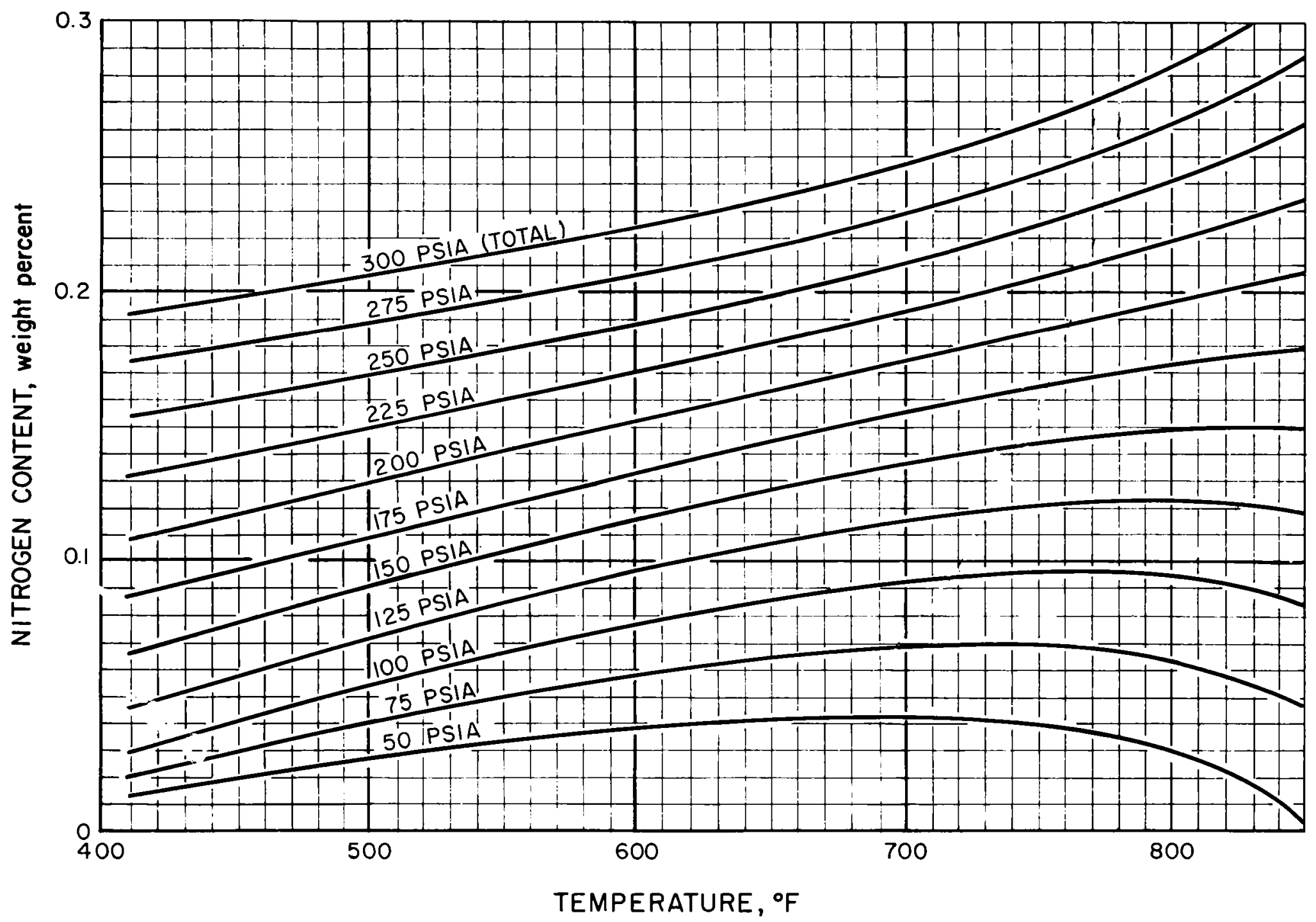

Figure 8. Solubility of Nitrogen in Unirradiated Santowax R 
is approximately $1,150^{\circ} \mathrm{F}$, which is hundreds of degrees higher than the maximum bulk coolant temperature or the maximum surface temperature in the organic cooled reactor design. All systems which contain organic coolant will be designed to conform with the recommendations of the National Bureau of Fire Underwriters, and all electrical equipment which could possibly come in contact with the coolant is designed in accordance with the National Electrical Code.

The absence of an oxidizing atmosphere within the heat transfer system eliminates the gas explosion hazard within the piping systems. A leak from the organic system could produce spontaneous ignition only if the organic temperature is high enough. The spontaneous ignition temperature for para-terphenyl and diphenyl is approximately $1000^{\circ} \mathrm{F}$, which strongly indicates the negligible probability of spontaneous ignition of any Santowax-R which might leak from the heat transfer systems.

The radiolytic decomposition of the organic coolant represents a small but realistic portion of the total ship's operating cost. Using a $G_{p}$ value of 0.07 molecules of HBC formed per 100 ev energy absorbed, and $4 \%$ of the total energy absorbed in the coolant, the radiolytic damage rate is $1.064 \mathrm{lbs} / \mathrm{Mwt}-\mathrm{hr}$. When the ship is operating at the normal conditions of 27,250 SHP, the reactor power level is $77.2 \mathrm{Mwt}$. Using $17 \notin$ per $\mathrm{lb}$ for new coolant, makeup cost is approximately $0.51 \mathrm{mills} / \mathrm{SHP}-\mathrm{hr}$. Organic coolant temperatures during reactor operation are low enough that the pyrolytic damage rates are negligibly small in comparison to the radiolytic damage rates.

Suggested methods for reducing coolant makeup costs may be itemized as follows:

1. Use of lower cost feed materials

2. Use of additives to lower decomposition rate

3. Use of converted high boilers

4. Sale of by-products from the high boiler compounds

5. Use of stable moderators

All of these methods are currently under investigation at Atomics International as potential means of reducing coolant makeup costs. Additives have already been 
found which lower organic decomposition rates, though insufficient information is available to make costs analyses. It is unlikely that the decomposition rate will ever be reduced to zero. However, it may be possible to lower it by $50 \%$ or more by manipulation of the chemical equilibria involved and by adding radiation damage inhibitors.

TABLE I

FLAMMABILITY AND EXPLOSIBILITY* PROPERTIES OF POLYPHENYLS

Para-

Santowax-R Terphenyl
Diphenyl

\section{Liquid}

Flash point, $\left({ }^{\circ} \mathrm{F}\right)$

375

397

232

Flame point, $\left({ }^{\circ} \mathrm{F}\right)$

460

460

255

Spontaneous ignition temperature $\left({ }^{\circ} \mathrm{F}\right)$

993

1004

Temperature limits of flammability

for saturated vapor-air mixtures

Lower $\left({ }^{\circ} \mathrm{F}\right)$

Upper $\left({ }^{\circ} \mathrm{F}\right)$

397

606

$\underline{\text { Powder }}$

Ignition temperature of dust cloud $\left({ }^{\circ} \mathrm{F}\right) \quad 1148$

Relative flammability (\%)

In furnace at $1292^{\circ} \mathrm{F}$

In standard spark apparatus

$90+$

$90+$

Minimum energy required for ignition

of dust cloud by electric spark from

condenser discharge (joule)

0.8

Minimum explosive concentration

$\left(\mathrm{oz} / \mathrm{ft}^{3}\right)$

0.035

*M. McEwen, "Organic Coolant Data Book, " Monsanto Chemical Company Technical Publication, No. AT-1, July 1959 (Supplemented by recent Atomics International Data). "Explosibility Characteristics of Biphenyl and Para-Terphenyl, "Bureau of Mines, Division of Explosives Technology, Report No. 3590, April 1957. Liquid sprays of these materials at temperatures up to $900^{\circ} \mathrm{F}$ did not ignite spontaneously when released into atmosphere whose temperature was about $27^{\circ} \mathrm{F}$. Ignition of these sprays could only be obtained upon the introduction of an ignition source near the outer fringes of the liquid spray. "Explosibility of Santowax-R Powder," Bureau of Mines, Division of Technology, Report No. 3538, July 1956. 


\section{B. FUEL}

Enriched uranium fuel materials which can be employed in organic moderated and cooled systems include uranium molybdenum alloys, uranium carbide, and uranium dioxide. All these fuel materials are chemically compatible with the organic coolant and sufficient radiation damage tests have been conducted to illustrate their dimensional stability under reactor operating conditions. Uranium dioxide fuel was selected for this application because it represented the minimum overall fuel cycle cost evaluated in accordance with current fuel technology and a four year construction schedule. Uranium molybdenum and uranium carbide fuel elements can be produced at a cost somewhat less than uranium dioxide elements but sufficient irradiation test data is not yet available to justify their application at high burnups.

In general, $\mathrm{UO}_{2}$ fuel elements have the advantage of being chemically inert to organic coolants and exhibit outstanding resistance to radiation damage at high burnup. The relatively high burnups to which $\mathrm{UO}_{2}$ fuel elements may be irradiated without concomitant dimensional change has the effect of reducing both the fabrication and reprocessing costs associated with the fuel cycle. These various factors have opposite effects upon the economic desirability of oxide fuel to the extent that each must be fully evaluated in relation to a specific reactor design.

The data in Table II on $\mathrm{UO}_{2}$ represent burnups in a range from $1800 \mathrm{MWD} /$ $\mathrm{MTU}$ to $25,000 \mathrm{MWD} / \mathrm{MTU}$, with calculated central temperatures from $2318^{\circ} \mathrm{F}$ to greater than $4982^{\circ} \mathrm{F}$. There are no dimensional changes at the lower burnups and the changes are slight at burnups of 22,000 MWD/MTU and 25,000 MWD/MTU. These data are based on relatively small test specimens and do not necessarily predict in-pile behavior of full-scale reactor fuel elements. While $\mathrm{UO}_{2}$ is isotropic, there is a tendency for decrepitation to occur or for central melting or sublimation at high burnups. The data in Table II concerning those $\mathrm{UO}_{2}$ specimens where central melting or sublimation has occurred do not indicate any gross dimensional changes.

Pressed $\mathrm{UO}_{2}$ pellets have been exposed to Santowax-R in static tests at $750^{\circ} \mathrm{F}$ for 480 hours. A weight gain of $2.6 \mathrm{mg} / \mathrm{cm}^{2}$-mo was indicated. No sign of deterioration was found. It was concluded that the weight gain was caused by occluded Santowax $-\mathrm{R}$. 
TABLE II

EFFECTS OF IRRADIATION ON BULK UO $2-$

\begin{tabular}{|c|c|c|c|c|c|c|c|c|}
\hline $\begin{array}{c}\text { Specimen } \\
\text { No. }\end{array}$ & $\begin{array}{l}\text { Heat Flux } \\
\text { Btu/hr-sq ft } \\
\times 10-3\end{array}$ & $\begin{array}{l}\text { Burnup } \\
\mathrm{Mwd} / \mathrm{t}\end{array}$ & $\begin{array}{l}\text { Calc. Central } \\
\text { Temperature } \\
\left({ }^{\circ} \mathrm{F}\right)\end{array}$ & $\begin{array}{l}\text { Tubing } \\
\text { OD }\end{array}$ & $\begin{array}{l}\text { Overall } \\
\text { Length }\end{array}$ & $\begin{array}{l}\text { Dimension } \\
\text { Diameter }\end{array}$ & $\begin{array}{l}\text { Lhanges } \\
\text { Length }\end{array}$ & $\begin{array}{c}\mathrm{UO}_{2} \\
\text { Center }\end{array}$ \\
\hline $12 \mathrm{H}$ & 170 & 1,800 & 2318 & 0.402 & 5.240 & 0 & 0 & not melted \\
\hline $1.3 \mathrm{H}$ & 300 & 3,800 & 3992 & 0.401 & 5.239 & 0 & 0 & not melted \\
\hline $16 \mathrm{H}$ & 340 & 4,200 & 4388 & 0.402 & 5.238 & 0 & 0 & not melted \\
\hline $17 \mathrm{H}$ & 250 & 2,700 & 3330 & 0.401 & 5.238 & 0 & 0 & not melted \\
\hline $14 \mathrm{H}$ & 220 & 4,400 & 2912 & 0.402 & 5.249 & 0 & 0 & not melted \\
\hline $15 \mathrm{H}$ & 370 & 10,900 & 4802 & 0.402 & 5.237 & 0 & 0 & not melted \\
\hline $18 \mathrm{H}$ & 420 & 13,500 & 4982 & 0.400 & 5.240 & 0 & 0 & not melted \\
\hline $19 \mathrm{H}$ & 300 & 6,900 & 3992 & 0.402 & 5.238 & 0 & 0 & not melted \\
\hline 825 & 330 & 14,000 & 4320 & 0.414 & 5.205 & 0 & 0 & not melted \\
\hline $83 S$ & 540 & 22,000 & 4982 & 0.414 & 5.222 & +0.012 & 0 & 0.200 hole \\
\hline 845 & 600 & 25,000 & 4982 & 0.414 & 5.224 & +0.015 & 0 & 0.230 hole \\
\hline $85 S$ & 300 & 12,000 & 3992 & 0.414 & 5.206 & 0 & 0 & not melted \\
\hline
\end{tabular}


Gross radial cracking due to the large thermal gradients in the fuel has been observed but this was not associated with significant external dimensional changes and does not seriously affect the conduction of heat in the pellet. Some circumferential cracking, which would have an adverse effect upon the heat transfer properties of the pellet, has been noted. However, this phenomenon appears to be independent of burnup since further cracking beyond the initial stage was not observed.

The release of fission gases from oxide fuel pellets at high burnup is controlled by the diffusion of gases in the oxide matrix. Since this is the case, the gas release is strongly dependent upon the density of the fuel compact and upon the temperature of the fuel material. Experimental evidence indicates that for fuel densities of about $95 \%$ of theoretical and fuel temperatures below the melting point $\left(\sim 5000^{\circ} \mathrm{F}\right)$ the gas released is limited to less than $3 \%$ of that produced as a result of fission. The effect of this gas release is to build up internal pressure in the fuel element and to dilute the conducting gas film, thereby causing higher fuel temperatures and an increase in the percentage of gas released.

A conclusion which may be drawn from present irradiation data is that $\mathrm{UO}_{2}$ fuel elements do not show an inherent tendency to distort during exposures up to 10,000 MWD/MTU or even higher. Gross cracking of the oxide pellets does occur early in core life, the transfer of heat deteriorates slowly with exposure, and there is a release of fission product gases from the oxide which increases with increasing temperature and decreasing density. If the design of the fuel element makes adequate allowance for these effects, it would appear that the fractional rate of failure of oxide elements in a reactor to burnups of 25,000 MWD/ MTU or higher will be reasonably low. Recognizing the above limitations, it is concluded that oxide fuel elements can be designed for organic cooled reactors which will yield high burnups and economical fuel cycles.

\section{CLADDING}

The primary function of a cladding material is to establish a reliable barrier between the fuel material and the coolant. Design requirements of a cladding material for uranium dioxide fuel with Santowax-R as the coolant can be summarized as follows: 
1. Restrict the migration of fission products from the fuel material to the coolant.

2. Provide suitable corrosion and erosion resistance to Santowax-R.

3. Exhibit chemical compatibility with the uranium dioxide fuel.

4. Provide adequate strength and creep properties at elevated temperatures.

5. Resist radiation damage.

6. Provide low neutron capture cross-section.

7. Provide high thermal conductivity for the removal of heat from the fuel element.

8. Be readily workable to permit fabrication of extended surface fuel elements.

9. Be readily available at low cost.

There are several materials, some currently under investigation and some already developed, which have suitable characteristics for use as the cladding material in a uranium dioxide fueled reactor cooled and moderated by Santowax-R. The most attractive material (consistent with the current state of cladding technology and a four-year ship construction schedule) is an alloy of aluminum and aluminum oxide powder designated $M-257 *$ by the Aluminum Company of America.

*1. John P. Lyle Jr., "Aluminum Powder Metallurgy Products, "Aluminum Company of America Brochure

2. Swiss patents 250118 and 259878

3. E. Gregory and M. J. Grant, "Aluminum Powder Products Compared, " Iron Age, Dec. 25, 1952, p. 69

4. John P. Lyle, Jr., "Excellent Products of Aluminum Power Metallurgy, "Metal Progress, Dec. 1952, p. 109

5. E. Gregory and M. J. Grant, "High Temperature Strength of Wrought Aluminum Powder Products, " Journal of Metals, Feb. 1954, p. 247

6. E. H. Dix, Jr., "Aluminum Alloys for Elevated Temperature Service," Aeronautical Sciences, Jan. 1956, p. 40 
Alloys of this type are commonly called aluminum powder metal or APM. The M257 APM alloy has a nominal 6-8\% $\mathrm{Al}_{2} \mathrm{O}_{3}$ content.

The APM products are characterized by unusually high strengths above $600^{\circ} \mathrm{F}$. The strengthening mechanism is probably similar to the precipitation hardened alloys except that the $\mathrm{Al}_{2} \mathrm{O}_{3}$ is insoluble and therefore does not redissolve at elevated temperatures. Elevated temperature tensile and yield strengths of M257 are compared in Table III with several conventional aluminum alloys.

It is seen that the M257 alloys are superior to the best conventional wrought aluminum alloys above $600^{\circ} \mathrm{F}$. The modulus of elasticity of M257 is $10 \times 10^{6} \mathrm{psi}$, the density $0.099 \mathrm{lb} / \mathrm{in}^{3}$, and the thermal conductivity about $105 \mathrm{Btu} / \mathrm{hr}-\mathrm{ft}-{ }^{\circ} \mathrm{F}$. The average coefficient of thermal expansion of M257 is lower than those for the conventional aluminum alloys and is $13.6 \times 10^{-6}$ per ${ }^{\circ} \mathrm{F}$ from 68 to $842^{\circ} \mathrm{F}$. Limited corrosion tests of M257 in polyphenyls have indicated excellent corrosion resistance. Corrosion testing in $\mathrm{NaCl}$ and industrial atmospheres show the M257 alloy to be equal to alloys 1100 and 3003, and superior to 2024-T4 and $6061-\mathrm{T} 6$.

The M257 alloy is expected to be compatible with metallic uranium and $\mathrm{UO}_{2}$ over the same temperature range as aluminum. However, due to the increased strength of APM alloys at elevated temperatures, the upper range of application may be extended into the region at which a reaction starts to occur with $\mathrm{UO}_{2}$. Preliminary experimental work with $\mathrm{UO}_{2}$ and $\mathrm{APM}$ has been encouraging. A recent test was conducted by Atomics International in which a $\mathrm{UO}_{2}$ sample was enclosed in APM alloy M257 using helium as a thermal bonding material. The sample was held at $900^{\circ} \mathrm{F}$ for 40 days. Upon examination, no chemical instabilities were observed between the $\mathrm{APM}$ and the $\mathrm{UO}_{2}$.

Ir radiation data obtained from Chalk River indicates alloy M257 to be stable to at least a total integrated fast neutron dose of $1.2 \times 10^{20} \mathrm{nvt}$. Data at $120^{\circ} \mathrm{F}$ and $520^{\circ} \mathrm{F}$ are reported in Table IV. 
TABLE III

TENSILE AND YIELD STRENGTHS

\begin{tabular}{|c|c|c|c|c|c|c|c|c|c|}
\hline \multirow[b]{2}{*}{$\begin{array}{c}\text { Temperature } \\
\left({ }^{\circ} \mathrm{F}\right)\end{array}$} & \multirow[b]{2}{*}{$\begin{array}{c}\text { Tensile } \\
(\mathrm{psi}) \\
(1000 \mathrm{hr})\end{array}$} & \multicolumn{2}{|l|}{ M257 } & \multicolumn{3}{|c|}{$2024-\mathrm{T} 4$} & \multicolumn{3}{|c|}{$2618-T 61$} \\
\hline & & $\begin{array}{c}\text { Yield } \\
\text { (psi) } \\
(1000 \mathrm{hr})\end{array}$ & $\begin{array}{c}1 \% \text { Flow } \\
(10,000 \mathrm{hr})\end{array}$ & $\begin{array}{c}\text { Tensile } \\
(\mathrm{psi}) \\
(1000 \mathrm{hr})\end{array}$ & $\begin{array}{c}\text { Yield } \\
\text { (psi) } \\
(1000 \mathrm{hr})\end{array}$ & $\begin{array}{c}1 \% \text { Flow } \\
(10,000 \mathrm{hr})\end{array}$ & $\begin{array}{c}\text { Tensile } \\
\text { (psi) } \\
(1000 \mathrm{hr})\end{array}$ & $\begin{array}{c}\text { Yield } \\
\text { (psi) } \\
(1000 \mathrm{hr})\end{array}$ & $\begin{array}{c}1 \% \text { Flow } \\
(10,000 \mathrm{hr})\end{array}$ \\
\hline 400 & 21,000 & 18,000 & - & 31,000 & 27,000 & - & 34,000 & 31,000 & - \\
\hline 600 & 17,000 & 15,000 & 8,800 & 8,000 & 5,500 & 1,500 & 9,000 & 6,000 & 1,600 \\
\hline 800 & 12,000 & 11,000 & 5,400 & 1,700 & 1,100 & - & 2,600 & 1,600 & - \\
\hline 1000 & 7,500 & 7,000 & - & - & - & - & - & - & - \\
\hline
\end{tabular}


TABLE IV

IRRADIATION STABILITY OF M257*

\begin{tabular}{c|cc|cc}
\hline \hline & \multicolumn{2}{|c|}{ Yield Strength (psi) } & \multicolumn{2}{|c}{ Elongation (\%) } \\
Temp. ${ }^{\circ} \mathrm{F}$ & Pre-Irradiation & Post-Irradiation & Pre-Irradiation Post-Irradiation \\
\hline 120 & 30,000 & 31,400 & 16 & 14 \\
520 & 19,000 & 20,000 & \multicolumn{2}{|c|}{ No Change } \\
\hline
\end{tabular}

*To be published PR-CM-17 from Chalk River

On the basis of these numbers, alloy M257 appears to be at least as stable as Type 304 SS.

Experience with APM products in Sweden for possible application as fuel cladding in a gas-cooled reactor project indicated that APM products produced in Europe containing 11 to $13 \% \mathrm{Al}_{2} \mathrm{O}_{3}$ were porous to fission gases at high temperatures. APM products with lower $\mathrm{Al}_{2} \mathrm{O}_{3}$ content have not illustrated the porosity characteristic of the European produced material. A sample of alloy M257 produced by Alcoa was tested by Atomics International for He leakage at $900^{\circ} \mathrm{F}$. No helium leakage was observed in the mass spectrometer test.

APM products have been fabricated in a variety of sizes as tubes, rod, and plate. Tubing from 6 inches down, with wall thickness in the range of 3 to $10 \%$ of the diameter, have been extruded. Sheet material down to a few mills in thickness has been rolled. Joining of APM products has been successful by pressurebonding techniques. Spot and seam welds have been successfully made on commercial pulsed seam welding machines. A metallic bond has been obtained by swaging. Recent experience at Atomics International with heli-arc welding indicates that high strength APM-to-APM welds may be obtainable. Normal fusion welding has not previously been successful with APM products due to porosity. During the fusion welding process the $\mathrm{Al}_{2} \mathrm{O}_{3}$ slags to the surface, leaving a low strength metallic aluminum region. It is expected a limited development program would demonstrate successful means of obtaining satisfactory welds on a commercial basis. 
Figures 9 and 10 are photographs illustrating a finned $A P M$ tube and a APM-to-APM end weld.

The neutron absorption cross section is approximately the same for the APM type alloys as it is for $2 \mathrm{~S}$ aluminum, the only difference being the slightly lower density and the presence of oxygen. The cost of fabricated APM shapes is now approximately $\$ 5.00 / 1 \mathrm{~b}$, but it is expected that eventually production items will not exceed twice the cost of aluminum alloys.

D. STRUCTURAL MATERIAL

One of the most significant advantages of using organic materials for the coolant and moderator of a nuclear reactor stems from the negligible effects of the organic materials on ordinary carbon steel equipment. Corrosion rates in the order of 0.5 milligrams $/ \mathrm{cm}^{2}$ per month have been measured in corrosion tests and the operation of the Organic Moderated Reactor Experiment has proven the suitability of carbon steel equipment with organic materials under reactor operating conditions. The reactor vessel, piping, pumps and heat exchangers can all be fabricated in accordance with conventional manufacturing procedures and techniques and comply with applicable codes. The use of carbon steel in the reactor system also permits the use of conventional equipment and operating procedures in the steam propulsion system. Conventional condenser designs can be employed for the main and auxiliary condensers. Since no stainless steel equipment is employed, in-leakage of sea water can be tolerated in accordance with conventional marine practice. 


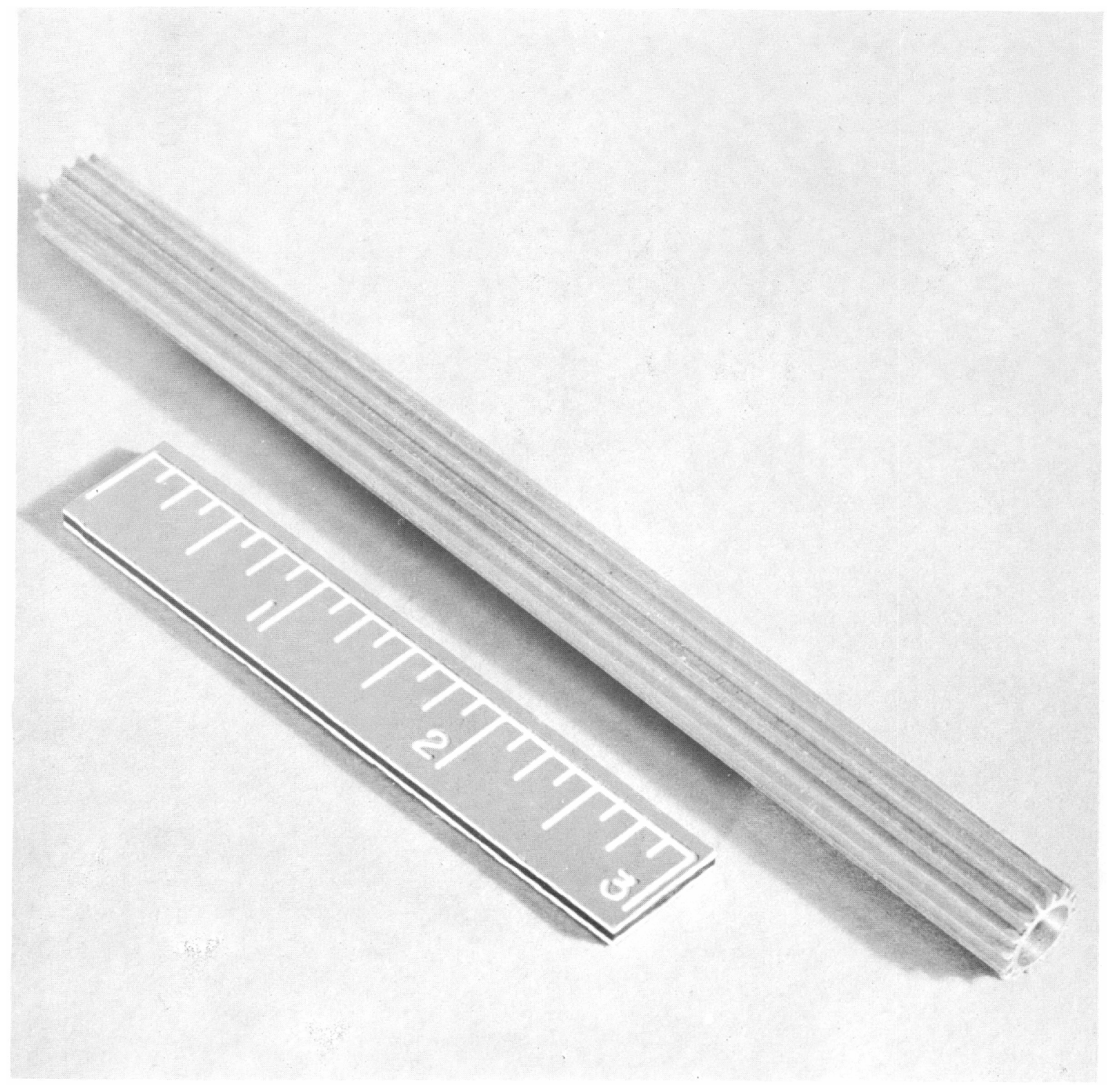

Figure 9. Finned APM Tube 


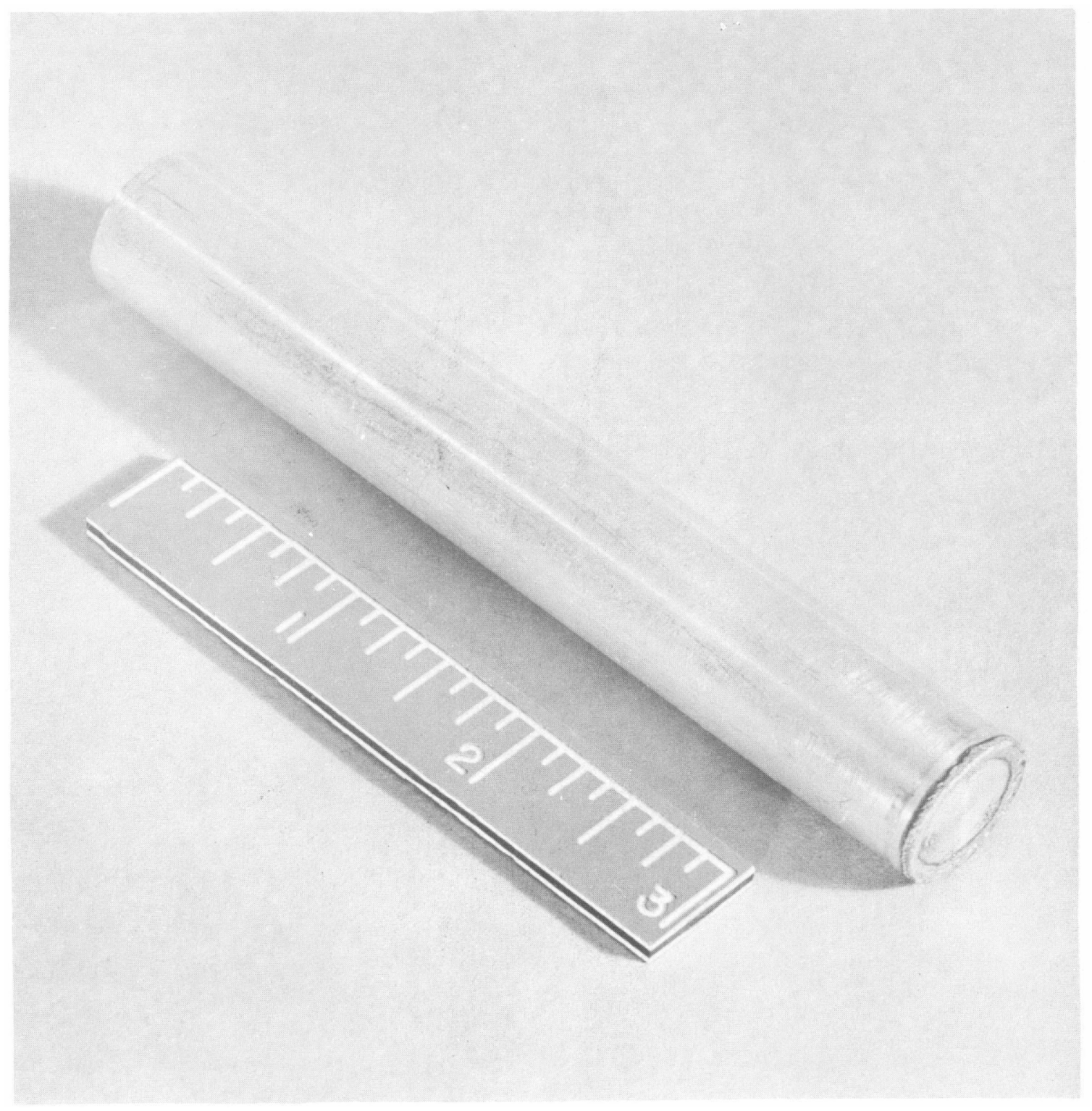

Figure 10. APM End Cap Weld

II -22 


\section{REACTOR AND PRIMARY LOOP}

\section{A. REACTOR VESSEL}

The reactor core tank is constructed of Type SA-204 Grade B low alloy steel. It is a cylindrical vessel 9 feet 3 inches in diameter by 21 feet 1 inch high with a welded dished head at the bottom and a removable flat head at the top. The design pressure and temperature of the reactor core tank are $300 \mathrm{psig}$ and $750^{\circ} \mathrm{F} \mathrm{respec-}$ tively requiring a wall thickness of $1-1 / 2$ inches. Twenty-one cylindrical control rod thimbles, located on 11-1/2 inch centers, penetrate the lower head of the reactor vessel and extend into the sub-pile room. The upper head, which is removable for fuel handling operations, is flanged and bolted. This head is sealed with a soft metallic gasket.

Two 18-inch primary coolant inlet nozzles are located 180 degrees apart in the reactor core tank about 4 feet above the top of the active core. The two outlet nozzles are located approximately $7-1 / 2$ feet above the active core, at 45 degrees from the inlet nozzles. There are two 16-inch nozzles provided to accommodate the instrumentation leads from the core. These nozzles are located near the top flange of the reactor vessel. One additional 14-inch instrumentation nozzle is provided to accommodate the power mapping tubes. The reactor drain and overflow line and the 14 -inch instrumentation nozzle are located at the same elevation as the main instrument nozzles.

The reactor core is located in the lower section of the reactor core tank. A section of the core showing the arrangement of fuel elements, control rods and thermal shields, is presented in Plate VI. There are 96 lattice positions in the core. Active fuel elements occupy 88 of these spaces. The remaining 8 spaces are occupied by 7 dummy elements and 1 neutron source element. Cruciform control rods divide the core into groups of four fuel elements. There is a 3/8-inch moderator gap between adjacent fuel elements in a group and a $7 / 8$-inch gap between each group of fuel elements. The control rods or their followers occupy most of the space between fuel element groups. The important dimensions and weights of the reactor vessel and structures are presented in Table V. 


\section{Reactor Core Tank}

Overall height including heads

Inside diameter

Design pressure, psig

Design temperature, ${ }^{\circ} \mathrm{F}$

Main coolant, nozzles, 18-inch diameter

Instrumentation nozzle, 14 -inch diameter

Drain nozzle, 4-inch diameter

Instrumentation nozzles, 16-inch diameter

Wall thickness, inches

Weight of vessel, $1 \mathrm{~b}$

Outer Thermal Shield

Inside diameter, inches

Wall thickness, inches

Height, inches

Weight, $1 b$

Inner Thermal Shield

Inside diameter, inches

Height, inches

Wall thickness, inches

W eight, lb

Core Support Structure

Inside diameter, inches

Height, inches

Wall thickness, inches

W eight, lb

Lower Grid Plate

Diameter, inches

W eight, Ib
21 feet-11 inches

9 feet -3 inches

350

750

2

1

1

2

$1-1 / 2$

72,000

97

6

96

70,400

73

71

1. 5

6,960

78 and 93

162

1. 5

17,720

77.5

3,400

III - 2 
Upper Grid and Control Rod Guide

Diameter at bottom support, inches $\quad 76$

Height, inches $\quad 56$

Weight, lb 5, 000

Fuel Elements

Number of sub-assemblies per element 4

$\begin{array}{ll}\text { Length of sub-assemblies, inches } & 67\end{array}$

Number of fuel rods per sub-assembly 25

Fuel rod lattice spacing, inches variable

Active length of fuel rods, inches 60

$\begin{array}{ll}\text { Overall length of fuel element, inches } & 78.25\end{array}$

$\begin{array}{ll}\text { Coolant flow area per fuel element, sq in. } & 13.6\end{array}$

Outside dimension of fuel element box, inches $\quad 5.125$

Wall thickness of SS fuel element box, inches 0.035

$\begin{array}{ll}\text { Total weight of fuel per element, kilograms } & 89.1\end{array}$

Total weight of uranium per element, kilograms $\quad \mathbf{7 8 . 6}$

Total weight of fuel element, lb 279

Control Rods

Poison material

Cladding material

$\mathrm{EU}_{2} \mathrm{O}_{3}$

Length of poison section, inches $\quad 54$

Total length of blade section, inches 66

Control rod shape

cruciform

Blade length, inches

4.5

W eight of control rod and follower, lb 107

Rod drive type

Total weight of rods and drives, lb

rack and pinion

307

Reactor Core

Total number of lattice positions

96

Average lattice spacing, inches

5.75

Total number of fuel elements 


\section{TABLE V (Continued)}

Reactor Core (Continued)

$\begin{array}{ll}\text { Number of dummy elements } & 7\end{array}$

Number of neutron source elements 1

Number of control rods 21

Equivalent core diameter, inches $\quad 60$

Equivalent core height, inches $\quad 60$

Equivalent reflector thickness, inches 6.5

Total weight of fuel in the core, kilograms 7,770

Total weight of uranium in the core, kilograms 6,850

Total weight of fuel core loading, lb 24,500

After the organic coolant enters the reactor tank, the coolant is deflected downward by the core support structure and flows in the annulus between the tank and the core support structure to the lower plenum. The core support structure is extended below the lower grid plate to avoid undesirable flow channeling around the peripheral elements. The coolant mixes in the lower plenum and then flows upward through the lower grid plate, which contains the orifices used to adjust the flow distribution through the active fuel elements, and through the upper grid and control rod guide assembly into a reservoir above the core. The coolant then flows downward through the annulus between the control rod guide assembly and the reactor vessel and out through the outlet nozzles.

The cruciform control rods are actuated from a sub-pile room below the reactor vessel and will be removed or replaced from above the core. The poison section of the rods are positioned above the core when fully withdrawn. The poison columns are supported on APM rod followers which are also cruciform in cross section, but with shorter blades. These followers are connected to the rod drives, which are contained in cylindrical thimbles that penetrate the bottom head of the reactor core tank and extend through shielding into the sub-pile room.

Thermal shielding, in the form of concentric steel shells, is provided to reduce thermal stresses in the reactor core tank wall. The thermal shield consists of two parts. The $1-1 / 2$ inch thick inner thermal shield is located inside 
the core support structure to reduce thermal stresses in the core support structure and to provide a means of limiting the direct transfer of heat from the hot coolant leaving the core and the cold coolant entering the core tank. This shield also eliminates direct radiation paths between the active core and the vessel in the region of the nozzle welds. Space is provided between the inner thermal shield and the core support structure to contain a layer of organic coolant. The 6 inch thick outer thermal shield located between the core support structure and the core tank minimizes thermal stresses due to gamma heating in the core tank.

The lower grid plate is composed of an egg-crate structure and a $1-1 / 2$ inch thick steel cover plate. The grid provides the structural support and the cover plate contains the orifice receptacles into which the fuel elements are seated. These seats act as seals to control the leakage flow of coolant into the interelement and control rod spaces. The grid assembly is supported by and bolted to a ring which is an integral part of the core support structure.

The upper grid and control rod guide assembly is made up of three substructures: the fuel element grid, the control rod guide, and the instrumentation grid. These grids are fabricated into one assembly which is supported by and bolted to a ring which is an integral part of the inner thermal shield. The fuel elements are locked into, and laterally supported by this structure. The grid structure is made from rectangular tubing and plate. The tubing provides a channel to each of the 22 fuel element groups through which coolant samples can be withdrawn to the Failed Fuel Element Detection and Location System. These coolant sampling tubes enter the reactor via two instrument nozzles near the top flange of the core tank.

The core support structure accepts the load of the inner thermal shield, the core and both grid plates. This structure is a cylindrical shell laterally restrained at the bottom and supported at the top by means of the flange which rests on the internal support ring welded to the inside of the reactor core tank. Thermal stresses are reduced by a 1 -inch thick layer of organic coolant between the support structure and the inner thermal shield. The support flange will also be protected from thermal stress by the insulation provided by a layer of organic coolant on the hot side of the flange. 
The control rod sheaths below the core protect the control rod followers from lateral forces due to coolant turbulence in the lower plenum. These sheaths also provide channels to control the flow of coolant around the control rods. The sheath is a 5 inch pipe which slides over a tapered nozzle at the bottom of the reactor vessel.

Fuel elements are removed from the core by a fuel handling cask which operates in conjunction with the upper rotating shields. During reactor operation the rotating shields and core access plug are fixed and become an integral part of the reactor vessel. During periods of fuel handling the rotating shields serve the functions of indexing the fuel handling cask for fuel element removal and insertion, and providing radiation protection to operating personnel.

\section{B. FUEL ELEMENTS}

The reactor core is fueled with uranium dioxide which is clad with finned tubing made of Aluminum Powder Metal (APM), Alcoa alloy M-257. This cladding material is composed of an $\mathrm{Al}-\mathrm{Al}_{2} \mathrm{O}_{3}$ matrix $\left(\sim 7 \% \mathrm{Al}_{2} \mathrm{O}_{3}\right)$ and possesses excellent creep rupture properties at elevated temperatures compared to ordinary aluminum. Properties of the fuel and cladding material were presented in Section II.

Several important design criteria and limitations imposed by the properties and performance of the fuel and cladding materials as an integral fuel rod under reactor operating conditions influenced the design of the fuel elements. The stressrupture properties of APM, the temperature dependence of the pyrolytic damage rate, and prevention of fouling of the heat transfer surfaces led to the selection of a maximum cladding temperature of $825^{\circ} \mathrm{F}$. Since fission gas release is known to be temperature dependent in the $\mathrm{UO}_{2}$ fuels, the fuel rods were designed to limit the maximum fuel temperature to a value well below its melting point. The maximum fuel temperature selected for this design was set at $4000^{\circ} \mathrm{F}$. If the center line temperature of the fuel is limited to a maximum of $4000^{\circ} \mathrm{F}$, it is estimated that the fraction of fission gas released will not exceed 5\%. Adequate void volume is provided in the fuel rod to limit pressure buildup within the rod due to gaseous fission product release. 
The fuel elements consist of four subassemblies of 25 fuel rods each, as sembled to form 100 vertical fuel columns housed in a stainless steel box measuring 5-1/8 inches on a side. The wall thickness of the box is 0.035 inches based upon the stresses produced by the pressure differential between the organic coolant flowing inside the box and the organic in the gaps between the boxes. Steel perforated webbing, $20 \mathrm{mils}$ thick, divides the box into four equal square sections and reduces the effective unsupported span length of the sides of the box, allowing a thinner box wall to be used and thereby reducing the steel content of the core. The overall length of the fuel element assembly is approximately $6-1 / 2$ feet and the active length of fuel within the element subassemblies is 5 feet. The detailed design features of the fuel element are shown in Plate VII and Figure 11.

Each of the fuel rods which make up the fuel subassemblies is composed of 0.33 inch diameter by 0.6 inch long $\mathrm{UO}_{2}$ pellets, stacked vertically to form a column 60 inches in length. Approximately 3 inches of gas space is provided at each end of the fuel rod. These spaces will initially be filled with helium gas at one atmosphere pressure at room temperature. The helium will also fill any space left between the outer surface of the fuel pellets and the inner surface of the cladding tube due to manufacturing tolerances. The presence of the helium will facilitate the conduction of heat from the fuel to the cladding and reduce fuel temperatures. The gas spaces at either end of the rod will ultimately act as a reservoir for the gaseous fission products released during the irradiation of the fuel rod and thereby limit the pressure buildup inside the cladding.

The APM cladding tubes are extruded with 16 helical fins measuring 55 mils in height. These fins serve to increase the effective heat transfer surface area of each fuel rod allowing the hottest element to be operated at the maximum power density compatible with a fuel centerline temperature of $4000^{\circ} \mathrm{F}$.

\section{CONTROL RODS AND DRIVES}

Twenty-one cruciform control elements are provided in the reactor core to regulate power, provide negative reactivity insertion for emergency shutdown, and permit shaping of the radial power distribution. In the central control region of the core, there is one rod for every four fuel elements. The arrangement of fuel elements and control rods in the core is shown in detail in Plate VI. 


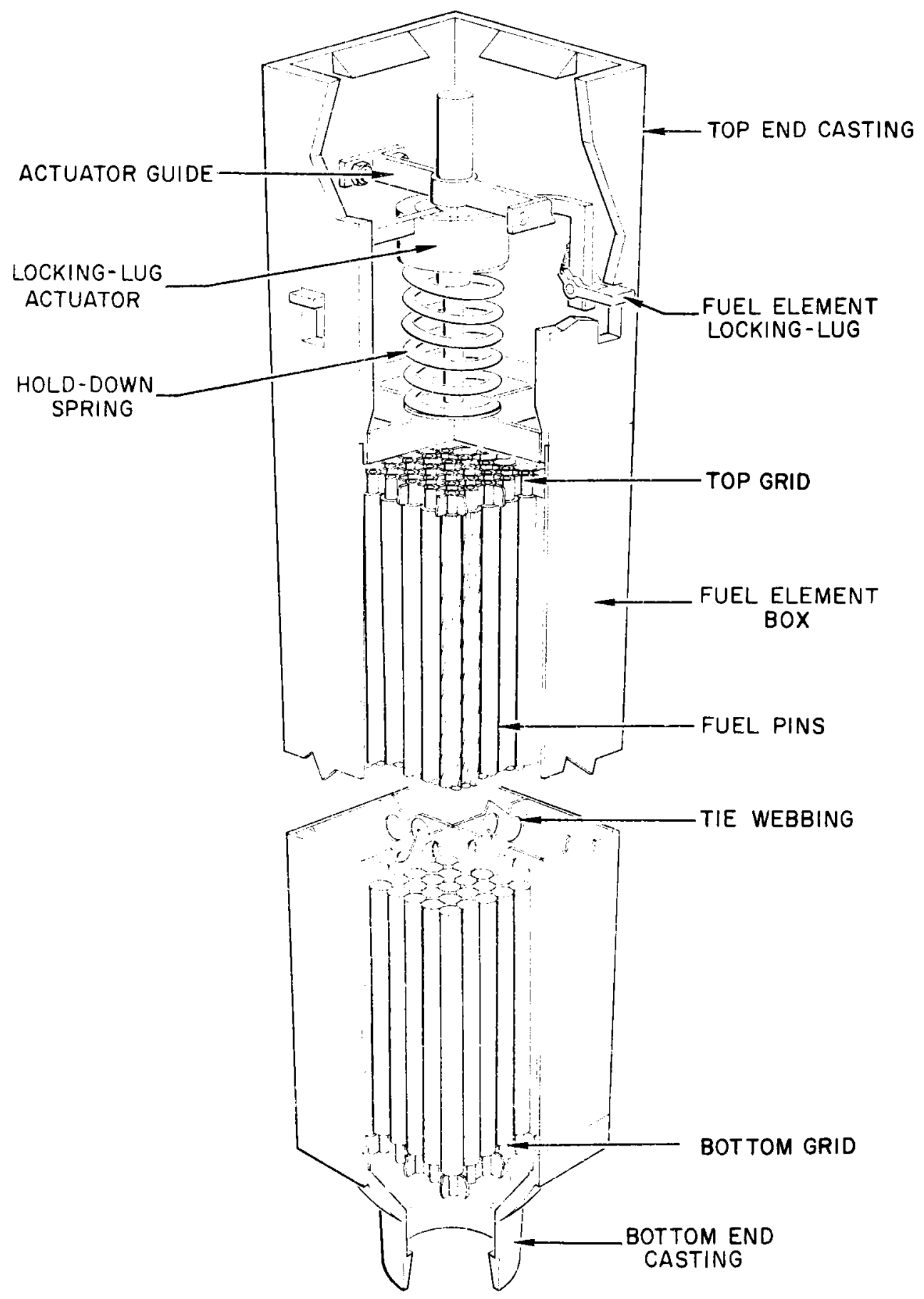

Figure 11. Fuel Element

III -8 
The poison section of the control elements consists of a cruciform beam 4-1/2 feet in length. The blades are 0.25 inch thick and 4-1/2 inches from center line to tip. The blades are composed of 0.200 inch of $\mathrm{EU}_{2} \mathrm{O}_{3}$ covered by stainless steel cladding 0.025 inch thick.

The cruciform control rods and their followers are supported by and connected to the control rod drive mechanism by round metal rods. Each assembly of the cruciform rods and rod followers weighs about 110 pounds.

The control rod drive is of the rack-and-pinion type and is mounted below the reactor vessel. The mechanism is housed in several flanged housings which protrude into the subpile room from the reactor vessel. The rack is connected to the cruciform section of the control rods by a rack extension and the rod follower which join at the snubber piston. The control rod drive is illustrated in Plate VIII.

The snubber is a device consisting of a piston moving into a tapered cylinder. The purpose of the snubber is to act as a shock absorber to arrest the downward motion of the control rods during a fast insertion (scram). The snubber is a hydraulic device utilizing the coolant in the reactor vessel as the damping fluid. The cylinder of the snubber forms an integral part of the reactor vessel.

Besides the snubber, the control rod drive consists of a rack, pinion, associated bearings and shaftings, shaft seal, spring motor, magnetic clutch, rod hold-in latch, position transmitter and a drive motor with integral reduction gearing. Due to the limited space between drives, the gear motor is connected to the magnetic clutch by means of a flexible shaft or optional rigid rod and universal joint system. This arrangement permits greater accessibility to both drive and gear motor. The gear motor is positively engaged with the pinion shaft by means of the magnetic clutch. Failure or interruption of the clutch electrical current automatically causes the rod to be rapidly inserted into the core by gravity aided by the force of the spring motor. The spring motor consists of two drums one of which is attached to the pinion shaft. A thin metal tape is wound on the other drum in such a manner that the tape has the tendency always to rewind on that drum. When the pinion shaft revolves driving the control rods out of the core the tape winds onto the shaft supported drum; however, if the holding force of the 
gear motor is interrupted by declutching, the tape reels back onto its original drum. The rewinding force is sufficient to overcome the inertia and friction of the pinion shaft and its attached bearings, seal, pinion, and clutch plate. The spring motor is also able to accelerate the rod during rapid insertion with enough force to overcome resisting loads due to motions such as listing or pitching. A rod hold-in latch device is provided which engages the rack when the rod is in the core preventing its withdrawal from the core due to other forces until a solenoid is energized releasing the latch. Coolant is allowed to flow through the rod drive assembly constantly, cooling the assembly and also discouraging the buildup of deposits in the device. This coolant flow is prevented from leaking out of the mechanism around the pinion shaft by means of the pinion shaft seal. This seal is a gas pressure back up type and is pressurized by an inert gas supply. The position of the rod is constantly supplied to the control room by means of a selsyn transmitter, gear-driven by a gear on the clutch plate.

\section{HEAT TRANSFER LOOP}

The basic objective of the heat transfer system is the transfer of thermal energy from the reactor core to a non-radioactive steam system which is located in an accessible area external to the radiation field of the reactor.

The heat transfer system is composed of two identical heat transfer loops, designed for $300 \mathrm{psig.} \mathrm{Each} \mathrm{loop} \mathrm{circulates} \mathrm{coolant} \mathrm{between} \mathrm{the} \mathrm{reactor} \mathrm{vessel}$ and the steam generator, and is provided with a circulating pump and isolation blocking valves. The components are connected by 18 inch diameter pipe. Coolant flow and temperature control instruments are provided. In order to maintain a constant steam pressure at the superheater outlet for different load conditions, a bypass line is placed around the steam generator and superheater to control the flow of coolant to the heat transfer equipment at low power. Control valves are provided to regulate this flow.

Both heat transfer loops are located in the same process room, along with their pump, steam generator and associated instrumentation and piping. The reactor drain tank and pressure relief lines are also in this room. The block valves are located in the process room, as close to the reactor vessel as possible. All instruments in the heat transfer loops are remote read-out and all control and normally operated valves are remotely positioned from the main control board.

III- 10 
The main circulating pumps, shown in Figure 12, are vertical turbine processtype pumps with individual pump tanks. They are rated at $12,900 \mathrm{gpm}$ at a total discharge head of 115 feet as shown in Figure 13. The pumps are driven by vertical solid-shaft $500 \mathrm{hp}, 440$ volt, 3 phase, 60 cycle motors. The pumping unit is constructed of low-carbon steel castings, stainless steel fitted, and with stainless steel impellers. The pump radial bearings located in the organic fluid are the hydrostatic type with hard-faced steel running surfaces, with full pump discharge pressure supplied to the shaft at the bearing surfaces. This provides equalizing hydraulic forces on the shaft with essentially no wear, thereby assuring relatively maintenance-free operation. The pump shaft has a high-temperature mechanical seal with a water-cooled jacket and includes an external labyrinth to contain the leakage in the event of total seal failure. The labyrinth is piped to a drain and storage system to retain the leaking organic fluid. The seal arrangement is installed above the pump base to provide accessibility to the seal without requiring disassembly of the piping or driver connections.

The heat transfer loops are provided with 16 inch power-operated block valves at each inlet and outlet connection to the reactor. The valves are located as close to the shielding as possible, however, they are accessible for normal maintenance and manual operation. The valves are instrumented and powered for automatic quick closing, and have remote operation features. An interlock prevents accidentally closing off more than one loop at any time to retain emergency convective cooling capability. The valves are constructed of cast carbon steel, with chromium iron alloy and nickel copper alloy trim components, and have a backseating feature when in the full open position. The valves have a plain bonnet and conventional style stuffing box with high-temperature metallic and semi-metallic packing. The valves are butt welded to the pipe.

Each heat transfer loop is provided with a 16-inch gate valve downstream of the steam generator bypass, and with a 12 -inch venturi-ball valve in the bypass line. These valves are modified to prevent $100 \%$ closure in order that a small stream of coolant will flow through each section of the loop at all times, thereby maintaining system temperature. The valves are positioned in response to a flow signal from the main steam line, thus regulating the flow of coolant through the steam generators in proportion to turbine plant load. The control gate valves 


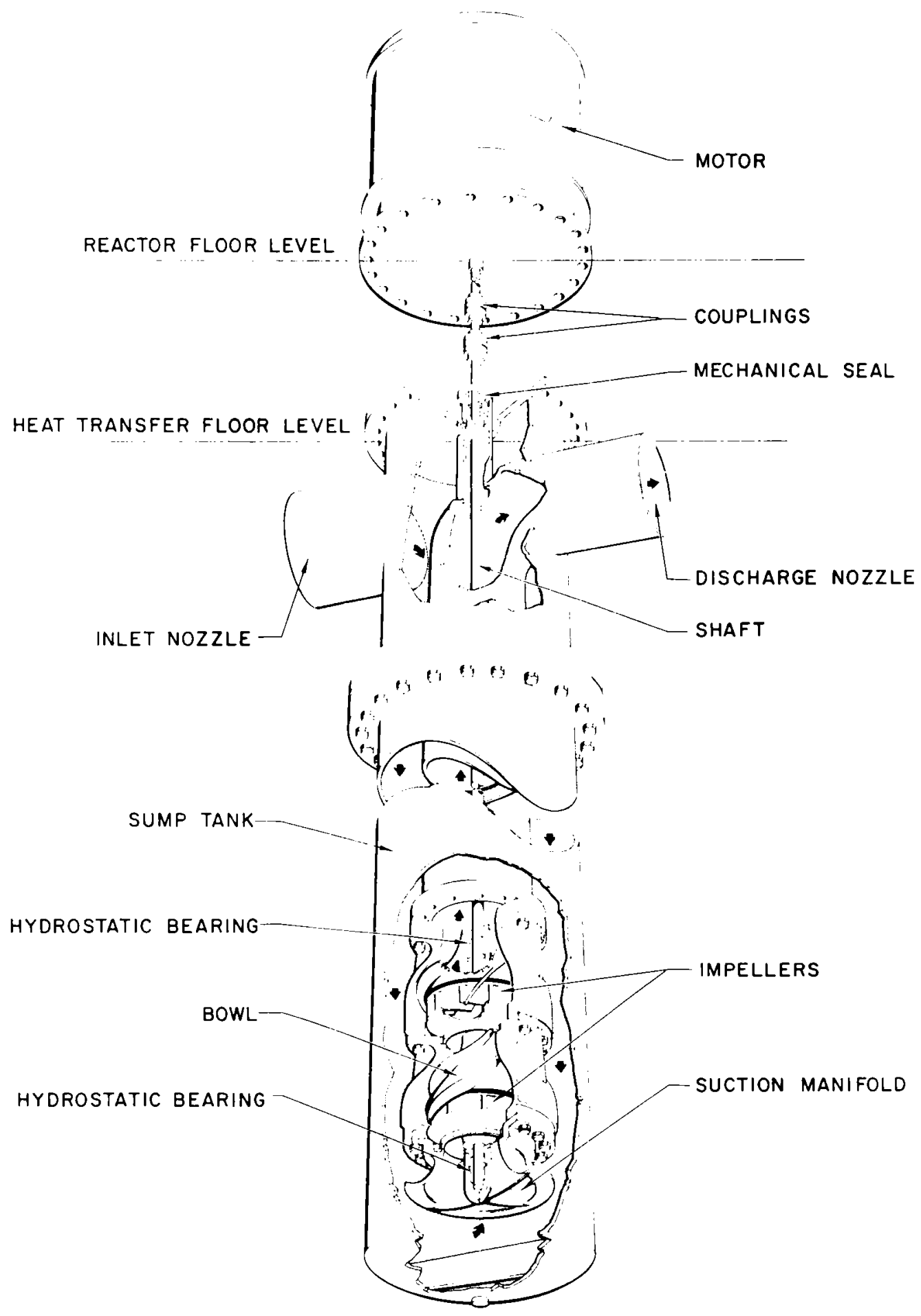

Figure 12. Circulating Pump

III -12 


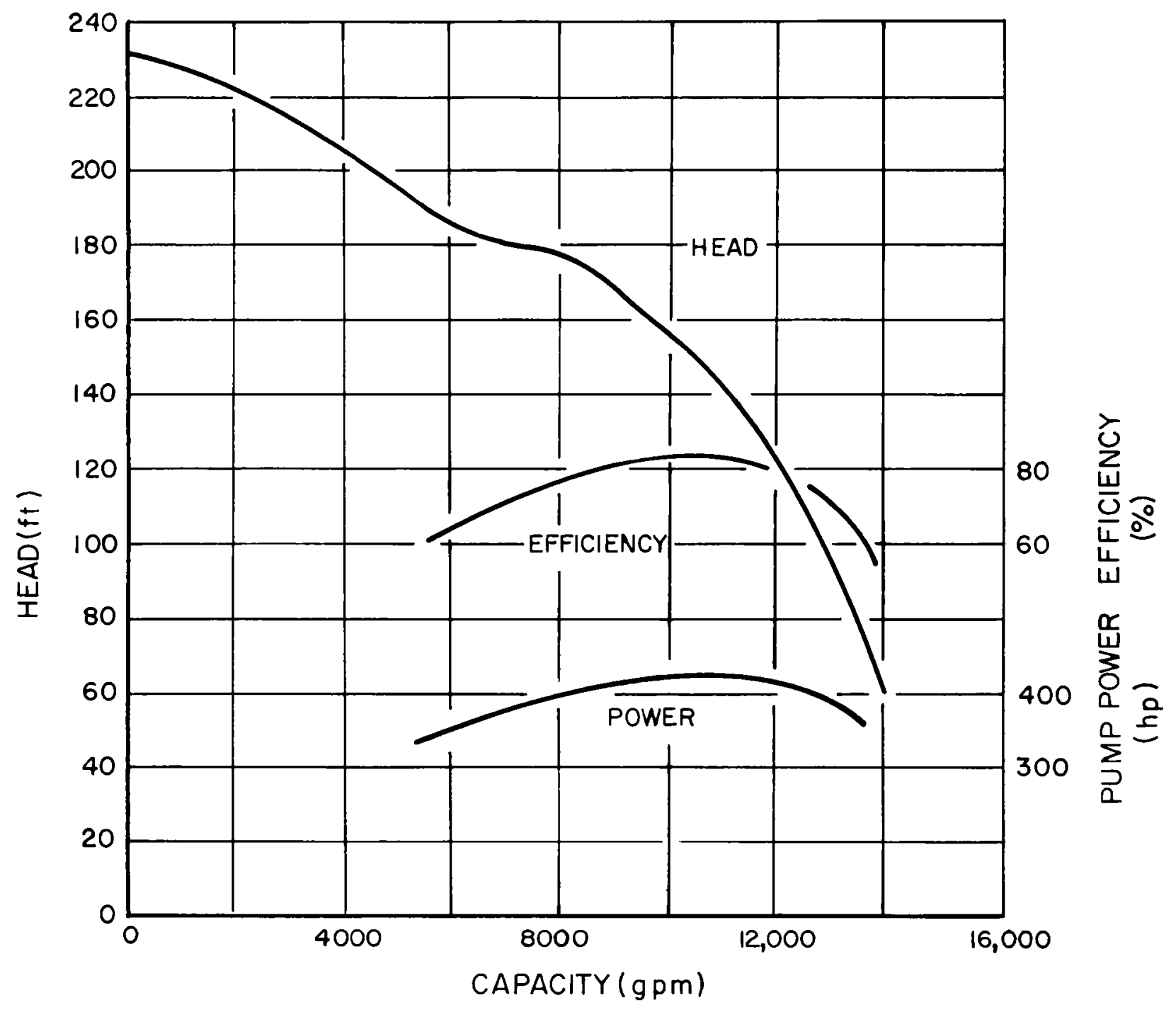

Figure 13. Main Circulating Pump Performance Characteristics 
have identical features to the main block valves. The venturi-ball valves on the bypass lines are constructed of cast carbon steel, with chromium-iron trim, hard faced with No. 6 Stellite. Plain bonnets and conventional style stuffing boxes are provided, filled with high temperature metallic or semi-metallic packing. The valves are direct-welded to the line.

The steam for the turbine is generated in two boiler-superheater units, each connected to one of the primary organic coolant loops. Except for common feedwater supply lines and steam headers with unit isolation valves, the steam generators are in no way interconnected, either on the organic or steam side, and can be shut down individually for control purposes or maintenance. The boiler is a conventional vertical type heat exchanger with $\mathrm{U}$-tube bundle to avoid thermal expansion problems of the tubes. The superheater is a vertical exchanger with straight tubes in fixed tube sheets. The tube size in both units is 5/8-inch diameter by No. 16 BWG wall thickness. As indicated in Figure 14, the superheater and boiler vessel are positioned vertically with the superheater located at a lower elevation to facilitate piping and equipment layout. Under full-load conditions, the coolant enters the superheater at $675^{\circ} \mathrm{F}$ and leaves the boiler at $620^{\circ} \mathrm{F}$. The coolant flows through the shell side of the superheater and the tube side of the boiler. The coolant velocity through the tubes is approximately 12 feet per second. Coolant pressure drop through the boiler-superheater unit is 18 psi at full flow.

Feedwater is supplied to the boiler at the same elevation as normal water level. An internal downcomer supplies the feedwater to the heat transfer area. The steam generated in the boiler passes through the moisture separators and steam dryers before entering the superheater. This moisture separation equipment, in conjunction with the large steam disengagement area, is capable of maintaining a load change rate of $20 \%$ to $80 \%$ of nominal power in 10 seconds with total solids carryover not to exceed 1 ppm with a boiler water concentration of $2000 \mathrm{ppm}$.

Each boiler-superheater unit is designed to generate $150,000 \mathrm{lb} / \mathrm{hr}$ steam at 450 psig, $650^{\circ} \mathrm{F}$ at the superheater outlet, with an organic coolant flow rate of $5.65 \times 10^{6} \mathrm{lb} / \mathrm{hr}$, and boiler feedwater at $330^{\circ} \mathrm{F}$. The steam pressure drop through the steam generator is approximately $15 \mathrm{psi}$. 


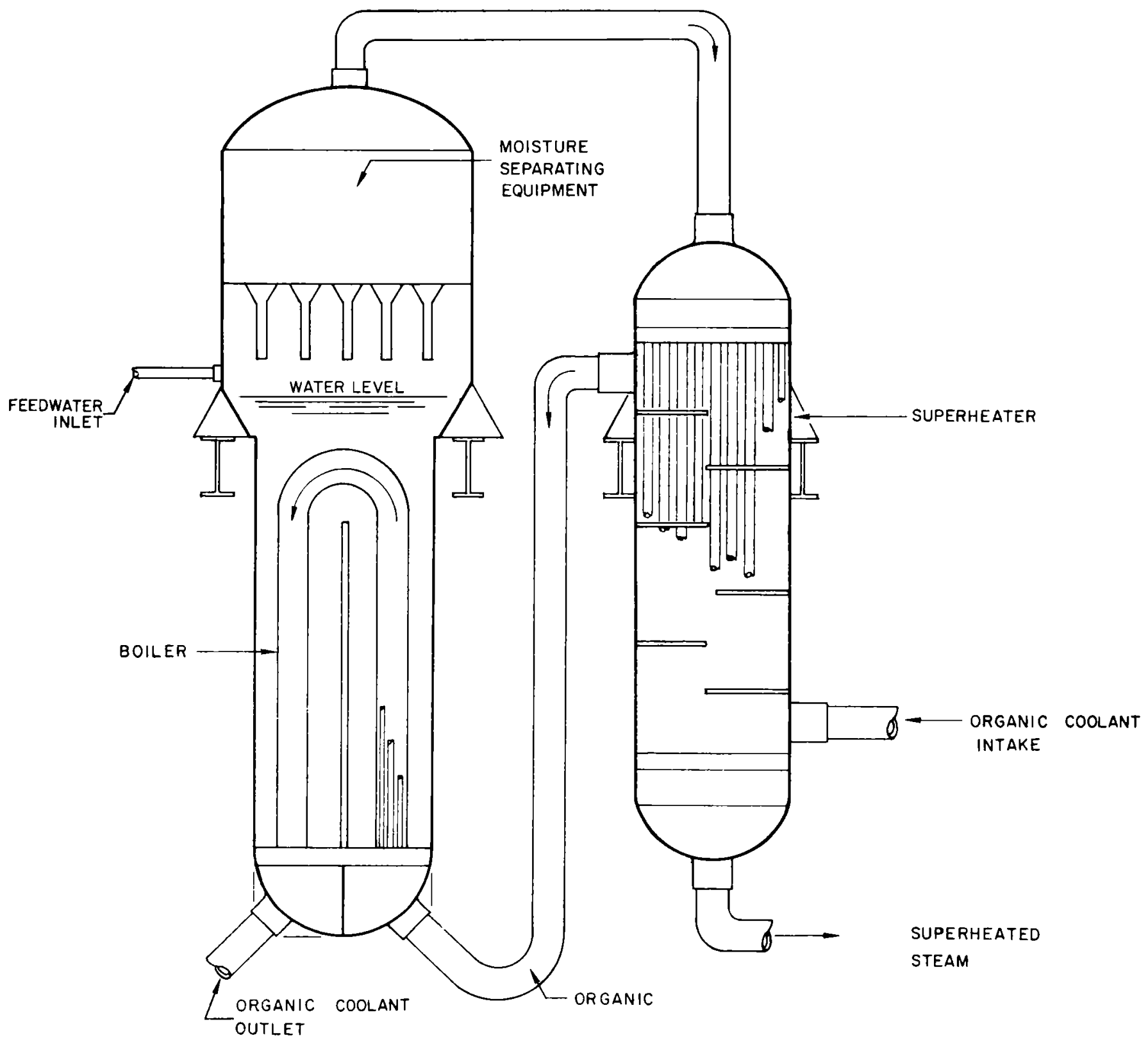

Figure 14. Steam Generator and Superheater 
The overall heat transfer coefficients used for sizing the boiler and superheater surfaces are $200 \mathrm{Btu} / \mathrm{ft}^{2}-\mathrm{hr}-{ }^{\circ} \mathrm{F}$ and $100 \mathrm{Btu} / \mathrm{ft}^{2}-\mathrm{hr}-{ }^{\circ} \mathrm{F}$ respectively, based on heat transfer studies on the coolant, and applying appropriate fouling factors. The heat exchanging surfaces for each unit are:

$\begin{array}{ll}\text { Boiler } & 3835 \mathrm{sq} \mathrm{ft} \\ \text { Superheater } & 2215 \mathrm{sq} \mathrm{ft}\end{array}$

The steam generators are completely shop assembled and are fabricated of low carbon steel throughout, in accordance with the applicable sections of the ASME codes. Boilers and superheaters are of all welded construction to preserve the integrity of the system, and are pressure and radiograph tested in accordance with Code requirements. In addition, all sections in contact with the organic coolant are halogen leak tested. Manholes and hand holes are provided for inspection of internals.

Each heat transfer loop is provided with a flowmeter in the bypass line and in the main circuit upstream of the reactor. These flowmeters are equipped with four sets of taps for measuring pressure differential. One set of taps in the bypass meter provides a signal for flow control and is recorded. Three sets of signals in both meters are available for the reactor safety circuit. Carbon steel flow tubes with stainless steel throats are used for the metering devices and are designed for 400 inches of water maximum pressure differential. Flanged connections are provided for convenient removal of individual flowmeter assemblies whenever necessary.

A 2000 gallon carbon steel vertical surge tank is provided to cushion minor pressure surges in the system and to act as a reservoir of coolant in the event of a very rapid contraction in volume due to temperature lowering. The tank is positioned in the piping to the reactor on one loop between the r eactor and the block valves. A nitrogen supply line is connected to the tank to provide a gas cushion in the system. The tank is connected to the heat transfer loop piping with a loop seal, and this connecting line is provided with a remote operated valve to enable isolating this tank from the system.

The piping on the main circuit in each heat transfer loop is type ASTM A-106, Grade $B$ carbon steel. The main circuit and the bypass piping is 3/8-inch wall 
thickness on all lines of 12 inches diameter or larger. All connecting lines 2 inches through 10 inches in diameter are schedule 40, and all lines under 2 inches are schedule 80. An all-welded fabrication is employed for the entire heat transfer system, with the exception of the flowmeters and the main coolant pumps. These connections are made up with ring joint flanges, using soft iron gaskets. Adequate flexibility has been designed into the piping to minimize stresses from thermal expansion. All piping in the heat transfer system is steam traced and insulated.

All straight piping is covered with aluminum jacketed calcium silicate segmental insulation. All pipes 1-1/2 inches and smaller in diameter are covered with single layer insulation. All pipes 2 inches and larger which are below $600^{\circ} \mathrm{F}$ temperature also have single layer insulation. All pipes 2 inches and larger which are at $600^{\circ} \mathrm{F}$ or above are covered with two layer insulation. Flanges, elbows and other fittings, 6 inches and larger, are covered with wedge shaped sections of sectional insulation, held in place with tie-wires, and the joints filled with insulating cement. Elbows and fittings 4 inches and smaller are insulated with insulating cement. An asbestos finishing cement is applied over the insulated elbows, flanges, and other fittings. Vessels are insulated with calcium-silicate block insulation. An asbestos finishing cement is applied as a finish coat over the insulation.

The heat transfer system is designed for approximately constant flow through the reactor, and variable flow through the steam generators. At full reactor power, both loops are in operation, with the main block valves open and the main coolant pumps circulating Santowax $R$ from the reactor through the steam generator and back to the reactor. The control gate valve downstream of the bypass line in each loop is in the full open position, and the venturi-ball valve in the bypass line is closed, with only a small flow through this line to keep it hot. Under normal operating conditions, both loops will be in service, however, it is feasible to maintain operations at approximately $55 \%$ of plant rated power with only one loop running. The plant should not be operated for extended periods of time with one loop in service, because the coolant circulation rate to the reactor vessel would be inadequate to prevent fouling. 
At reduced power demand, the coolant flow to the steam generator is reduced proportionately. This is accomplished by opening the venturi-ball valve in the bypass line and allowing a controlled amount of coolant to bypass the generator. As power demand decreases, the coolant flow through the bypass increases. The venturi-ball valve has ample capacity for the coolant bypassing required for normal operations. At low power demand, where it becomes necessary to bypass large quantities of coolant, it is necessary to reduce the flow to the steam generator by throttling the 16 -inch control gate valve in incremental steps and the venturi-ball valve is modulated to obtain the required flow through the steam generator. The plant control system is programmed to give the above sequence of valve operations. Both loops are modulated in equal amount under normal operations. The control valves are interlocked to prevent accidental closure of all valves in one loop at any time. 


\section{REACTOR AUXILIARY SYSTEMS}

\section{A. PURIFICATION SYSTEM}

The coolant purification system has two functions: the control of the high boiler compound (HBC) content of the heat transfer system, and the removal of particulate matter from the coolant makeup streams. The HBC content of the reactor coolant is controlled to approximately $30 \%$ by weight by processing a stream of coolant from the reactor through a distillation unit. The rate of processing is determined by the rate of $\mathrm{HBC}$ formed by radiolytic and pyrolytic damage in the reactor. New coolant makeup is heated to $675^{\circ} \mathrm{F}$ by a $5 \mathrm{kw}$ heater and is mixed with coolant from the main heat transfer system. This mixture is fed to the flash section of the distillation column at a controlled rate. The flash chamber is maintained at a pressure of 1 psia, thereby causing approximately $68 \%$ of the feed to flash to vapor. The remaining liquid flows down through the lower packed section to the heated still bottom to effectively strip most of the coolant from the HBC and particulate matter. The HBC then flows by gravity from the column into a holdup tank, then into the HBC incinerator for disposal by burning. If the activity in the $\mathrm{HBC}$ is excessive the $\mathrm{HBC}$ can be stored in a 15,000 gallon storage tank. This tank is adequately sized to store all the HBC produced on a round trip. At the end of the trip the $\mathrm{HBC}$ is pumped by a gear pump to decay storage tanks on shore.

Vapors leaving the still flow to the still condenser where most of the coolant vapors are condensed. The temperature in the condenser must be high enough to keep the condensed coolant in a liquid state. A pressurized water cooling system is used, employing pressurized boiler feedwater. The boiler feedwater from the condensers is returned to the system via the deaerator heater, thereby returning this useful heat energy to the system. The condensed organic material drains to the 500-gallon purification product receiver tank.

Only a small amount of organic material is in the vapor stream leaving the condenser and this concentration is reduced in one of two full capacity freeze traps. The freeze traps are horizontally-mounted fin tube condensers with cooling water flowing through the tubes at the coolant temperature. The organic 
material freezes out on the condensing surfaces for a 24 hour period. At the end of this time the alternate trap is placed in service and the fouled trap is taken off stream. The steam tracing on the body of the trap provides sufficient heat to melt the organic material in the trap, allowing it to drain to the purification product receiver tank. One of two $5 \mathrm{gpm}$ coolant makeup pumps transfers the purified coolant from the purification product receiver tank to the degasification system.

The constitution of the noncondensable gases leaving the freeze traps is water vapor, nitrogen, hydrogen and a negligible amount of organic material. The water is removed in the water condenser before the gases pass through the vacuum pump to the gas handling system. Vacuum in the stills, condensers, and freeze traps is maintained by two $2 \mathrm{scfm}$ rotary vacuum pumps provided in parallel arrangement, with one pump as a spare.

\section{B. DEGASIFICATION AND PRESSURIZATION SYSTEM}

The purpose of the degasification and reactor pressurization system is the following: (1) to remove gaseous decomposition products which are produced as a result of the pyrolytic and radiolytic damage to the organic coolant; (2) to remove water vapor which may be introduced through minor leaks in the heat exchangers; (3) to maintain uniform pressure in the reactor and organic loop heat exchange systems; and (4) to provide a volume for thermal expansion of the coolant.

The degasification and reactor pressurization system is a complete circuit originating in the reactor outlet piping and terminating in the reactor inlet piping. The flow of coolant from the degasifier is regulated by manually positioning a flow controller located downstream of the pressurizing pumps to the desired flow rate, approximateiy $220 \mathrm{gpm}$. However, the flow of coolant to the degasifier, which is also the expansion reservoir for the reactor system, is regulated by the pressure control valve to maintain the desired pressure at the reactor core. When the bulk coolant changes temperature the flow automatically varies to compensate for the volume change. Under steady state the flow to and from the degasifier is equal. Two horizontal centrifugal pressurizing pumps are provided, each of which is capable of delivering the full $220 \mathrm{gpm}$ of coolant. 
The degasifier is a 1000 gallon horizontal carbon steel tank fitted with internal spray headers to facilitate diffusion of gases out of the coolant. The degasifier operates at approximately 6 psia. Vapors leaving the degasifier flow to the degasifier condenser where approximately $97 \%$ of the coolant vapor and $6 \%$ of the water vapor present are condensed. The condensate is returned to the degasifier. Vapors leaving the degasifier condenser flow to the after condenser where $95 \%$ of the coolant vapor and $1 \%$ of water vapor present are condensed. This condensate is also returned to the degasifier tank.

The coolant medium for the degasifier condenser and after condenser must be at a temperature which is high enough to prevent freezing of the organic liquid. Pressurized boiler feedwater is used for this service. The boiler feedwater from the condenser is returned to the system via the deaerator heater, thereby returning this heat energy to the system.

A small amount of coolant is in the vapor stream leaving the after condenser and this concentration is further reduced in one of two freeze traps before the vapor stream enters the waste gas handling system. The freeze traps are horizontally-mounted fin tube condensers. Cooling water flows through the tubes, flow controlled to maintain a $150^{\circ} \mathrm{F}$ vapor outlet temperature. At this temperature, the coolant freezes out on the condensing surfaces for a 24 hour service period, at the end of which time the alternate trap is put into service and the fouled trap taken off stream. The stream tracing on the body of the fouled trap will heat the unit up sufficiently to melt the coolant, which will then drain to the degasifier tank. Vacuum in the degasifier and condensers is maintained by two 10 scfm conventional rotary vacuum pumps provided in parallel arrangement, with one pump as a spare.

All Santowax $R$ is purified before it is charged to the reactor process system, and because corrosion products are considered negligible, it is not anticipated that any particulate matter will be present in the bulk coolant. However, in the event particulate matter does enter the system, facilities are provided in the degasifier circuit for its removal. Particles of 5 micron size or larger are removed in a disposable cartridge type filter, positioned upstream of the degasifier tank. The full degasifier stream flows through this unit continuously. In 
the event that fine particulate matter is also present, a portion of the degasifier stream is processed through a continuous solid bowl centrifuge. The solids which collect in the bowl are removed by backwashing. This centrifuging operation is conducted only when warranted.

Degasification may also be performed in the purification still, though not as efficiently as in the degasifier, and pressurization can also be accomplished at the surge tank liquid surface; permitting the degasification circuit to be temporarily shut down for repair without shutting down the reactor.

\section{DECAY HEAT REMOVAL AND EMERGENCY COOLING}

A major requirement for the plant is the continuous and safe removal of decay heat from the reactor after shutdown. Under normal operations this is provided by using the steam generators in the heat transfer system. An auxiliary decay heat removal system is provided for emergency conditions, such as operating the reactor with one loop out of service.

The heat removal rate required is a function of time, and is shown by the decay heat curve in Figure 15. For a normal plant shutdown, with electric power available, the decay heat is removed from the reactor by continuing the circulation of coolant through the heat transfer system. The steam generated as a result of this is dumped into the turbine condenser through the turbine bypass system.

For emergency conditions, such as a total loss of electric power which would make the main coolant pumps and the condenser circulating water pumps inoperable, the decay heat is removed from the reactor by natural convection flow through the heat transfer system. This is provided for in the design of the system, by locating the thermal center of the steam generators at a suitably higher elevation than the thermal center of the reactor core. However, to assist the removal of sensible heat from the core during the period of normal flow decay, flywheels and pony motors are provided on the main coolant pumps. With the arrangement shown on Plate III decay heat can be removed by natural convective cooling. This heat removal rate can be increased by reducing the steam generator pressure, which would result in lowering the reactor inlet temperature.

IV -4 


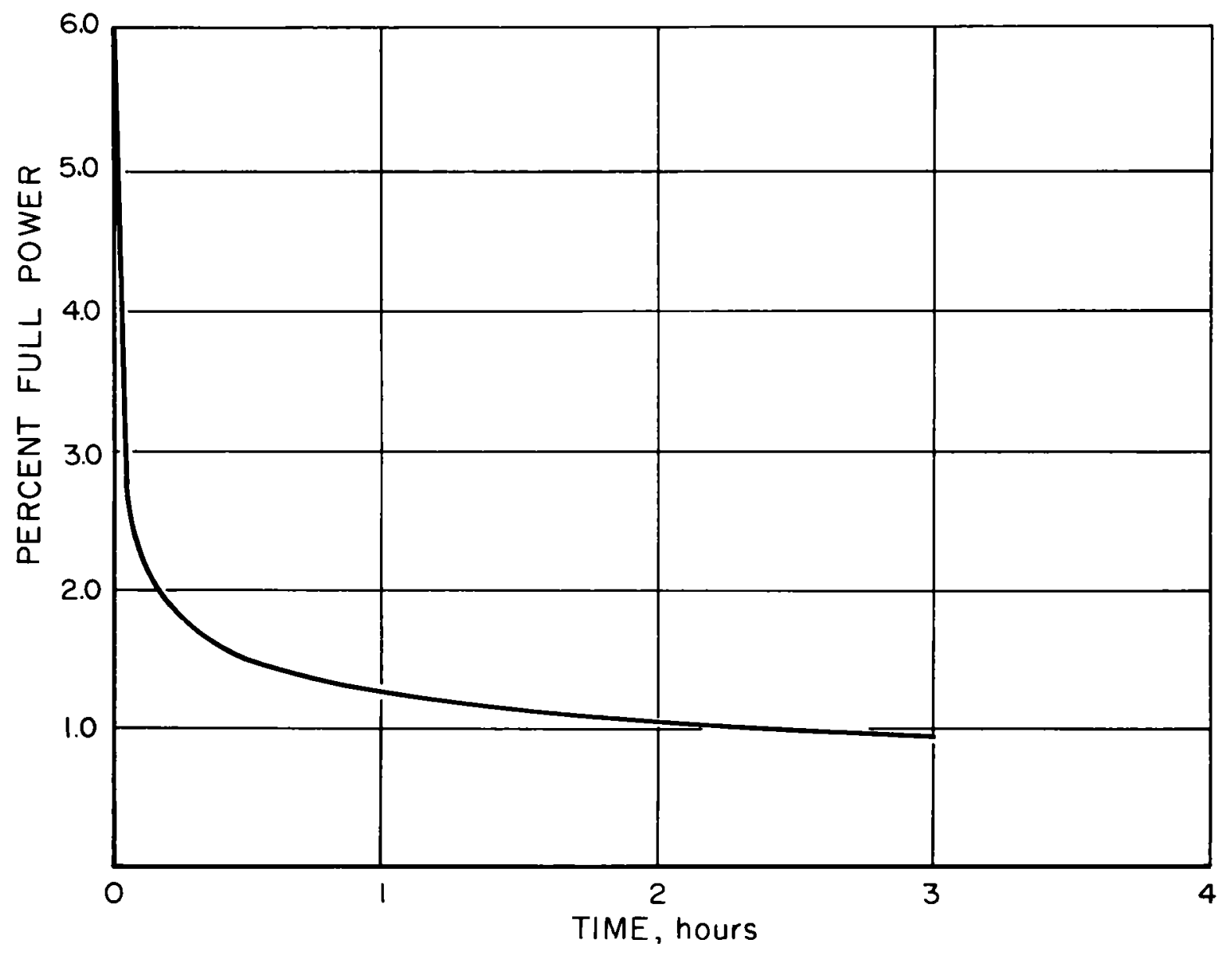

Figure 15. Decay Heat Generation 
For conditions where neither steam generator can be used for decay heat removal, the decay pumps circulate coolant through the decay heat exchanger where the heat is transferred to a pool of boiler feedwater. This water is thus heated and boils, causing vapors to pass to the air fin condenser located on the main deck. This system is pressurized at 50 psia in order to maintain a boiling temperature above the melting point of the coolant.

As heat is removed from the coolant in the steam generators, a portion of the steam thus produced is used to operate one of three steam-turbine-driven boiler feedwater pumps, which take suction from the turbine condenser hot-well. For emergency operations these pumps are connected to the 10,000 gallon makeup water storage tank. Safety features for an extended period of time beyond this are discussed in Section VIII. Steam produced in excess of the requirements of the turbines is exhausted to the atmosphere through pressure controlled relief valves.

\section{COOLANT DRAINS, VENTS AND FILLS}

Process drains are provided for all equipment and piping containing organic coolant except the reactor. A system of drain headers connected to the low points of the coolant lines and relief headers drains directly into a 10,000 gallon drain tank located in the reactor room. The reactor can be drained by gravity only down to the level of the block valves in the coolant return line ensuring that the reactor core cannot be drained inadvertently. The lower part of the reactor can be emptied only by pressurized transfer.

The drain tank is sized to contain the total capacity of both coolant loops or the entire contents of the reactor. If the reactor is drained, the organic liquid in the coolant loops will be retained in the loops. Organic liquid is transferred from the drain tanks by two $50 \mathrm{gpm}$ centrifugal pumps. The manifolded discharge from the drain tank pumps flows through a 50 micron disposable cartridge filter to either the reactor coolant system or the purification system for processing. The auxiliary systems drain to appropriate tanks where the organic liquid may be held up or transferred to the drain tank by gas pressurization or existing pumping facilities.

IV -6 
The high points of the organic coolant system are vented to the top of the reactor drain tanks. The drain tanks are in turn vented to the relief system condenser. The organic heat transfer system can be filled by transfer from the reactor drain tanks, the degasifier tank or the purification system product receiver tanks. Prior to filling, the system is thoroughly purged with nitrogen gas. All vent, drain, relief and fill lines are insulated and steam traced.

\section{E. PRESSURE RELIEF}

A pressure relief system is provided to protect against over-pressure in any part of the process systems. All equipment and associated piping are protected by relief valves or rupture discs in accordance with the ASME and ASA Code. The relieving devices are installed on all equipment which could be subjected to over-pressure due to an operational error or equipment failure. Most important of the relieving systems are those on the main heat transfer loops. Two 6 inch by 8 inch relief valves on each loop provide sufficient capacity to relieve the complete flow of coolant caused by flashing water which would enter the loop if one steam generator tube should completely rupture below the water level. These relief valves are piped to a relief header running to the reactor drain tank which in turn is vented to the relief condenser.

Two power actuated relief valves are provided on the steam side of each steam generator and are tripped by a rise in main heat transfer loop pressure. This will reduce the differential pressure between the steam system and the heat transfer system, thus reducing flow. These valves are set to close if the pressure in the organic coolant system approaches that in the boiler. A power actuated shut-off valve is provided on the feedwater to each steam generator which will also trip on high coolant loop pressure. This will limit the supply of water available during a tube rupture. One 3 inch by 4 inch pressure relief valve is provided on the reactor coolant header inside the block valves to provide for pressure relief if the reactor should become blocked in. Vapors and gases from the reactor drain tanks are condensed or scrubbed in the 2500 gallon relief system condenser and associated scrubber. If a large volume of noncondensable gas such as purge nitrogen is vented to the relief system, it is normally discharged through a monitored line to the stack. 


\section{F. NITROGEN SYSTEM}

The purposes of the nitrogen system are to provide a pressurized inert cover gas in the reactor surge tank, to provide an inert atmosphere in tanks containing organic coolant or its vapors to minimize the fire or explosion hazard and to supply an inert gas for purging the heat transfer system.

The system consists of a bank of nitrogen cylinders connected to a main header with a pressure reducing station which maintains the supply pressure at approximately $60 \mathrm{psig}$. A relief valve is provided on the header to protect the equipment and piping system downstream. Small pressure control valves provide the nitrogen at approximately $45 \mathrm{psig}$ as required at each unit. The nitrogen supply consists of 16 cylinders, each having a capacity of 230 scf or a total capacity of 3500 scf. This provides sufficient nitrogen to permit approximately seven purges of one heat transfer loop.

\section{G. NEW COOLANT STORAGE AND HANDLING}

The amount of decomposition products generated is approximately $2040 \mathrm{lb}$ per day, or $112,000 \mathrm{lb}$ for a round trip. Facilities must be provided to continuously supply new coolant makeup to the primary system in equal quantity to the decomposition rate. An 18,000 gallon new coolant storage tank is provided, which will give ample storage capacity for the round trip. In the event that suitable dock facilities for molten coolant delivery cannot be obtained, new coolant will be purchased in package form. The storage tank is insulated and is equipped with plate steam coils, with ample heating capacity to melt the new coolant. New coolant is introduced into the feed stream to the purification system by a manually set controlled volume pump. Feed rate is adjusted to make up for decomposition products removed from the heat transfer system.

\section{H. PREHEATING}

Santowax $R$ has an upper melting point of approximately $300^{\circ} \mathrm{F}$. Therefore all organic coolant piping and equipment in the process systems must be initially preheated before the coolant is charged. In tankage and intermittently-circulated lines which are not heated by process requirements, heat has to be continuously 
supplied to keep the organic coolant in a liquid state. Finally, in the event of shutdown or temporarily restricted flow in all parts of the process system, except the reactor, heat will also have to be supplied. The heat required to keep organic coolant fluid in these lines and equipment is supplied from the 250 psig steam system which is always in operation. This system will serve to preheat all lines and equipment except the reactor and steam generating equipment. The steam generating equipment will be preheated by circulating hot pressurized water through the equipment on the steam side. The 250 psig steam system heats the water in an exchanger and an auxiliary pump is used for circulation. The reactor is preheated initially by circulating hot air at $500^{\circ} \mathrm{F}$ through temporary ducting. An electric heater and blower are used. Thermocouples are provided at various points throughout the system to check the preheat temperatures.

When the system is preheated to approximately $350^{\circ} \mathrm{F}$, molten coolant which has been purified in the distillation section is charged to the system. When the reactor and one coolant loop are filled, the circulating pump in the loop is started and the energy dissipated from pumping serves to further preheat the system. The remaining coolant loop is filled and the entire system circulated.

\section{BIOLOGICAL SHIELD COOLING SYSTEM}

The purpose of the biological shield cooling is to provide adequate cooling thereby protecting it from damage due to excessive temperature. The shield cooling load, both sensible and gamma, is estimated to be approximately $600,000 \mathrm{Btu} / \mathrm{hr}$. This heat with no external cooling would result in raising the temperature of the shielding water excessively, causing it to boil, with a resultant increase in system pressure. It is desirable to keep this temperature below $150^{\circ} \mathrm{F}$, and therefore $115^{\circ} \mathrm{F}$ was taken as a design maximum. Cooling is accomplished by circulating the primary shield water through an externally located heat exchanger where this heat is removed. Distilled borated water is used for the primary shield. An expansion tank is provided in the cooling circuit, with provision for adding distilled water makeup.

\section{J. WASTE GAS HANDLING}

The waste gas handling system separates the radioactive fission product gases from the non-radioactive waste gas for storage and final disposal. Hydrogen 
and hydrocarbon gases are generated by the decomposition of the organic coolant at about $4 \mathrm{scfh}$. Until the plant experiences ruptured fuel elements the waste gas stream from the degasifier and purification still consists essentially of these materials. However, with small breaks in the fuel cladding fission product gases are released to the reactor organic coolant and the gas streams will contain small quantities of the radioactive isotopes of xenon and krypton, and trace quantities of bromine and iodine. The stream is monitored continuously for radioactivity concentration. The radiation indicator controller allows the gas to flow to the stack while the activity is low enough to permit mixing the gas stream with the ship ventilation system discharge so that the air discharged to the stack is below the maximum permissible concentration for unidentified isotopes. When the radiation content approaches the limiting value the stream is diverted to the waste gas handling system to separate the xenon and krypton from the nonradioactive gases.

When the gas stream is diverted to the waste gas handling system, hydrogen and hydrocarbons contaminated with radioactive xenon and krypton flows up a packed absorption column and is contacted by Amsco solvent. This material is a specific absorber for the xenon and krypton removing them from the hydrogen carrier gas. The various hydrocarbon gases present will also be absorbed, however this will not effect the absorptivity of the Amsco solvent for xenon and krypton to any appreciable degree. In the event that the concentration of xenon and krypton in the Amsco builds up to its saturation level, any breakthrough in radioactivity from the packed column will be detected by the radioactivity indicator. An alarm is sounded, informing the operator that the Amsco solvent has lost absorption efficiency and requires some purging.

\section{K. LIQUID ORGANIC WASTE HANDLING}

The liquid organic waste handling facilities on board ship are designed to incinerate or store the high boiler compound (HBC) obtained in the purification system. Polymerization of the organic coolant generates approximately $85 \mathrm{lb} / \mathrm{hr}$ of HBC. OMRE operating data shows that the iodine and bromine isotopes combine with the HBC and the coolant making it very radioactive. The HBC is separated from the coolant in the distillation unit, and is stored in a 15,000 gallon

IV -10 
tank or burned. This tank is adequately sized to contain all the HBC generated on a 54 day round trip. When the ship reaches port the contents of the storage tank are pumped to a barge or shore facilities for decay storage and ultimate disposal by burning.

\section{AQUEOUS WASTE DISPOSAL SYSTEM}

The purpose of the aqueous waste disposal system is to prevent the uncontrolled discharge of contaminated water from the ship. The only continuous sources of aqueous waste are from the water condensers in the degasification and purification systems. Other aqueous waste is generated batchwise from the relief system condensers and the gas scrubber. The continuous waste is approximately 2 gallons per hour and contains trace quantities of iodine and bromine, plus negligible quantities of particulate matter and organic material.

This aqueous waste generated from the degasification and purification systems is collected in a 2500 gallon tank, which is large enough for round trip requirements. At arrival at the home port, the aqueous waste is transferred to a barge for final disposal. The relief system condenser and gas scrubber contain approximately 2500 gallons of contaminated water. This can also be transferred to the barge for final disposal when the ship is in port.

\section{SOLID WASTE DISPOSAL}

These facilities provide a means for the safe handling of solid radioactive waste. Solid radioactive wastes such as, contaminated clothing, equipment, filter pads and small quantities of very high level liquids are transported to a shielded area for temporary storage and accumulation. When the ship arrives at the home port, the contents are transferred to the barge for final disposal.

\section{N. DECONTAMINATION FACILITIES}

The decontamination room provides an area in which contact decontamination can be performed on large or small components with safety to the operating personnel. The specially designed room is equipped with ventilation safeguards, fire protection, and radiation monitoring which permit the operation of equipment designed to manually decontaminate the surfaces of reactor plant equipment 
without endangering operating personnel, the plant or the public. Therefore, only parts having an activity level less than about $50 \mathrm{mr} / \mathrm{hr}$ may be handled. The decontamination is performed with conventional apparatus such as an ultrasonic cleaner for small parts, a steam cabinet and exhaust hood for larger parts. All effluents are held up and monitored before release.

IV -12 


\section{TURBINE PLANT}

\section{A. GENERAL DESCRIPTION OF POWER PLANT}

The main condensate and feedwater system is arranged as a closed, three stage feed heating system and will fully deaerate all of the feedwater. It consists of condensate pumps, air ejectors with combined inter, after and gland condensers, low pressure feedwater heater, direct contact deaerating feedwater heater with vent condenser, high pressure feedwater heater and feedwater pumps.

The steam conditions at the steam generator outlet for normal power are $450 \mathrm{psig}, 650^{\circ} \mathrm{F}$, with a feedwater temperature of approximately $325^{\circ} \mathrm{F}$. The steam flow to the high pressure turbine is $219,810 \mathrm{lb} / \mathrm{hr}$ as illustrated in Plate I.

The main turbines will develop 27, 250 SHP at approximately $109 \mathrm{rpm}$ and 30,000 SHP at approximately $113 \mathrm{rpm}$ when operating with steam at $425 \mathrm{psig}$ and $650^{\circ} \mathrm{F}$ with a vacuum of 28.0 inches of mercury.

Two turbine generators rated at $2000 \mathrm{kw}$ per unit are supplied for each ship, and have an overload rating of $25 \%$ for two hours. Each generator turbine exhausts to separate auxiliary condensers. Two auxiliary air ejectors, including gland condensers, are also supplied.

There are two main condensate pumps, each having sufficient capacity to handle the condensate from the main condenser under maximum power conditions. The pump takes suction from the main condenser hotwell and discharges through the main air ejector to the low pressure feedwater heater.

There are two auxiliary condensate pumps, each having sufficient capacity to handle the maximum condensate and drains from one auxiliary condenser. The auxiliary condensate discharges through the auxiliary air ejector inter, after and gland condenser to the main condensate system after the main air ejector assembly.

There are three main feedwater pumps which take suction from the deaerating feedwater heater and discharge through the high pressure feedwater heater to the steam generator. 


\section{B. DESCRIPTION OF MAIN TURBINES AND REDUCTION GEARS}

Each main propelling unit consists of a double reduction geared compound marine turbine. The turbines consist of one high pressure ahead turbine and one low pressure ahead turbine, each in a casing of its own, connected to one double reduction gear. The astern turbine is located in the forward end of the low pressure turbine casing.

The steam flows aft through the high pressure turbine and forward through the low pressure turbine and exhausts downward to a condenser bolted to and supported by the turbine.

The main turbines are capable of developing a normal SHP of 27, 250 at 109 propeller rpm and a maximum continuous SHP of 30,000 at $113 \mathrm{rpm}$ when supplied with steam at $425 \mathrm{psig}, 650^{\circ} \mathrm{F}$ and exhausting to a vacuum of 28.0 inches of mercury. The turbines are designed for three points of extraction.

The astern turbine is capable of developing $80 \%$ of the ahead torque at $50 \%$.

The machinery conforms to the rules prescribed by the American Bureau of Shipping, U.S. Coast Guard and American Institute of Electrical Engineers, Marine Rules No. 45.

\section{Turbines-General}

The power is divided approximately equally between the two turbines at full power.

Nozzles are divided into groups for the purpose of obtaining the best efficiency at varying speeds of the ship. The main nozzle group is controlled by the main throttle valve. Each other group of nozzles is controlled by the throttle valve, but has in addition, separate hand operated nozzle control valves built into the turbine casing.

The stresses of the turbine rotors, including blading, is moderate and will not exceed one-third of the yield strength of the material at a speed corresponding to $103.2 \%$ of normal speed. Turbine casings and diaphragms are split on the horizontal centerline. The turbines are designed to allow expansion in any direction without affecting the alignment of the rotors. The forward end of the 
high pressure turbine is supported on an I-beam having a thin web to allow for fore and aft expansion of the turbine.

\section{High Pressure Turbine}

The high pressure turbine is of the impulse type consisting of several single row stages. The nozzles are of the built-up type with accurately machined surfaces from inlet to exit. Nozzle blades are of stainless steel of grade proven to be highly resistant to corrosion and erosion under working conditions. Nozzle blocks are renewable and separate from chest. The turbine casing is of cast carbon steel with integral nozzle chest. The exhaust end of the casing is of carbon steel.

The rotor is machined from a solid forging, finish machined all over and accurately balanced. The high pressure turbine thrust bearing is of the sixshoe Kingsbury cage type. An extraction opening is provided to extract steam for feed heating purposes.

\section{Low Pressure Turbine}

The low pressure turbine is of the single flow impulse type. The rotor is a combination of solid and built-up types. The ahead rotor blading is of corrosion resisting steel. Thrust is to be carried by a six-shoe Kingsbury cage type thrust bearing.

The low pressure turbine casing is made of a combination of cast carbon steel castings and fabricated steel welded together and split on the horizontal centerline. A manhole is provided for access, located in the turbine exhaust. The turbine casing is made suitable for supporting the weight of the condenser.

Properly formed annular baffles are provided between the last row of ahead blading and the astern turbine to prevent impingement of the exhaust from astern turbine to ahead blades and vice versa. An extraction opening is provided to extract steam for feed heating purposes.

\section{Astern Turbine}

An impulse type astern turbine is incorporated in the forward end of the low pressure turbine casing, with the steam chest separate from the main casing, arranged to guard against excessive heat stresses when astern turbine is in operation. The astern casing is made of carbon steel. 
All turbine blades are of corrosion resisting steel. The stationary blade ring and the diaphragm of the astern turbine is split at the horizontal centerline.

5. Flexible Couplings

Flexible all-metal couplings of the fine tooth type are fitted between each turbine shaft end and pinion to allow for axial and lateral movements of rotors and shaft. Coupling is arranged to permit removal of pinions without disturbing turbine rotors (or vice versa).

6. Turbine Glands

Shaft packing of the labyrinth type is installed in both the high pressure and low pressure turbines where the turbine spindle ends pass through the casings. These glands are arranged for steam sealing to prevent either steam from leaking out of the casing or air into the casing.

\section{Turbine Bearings}

The forward bearings of both the high pressure and low pressure turbines consist of a journal bearing and a pivoted segmental six-shoe Kingsbury type thrust bearing. Bearing shells are of steel backed with surfaces lined with tin base babbitt. The after bearings of high pressure and low pressure turbines consist of horizontally split journal bearings.

\section{Turbine Governors}

A governor system is furnished consisting of an oil pump at the forward end of both high pressure and low pressure turbines which actuate a regulator thereby controlling the steam-operated governor valve. This system prevents overspeeding during ahead operation.

\section{Emergency Operation}

In case of emergency, either the high pressure or low pressure turbine can be operated independently of the other. For this purpose, an emergency exhaust pipe is provided to connect the high pressure turbine exhaust to the exhaust of the low pressure turbine.

\section{Operating Valves}

The maneuvering valves are manually operated, single seated, balanced type valves. There is one ahead maneuvering valve, one astern maneuvering 
valve, and one astern guarding valve. Before the steam enters these maneuvering valves, it passes through a steam strainer. The maneuvering valves may be located to suit the installation in the ship. An oil and spring actuated speed limit governor is provided together with a control valve in the main steam line ahead of the forward maneuvering valve.

\section{Reduction Gears}

Reduction gears are of the double reduction type, arranged to allow the condenser to be installed under the low pressure turbine.

12. Casing

The gear casing is of cast and welded steel construction and is split so as to make the bearings and rotating parts readily accessible. The casings are divided on the horizontal centerline of the main gear and also on the horizontal centerline of the first reduction wheels. The main frame is of heavy box-girder construction. Gear casings are provided with vapor vent connections.

Inspection plates fitted with suitable locks are provided over each pinion and in other required locations. All casing joints are provided with taper dowels to insure correct assembly and alignment. Oil vapor seals are provided where shafts pass through gear casings. The gears are to be so arranged that they permit removal of the first reduction pinions without disturbing the turbines, or vice versa.

\section{Pinions and Gears}

The pinions and gears are of the double helical type. Pinions are of the two bearing type, and total length of faces, including gap, does not exceed two and one-half times their pitch diameter. All rotating parts are balanced.

14. Bearings

The bearing shells are of steel, made in halves and lined with babbitt. The bottom halves are arranged to roll out without removing pinions and gears. Lifting yokes of satisfactory design are provided for this purpose.

15. Gauges and Thermometers

A pressure gauge is fitted on the main lubricating oil manifold. Ther mometer and sight flow or spinner fittings are installed on all bearings including 
the main thrust bearing. Gauges and fittings are visible to operating personnel. Sight flow or spinner glass are Pyrex or equal.

\section{Turning Gear}

The aft end of one high speed pinion shaft is provided with a suitable extension for a turning gear, the housing for which is rigidly secured to the main gear case. The turning gear is operated by an electric motor through worm gears with suitable disconnecting clutch and is capable of turning the propeller shaft and connections one complete turn in eight minutes and also, is capable of being operated continuously without overheating. The motor meets the requirements of the Classification Societies and is in accordance with the latest A.I.E.E. Marine Rules. The high speed pinion not connected to the motor driven turning gear is squared for a ratchet type of hand turning gear.

\section{Main Thrust Bearing}

The main propeller thrust bearing is of the double eight-shoe type located in a separate housing aft of the reduction gear coupling. An oil tight cover is provided between the main gear and the thrust bearing housing.

\section{Low Lube Oil Protection}

Protection against low oil pressure is provided by means of a regulating valve which shuts off the supply of steam to the unit if the oil pressure falls below a predetermined value.

\section{DESCRIPTION OF AUXILIARY TURBINE GENERATORS}

There are two $2000 \mathrm{kw}, 450$ volt, 3 phase, 60 cycle, 0.8 power factor, $2500 \mathrm{KVA}$ turbine generators per ship. Each unit is entirely self-contained and complete with accessories. These units will operate satisfactorily while the ship is rolling at an angle of 30 degrees, listing permanently 15 degrees to either side and a permanent inclination of 5 degrees fore and aft.

Each unit is designed to operate normally at $425 \mathrm{psig}, 650^{\circ} \mathrm{F}$ at the turbine throttle, exhausting to 2.0 inches mercury absolute at the turbine exhaust flange. It is capable of developing $125 \%$ normal load under designed steam conditions for two hours. 
Each unit is equipped with a closed pressure oil system which serves both lubricating and speed governing purposes and a system of controls which includes a regulating governor and an overspeed trip governor along with emergency stop for protection against low oil pressure and excessive back pressure.

The turbine generator sets conform to the requirements of the American Bureau of Shipping, U.S. Coast Guard, and American Institute of Electrical Engineers, Marine Rules No. 45 and related regulatory bodies.

\section{Turbine}

The turbine is of the multistage impulse type, designed and constructed so that no injurious distortions will occur with changes in load. The complete rotor is in dynamic balance. The turbine blading is of corrosion resisting steel. The rotor, including blading, has a minimum factor of safety of 3 based on the yield point when operating at rated load and speed. The turbine steam chest and casing is of carbon steel.

The turbine operates at the optimum speed and drives the generator through reduction gearing at $1200 \mathrm{rpm}$. A manually and motor operated speed changer is included for the purpose of changing the speed of the unit while in operation.

The turbine nozzle valves are of the multi-valve type and are controlled automatically by the governor system. As the load (and consequently the demand for steam) increases, the valves open progressively. The procedure is reversed as the load decreases. The turbine nozzles, and the nozzle partitions of the diaphragms are of corrosion resisting steel. The diaphragms are of steel.

\section{Turbine Control}

A throttle trip valve is furnished which contains the conventional handwheel throttle together with a quick closing device which operates to shut off the flow of steam immediately if the speed of the turbine should exceed a predetermined rate. This device can be tripped manually if desired.

A combination mechanical and oil operated speed regulating device is furnished which controls automatically the multisteam valve arrangement. The drop-in speed from no load to full load will not exceed 3.5\%. The speed regulation 
curve will not vary more than $1 \%$ from a straight line drawn between the speeds at $20 \%$ and $100 \%$ load.

The control system also includes a low oil pressure stop which shuts down the unit if the oil pressure drops below a predetermined amount and a similar device to shut down the unit if the back pressure should become excessive.

\section{Bearing $\mathbf{s}$}

The main bearing shells of the turbine are horizontally split and lined with high grade babbitt. They are arranged for pressure lubrication. These bearings are removable without removing the turbine rotor.

The turbine thrust bearing is of the pivoted segmental type to maintain the correct axial relations between rotating and stationary parts and is designed to take thrust in both directions.

\section{Turbine Packing}

Labyrinth shaft packing is provided where the turbine shaft passes through the turbine casing and the turbine glands are steam sealed.

\section{Insulation and Lagging}

The high temperature parts of the turbine are covered with heat insulation and sheet steel lagging.

\section{Reduction Gear}

The reduction gear is of the planetary, double helical type. Sun and planets (externally toothed) are of heat treated forged steel, nitrided to a minimum hardness of 75 Rockwell $30 \mathrm{~N}$ scale. Internally toothed gears are of forged steel with a minimum Brinell hardness of 260 . The gear is connected to the turbine by a flexible coupling and to the generator by a solid coupling.

\section{Generators}

Two generator sets are provided. Each generator has a continuous capacity of $2000 \mathrm{kw}, 0.8$ power factor, 450 volts, 3 phase, 60 cycles. They are totally enclosed and fitted with double tube 90-10 copper-nickel alloy salt water air coolers, equipped with suitable thermometers for reading the temperature of 
the air to the generator. Generator fans and coolers provide adequate $50^{\circ} \mathrm{C}$ air (without excessive back pressure on the fans or excessive salt water velocity through the tubes) with the generators operating continuously at full rated load in a $50^{\circ} \mathrm{C}$ ambient with sea water at $85^{\circ} \mathrm{F}$ and a cleanliness factor of $85 \%$.

The main generator leads are brought out on the under side of the generator frame and secured to laminated phenolic supports so as to avoid transmittal of strain to the internal connections. The terminals are arranged to prevent drops of water which may travel along the surface of the generator from running onto the terminals. The main terminal lugs are of the solderless type. The main terminal conduit box has a removable access cover on one side and is open on the bottom. A voltage regulator of the static type, to operate with each exciter, is furnished. The regulator is capable of withstanding shipboard conditions of vibration and moisture.

The turbine generator sets will operate successfully in parallel at all generator loads. Generator components, including items such as terminals, heaters and brush rigging, are designed and secured in such a manner as to provide ready access. Generator bearings are split sleeve type, pressure lubricated from the common lubricating system. It is possible to remove sleeves without removing rotor or driving coupling.

\section{Performance}

With the turbine operating at normal steam conditions of $425 \mathrm{psig}, 650^{\circ} \mathrm{F}$ at the turbine throttle, exhausting to 2.0 inches mercury absolute, the steam rate will not exceed the following:

$\begin{array}{lll}\text { Load } & 2000 \mathrm{kw} & 1500 \mathrm{kw} \\ \mathrm{lb} / \mathrm{kw}-\mathrm{hr} & 11.2 & 11.46\end{array}$





\section{REACTOR DESIGN}

\section{A. CORE PHYSICS}

The basic philosophy of the nuclear design of the reactor is to achieve high power density, reduce hot channel factors to a minimum, assure safe operation, and obtain low fuel costs. This requires that the reactor be designed for long fuel exposure - exceeding 10,000 MWD/MTU - and extensive and careful fuel element and control rod programming throughout lifetime. The long fuel exposure and control rod programming imply that a large amount of excess reactivity must be built into the core, expecially for the first cycle. Safety requirements require that the core be undermoderated so that sufficiently large negative temperature and void coefficients will result. High power density is achieved by using many small diameter fuel rods, with extended surface, on a tight lattice spacing. Good economics demand high conversion ratios and low organic damage rates, both indicating the need for a tight, undermoderated lattice. Reduction of flux peaking factors to a minimum requires the elimination of large coolant gaps between adjacent fuel elements and extensive control rod programming. It was necessary to meet temperature limitations at fuel rod centers and fuel rod surfaces, maintain minimum flow velocities to minimize fouling, and prevent bulk boiling near fuel element outlets due to control rod power perturbations throughout lifetime.

The methods used for the nuclear analysis of the reactor are well known and widely used at Atomics International and other reactor engineering installations. Extensive use was made of digital machine calculations on the IBM-709. Calculations were performed for the initial core loading. These calculations do, however, permit at least qualitative discussion of the characteristics of future core loadings when fuel cycle programming will be employed.

Microscopic thermal cross sections were obtained from BNL-325 Second Edition. Hydrogen scattering cross sections have been measured at thermal energy for hydrogen bound in water and in the organic butadiene, $\mathrm{C}_{6} \mathrm{H}_{4}$. Previous calculations on organic systems had assumed that the hydrogen cross section in Santowax $\mathrm{R}, \mathrm{C}_{18} \mathrm{H}_{14}$, would be about the same as that for butadiene, but recent experiments at Atomics International indicate that the cross section should be slightly lower, closer to that of water. Transport cross sections for hydrogen 
were derived from the measured scattering cross sections using the well known method of Radkowsky. Transport cross sections for carbon in the organic terphenyl assumed that the carbon was fairly tightly bound and not free. All thermal cross sections, for both reflector and core, were averaged over a Wigner-Wilkins spectrum using the IBM-709, SOFOCATE code. Disadvantage factors were allowed for in calculating the spectrum, although control rod effects were not. A thermal cutoff energy of $0.625 \mathrm{ev}$ was used. Average thermal cross sections, are given in Table VI.

\section{TABLE VI}

\section{MICROSCOPIC THERMAL CROSS SECTIONS}

\begin{tabular}{l|c}
\hline \hline Hydrogen Scattering & 33.65 \\
Hydrogen Transport & 19.80 \\
U-235 Absorption & 367.6 \\
U-235 Fission & 306.2 \\
Q-25 & 0.2005 \\
S-25 & 2.0574 \\
Unit A & 0.5722 \\
\hline
\end{tabular}

Unit A may be interpreted as the effective cross-section of a $1 / \mathrm{V}$ absorber having a 1 barn cross-section at $2200 \mathrm{M} / \mathrm{S}$. The above values have been averaged over a Wigner-Wilkins spectrum at $650^{\circ} \mathrm{F}$.

Calculations to determine thermal flux distributions in and around individual fuel rods were done in cylindrical geometry, three regions, by the spherical harmonics method in $P_{3}$ approximation, using the I- 2 code for the IBM-709. Effective homogenized cross sections for the fuel rod region in the fuel element (subassembly) were obtained by flux and volume weighting the cross sections of the respective component materials.

Thermal flux calculations for the square fuel element cell were done with two-dimensional, $x-y$ geometry, two-group diffusion theory using the PDQ code for the IBM-709. It has been found the PDQ calculations of fuel element flux peaking factors are more accurate (compare better with experiments) if Maxwellian cross sections are used instead of Wigner-Wilkins averages. This is because the larger Maxwellian averaged cross sections produce larger 
diffusion theory flux gradients, approximately compensating for the inability of diffusion theory to accurately predict large gradients in small regions. So for this, and only this calculation, pseudo-Maxwellian cross sections were used by correcting all absorption cross sections with the ratio of a unit 1 -over-v cross section in a Maxwellian and in the appropriate Wigner-Wilkins spectrums. Hydrogen transport cross sections for this particular calculation were actually averaged over a Maxwellian spectrum. Effective thermal cross sections for the whole core were obtained by flux and volume weighting the appropriate WignerWilkins cross sections for the component materials. Note that the fluxes calculated by Maxwellian cross sections were used to weight the Wigner-Wilkins cross sections.

All fast group constants for both two-group and four-group calculations were calculated on the IBM-709 using the MUFT-4 code. The cross sections on the MUFT - 4 library tape came from many sources, but most of the angular distributions used were taken from BNL-400. Hydrogen slowing down was treated by the $P-1$ Selungut-Goertzel approximation instead of the rigorous $P-1$ because of better agreement with measured reflector savings for similar reactors. The difference in reactivity between the two treatments is small. Slowing down by carbon and aluminum was treated by the consistent age approximation (GreulingGoertzel method) and all other elastic scattering moderation by the ordinary age approximation. The method included treatment of all inelastic scattering. The parameters $\xi, \gamma=\overline{\Delta \mu} / 2 \xi$, and $\bar{\mu}$ for carbon and aluminum were obtained as a function of energy by numerical integration using the measured angular distributions. Hydrogen scattering at reactor neutron energies is isotropic.

The MUFT-4 treatment of U-238 epithermal absorption was slightly modified. The effective resonance integral of $\mathrm{UO}_{2}$ measured by Hellstrand, $5.25+26.6 \sqrt{\mathrm{S} / \mathrm{M}}$ was separated into smooth and resonance capture components and put on the library tape so that calculations would duplicate the exact measurements in the Swedish heavy water reactor. It is to be noted that the apparent resonance integral in a hydrogen moderated reactor is significantly larger than in a deuterium moderated reactor (because of the shape of the epithermal spectrum) and this is taken into account by the new method. The relative absorption of each resonance is proportional to the parameter $\Gamma \sqrt{\sigma_{a_{0}} / E}$ which is more appropriate than the conventional MUFT-4 treatment which was originally designed for homogeneous mixtures. 
Application of conventional Dancoff-Ginsberg corrections to the effective surface of the fuel rods to allow for shadowing in resonance capture is complicated by the presence of the aluminum cladding, which is nearly an apparent void. Upper and lower bounds to the correction were calculated by homogenizing the organic up to the $\mathrm{UO}_{2}$ rod surface and by homogenizing the rod out to the organic (for the correction factor, not for determining $S / M$ ). The Doppler broadening coefficient of the resonance integral used for the calculations was $1.5 \times 10^{-4} /{ }^{\circ} \mathrm{C}$.

Resonance absorption, both fission and capture, for other elements was also considered. The resonance capture integral used for stainless steel was 2.I barns, the value recently measured in the Yankee critical experiment.

Control rod cell calculations were done by two-group diffusion theory on the two dimensional, $x-y$ geometry, PDQ code for the IBM-709. Each region, cruciform control rod, organic gaps, fuel element box, and fuel regions, was mocked up explicitly and MUFT - 4 fast constants and SOFOCATE thermal constants were used. The rods were treated as thermally black by applying the logarithmic derivative boundary conditions on the flux, $\left(2.13 \mathrm{D}_{2}\right)^{-1}$, at their actual surface, where $D_{2}$ is the effective thermal diffusion coefficient for the entire cell. Since the poison material used in the control rods (18 wt \% europium oxide in stainless steel) has about the same worth at 0.200 inch thicknesses as massive hafnium, effective epithermal absorption cross sections found empirically for hafnium were used in the analysis. The fast absorption cross section for the rod of $0.169 \mathrm{~cm}^{-1}$ was derived using a PDQ analysis identical to the one used here. Fast constants for the cell regions, excluding the rod, were determined using a MUFT-4 calculation for the entire cell and then separating the constants into component regions. This could only be done approximately for the diffusion coefficients and the removal cross sections, but this does not significantly affect the calculations. Results were processed to obtain effective epithermal and thermal poison cross sections for the core constants.

Overall radial core flux distributions and criticality calculations were done on the IBM-709 with the WANDA code, using two-group diffusion theory in onedimension. Regions containing control rods were simulated with poison cross sections. 
Temperature and void coefficients of reactivity were calculated by perturbing the particular reactor parameter, repeating the entire calculation, and comparing the multiplication constant for the system.

The fuel burnup calculations were of a preliminary nature and were completed on an analog computer. The flux was assumed to be constant across the core, a good assumption at the beginning of a core cycle, but becoming progressively worse as burnout proceeds. Stable fission product poisoning was assumed to be 50 barns per fission product pair. It was intended to do CANDLE code calculations on the IBM-709 to determine burnup behavior, but this was not done due to the inability of the code to handle the complex control rod programming method.

A brief summary is given of the parameters affecting the reactor physics calculations:

1. Core. The reactor core is approximately a right circular cylinder, 5.0 feet high and 5.06 feet in diameter. It contains 88 square fuel elements on a close-packed square lattice and 21 cruciform control rods. The core is reflected on all sides by organic coolant. The radial reflector is partially poisoned by dummy fuel elements around the periphery of the core. The end reflectors are also partially poisoned due to the upper and lower grid assemblies.

2. Fuel Element. The active fuel element consists of 100 APM clad $\mathrm{UO}_{2}$ rods in a 0.035 -inch thick steel box, 5.125 inches square and 5.0 feet long. The fuel elements are located on a 5.750 -inch square lattice leaving a $3 / 8$ inch gap between elements.

3. Fuel Rod. Uranium dioxide fuel pellets 0.33 inches in diameter and having a cold density of $10.5 \mathrm{gm} / \mathrm{cm}^{3}$ (hot, $10.3 \mathrm{gm} / \mathrm{cm}^{3}$ ) are contained in APM tubes. These tubes have minimum wall thickness of 0.015 inch and are externally finned.

4. Control Rods. Cruciform control rods with $1 / 4$ inch thick blades are located between the fuel elements in a 7/8-inch gap. The thickness of the poison region is $0.200 \mathrm{inch}$. The poison material in the rods is $18 \% \mathrm{Eu}_{2} \mathrm{O}_{3}$. 
Using the methods previously described, a detailed analysis was made of all important core parameters. The results are presented in tables (VI through $\mathrm{X}$ ) and figures $(16-19)$.

TABLE VII

$\underline{\text { REACTOR CONST ANTS }}^{*}$

\begin{tabular}{|c|c|c|}
\hline Item & Data & Remarks \\
\hline Fuel & $\mathrm{UO}_{2}$ & $\begin{array}{l}10.5 \mathrm{gm} / \mathrm{cc} \text { cold } \\
10.3 \mathrm{gm} / \mathrm{cc} \text { hot }\end{array}$ \\
\hline Moderator & $\mathrm{C}_{18} \mathrm{H}_{14}$ & Santowax R \\
\hline $\begin{array}{l}\text { Moderator/Fuel Volume } \\
\text { Ratio }\end{array}$ & 2.329 & $\begin{array}{l}\text { Unit Cell without } \\
\text { Control Rod }\end{array}$ \\
\hline Initial Enrichment & $3.7 \mathrm{a} / \mathrm{o}$ & \\
\hline Effective Multiplication & 1.144 & \\
\hline Initial Reactivity & $12.6 \% \Delta \mathrm{K} /{ }^{\circ} \mathrm{F}$ & \\
\hline Initial Conversion Ratio & 0.614 & \\
\hline $\begin{array}{l}\text { Fuel Temperature } \\
\text { Coefficient }\end{array}$ & $-2.16 \times 10^{-5} \Delta \mathrm{K} /{ }^{\circ} \mathrm{F}$ & \\
\hline $\begin{array}{l}\text { Moderator Temperature } \\
\text { Coefficient }\end{array}$ & $-3.89 \times 10^{-4} \Delta \mathrm{K} / \mathrm{F}$ at $650^{\circ} \mathrm{F}$ & \\
\hline $\begin{array}{l}\text { Moderator Void } \\
\text { Coefficient }\end{array}$ & $-0.887 \times 10^{-3} \Delta \mathrm{K} / \%$ & \\
\hline $\begin{array}{l}\text { Average Moderator } \\
\text { Temperature }\end{array}$ & $650^{\circ} \mathrm{F}$ & \\
\hline $\begin{array}{l}\text { Axial Power Peaking } \\
\text { Factor }\end{array}$ & $<1.50$ & \\
\hline $\begin{array}{l}\text { Radial Power Peaking } \\
\text { Factor }\end{array}$ & $<1.45$ & \\
\hline Element Power Peaking & $<1.55$ Rod In & \\
\hline & $<1.54 \operatorname{Rod}$ Out & \\
\hline Total Control Rod Worth & $-24.7 \% \Delta \mathrm{K} / \mathrm{K}$ & \\
\hline Reactivity Lifetime & $\sim 12,000 \mathrm{MWD} / \mathrm{MTU}$ & \\
\hline Average Thermal Flux & $\begin{array}{c}1.45 \times 10^{13} \text { neutrons/ } \\
\mathrm{cm}^{2} \mathrm{sec}\end{array}$ & Full Power \\
\hline
\end{tabular}

* Includes all of the important nuclear characteristics of the core. The initial effective multiplication is large enough to permit long burnup when coupled with the initial conversion ratio. The temperature and void coefficients are both negative and large.

VI-6 
TABLE VIII

CROSS SECTIONAL AREAS AND VOLUME FRACTIONS ${ }^{*}$

\begin{tabular}{l|r|r}
\hline \hline & in $^{2}$ & $\%$ \\
\hline $\mathrm{UO}_{2}$ & 8.553 & 25.87 \\
$\mathrm{APM}$ & 3.439 & 11.04 \\
Organic In Box & 13.120 & 39.68 \\
Organic Outside & 6.797 & 20.56 \\
Steel Web & 0.231 & 0.69 \\
Steel Box & 0.713 & 2.16 \\
Unit Cell & 33.063 & \\
\hline
\end{tabular}

HOMOGENIZED NUMBER DENSITIES AT $650^{\circ} \mathrm{F}\left(\mathrm{cm}^{-3} \times 10^{-24}\right)$

\begin{tabular}{l|l}
\hline Hydrogen & 0.000220 \\
Oxygen & 0.0119 \\
Carbon & 0.0252 \\
Iron & 0.00242 \\
Aluminum & 0.00665 \\
U-235 & 0.000220 \\
U-238 & 0.00573 \\
\hline
\end{tabular}

* Values given in this table were computed for the temperatures and geometries involved. 
TABLE IX

TWO-GROUP CONSTANTS*

\begin{tabular}{l|c|l|l}
\hline \hline Region & Constants & \multicolumn{2}{|c}{ Neutron Energy Groups } \\
\hline \multirow{4}{*}{ Core } & & 1 & 2 \\
& $\sum_{\mathrm{a}}$ & 1.18 & 0.458 \\
& $\sum_{\mathbf{r}}$ & 0.00976 & 0.0831 \\
& $\sum_{\mathrm{f}}$ & 0.00731 & 0 \\
& $\mathrm{f}_{\mathrm{i}}$ & 1.000 & 0.139 \\
& $\mathrm{D}$ & 1.622 & 0 \\
& $\sum_{\mathbf{a}}$ & 0.000155 & 0.405 \\
& $\sum_{\mathbf{r}}$ & 0.0248 & 0.00582 \\
\hline
\end{tabular}

$f_{i}=$ fraction of fission spectrum in respective group

* The thermal cross sections have been averaged over a Wigner-Wilkins spectrum and are flux and volume weighted. The MUFT-4 digital code was used to obtain the fast constants. 
TABLE X

NEUTRON ECONOMY (PERCENT EFFICIENT NEUTRONS)

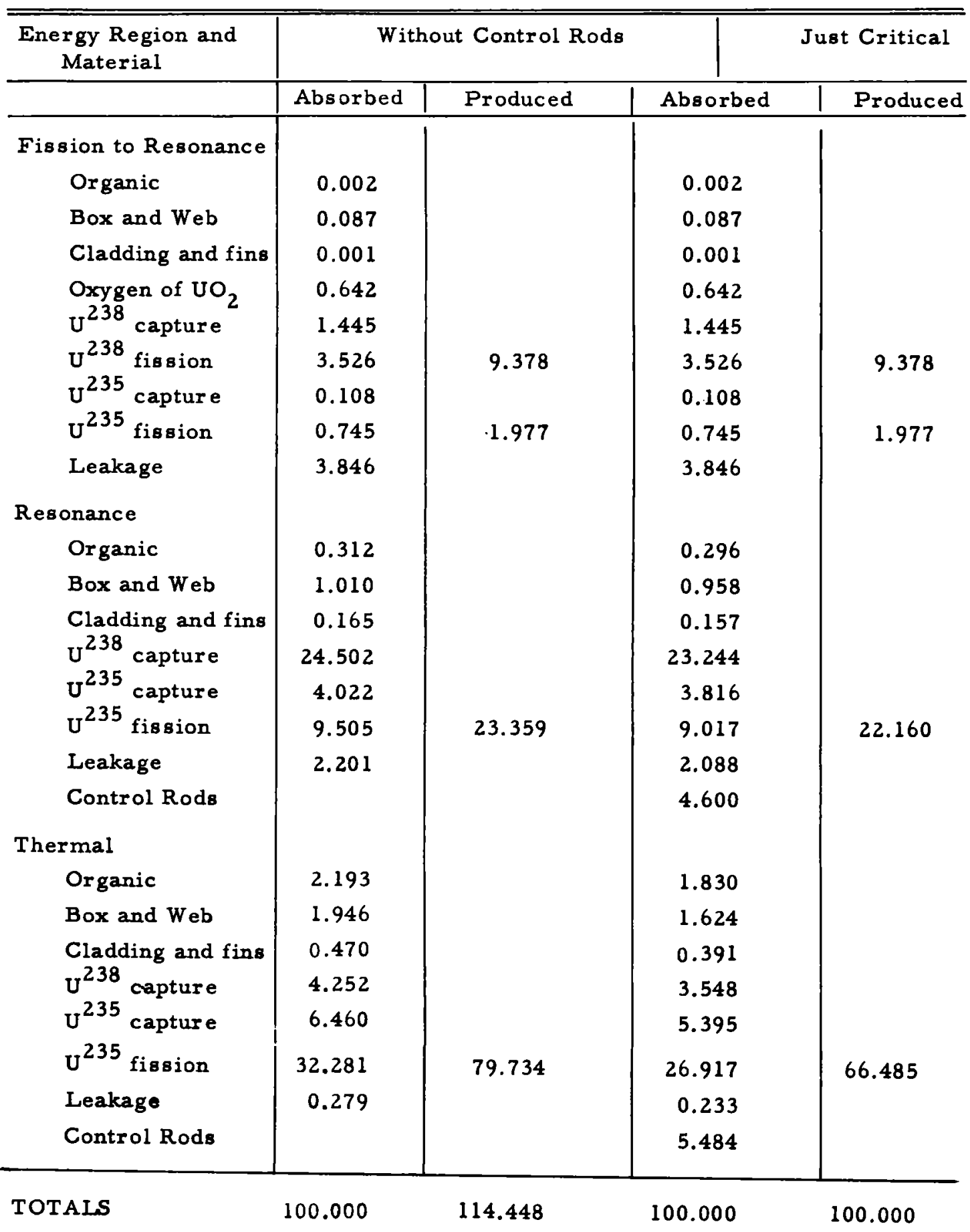




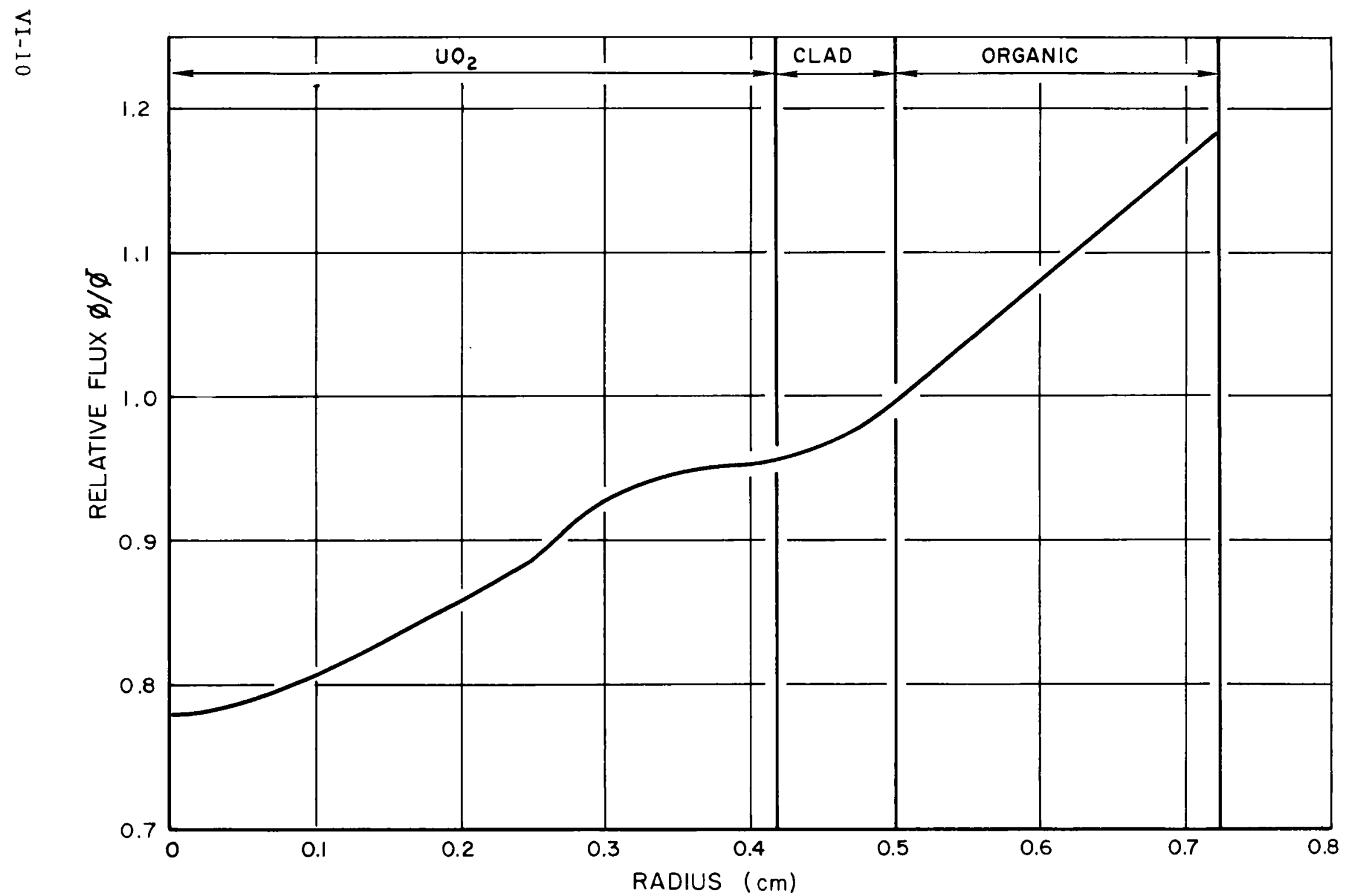

Figure 16. Thermal Flux Distribution Around a Single Fuel Rod 


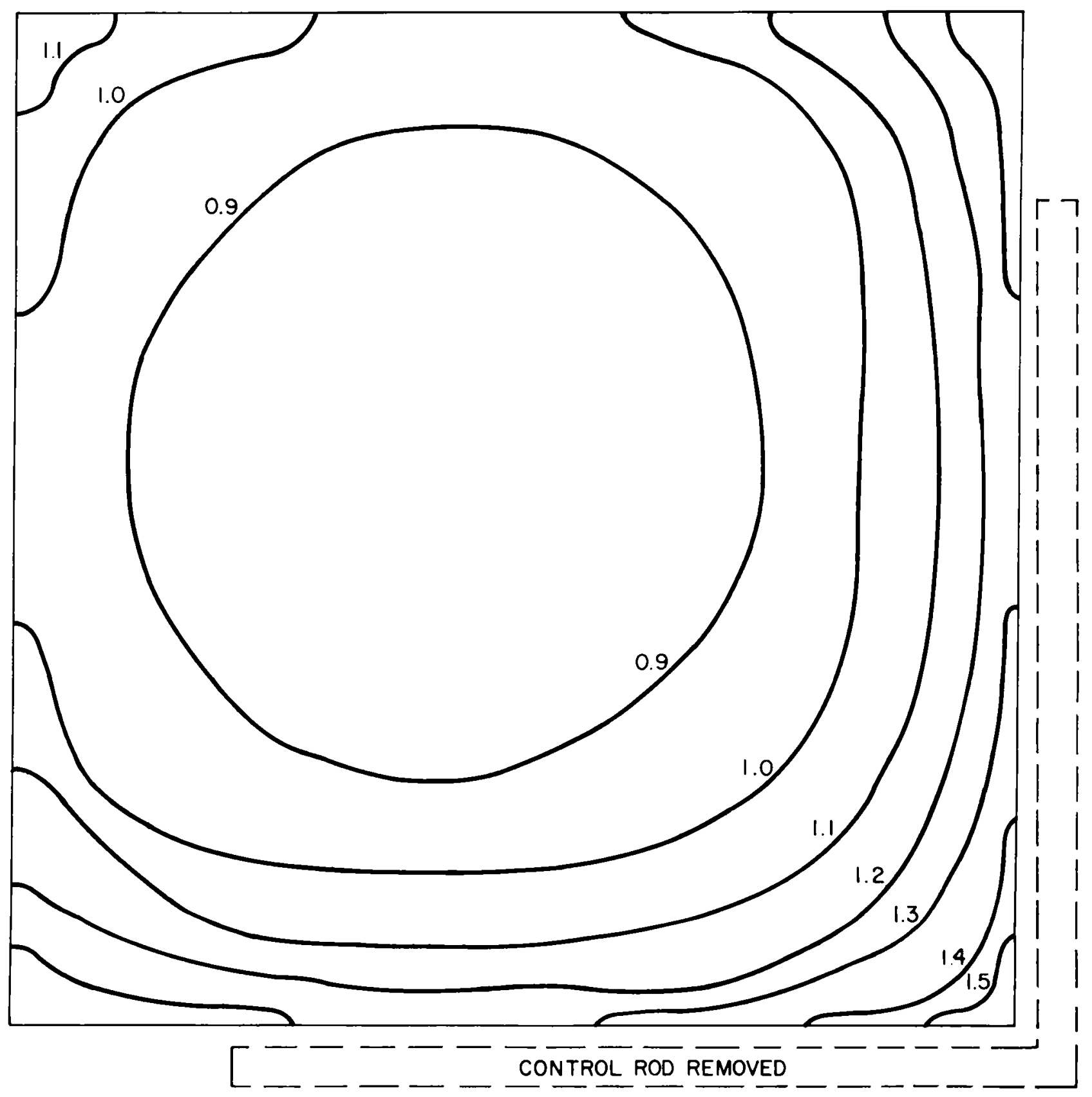

Figure 17. Power Distribution in a Fuel Element 


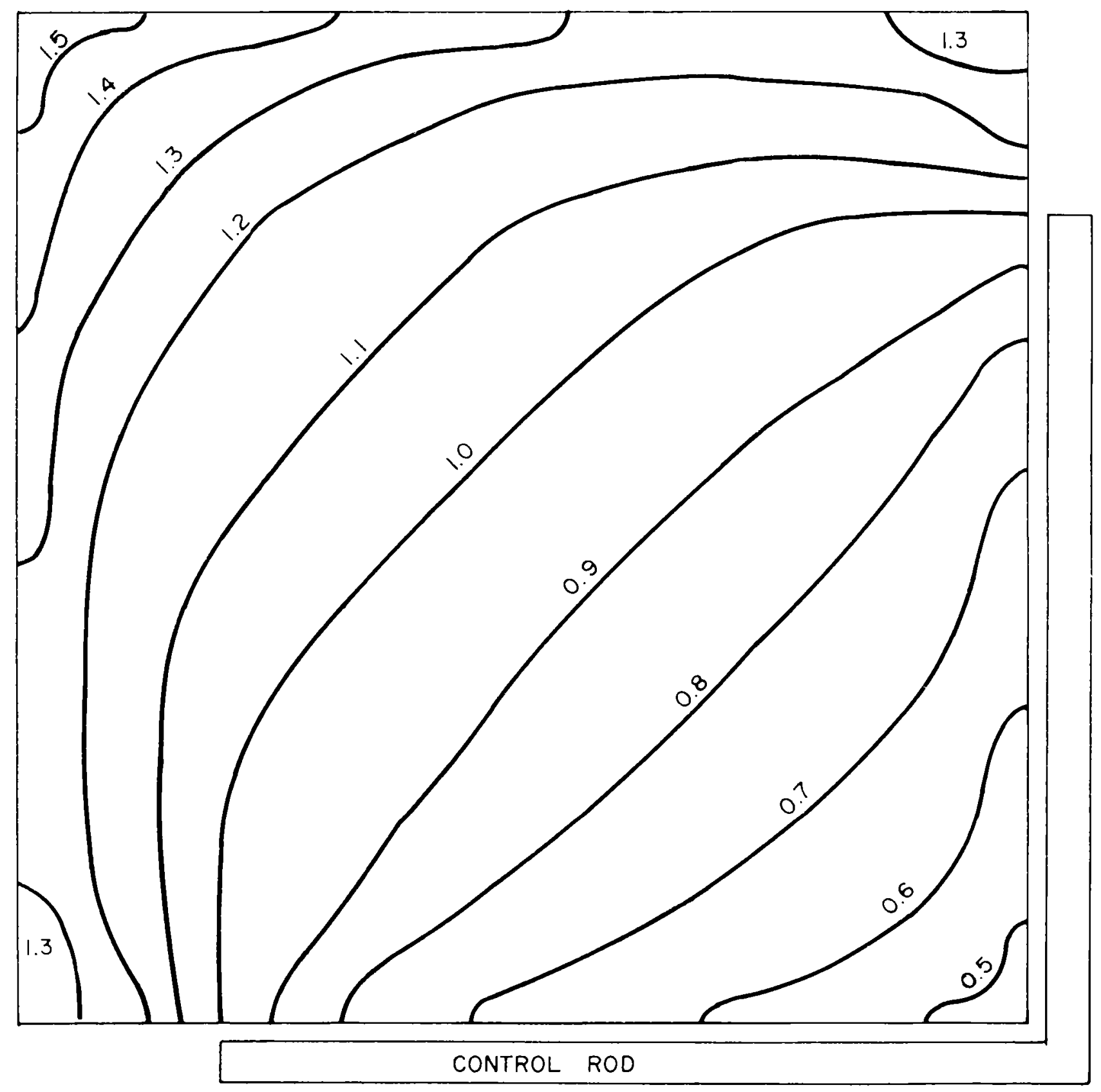

Figure 18. Power Distribution in a Fuel Element Adjacent to a Control Rod 


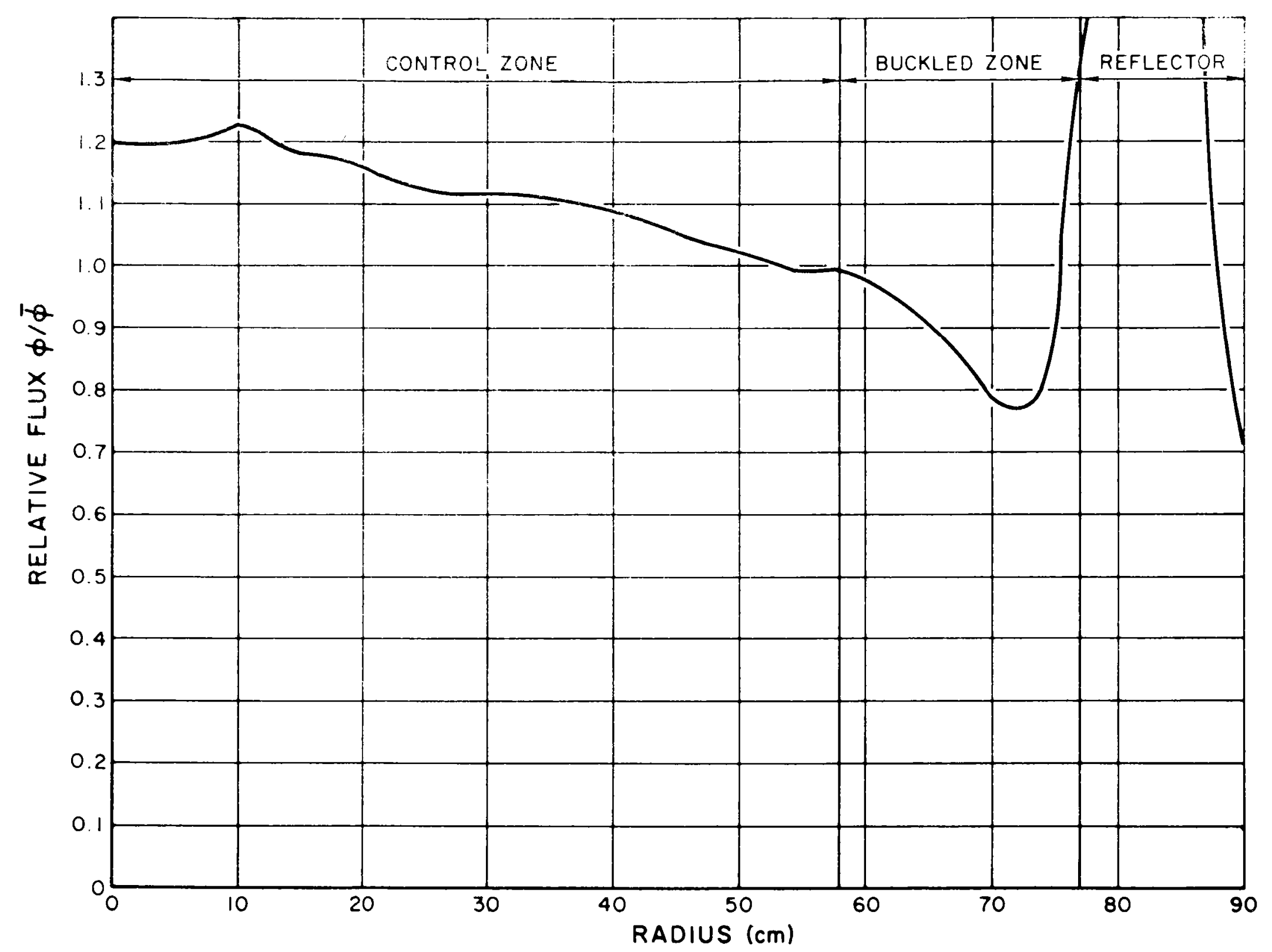


The preceding description has dealt with the initial core parameters. During irradiation, the heavy isotope concentration of the fuel undergoes significant changes. The effects of these isotope changes will be reflected in nearly all of the basic core parameters.

During burnup, there are three basic changes in the isotopic concentration of the fuel. There is a depletion of U-235 due to fission and neutron capture. Neutron capture of U-238 results in a buildup of plutonium isotopes. In addition, there is a buildup of fission products from the fissioning of U-235, Pu-239 and Pu-241. The depletion of U-235 tends to decrease the reactivity of the core, while the buildup of fissionable plutonium isotopes tends to increase the reactivity. Fission products act as poisons which reduce the reactivity of the core.

An electronic analog computer was used to solve the differential equations governing the changes in heavy isotope concentration. In order to facilitate solution of the equations, the following assumptions were made:

1. All microscopic cross sections remain constant during burnup!

2. U-238 concentration is constant.

3. Half lives of $\mathrm{U}-239$ and $\mathrm{Np}-239$ are zero.

4. Effect of U-236 is negligible.

5. Effect of Pu-242 is negligible.

6. Reactor power is constant.

The thermal cross sections used were modified to account for epithermal effects since this method is, of necessity, a one group treatment. Calculation of isotope concentrations in this manner is not as accurate as might be desired, but does provide a good first approximation.

The effect of burnup on reactivity was accomplished by perturbation of the results of previous multi-group criticality calculations. Fission product poisoning was simulated by addition of an absorption cross section of 50 barns per fission. This method of calculation assumes a uniform burnup over the core. This is a good approximation at the beginning of core life when the flux is flat, but becomes worse as the core burns out and the flux distribution becomes more non-uniform. 
Figure 20 shows the changes in heavy isotope concentration during burnup and Figure 21 gives the variation of effective multiplication. The curve of $k_{\text {eff }}$ is based on a uniform burnup of the core, i.e., a uniform flat flux throughout core life. This curve indicates a reduction in reactivity as the U-235 burns out and fission product poisoning increases. The reactivity lifetime of the first core loading is shown to be about $12,000 \mathrm{MWD} / \mathrm{MTU}$, but the assumption of uniform burnup tends to give rather optimistic results. It may be deduced, however, that a burnup of 10,000 MWD/MTU can be attained with the initial core loading.

To obtain the most efficient use of the fuel, it is necessary to obtain the maximum possible burnup of every fuel element inserted in the reactor. With uranium oxide fuel, the burnup which can be attained is limited by the depletion of $\mathrm{U}-235$ and the buildup of fission product poisons. The reactivity lifetime of a new core carried to burnout without fuel shifting is about 10,000 MWD/MTU. If this burnup could be extended without increasing the initial enrichment of the fuel, a considerable saving in fuel cycle costs may be realized. There are several methods of fuel programming which will permit an increase in fuel element burnup over that attainable with a single core loading. By programming the insertion of new fuel elements, it is possible to attain fuel element burnup of $14,000 \mathrm{MWD} / \mathrm{MTU}$ in a portion of the core while maintaining the average burnup over the core below 10,000 MWD/MTU. A short description of various fuel programs is given below.

1. Fuel reloading by core. The entire core is reloaded with new fuel elements each time the reactivity lifetime is reached.

2. Fuel reloading by zone. All of the fuel elements in one radial zone are replaced when the reactivity lifetime is reached.

3. Fuel reloading for uniformly graded exposure. Fuel elements in the radial zones are replaced at a rate proportional to the power density in the zones. At steady state, the average exposure of the fuel elements in the core is nearly independent of radial position.

4. Radially graded exposure - new fuel at center. Fuel elements are moved from central positions toward the periphery of the core during burnup. All new fuel is loaded into central positions and discharged from the outer positions. 


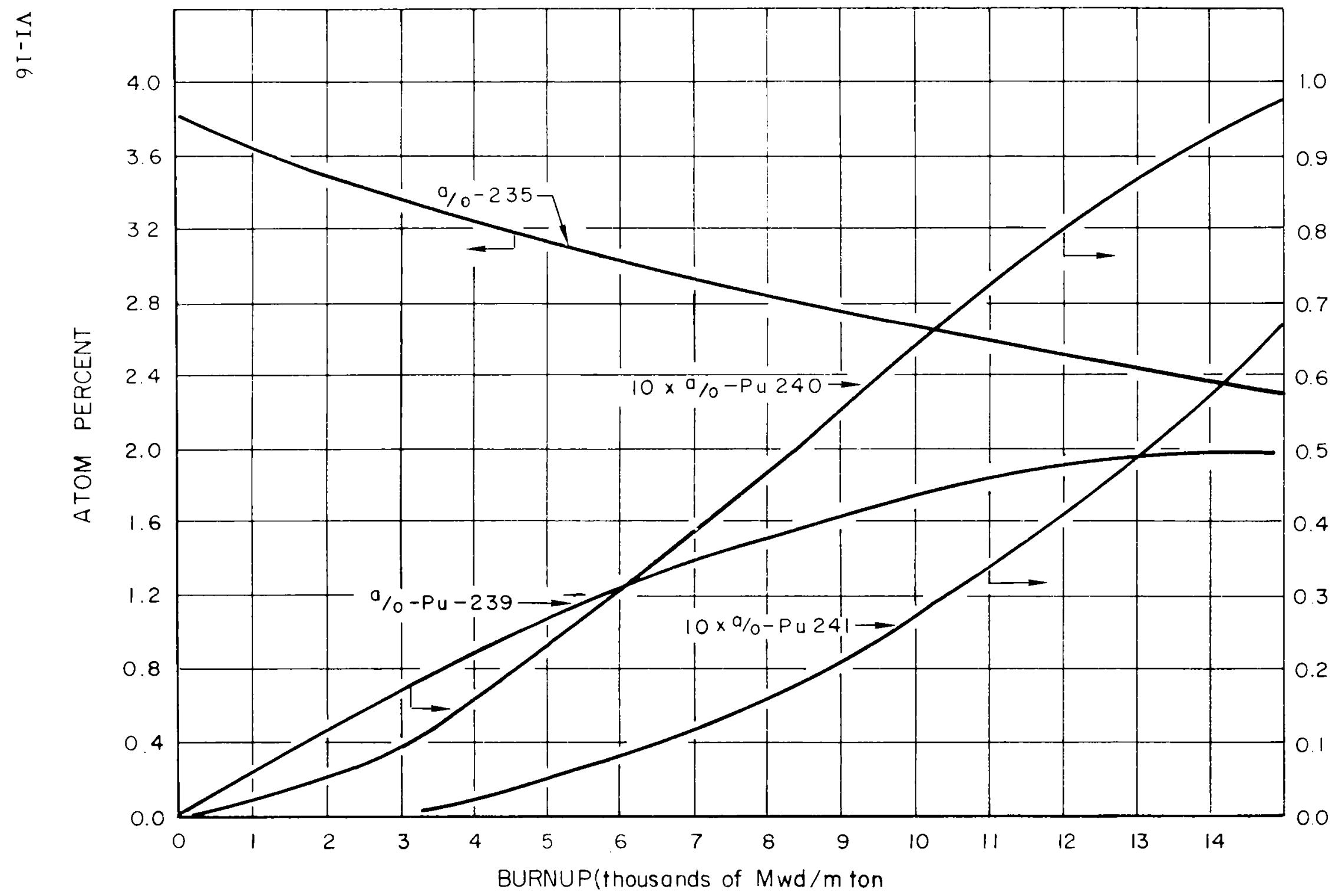

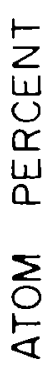

Figure 20. Heavy Isotope Buildup During Burnup 


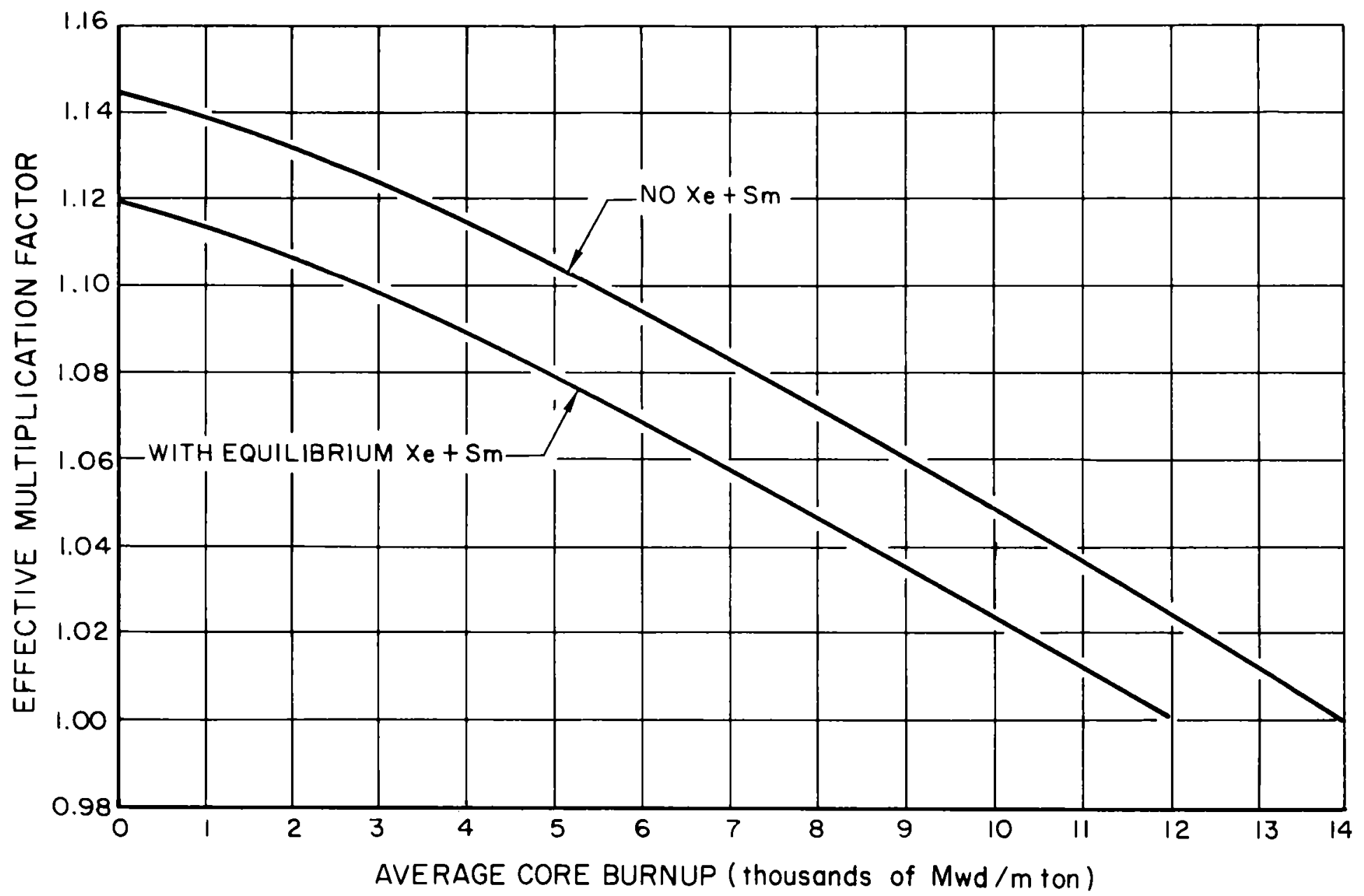

Figure 21. Reactivity Lifetime of Initial Core 
5. Radially graded exposure - New fuel at periphery. Fuel elements are moved from outer positions toward the center of the core during burnup. All new fuel is loaded into the outer positions and discharged from the central positions.

It appears that a fairly flat radial power distribution can be attained if the region of the core outside of the control zone has a high buckling. The control zone represents the central $2 / 3$ of the core. In the control zone, control rods are used to maintain zero buckling. Thus, the most desirable fuel program is a combination of methods 3 and 5 above. New fuel is loaded at the periphery of the core. When partially burned out, this fuel will be moved into the control zone to maintain a positive material buckling.

The buckled zone of the core contains about one third of the fuel elements. When operating on the "steady state" fuel cycle, these fuel elements will be burned to about 5,000 MWD/MTU. At this time, half of the fuel elements in the control zone will be removed from the core and replaced by the fuel elements from the buckled zone. New fuel will be loaded into the buckled zone and the reactor operation re-initiated. During the next refueling operation, the other half of the elements in the control zone will be removed from the core. In this way, it is possible to burn fuel elements to an average exposure of 14,000 MWD/MTU while maintaining the average exposure of the core below 10,000 $M W D / M T U$.

One consequence of this fuel program is the location of fuel elements which have undergone different exposures occupying adjacent positions in the core. This will cause local peaking of the power distribution. However, during "steady state" operation, the element and radial peaking factors will be lower than the design conditions and this additional peaking factor can be tolerated.

After the initial core loading, the reactor will be operated for approximately 3 years. At the end of this time, the average exposure of the core will be nearly $10,000 \mathrm{MWD} / \mathrm{MTU}$ and the radial peak-to-average power ratio will be very near to the design condition of 1.45. Highly depleted fuel elements which have been in the reactor 48 months, achieving a burnup of $14,000 \mathrm{MWD} / \mathrm{MTU}$, will be removed from their control zone position in the reactor and transferred to the refueling barge. The elements from the buckled zone will be placed in these 
locations and new fuel will be loaded into the buckled zone. Elements remaining in the control zone are uniformly mixed with elements inserted from the buckled zone. This procedure will be repeated every 16 months. At each refueling, the $1 / 3$ of the fuel elements in the control zone which have the greatest exposure will be removed from the core.

Since the core contains 88 elements for a full loading, approximately 29 are removed to the storage facility, 29 are repositioned in the core and 29 new fuel elements are inserted during each fuel change.

\section{B. CORE HEAT TRANSFER AND FLUID FLOW}

The core is a single-pass system with coolant flow in the upward direction. Approximately $97 \%$ of the flow is through the fuel elements. The remaining $3 \%$ flows outside of the fuel elements to serve as coolant for the control rods, inner thermal shield, and grid plates. Flow distribution through the fuel elements is controlled by individual fuel element orifices located at the lower end of each fuel element. The orifices are sized to obtain a flow distribution which will result in a uniform coolant outlet temperature from all fuel elements.

Fuel element heat transfer is effected by both convective and subcooled boiling heat transfer, the latter prevailing only at the surface of the higher power fuel pins in the elements. Inasmuch as the coolant is subcooled in all channels in the core, the vapor generated by boiling heat transfer is restricted to a thin region adjacent to the fuel pin surface. The control rods, inner thermal shields and grid plates are cooled by free convection heat transfer, plus surface subcooled boiling where the heat flux is sufficiently high.

The following limitations were used in the thermal performance calculations for the core:

1. A maximum surface temperature of $825^{\circ} \mathrm{F}$. When the fuel element surface temperature is increased, there is an increasing tendency for the surface to become fouled due to the thermal decomposition of the organic coolant. Boiling loop tests at Atomics International with a terphenyl mixture containing high boiler compound indicate that surface fouling is insignificant at a surface temperature of $825^{\circ} \mathrm{F}$ and adequate flow velocities. 
2. A maximum $\mathrm{UO}_{2}$ temperature of $4000^{\circ} \mathrm{F}$. The melting point of $\mathrm{UO}_{2}$ is approximately $5000^{\circ} \mathrm{F}$. This temperature limitation was imposed to limit the amount of fission gases, release of which increases with increase in temperature. The release of fission gases must be limited to prevent excessive internal pressure in the fuel pins. With additional data on the effect of temperature on fission gas release and/or with modifications in fuel pin design, it may be possible to increase the maximum permissible $\mathrm{UO}_{2}$ temperature.

3. Maximum heat flux not greater than half of the burnout heat flux. With this ratio of burnout heat flux to maximum heat flux, the burnout heat flux will not be reached in any anticipated transients with the protective system in operation.

4. No bulk boiling in any part of the core. This limitation was imposed due to uncertainty in local flow stability in the fuel element under conditions of local bulk boiling.

Table XI lists the thermal and flow data for the core when operating at the design power level. Due to changes in the power distribution in the core during the core life, the maximum temperatures, heat fluxes, etc. will vary with time. The values shown in the table are at the end of core life and are the highest expected at any time. The maximum heat generation rate for APM jacketed, 0.33 -inch diameter $\mathrm{UO}_{2}$ pin operating with a center temperature of $4000^{\circ} \mathrm{F}$ and a jacket surface temperature of $825^{\circ} \mathrm{F}$ was calculated to be $8.56 \mathrm{kw} / \mathrm{ft}$, based on the following assumptions:

Uniform heat generation in $\mathrm{UO}_{2}$

Gas gap of 0.001 inch between $\mathrm{UO}_{2}$ surface and APM jacket.

Thermal conductivity as follows:

$$
\frac{\text { Material }}{\mathrm{UO}_{2}}
$$

APM

$$
\begin{aligned}
& \frac{k,(B t u / h r-f t-F)}{1135 T^{-0.9} ; T=\text { degrees Rankine }} \\
& 0.051
\end{aligned}
$$

110

The amount of extended surface was determined on the basis of a maximum heat generation rate of $8.56 \mathrm{kw} / \mathrm{ft}$ of pin and a maximum heat flux of one-half of the burnout heat flux. 
The burnout heat flux for Santowax $\mathrm{R}$ with $30 \%$ high boiler compound was calculated using the lower band ( $-33 \%$ of the mean burnout heat flux data) of the Griffith correlation.* Burnout heat fluxes for Santowax R, ortho- and metaterphenyl mixtures, and diphenyl have been experimentally determined and are found to be correlated by the Griffith correlation.

Figures 22 and 23 show the temperature distribution for the highest power fuel pin with and without hot channel factors, respectively. It is seen that boiling occurs only on part of the surface. There will be no boiling around most of the fuel pins in the core.

The hot channel factors used in the reactor thermal performance calculations are shown in Table XII. F $\triangle_{t}$ is the hot channel factor applied to the coolant temperature rise. $F \theta$ is the hot channel factor applied to the film drop for convective heat transfer. F $\phi$ is the hot channel factor applied to the heat flux. These hot channel factors are based on estimated manufacturing tolerances for the fuel elements, estimated flow distribution within an element, and estimated flux peaking due to reasons indicated in the table. The hot channel factors used are certainly conservative values due to the highly unlikely basis on which they were computed. That basis assumes that all of the factors which contribute to the hot channel factors occur simultaneously at the hottest spot in the hot channel.

Figure 24 shows the variation of some pertinent temperatures as a function of load for two and one loop operation. The flow rate remains constant regardless of load. With only one loop in operation, the flow rate is approximately $58 \%$ of full flow, and the maximum load on the reactor will be $58 \%$ of design power. The mixed mean coolant outlet temperature is held at $675^{\circ} \mathrm{F}$ regardless of load. Hence, with the flow rate held constant, the coolant inlet temperature increases with decrease in load. The maximum local coolant outlet temperature curves, which decrease with decrease in load, are based on the assumption of no coolant mixing, hence, the actual maximum local coolant outlet temperatures will be lower. The curve for maximum surface temperature, which decreases with decrease in load, is based on the assumption that there is boiling in the core regardless of load. Actually, the amount of boiling will decrease and may become non-existent with decrease in load, so that the actual maximum ourface temperature will be less than or equal to the maximum possible surface temperature indicated by the curve.

*P. Griffith, "The Correlation of Nucleate Boiling Burnout Data." ASME paper No. 57-HT-21, August, 1957. 
TABLE XI

THERMAL AND FLOW DATA FOR CORE

Coolant Temperatures (F)

Inlet

Mixed mean outlet

Maximum local outlet (with hot channel factors)

Saturation at center of core

Fuel Rod Temperatures $(F)$

Maximum cladding surface

Maximum $\mathrm{UO}_{2}$ surface

Maximum $\mathrm{UO}_{2}$

Thermal power of reactor (Mw)

Power transferred across

fuel rod surface

Power generated in coolant, thermal shields, etc.

Heat Fluxes (Btu/hr $\mathrm{ft}^{2}$ )

Burnout

Maximum

Average

Heat generation rate in fuel pins ( $\mathrm{kw} / \mathrm{ft}$ )

Maximum

Average

Surface area of fuel rod $\left(\mathrm{ft}^{2} / \mathrm{ft}\right)$

Effectiveness of surface area

Pressure at center of core (psia)

620

675

$703^{*}$

775

825

1450

4000

93

86.5

6.5

Pressure drops (psi)

Core

Reactor tank, exclusive of core

Total pressure drop from inlet

to outlet nozzles

250,000

125,000

28,700

8.56

1.97

0.0243

0.96

34

Flow rate ( $1 \mathrm{bs} / \mathrm{hr}$ )

Through fuel elements

Leakage around fuel elements

Total flow rate

Velocities in fuel elements (ft/sec)

Maximum

Average

Minimum

6.9

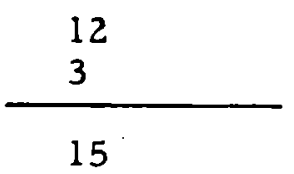

$10.96 \times 10^{6}$

$\frac{0.34 \times 10^{6}}{11.3 \times 10^{6}}$

10.0

5.0

* This figure assumes no coolant mixing in the fuel elements. Since there will be mixing, the actual maximum local coolant outlet temperature will be somewhat lower. 


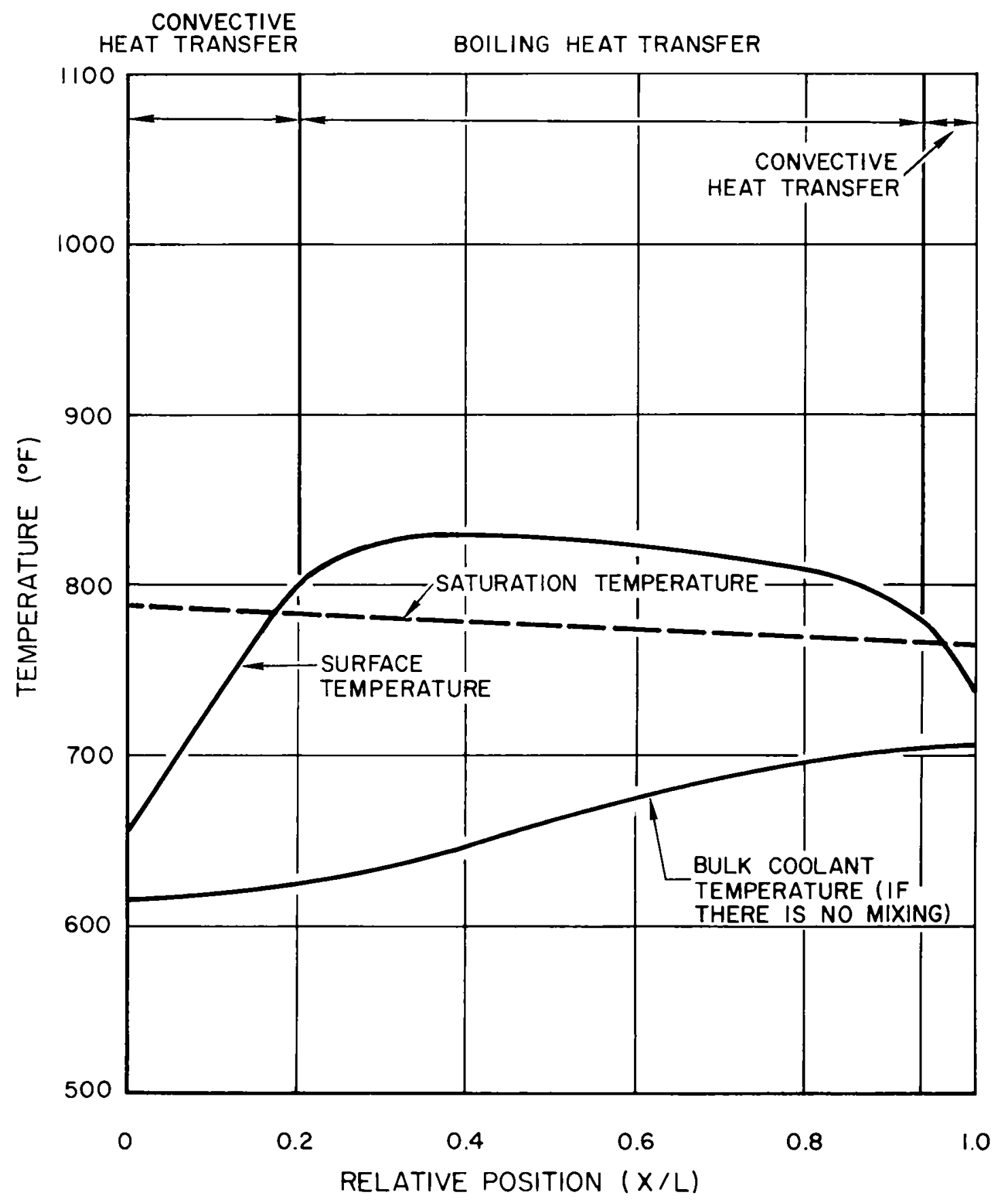

Figure 22. Temperature Distribution for Hottest Fuel Pin with Hot Channel Factors 


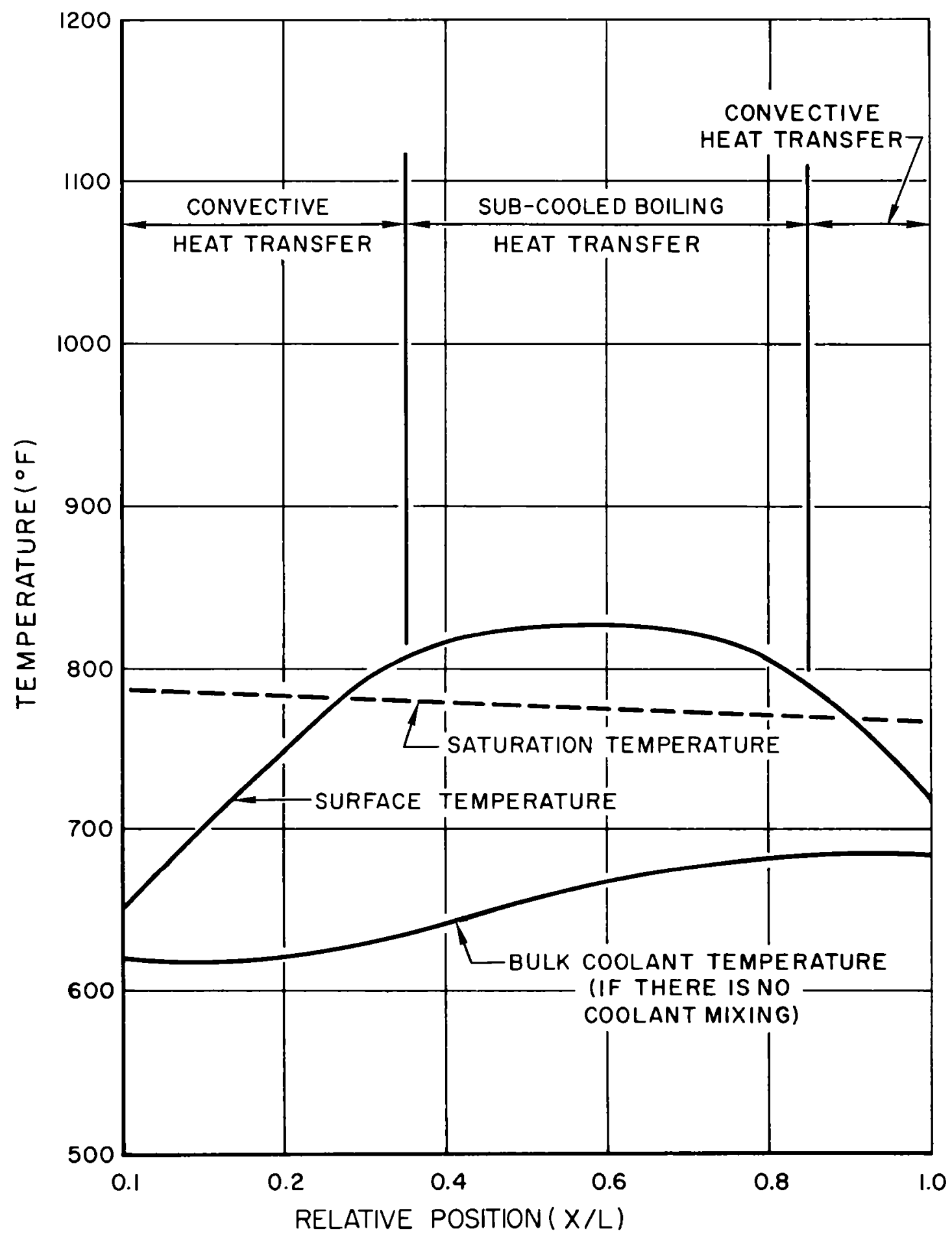

Figure 23. Temperature Distribution for Hottest Fuel Pin without Hot Channel Factors 
TABLE XII

HOT CHANNEL FACTORS USED FOR ORGANIC MODERATED AND COOLED CORE WITH SUBCOOLED BOILING

\begin{tabular}{l|c|c|c}
\hline \multicolumn{1}{c|}{ Factors } & $F_{\Delta t}$ & $F_{\theta *}$ & $F_{\phi}$ \\
\hline 1. Variation in fuel density density and/or & & & \\
$\quad \quad$ diameter & 1.00 & 1.02 & 1.02 \\
2. Variation in U-235 disperson & 1.00 & 1.02 & 1.02 \\
3. Power peaking at ends of fuel pins & 1.00 & 1.04 & 1.04 \\
4. Flux uncertainty & 1.10 & 1.10 & 1.10 \\
5. Power Peaking due to insertion of & & & \\
$\quad$ fresh fuel elements & 1.05 & 1.05 & 1.05 \\
6. Uncertainty in convective heat transfer & & & \\
$\quad$ coefficient & - & 1.17 & - \\
7. Non-uniform flow distribution in fuel & 1.08 & 1.07 & - \\
$\quad$ element and imperfect orificing & 1.25 & 1.56 & 1.25 \\
\hline$\quad$ Total Product & &
\end{tabular}

${ }^{*} F_{\theta}$ applies only for convective heat transfer

\section{SHIELDING}

The reactor shield is designed to the maximum annual crew dose of 5 rem. On this basis, the design dose rate is $1.5 \mathrm{mrem} / \mathrm{hour}$ for a 40 hour work week and a 1.88 rem per year emergency reserve radiation exposure. This is based on the full speed operating condition ( $100 \%$ of cruise power). The following table shows the flexibility of the $1.5 \mathrm{mrem} /$ hour dose rate.

\begin{tabular}{c|c|c}
\hline $\begin{array}{c}\text { Length of Work } \\
\text { Week, hours }\end{array}$ & $\begin{array}{c}\text { Annual Dose, } \\
\text { rem }\end{array}$ & $\begin{array}{c}\text { Annual Reserve } \\
\text { Dose, rem }\end{array}$ \\
\hline 40 & 3.12 & 1.88 \\
48 & 3.74 & 1.26 \\
56 & 4.38 & 0.62 \\
\hline
\end{tabular}




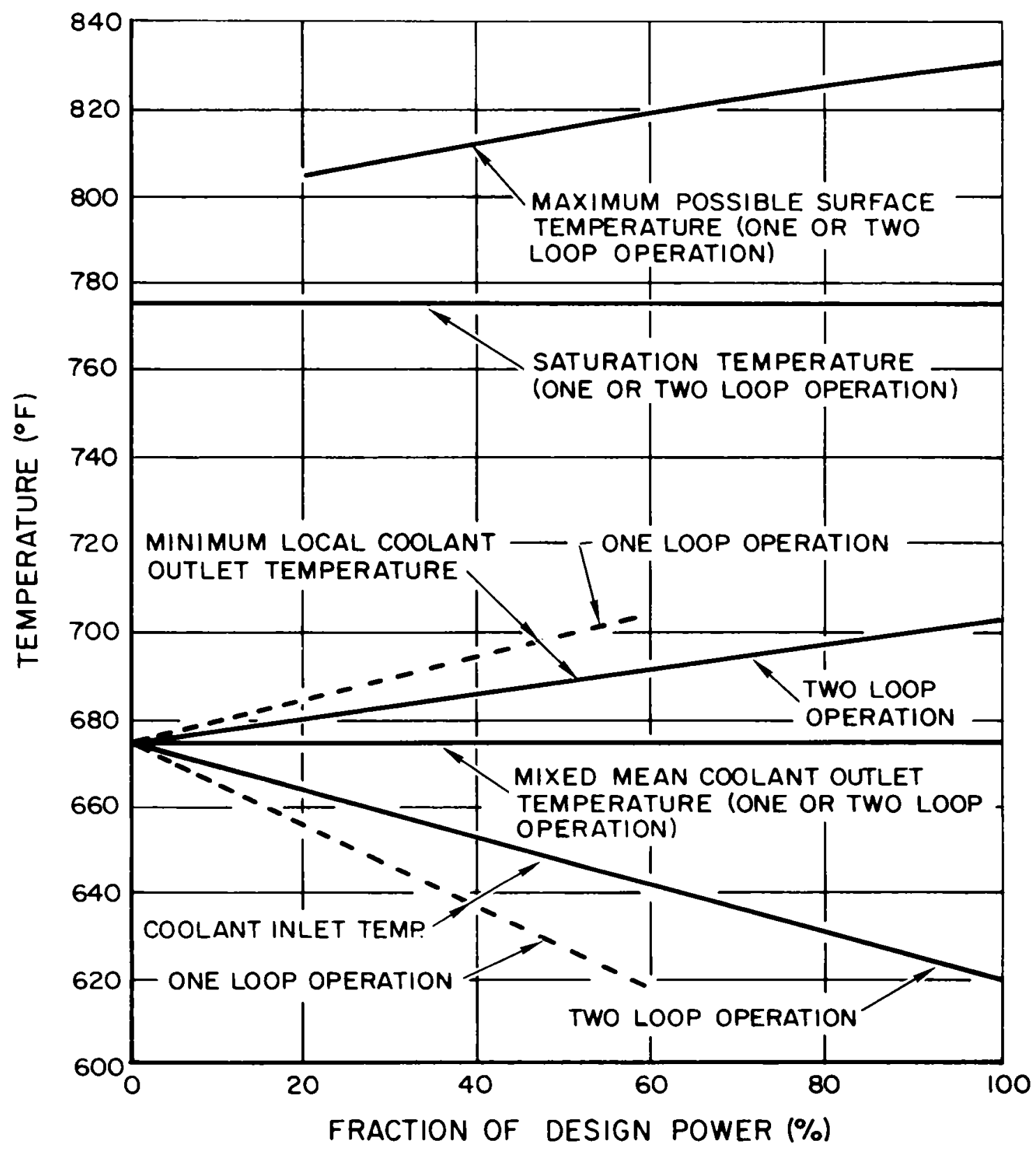

Figure 24. Part Load Temperature 
It is felt that an annual reserve radiation exposure is necessary in order for the crew to cope with minor malfunctions of equipment located in areas where the dose rate exceeds $1.5 \mathrm{mrem} /$ hour. Major repair, however, may be done by other personnel at the port facilities.

Compartmentalization of the reactor areas according to their relative accessibility requirements is the shielding design concept in this system. The primary radial reactor shield reduces the dose rate from the reactor to that from the primary coolant equipment in order to get a minimum dose rate in the reactor compartment. The secondary shield which surrounds the reactor compartment reduces the dose rate from the reactor compartment to $1.5 \mathrm{mrem}$ per hour.

The major source of radiation in the reactor compartment during operation at full power is the primary coolant activity. During normal operation, that is, operation without fission products in the coolant, the primary coolant activity is $1.8 \mu \mathrm{c} / \mathrm{cc}$. This activity 24 hours after shutdown is reduced to $0.23 \mu \mathrm{c} / \mathrm{cc}$. Since the design has been undertaken to allow for some fission products leaking into the primary coolant, the secondary shield has been designed to attenutate the radiation from a primary coolant activity of $10 \mu_{\mathrm{c}} / \mathrm{cc}$ to $1.5 \mathrm{mrem} / \mathrm{hour}$. This enables the ship to be operated despite minor leaks of fission products into the primary coolant.

1. Reactor Compartment

The primary radial shield is illustrated in Plate VI and the resulting dose rates at its surface are tabulated below:

\section{Source}

Fast Neutrons

Thermal Neutrons

Gamma Rays

Total During Operation

24 hours after Shutdown

\section{Dose Rate}

$0.003 \mathrm{rem} / \mathrm{hr}$

0.002

0.47

$0.475 \mathrm{rem} /$ hour

$5 \mathrm{rem} /$ hour

The water in the primary radial shield is only required to a depth of 6 feet above the top of the core.

The dose rates on the primary coolant equipment are listed in Table XIII. 
DOSE RATES 1 FOOT AWAY FROM THE PRIMARY COOLANT

EQUIPMENT IN THE REACTOR COMPARTMENT

\begin{tabular}{|c|c|c|c|c|}
\hline \multirow{2}{*}{$\begin{array}{c}\text { Primary } \\
\text { Coolant System } \\
\text { Component }\end{array}$} & \multicolumn{2}{|c|}{$\begin{array}{c}\text { Dose Rate With a Coolant } \\
\text { Activity of } 1.8 \mu \mathrm{c} / \mathrm{cc}\end{array}$} & \multicolumn{2}{|c|}{$\begin{array}{c}\text { Dose Rate With a Coolant } \\
\text { Activity of } 10 \mu \mathrm{c} / \mathrm{cc}\end{array}$} \\
\hline & Full Power & $\begin{array}{l}24 \text { hours after } \\
\text { shutdown }\end{array}$ & Full Power & $\begin{array}{c}24 \text { hours after } \\
\text { shutdown }\end{array}$ \\
\hline $18 "$ Dia. Piping & $0.30 \mathrm{rem} / \mathrm{hr}$ & $38 \mathrm{mrem} / \mathrm{hr}$ & $1.7 \mathrm{rem} / \mathrm{hr}$ & $0.80 \mathrm{mrcm} / \mathrm{hr}$ \\
\hline *Steam Generator & $0.53 \mathrm{rem} / \mathrm{hr}$ & $67 \mathrm{mrem} / \mathrm{hr}$ & $3.0 \mathrm{rem} / \mathrm{hr}$ & $1.43 \mathrm{mrcm} / \mathrm{hr}$ \\
\hline *Surge Tank & $2.6 \mathrm{rem} / \mathrm{hr}$ & $0.33 \mathrm{rem} / \mathrm{hr}$ & $14 \mathrm{rem} / \mathrm{hr}$ & $0.66 \mathrm{rem} / \mathrm{hr}$ \\
\hline *Superheater & $1.5 \mathrm{rem} / \mathrm{hr}$ & $0.19 \mathrm{rem} / \mathrm{hr}$ & $8.4 \mathrm{rem} / \mathrm{hr}$ & $0.40 \mathrm{rem} / \mathrm{hr}$ \\
\hline $\begin{array}{l}\text { †Organic Drain } \\
\text { Tank }\end{array}$ & $0.48 \mathrm{rem} / \mathrm{hr}$ & $61 \mathrm{mrem} / \mathrm{hr}$ & $1.6 \mathrm{rem} / \mathrm{hr}$ & $0.76 \mathrm{rem} / \mathrm{hr}$ \\
\hline
\end{tabular}

* The dose rates from the steamgenerator, surge tank and superheater will be negligible when the organic is drained to the drain tank.

fOrganic drain tank is shielded with $1-3 / 4$ in. of lead. 
The dose rates on the reactor top shield (plate VI) are as follows:

FULL POWER WITH $10 \mu \mathrm{c} / \mathrm{cc}$ COOLANT ACTIVITY

Source

Core Gamma

Pool Gamma

Fast Neutron

Thermal Neutron

Total
Dose Rate

$1.3 \mathrm{mrem} /$ hour

$<0.01 \mathrm{mrem} /$ hour

$<0.01 \mathrm{mrem} / \mathrm{hour}$

$<0.01 \mathrm{mrem} / \mathrm{hour}$

$1.3 \mathrm{mrem} /$ hour

DOSE RATE ON THE SURFACE OF THE TOP POOL 24 HOURS AFTER SHUTDOWN WITH $10 \mu \mathrm{c} / \mathrm{cc}$ COOLANT ACTIVITY AT SHUTDOWN

Source

Dose Rate

Core Decay Gammas

$0.02 \mathrm{rem} / \mathrm{hour}$

Pool Decay Gammas

$\frac{0.14 \mathrm{rem} / \mathrm{hour}}{0.16 \mathrm{rem} / \mathrm{hour}}$

Total

$0.16 \mathrm{rem} / \mathrm{hour}$

The bottom shield forms the ceiling of the sub-pile room. Dose Rates on the Reactor Bottom Shield (plate VI) are as follows:

FULL POWER WITH $10 \mu \mathrm{c} / \mathrm{cc}$ COOLANT ACTIVITY

Source

Fast Neutrons

The rmal Neutrons

Core Gamma Rays

Pool Gamma Rays

Total
Dose Rate

$4.6 \mathrm{rem} / \mathrm{hour}$

$0.02 \mathrm{rem} / \mathrm{hour}$

$0.02 \mathrm{rem} /$ hour

$\frac{<0.001 \mathrm{rem} / \mathrm{hour}}{4.64 \mathrm{rem} / \mathrm{hour}}$ 
The dose rate on the reactor bottom shield 6 hours after shutdown, with a primary coolant activity of $10 \mathrm{c} / \mathrm{cc}$ at shutdown, will be $6 \mathrm{mrem} / \mathrm{hour}$, and this will be due entirely to the decay gamma rays from the core.

The overall reactor dose rates are summarized in Table XIV.

TABLE XIV

SUMMARY OF THE RADIATION LEVELS IN THE REACTOR COMPARTMENT

\begin{tabular}{c|c|c|c|c|c}
\hline \hline $\begin{array}{c}\text { Primary } \\
\text { Coolant } \\
\text { Activity }\end{array}$ & Full Power & $\begin{array}{c}24 \text { Hours after } \\
\text { Shutdown }\end{array}$ & Full Power & $\begin{array}{c}24 \text { Hours after } \\
\text { Shutdown }\end{array}$ \\
\cline { 2 - 4 } $\begin{array}{c}1.8 \mathrm{c} / \mathrm{cc} \\
\text { (Normal } \\
\text { Activity) } \\
10 \mathrm{c} / \mathrm{cc}\end{array}$ & $0.50 \mathrm{rem} / \mathrm{hr}$ & $62 \mathrm{mrem} / \mathrm{hour}$ & $\begin{array}{c}\text { None, except } \\
\text { in emergency }\end{array}$ & $\begin{array}{c}1 / 2 \mathrm{hr} \text { per } \\
\text { week or } \\
\text { greater } \\
1 / 2 \mathrm{hr} \text { per } \\
\text { week or } \\
\text { greater }\end{array}$ \\
\hline
\end{tabular}

*Compartment dose rate when the surge tank, superheater and steam generators are drained.

\section{Hot Storage and Waste Gas Area}

The shielding requirements for the hot storage and waste area are listed in Table XV. The various pieces of equipment were shielded to the following criteria:

a. The secondary shield will attenuate the resulting dose rate from the equipment to $1.5 \mathrm{mr} / \mathrm{hr}$ or less for full reactor power and $10 \mu \mathrm{c} / \mathrm{cc}$ coolant activity.

b. The dose rate from the equipment in the hot storage and waste gas area will be of the same order of magnitude as that in the reactor compartment 24 hours after shutdown.

The accessibility to the hot storage and waste gas area is governed by that to the reactor compartment. 
TABLE XV

SHIELDING REQUIREMENTS FOR HOT STORAGE AND WASTE AREA

\begin{tabular}{|c|c|c|c|c|c|}
\hline \multirow{2}{*}{$\begin{array}{l}\text { Hot Storage and } \\
\text { Waste Gas Area } \\
\text { Component }\end{array}$} & \multicolumn{2}{|c|}{$\begin{array}{l}\text { Specific Activity of Material } \\
\text { in the Component }\end{array}$} & \multicolumn{2}{|c|}{$\begin{array}{c}\text { Dose Rate } 1 \mathrm{ft} \text { from the } \\
\text { Component }\end{array}$} & \multirow{2}{*}{$\begin{array}{l}\text { Component } \\
\text { Shielding }\end{array}$} \\
\hline & Full Power & $\begin{array}{c}24 \begin{array}{c}\text { hours after } \\
\text { shutdown }\end{array} \\
\text { shutown }\end{array}$ & Full Power & $\begin{array}{l}24 \text { hours after } \\
\text { shutdown }\end{array}$ & \\
\hline $\begin{array}{l}\text { High boiler } \\
\text { Component Tank }\end{array}$ & $15 \mu \mathrm{c} / \mathrm{cc}$ & $0.45 \mu \mathrm{c} / \mathrm{cc}$ & $2.4 \mathrm{rem} / \mathrm{hr}$ & $7 \mathrm{l} \mathrm{mrem} / \mathrm{hr}$ & $\begin{array}{l}2-1 / 2 \text { in. lead } \\
\text { shielding }\end{array}$ \\
\hline $\begin{array}{l}\text { Used Waste } \\
\text { Amsco }\end{array}$ & $\begin{array}{l}\text { Coolant Acti - } \\
\text { vity }=1.8 \mu \mathrm{c} / \mathrm{cc}\end{array}$ & $0.23 \mu \mathrm{c} / \mathrm{cc}$ & $4.1 \mathrm{mrem} / \mathrm{hr}$ & $4.1 \mathrm{mrem} / \mathrm{hr}$ & $\begin{array}{l}3 / 8 \text { in. lead } \\
\text { shielding }\end{array}$ \\
\hline $\begin{array}{l}\text { Used Waste } \\
\text { Amsco }\end{array}$ & $\begin{array}{l}\text { Coolant Acti - } \\
\text { vity }=10 \mu \mathrm{c} / \mathrm{cc}\end{array}$ & $0.48 \mu \mathrm{c} / \mathrm{cc}$ & $2.4 \mathrm{rem} / \mathrm{hr}$ & $110 \mathrm{mrem} / \mathrm{hr}$ & \\
\hline $\begin{array}{l}\text { Backwash } R e- \\
\text { ceiver for the } \\
\text { Centrifuge }\end{array}$ & $6.0 \mu \mathrm{c} / \mathrm{cc}$ & $0.29 \mu \mathrm{c} / \mathrm{cc}$ & $2.4 \mathrm{rem} / \mathrm{hr}$ & $110 \mathrm{mrem} / \mathrm{hr}$ & $\begin{array}{l}3-1 / 2 \text { in. lead } \\
\text { shielding }\end{array}$ \\
\hline
\end{tabular}


The accessibility to the hot storage and waste gas area is governed by that to the reactor compartment.

3. Process Area on the 31 Foot Elevation

The process areas on the 31 foot Elevation are shielded from the radiation in the reactor compartment and the hot storage and waste gas area by a $3-1 / 4$ inch iron secondary shield. The individual pieces of equipment in the process areas will be shielded to $15 \mathrm{mrem} / \mathrm{hr}$ maximum to permit limited access.

The shielding requirements for the process areas are tabulated as follows:

\begin{tabular}{|c|c|c|c|}
\hline \multirow[t]{2}{*}{ Area and Component } & \multicolumn{2}{|c|}{$\begin{array}{l}\text { Dose Rate } 1 \text { foot from } \\
\text { the Component for the Given } \\
\text { Coolant Activity }\end{array}$} & \multirow{2}{*}{$\begin{array}{c}\text { Component } \\
\text { Shielding }\end{array}$} \\
\hline & $1.8 \mu \mathrm{c} / \mathrm{cc}$ & $10 \mu c / c c$ & \\
\hline Purification still & $1.5 \mathrm{mrem} / \mathrm{hr}$ & $8.4 \mathrm{mrem} / \mathrm{hr}$ & $\begin{array}{l}3-5 / 8 \text { in. lead } \\
\text { shielding }\end{array}$ \\
\hline \multicolumn{4}{|l|}{ Degasification } \\
\hline a. Degasifying Tank & $1.4 \mathrm{mrem} / \mathrm{hr}$ & $7.6 \mathrm{mrem} / \mathrm{hr}$ & $\begin{array}{l}4-1 / 8 \text { in. lead } \\
\text { shielding }\end{array}$ \\
\hline b. Centrifuge & $2.2 \mathrm{mrem} / \mathrm{hr}$ & $12 \mathrm{mrem} / \mathrm{hr}$ & $\begin{array}{l}3-5 / 8 \text { in. lead } \\
\text { shielding }\end{array}$ \\
\hline c. Filter & $1.3 \mathrm{mrem} / \mathrm{hr}$ & $7.1 \mathrm{mrem} / \mathrm{hr}$ & $\begin{array}{c}2-1 / 8 \text { in. lead } \\
\text { shielding }\end{array}$ \\
\hline
\end{tabular}

4. Secondary Shield

The secondary shield will reduce the dose rates in the reactor compartment and from the hot storage and waste gas area to $1.5 \mathrm{mrem} / \mathrm{hr}$ in areas of 40 hour per week access and to $15 \mathrm{mrem} / \mathrm{hour}$ in the process areas on the 31 foot Elevation which have limited access.

The secondary shield on the two sides and front of the reactor compartment will consist of a cofferdam with steel and water thicknesses of 1 inch and 3 feet respectively for the unloaded condition. When the ship is loaded, the water will be drained from the cofferdam, and the cargo oil will serve as shielding. 
The rear cofferdam will consist of 1 inch of steel and 4 feet of reserve oil which will be used to power the auxiliary boiler in event the reactor is disabled. Water may be pumped into this cofferdam to maintain the shield as the reserve oil is used.

The top of the reactor compartment will be shielded with $3-1 / 2$ inches of iron plus 2 feet of water encapsulated in pressurized tanks; the bottom of the reactor compartment will be amply shielded for gamma rays by the inner bottom and surrounding water when the ship is in the water. Access to the inner bottom 24 hours after shutdown is permissible.

A shielded tunnel leading from the engine room to the subpile room has been provided. This tunnel lies between two inner bottom girders and is shielded with 2-1/2 inches of steel (including girder thickness) to permit use of the tunnel for access to the subpile room 6 hours after shutdown.

The thermal neutron leakage from the primary reactor shield will not activate the ship's structure or machinery. 



\section{PLANT OPERATION}

\section{A. INSTRUMENTS AND CONTROLS}

The contents of this section describe the control and instrumentation systems for the reactor plant. These systems may be divided into the following classifications:

1) The reactor plant control system which provides automatic load following control in the power range and non load-following control of both the reactor and the heat transfer system during startup and normal shutdown.

2) The reactor plant instrumentation systems which provide information to:

The reactor plant control system for automatic control.

The reactor plant protective system for plant and personnel safety. Operating personnel to enable them to make correct and necessary decisions for plant operation.

3) The reactor plant protective system which provides protective actions to minimize or prevent thermal damage or excessive pressures due to misoperation or malfunctioning of plant equipment.

4) The radiation monitoring system.

To provide for safe and efficient operation of the overall plant, all necessary information display and manual control equipment is located in one centralized control area. Essential portions of the control systems will be capable of either manual or automatic control within limits as defined by the setpoints where automatic protective action will occur. Automatic control of all portions of the plant is used to the fullest extent possible to minimize the number of operating personnel required.

\section{Reactor Plant Control System}

The primary function of the reactor plant control system is to automatically regulate power output in accordance with turbine shaft power and auxiliary steam 
demand over the range of 10 to $120 \%$ of nominal plant capacity. Satisfactory load following characteristics will be provided with this system for ramp load increases up to $6 \%$ per second and any step load decrease over the entire automatic control range.

Secondary functions of the system are:

To provide semi-automatic control functions for power operation below $10 \%$ of nominal load, for startup, and for shutdown operations.

To maintain constant reactor organic outlet temperature in the control range.

To maintain constant turbine throttle inlet steam pressure in the control range.

To provide variable flow control in the steam generators to meet variable load demands while maintaining approximately constant reactor flow.

To maintain constant boiler water level at all loads.

To provide steam dump control for large abrupt load reductions.

As a result of core heat transfer characteristics, approximately constant organic flow in the core is desired at all load levels. To obtain variable load capability at the steam generator a constant flow pump with a controlled flow bypass line is used to provide approximately constant core flow and variable steam generator flow. To maintain satisfactory turbine efficiency at all loads a minimum charge in superheat steam temperature is desirable over the load range. This is accomplished by holding superheater organic inlet temperature constant over the controlled load range.

The selection and design of the control system components adhere to the following criteria wherever technically and economically feasible:

Use of conventional equipment of proven reliability.

Duplicate equipment where high reliability is required.

Fail-safe provisions for critical control components.

Self-test capability for infrequently active components.

VII-2 
On-line maintenance for critical control components.

Smooth transition from manual to automatic control.

Accessibility and simplicity of manual control equipment.

Absolute stability of the overall control system and sub-systems.

The method of control used to satisfy the various functional requirements of the control system is shown on Figure 25. A description of the operation of each unit in the system is given below.

The flow demand computer accepts input signals proportional to total steam flow and steam pressure, and computes a flow demand signal for input to the coolant flow controller in each of the two organic coolant loops. The portion of the total power demand provided by each coolant loop is determined by the operator, and the computer programs the coolant flow in each steam generator to insure that the sum of the separate loop demand signals is equal to the total plant demand signal.

The coolant flow controller provides a signal to the organic bypass valve positioner to maintain the coolant flow in the superheater and boiler equal to the flow demand for that loop. A conventional three mode controller is used in each loop. The valve position command signal is transmitted to the bypass control valve and to the steam generator coolant throttle valve. Throttling is initiated when the bypass valve is fully open.

The function of the thermal power computer is to develop a nuclear power demand signal as a function of the coolant temperature at the inlet to the reactor and the coolant mass flow rate in the reactor. The total coolant mass flow rate in the reactor is computed by summing the measured coolant mass flow rates from each coolant loop. The average coolant temperature at the reactor inlet is measured by three fast acting resistance thermometers in the reactor inlet plenum. The nuclear power demand signal is computed.

The temperature of the coolant at the outlet of the reactor is held constant for all power level and flow conditions in the automatic control range. A reactor outlet temperature error signal is obtained by comparing the measured outlet temperature with the set point. Thermocouples designed for fast time response are located in the outlet coolant strearn of each fuel assembly to measure the core 


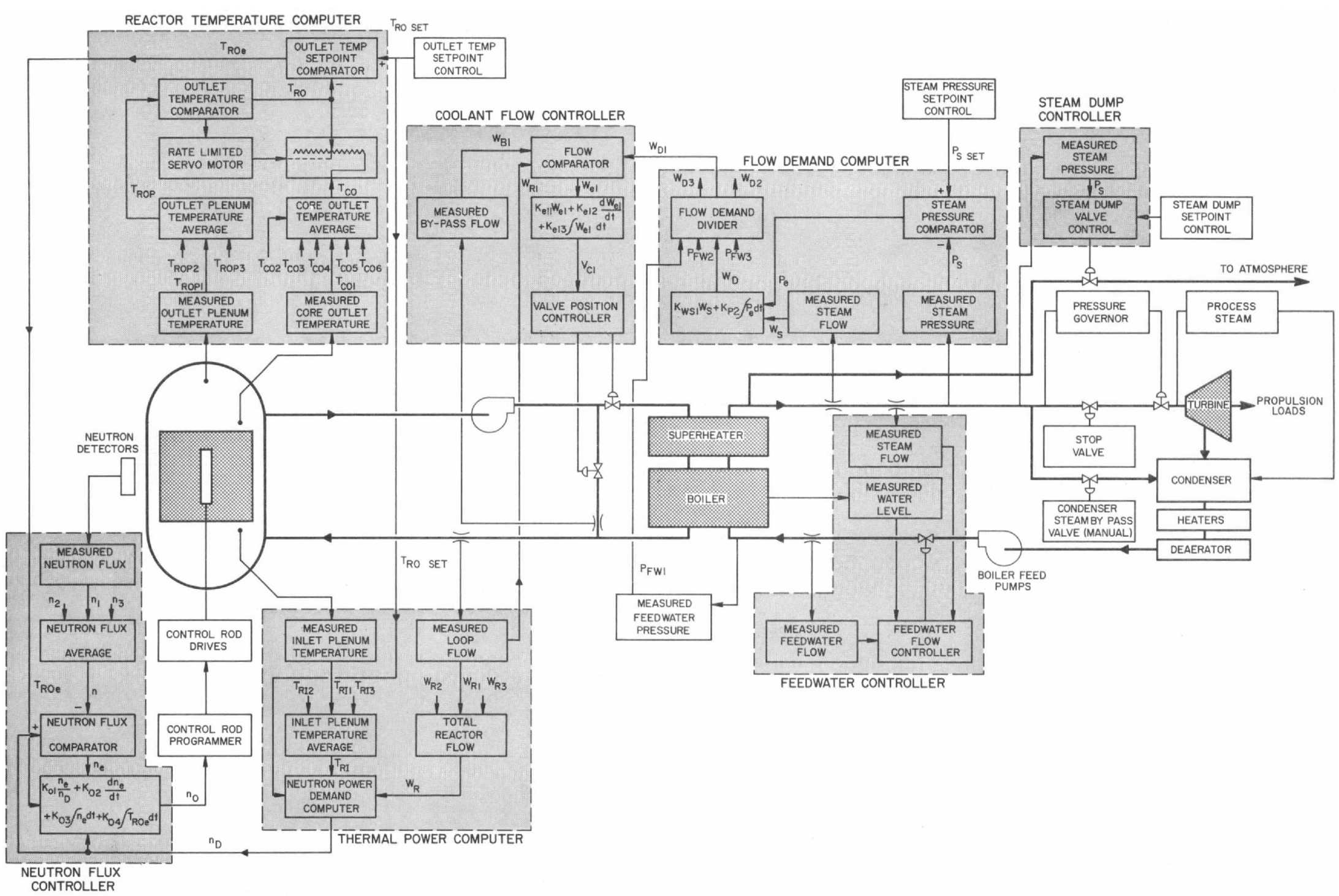

Figure 25. Reactor Plant Control System 
outlet temperature. An average core outlet temperature is obtained by summing the signals from six selected thermocouple positions.

The neutron flux controller provides a control rod demand signal by operating on the neutron power demand signal, a neutron power error signal and the temperature error signal from the reactor temperature computer. The neutron power error signal is produced by comparing the neutron power demand signal with the average flux measured by the three power range neutron detectors. Three mode control action is performed on the neutron power error signal with the proportional action inversely proportional to the neutron power demand signal.

The function of the control rod programmer is to position the groups of control rods in a predetermined sequence in response to neutron flux demand signals from the neutron flux controller. The program by which the rods are moved is computed to insure a minimum of neutron flux peaking due to control rod perturbations, and provides for automatic reactor power control and power setback.

The function of the feedwater controller is to maintain constant feedwater level in the boiler for all load conditions. A conventional three element controller is used on each boiler. Control action is derived by matching feedwater flow to steam flow and resetting on feedwater level error. The controller is compensated for ship motion about all three axes.

The steam dump controller operates on steam header pressure and a set value of steam dump pressure. The control system is designed to dump the full power steam flow to the condenser in the event of large decrease in load. The error between the set pressure and the actual pressure is used as a demand signal to the positioner of the steam dump valve. During normal operation the dump set pressure will be set at approximately 435 psig. The dump set pressure can be manually set at any pressure between 435 psig and atmospheric pressure.

\section{Reactor Instrumentation}

The reactor instrumentation systems include those instruments used for the measurement of neutron flux internal and external to the reactor core, temperatures within the reactor vessel and the instruments required to detect and locate a failed fuel element. 

a. Nuclear Instrumentation System

The functions of the nuclear instrumentation system are:

To provide a means of continuously monitoring reactor power level from shutdown to full power.

To provide signals to the plant protective system for alarm, power setback, and scram purposes.

To provide signals to the plant control system for automatic regulation of reactor power level.

The following performance requirements and design criteria were used as a basis for the design of the nuclear instrumentation system:

The instrumentation shall cover the entire neutron flux range at all times.

A minimum of one decade overlap shall be provided between successive flux ranges.

A minimum of two instrument channels shall be provided for each range. In event of any single failure this leaves one or more channels operable. Duplication also provides a check on the agreement of both channels.

The nuclear instrumentation system shall meet all requirements of the plant control and plant protective systems.

Fail-safe design shall be provided wherever feasible to insure maximum protection should there be a component or power failure.

Where feasible, the control channels shall be designed to fail "as is". Such failures will initiate manual or semi-automatic control before protective action occurs.

A minimum of three channel coincidence shall be provided for all instrumentation channels associated with the plant protective and plant control systems.

The nuclear instrumentation system provides continuous indication of reactor power level by monitoring the neutron leakage flux from the reactor. 
Neutron flux from source level to $150 \%$ of full reactor power varies over a span greater than eleven decades. Since no single neutron detecting instrument can satisfactorily cover the entire flux span, the system is divided into three ranges; the source, intermediate, and power ranges with positive overlapping between successive ranges. For reactor startup, the source and intermediate range instruments are utilized. Eleven separate neutron instrument channels are employed in this system as shown on the nuclear instrumentation block diagram, Figure 26. The neutron detectors are housed in instrument thimbles located around the reactor core tank. The thimbles are cooled and contain the necessary gamma shielding and neutron moderator material to obtain optimum detector performance.

The source range instruments (channels I and II) are duplicate and independent channels and monitor the neutron flux from shutdown, or source level, to five decades above this level. These instruments are high sensitivity multielement boron triflouride proportional counters. A mechanism is available to withdraw the detectors from high neutron and gamma fields during high power operation. This allows continuous channel operation, prevents detector radiation damage, and provides positive indication that the channel is in proper operating condition in the event of a scram and subsequent startup. A pulse rate and period computer receives signals from the $\mathrm{BF}_{3}$ detector and computes the logarithm of the count rate and reactor period. These computed signals are transmitted to indicators and recorders located in the control room.

The intermediate range instruments (channels III and IV) also employ duplicate independent channels. These channels provide coverage for approximately seven decades of power level and overlap the upper portion of the source range and lower portion of the power range. A boron-lined compensated ionization chamber is used for the detection of thermal neutrons. A log current and period computer converts the current from the ionization chamber to a voltage proportional to the logarithm of the current. Differentiation of this voltage provided a signal inversely proportional to reactor period. Log current and period signals are transmitted to indicators and recorders in the control room.

Seven channels monitor neutron flux from 1 to $150 \%$ of full reactor power. Boron-lined uncompensated ionization chambers are used. A current 


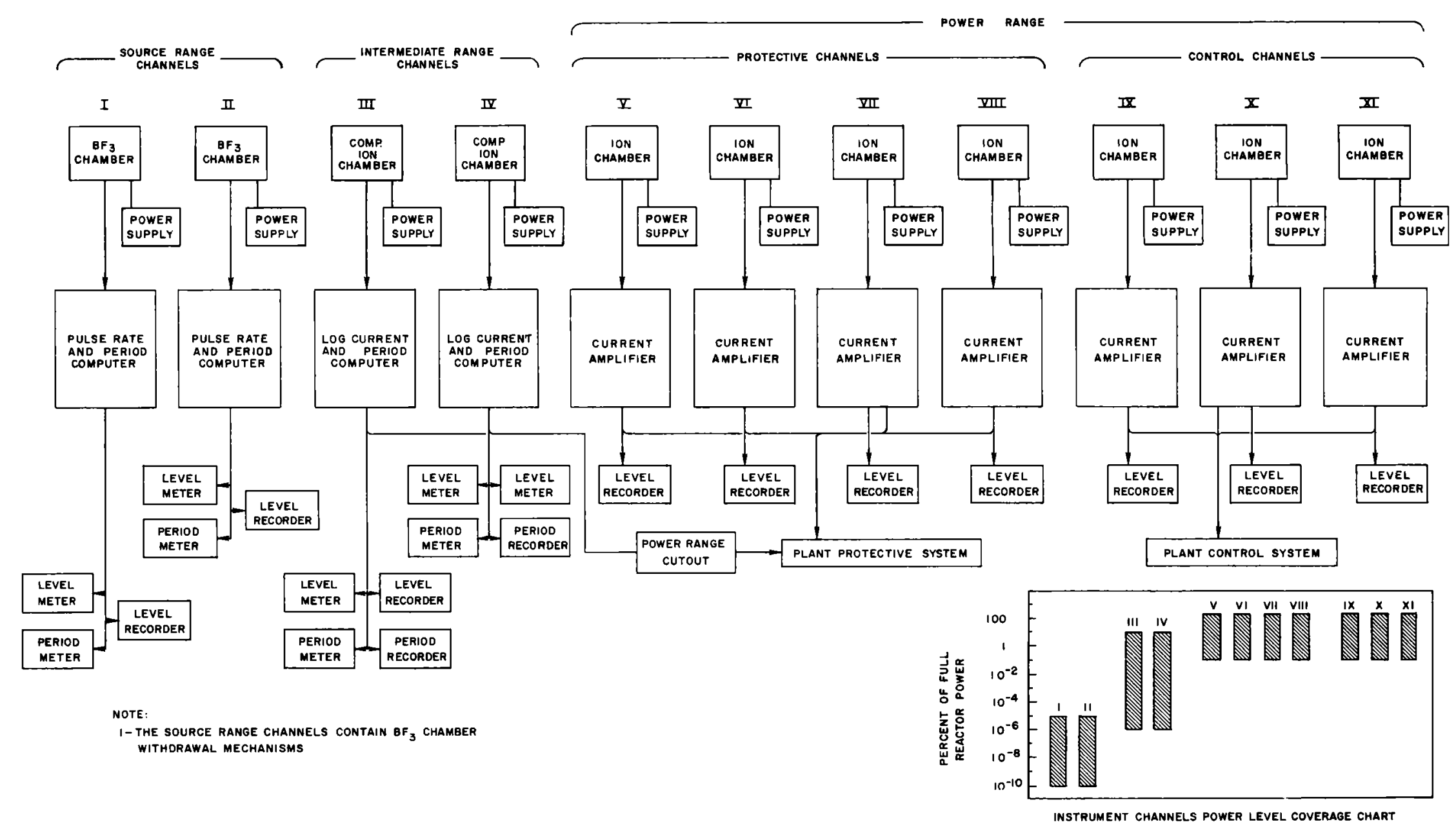

Figure 26. Nuclear Instrumentation 
amplifier receives the output current from each detector and supplies signals proportional to this current to the plant control system, protective system, alarm system, recorders, and period cutout curcuit. Four of these channels furnish signals to the protective system to setback and scram the reactor when abnormal conditions prevail. The four channel system in coincidence provides false shutdown protection and safety reliability. The remaining three channels furnish signals to the reactor plant control system. Three channels are utilized to improve the reliability of the control system and provide two modes of operation auctioneered or average. The auctioneered method automatically selects the highest of three signals.

\section{b. Core Instrumentation System}

The function of the core instrumentation system is to obtain static and transient temperature measurements in the reactor core. These measurements are required:

For detection and location of hot fuel channels.

To provide signals to the reactor plant protective system for alarm, power setback, and scram purposes.

To provide signals to the reactor plant control system for the purpose of automatically regulating reactor power level.

To aid in manual rod shimming when adjusting for proper fuel channel outlet temperature.

To provide permanent records of core operating history.

To aid in determining locations of failed fuel elements.

The coolant temperature at the outlet of each fuel element is measured with fast response thermocouples. The thermocouples are iron-constant and insulated with magnesium oxide and sheathed with stainless steel tubing. A selected number of these measurements are transmitted to the reactor plant protective system where they initiate a power setback or scram when the temperatures deviate beyond predetermined safe limits.

In addition to the temperature signals supplied to the protective system, one signal from each fuel element is supplied to a digital data logging system. 
The data logger provides the reactor operator with a continuous visual display of reactor core fuel channel outlet temperatures and initiates audible and visual alarms when these temperatures exceed predetermined values.

To consolidate data for recording purposes, the data logging system also receives signals from plant variables other than the fuel element outlet temperatures. These signals are neutron flux level in the power range, reactor inlet and outlet temperatures, organic system pressures, coolant flow in each loop and the steam system pressures, temperatures, and flows.

The core instrumentation system also employs fast response high accuracy resistance thermometers. These elements measure the coolant temperatures in the inlet and outlet plenums of the reactor. This information is transmitted to the reactor plant control system where it is utilized in the automatic regulation of reactor power level.

\section{c. Core Power Mapping System}

A core power mapping system is provided to assist in obtaining maximum core life by shaping the coreflux distribution. The system measures neutron flux levels at various locations within the core and the coolant outlet temperature of each fuel element. This data is processed, along with reactor power history data, to obtain the radial and axial neutron flux and power density distribution throughout the core. The optimum position of each flux shaping rod is computed as a function of flux and power distribution and estimated spatial fuel burnup.

In operation, the system will automatically provide a continuous digital record of the in-core measurements. This data is assimilated at approximately four week intervals, to coincide with time in port, or whenever operating conditions warrant control rod reprogramming. All the data required for computation of optimum rod positions is then transmitted (via radio or cable) to a land based computer facility."

The digital computer is provided with an appropriate core analysis program which accepts the transmitted data. The program is corrected with

\footnotetext{
*Because of the widespread use of general purpose digital computers in business and industry, it is expected that an IBM, Remington Rand or Burroughs computer facility may be contracted on the east coast or in the Philadelphia area.
}

VII -10 
each new set of data and computes the current optimum control rod postions for the flattened flux condition at nominal reactor power. This information is then transmitted back to the ship where the rods are reset to the new positions.

This system eliminates a shipboard computer and the personnel required for operation and maintenance. In addition, a larger computer may be used for the core analysis which permits use of a more comprehensive program.

The in-core measurements are made with neutron sensitive detecting elements located at selected positions in the core. One quadrant of the core is fully instrumented with about 20 detectors. Each other quadrant will contain three detectors. Instrumentation is provided for continuously recording the instantaneous and integrated neutron flux signals and the coolant temperatures at the outlet of each fuel element. These fuel element effluent temperatures are also used for plant control.

A simplified block diagram of the core power mapping system is shown in Figure 27.

The following performance requirements and design criteria were used as a basis for the conceptual design of the core power mapping system.

a) The system shall be designed to obtain measurements of timeintegrated axial and radial neutron flux distributions within the the core and measurements of instantaneous neutron flux at various points within the core.

b) The system will compute the flux and power density distributions throughout the core by use of a digital computer which will simulate the core physics, with a mathematical model. The measured parameters listed in (a) above, will be used to correct accumulated computational errors in the mathematical model at intervals during the life of the core.

The digital computer will also be used to compute an estimate of the average fuel burnup in each fuel element. These data will be checked against the measured total power output of the fuel elements. 


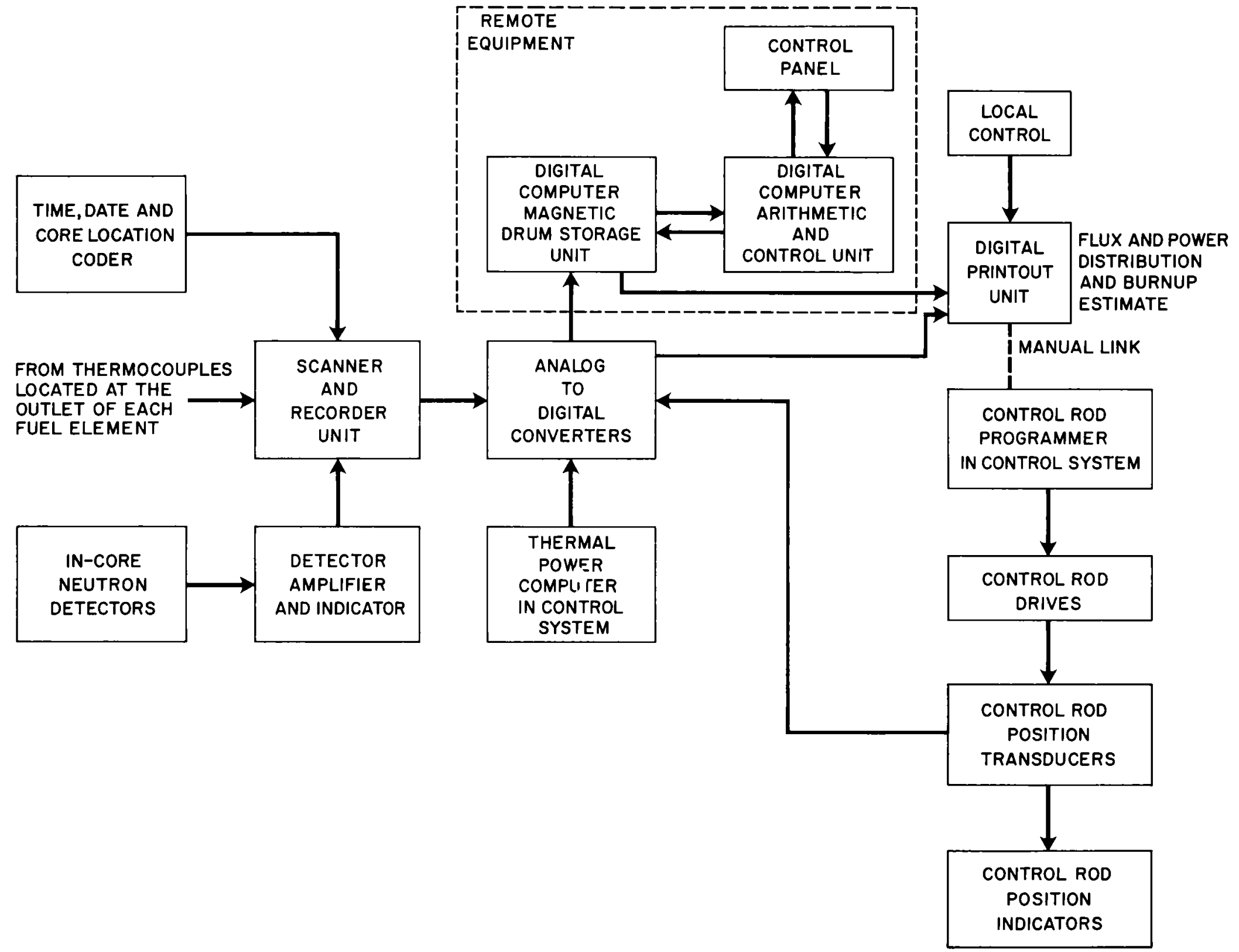

Figure 27. Core Power Mapping System 
c) The measuring and recording system shall be capable of continuous operation and shall be designed to require a minimum of manual operation.

d) The system shall employ tried and proven techniques and equipment to the fullest extent possible. Where the life of a component is an important factor in its design or selection, the component shall have a design life of not less than 20 years. This requirement will not apply to components external to the reactor core tank if such components are designed to be easily replaced in service.

e) The penetrations of the reactor core tank by instrument headers shall not impair or limit the containment integrity of the reactor.

f) The placement of instruments within the reactor core shall not necessarily interfere with the normal loading and unloading of fuel elements, or the replacement of control rod elements.

g) The detecting elements shall be designed for continuous operation within the reactor core under full rated power conditions. The maximum expected detector temperature is $750^{\circ} \mathrm{F}$, neutron flux approximately $10^{14} \mathrm{n} / \mathrm{cm}^{2}-\mathrm{sec}$, and maximum gamma heating approximately 12 watts per gram of absorbing material.

h) The design temperature of all components within the reactor core tank shall be $800^{\circ} \mathrm{F}$.

Neutron-sensitive boron thermopiles* are used for instantaneous and time integrated thermal neutron flux measurements at given points within the reactor core. The thermopiles are fixed in the core at positions preselected to provide the most accurate and useful flux data.

The boron thermopile detectors consists of a series arrangement of two thermo-electric couples. The detecting couple contains boron and is sensitive to thermal neutrons as well as the local temperature. The second couple is sensitive to temperature only and is connected in series opposition to the boron

*Preliminary investigation of the useful life and sensitivity decrease of boron thermopiles in a high neutron flux shows that these detectors may be suitable; if not, other types of detectors may be used. 
couple, thus providing temperature compensation. The output voltage is therefore a function of neutron flux only.

Arrangements will be made for periodic routine use of a computer in the Philadelphia area. The computer will employ a mathematical model of the reactor core to calculate neutron flux and power density as a function of spatial position in the core. When the reactor operating schedule calls for rod reprogramming, or whenever conditions warrant reprogramming, the computer is called upon to calculate the flux and power distributions at that time. The distributions are a function of the past operating history and the control rod positions then in effect. The calculated data are compared with the current readings by the computer and the program is internally corrected to agree with the measured values. The computer then calculates new optimum rod positions and the resulting flattened flux distributions. The new rod positions are manually set into the control rod programmer.

d. Fuel-Element-Failure Detection and Location System

In a heterogeneous reactor system employing clad fuel elements, the presence of gross fission products* in the coolant is an indication of a failure of the integrity of the fuel cladding material.

The containment philosophy for this conceptual design is based on the assumption that fission products may be circulating in the system as a result of fuel element cladding defects or failures, and that the plant will not be shut down until the fission product concentration in the coolant reaches a pre-determined level based on radiological hazards considerations. In the unlikely event that this maximum level is reached, the reactor will be shut down and the ship will continue, on take-home power, to the port where repairs may be made.

It has been concluded that one of the best methods of detecting a cladding failure is to detect the presence of fission products in the coolant. This conclusion is based on the premise that a defect in the fuel cladding will cause fission products or fissionable material to be present in the coolant and result in a radiological hazard.

*The term gross fission products refers to all the radioactive nuclides that result from nuclear fission. 
It is advantageous for the cladding failure detection system to be completely automatic in operation. The location of the failed fuel element should be indicated before continued operation causes fission products to be dispersed throughout the coolant system since it is difficult to locate the failed element in the presence of strong background activity. If the failed element is located at sea while under power, the reactor may be shut down and cooled before arrival in port where immediate repairs may begin. The ship will normally continue under power as long as the fission product concentration remains below the maximum permissible level.

A well-mixed organic coolant sample is taken from the effluent of groups of four fuel elements. Sampling groups of elements is sufficient to locate the area of failure and reduces the number of sampling tubes to 22 . This number of sampling points may be rapidly scanned with a single instrument system. A block diagram of the proposed fuel element failure detection and location system is shown in Figure 28.

The following performance requirements and design criteria were used as the basis for the design of this system:

a) The system shall be continuous and automatic in operation.

b) Each group of four fuel elements shall be monitored repeatedly so that it will not be necessary to remove more than the four elements in order to remove the defective fuel pin.

c) The system shall be capable of detecting and locating a fuel element from which the fission product release is the result of the diffusion of fission product gases through a failure in the fuel cladding.

d) The system shall be capable of detecting a new failure in the presence of an existing one.

e) The operation of the system shall not interfere with the normal operation of the reactor plant.

f) The system shall not prevent or interfere with the insertion or removal of fuel elements or control rod poison elements. 


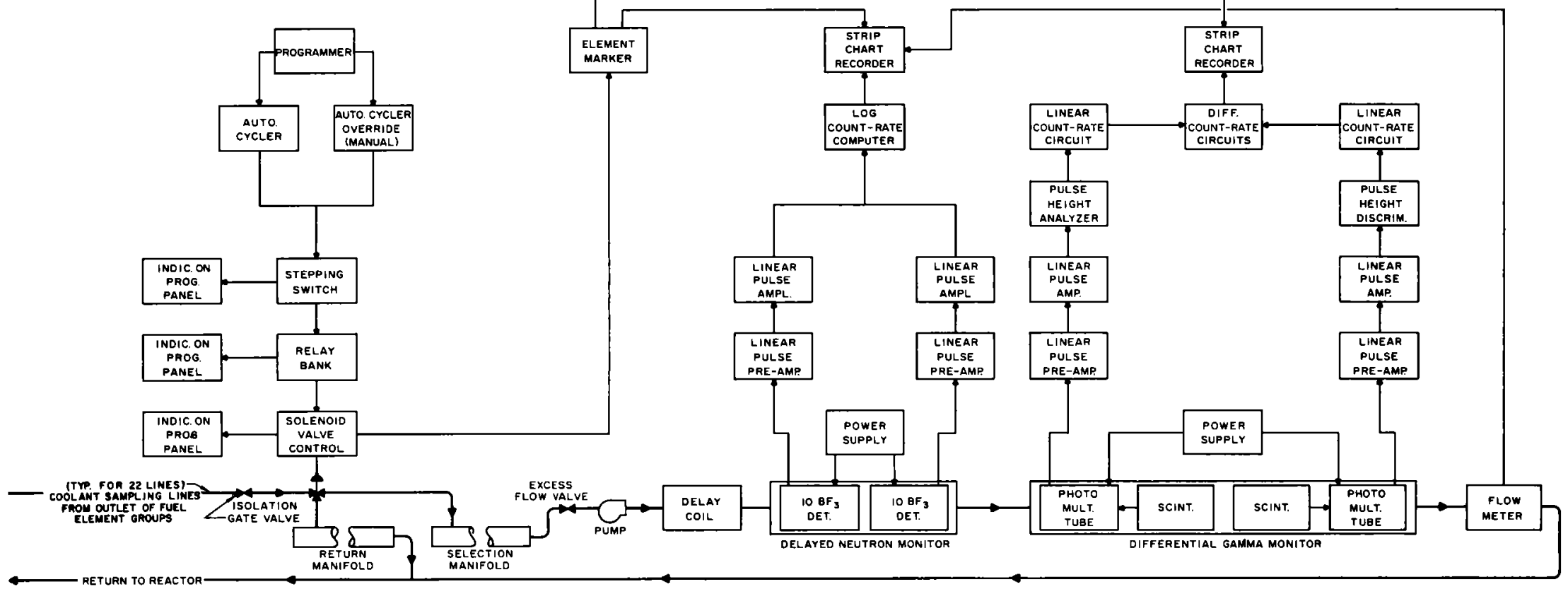

Figure 28. Fuel Element Failure Detection and Location System 
g) Where the life of a component is an important factor in its design or selection, the component shall have a design life of not less than 20 years. This requirement will not apply to components external to the reactor core tank if such components are designed to be easily replaced in service.

h) The system shall have no moving parts within the reactor core tank or biological shield.

i) Multiple systems shall be used external to the reactor and biological shield to insure reliability of operation.

j) The device used to indicate which fuel elements are being sampled shall be capable of maintaining its accuracy without adjustment during the life of the equipment.

k) All valves in the system shall be accessible for operation and maintenance during reactor operation without overexposure to personnel.

1) Manual override of automatic operation shall be provided so that it is possible for the plant operator to select any one of the fuel element groups for sampling and for any desired duration of sampling time.

m) A method of measuring, indicating, and recording the sample flow rate, the radiation level in the sample, and the position of the fuel assembly being sampled, shall be provided.

n) An alarm shall be provided to indicate system failure, low sampling flow, and high radiation level in the sample.

o) The system shall be designed for a normal operating temperature of $775^{\circ} \mathrm{F}$ at the inlet to the sampling valves and $150^{\circ} \mathrm{F}$ at the radiation detector location.

p) The coolant not being carried to the radiation detection elements shall be kept in continuous flow through suitable bypass lines and returned to the coolant system. 


\section{Reactor Plant Protective System}

The primary function of the reactor plant protective system is to protect the reactor and the organic heat transfer system from thermal damage and excessive pressures. The protective system is completely independent of the reactor plant control system, and functions only as an automatic pre-emergency or emergency device in the event that the control system fails to function properly. Separate and independent protective devices are provided for protection of the steam turbines.

The reactor plant protective system provides protective action by automatically reducing the reactor power level when an unsafe condition is detected in the reactor plant. In general, the speed of response of the detecting elements and the speed at which corrective action is taken is faster in the protective system than in other portions of the plant instrumentation and control system. Abnormal plant conditions requiring protective actions may result from:

Failure of electrical power

Failure of the control system

Misoperation by the plant operator

Failure of a plant component

Loss of turbine load.

Section VIII contains a detailed discussion of the various assumed accidents related to the organic cooled and moderated reactor concept in conjunction with the maritime tanker application.

The protective system design was based on the following performance requirements:

a) The system must protect the plant from thermal damage, or excessive pressures at all times. Protection of the reactor core will receive first priority.

b) The system must not unnecessarily interfere with the normal operation of the plant, and must not cause unnecessary shutdowns. 
c) No single component failure in the plant protective system shall prevent the necessary protective action from taking place.

d) The design shall be such that no corrective action must ever depend on the perception, decision, or action of a human operator.

e) The individual components and information channels shall be continuously self-monitoring with means to indicate a protective system failure, or imminent failure.

f) The components of the system shall be designed, if possible, so that each information channel and each component in the channel can be calibrated in place after installation in the reactor system.

g) The use of any component of the protective system for any other control function in the plant is not permitted.

h) The components shall be designed and constructed for convenient replacement with pre-tested spare units without interfering with the normal operation of the plant, or the function of the reactor plant protective system.

i) The operational readout, display, annunciator, and system controls shall be located on the main control board in the control area.

j) The annunciator alarm and power setback setpoints, and the scram trip level shall be either fixed as part of the equipment design, or automatically reset. No manual adjustment of protective system setpoints or trip level shall be necessary under any operating condition.

Electrical and mechanical interlocks are provided to prevent both automatic or manual mis-operation wherever possible. These interlocks are arranged to insure that certain operating conditions are met, and that the correct sequence of actions occur during startup, shutdown, stand-by, and power operation. In the event of manual mis-operation these interlocks will override operator action and give visual and audible warning.

Both visual and audible alarms are used to alert the operator of an approach to an undesired or unsafe operating condition, to indicate a manual or automatic 
mis-operation, and to provide information on the operability of installed stand-by or operating equipment, redundant instrumentation, control systems and components. All signals which may cause an automatic corrective action, by either the control system or protective system, have alarms associated with them. In most cases an alarm setpoint is established to sound an alarm before the atuomatic power setback point or scram point is reached.

Two types of automatic power reduction protective actions are provided to cover the situations in which the operator or the automatic control system fails to make proper corrective actions in response to an abnormal plant condition. These protective actions are power setback, and scram. Both actions are accompanied by annunciator signals which sound an audible alarm indicating the type of protective action taken, and the abnormal plant parameter.

The reactor power level setback is the first and least severe automatic protective action to reduce reactor power level. The interlock and annunciator protective functions act to prevent further control rod withdrawal, or give an alarm. The power setback is intended to correct any abnormal operating condition without resorting to a complete shutdown of the plant by a scram. Setback is accomplished by removing the reactor plant from automatic load following control, and causing all control rods to be inserted at the maximum controlled rate. This setback action is irreversible, and will continue as long as the abnormal condition exists. A setback is stopped when the abnormal condition no longer exists. In the usual case, the reactor will be subcritical when the setback action stops, and the reactor power level will continue to decrease unless the operator manually restores the reactor plant to automatic control.

A scram is a rapid emergency reduction in reactor power level brought about by gravity insertion of all the safety rods into the reactor core. A scram will occur when all other means of manual or automatic protective action has failed to correct an abnormal condition that is potentially dangerous to the reactor plant or personnel. The reactor may be scrammed manually if the plant operator is not satisfied that a serious operating condition is being adequately corrected.

When a reactor scram occurs, the steam flow to the turbine must be rapidly reduced and the organic bypass control valves closed, providing full organic flow to the steam generator to minimize thermal shock. The reactor plant protective 
system controls these operations by providing trip signals to the turbine protective system and the organic bypass and throttle valves. A block diagram of reactor plant protective system is shown in Figure 29. The system consists of circuits which provide automatic protective actions plus auxiliary circuitry for the detection of malfunctions or component failures in the system, and for functional testing. For simplicity, only the automatic power reduction protective functions are shown.

4. Radiation Monitoring Systems

The radiation monitoring systems perform the following three primary functions:

Monitor the radiation integrity of the reactor plant.

Provide signals which actuate fast closing dampers in the ventilation system and stack when excessively high radiation levels are reached.

Provide operating personnel with a knowledge of the radiation levels in the various areas in and around the reactor plant.

A block diagram of the various monitoring units in the radiation monitoring systems is shown in Figure 30.

a. Plant Integrity Monitoring System

The primary function of the plant integrity monitoring system is the detection and measurement of both normal and excessive radioactivity levels in and around the various compartments containing the reactor and organic process portions of the plant. The existence of abnormally high radiation levels in any of these areas is an indication of a failure in the containment integrity of the organic coolant heat transfer and process system, the fuel element cladding, or the biological shielding of the reactor. This system serves as an operational monitoring system to warn operating personnel of plant component malfunctions and failures that might not be detected by other means. The system also provides a continuous recorded history of radiation levels in the various areas of the plant.

The plant integrity monitoring system employs two basically different types of radiation monitoring devices; the area monitors which continuously measure and record the gamma radiation levels in the area, and the air particulate 


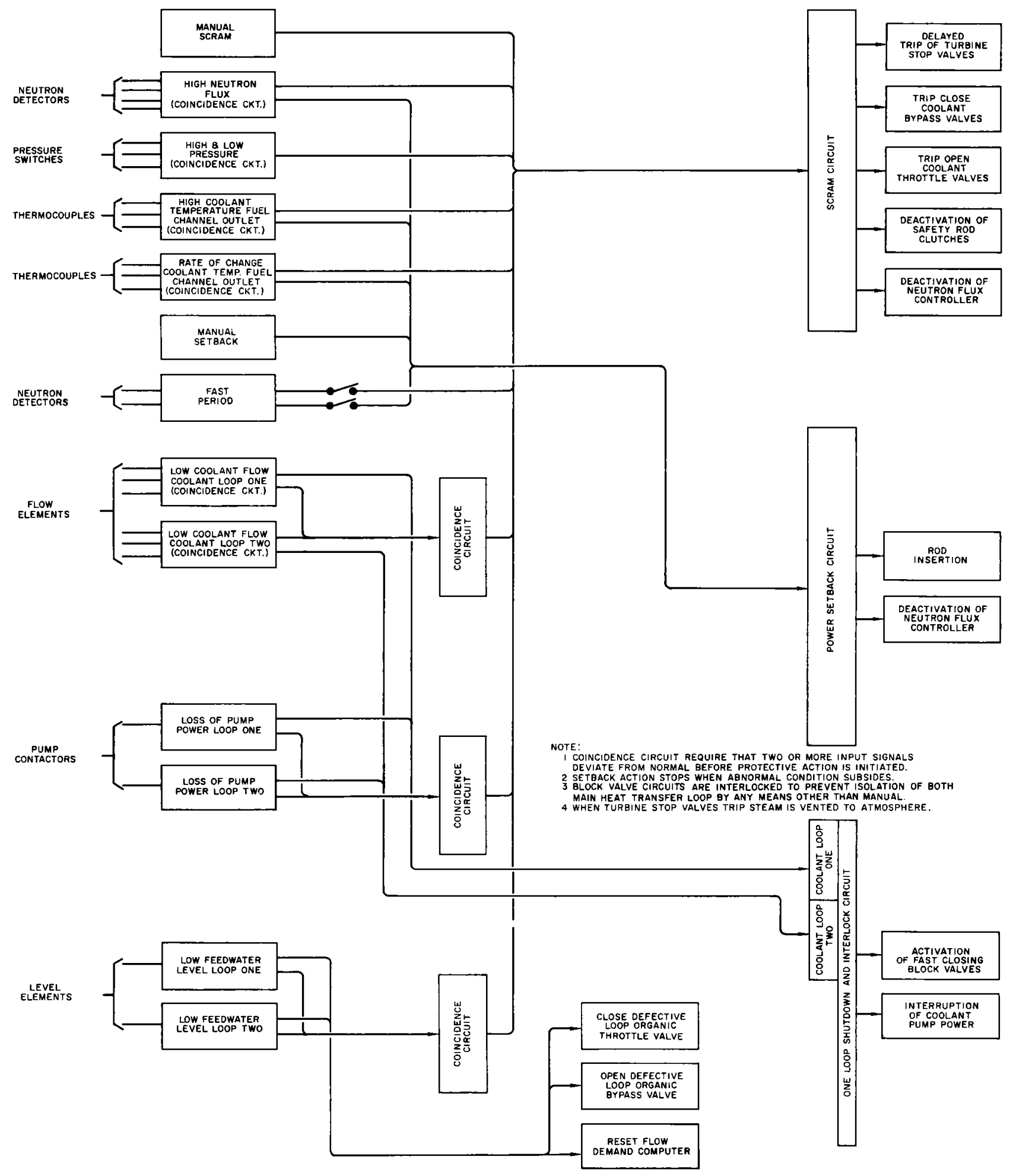

Figure 29. Reactor Plant Protective System 


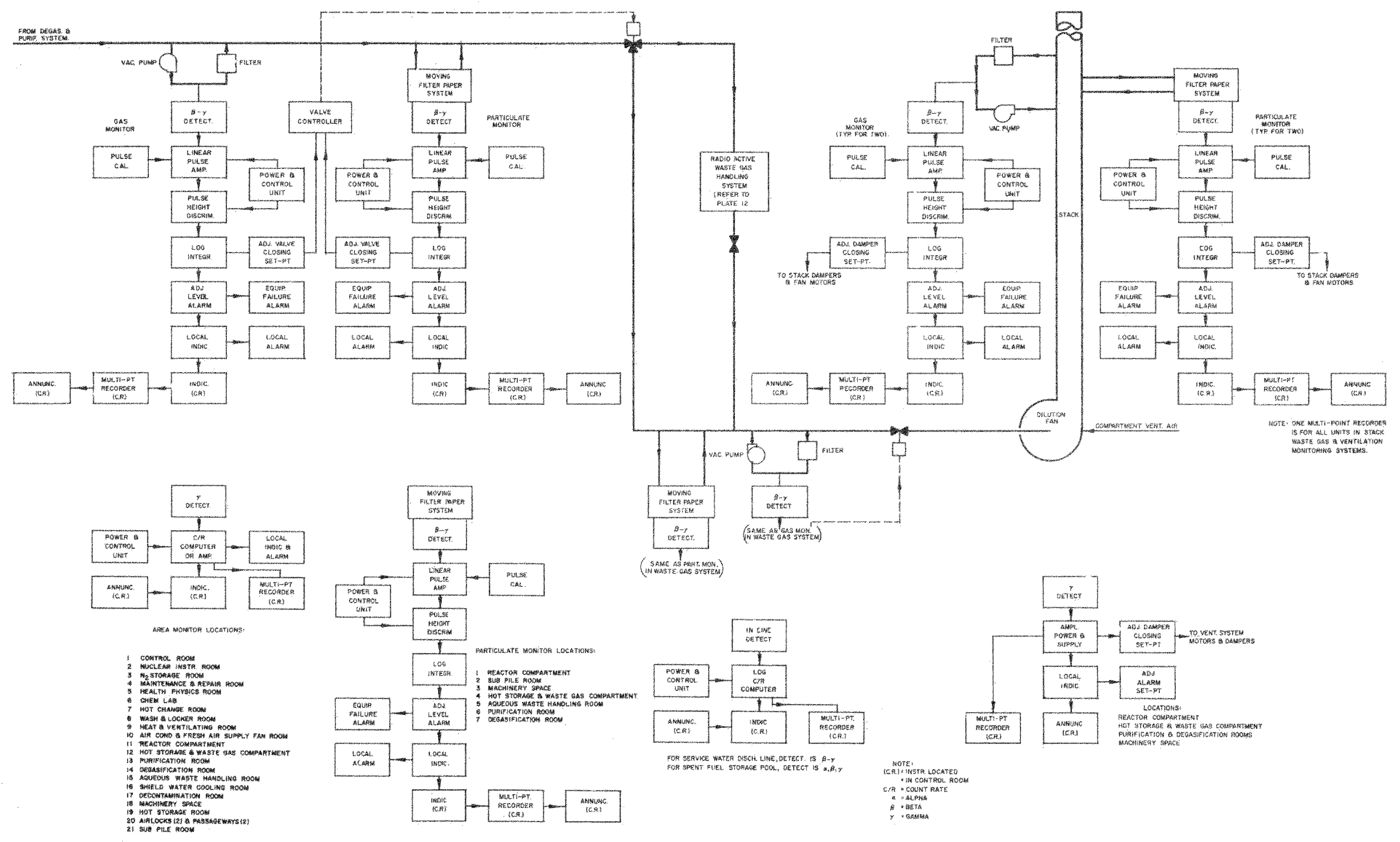


monitors which measure the concentration of radioactive particulate matter in the air. The detector units of the gamma area monitors are located to give an indication of the maximum gamma level in the area. The air monitors, in most cases, are located at the entrance of the exhaust ventilation duct in each compartment.

b. Ventilation Monitoring System

All of the compartments containing organic process equipment, including the reactor compartment, are provided with separate ventilation systems which discharge to the ventilation stack. The function of the ventilation monitoring system is to measure the radioactivity level in the air being discharged from each of these areas, to provide signals to operate fast closing dampers, and to stop the ventilation fans when the radiation levels exceed safe limits.

Gamma-sensitive ionization chambers located in the inlet to the exhaust ducts are used to monitor the discharged air. The signal from each ventilation monitor is displayed on remote indicators in the control room and recorded on a multipoint strip chart recorder. An adjustable alarm and damper closing set point and an annunciator are provided for each unit.

c. Waste Gas Monitoring System

The function of the waste gas monitoring system is to measure the concentration of radioactive particulate matter and gases in the gaseous exhaust from the degasification and purification systems, and in the discharge line leading from the decay storage tanks to the stack. An air particulate monitor and a gas monitor are located in each gaseous waste discharge line as shown on Figure 30 . If the concentration of particulate or gaseous activity from the Degasification and Purification Systems exceeds a predetermined level, as determined by the stack dilution factor, the monitor will close the damper valve in the gas discharge line.

\section{d. Stack Monitoring System}

All ventilation air passing through the reactor and process compartments, and all gaseous wastes are discharged to the atmosphere through the ventilation stack. The function of the stack monitoring system is to monitor this discharge to insure that the concentration of airborne radioactivity at deck level does not exceed the maximum permissible concentration permitted for ship personnel protection.

VII -24 
The stack monitors sample the stack discharge immediately downstream of the stack particulate filters, and act as a backup to the ventilation and waste gas monitoring systems.

Two air particulate monitors and two gas monitors are provided to insure that one monitor unit of each type is in operation at all times. The count rate signals from each monitor are displayed on remote indicators in the control room and recorded on a multipoint recorder. An adjustable alarm setpoint and annunciator are provided for each monitor unit.

In the event that the radioactivity level in the air passing up the ventilation stack exceeds the maximum allowable level, the monitor will shut off the stack dilution fans and close the stack dampers.

\section{e. Aqueous Waste Monitoring System}

The function of the aqueous waste monitoring system is to measure the radioactivity of liquid wastes discharged from processing equipment and the activity of stored liquid wastes. Separate beta-gamma monitors are used on all cooling water systems. The detection units are sufficiently sensitive to measure either beta or gamma concentrations of $10^{-6} \mu \mathrm{c} / \mathrm{cc}$ with a counting rate of at least twice background. Adjustable alarm setpoints and annunciators are provided for each unit. The counting rate is displayed on individual indicators, in the control room and recorded on a multipoint recorder.

\section{B. REACTOR OPERATION}

Preliminary plans for plant startup, operation, shutdown and maintenance have been developed to the extent necessary for assurance that the design characteristics, layouts, facilities and services specified meet reasonable requirements.

Initial startup is considered to include all preliminary equipment tests and inspections which are not part of the construction phase of work, and to extend through the period of testing until the plant is declared available for regular duty in the system. Plant operation is considered to include all procedures and requirements during the periods the equipment is producing useful power. Plant maintenace is considered to include requirements for repair, modification, preventive maintenance and other procedures when the equipment is not in operation. In this concept, maintenance specifically includes reactor refueling operations in contrast 
with conventional plants where fuel supply is normally considered an operating function. The necessity for removing the plant from operation to refuel is consistent with classifying the procedure as a maintenance function.

1. Initial Startup

A procedure of pre-operational testing and inspections of all equipment and systems is performed to demonstrate that the plant is built to specifications and that it is ready for fuel loading and initial startup. Each system is to be tested functionally and include, as appropriate, hydrostatic and cleanliness tests. Installation checks, response and sensitivity measurements, wiring checks, air flow tests, rotation checks, vibration checks and so forth. All safety and protective system circuits and interlocks are checked with simulated signals.

The preliminary tests and inspection phase is intended to verify the satis factory condition of systems prior to operation. A complete and detailed check list is run through to assure that all equipment is in proper condition for operation and that all safety circuitry and interlocks are operable and in service, and that valve and control settings are proper for startup.

The normal reactor plant organization is modified during initial startup to accommodate senior technical supervisors from the reactor manufacturer and other representatives of equipment suppliers. These representatives will assist in the direction of all activities relating to check-out, testing and approval for operation of systems within their design responsibility. They will consult with and advise the supervising startup engineer on all technical matters relating to their equipment and systems. They will instruct and assist reactor plant operators in organizing procedures for performance of the operation and maintenance of their respective equipment and/or systems and will be present for all important steps in demonstration of plant operating capability.

The following is presented to indicate the nature and scope. Details will be modified as the final planning and execution progress:

a) Plant auxiliary systems are placed in service.

b) The feedwater system and main coolant system are set up for preheating, using the auxiliary boiler for providing auxiliary steam to heat feedwater and steam trace all main loop components to minimum

VII-26 
operating temperatures. The reactor vessel is preheated by the use of forced hot air. When a desired temperature of preheating is obtained, the coolant is charged to the main loops and reactor by placing the purification system in service.

c) The neutron source is then inserted in the core and source range nuclear instrumentation checked and calibrated.

d) With the reactor full of hot coolant, fuel is loaded in the core while checking for criticality at each calculated half loading as determined by control rod withdrawal tests. At criticality the required physics measurement and calibrations are performed. Core loading is then completed to the required excess reactivity.

e) Test operation and response of all valves and pumps in the coolant and process systems is performed along with checking main coolant loop inertia by tripping the coolant pump in each loop, and in both loops simultaneously. A check follows of all instrumentation, controls, and protective system operations and calibrations.

f) The lube oil system and control oil system of the turbine is placed in service and the unit rotated on turning gear. All emergency turbine stop valves are closed and the drains and hand controlled steam dump valves opened to the condenser.

g) The feedwater system is set up for normal service and the steam generator levels lowered to operating range, followed by raising of control rods with the result of bringing the reactor plant to low power level.

h) As steam pressure rises the flow is hand controlled through the main steam header dump valves to the condenser. When the steam flow and pressure are sufficient, the main turbine unit is warmed up, tested and made ready in accordance with the manufacturer's estab. lished procedures.

i) After overspeed test and when the unit idling speed drops to normal, the overspeed trip is reset and normal no-load operation restored. The steam flow bypass is at this time reduced along with an increase 
of the reactor power until the turbine-generator supplies sufficient electrical power for the auxiliary load. The reactor load is manually increased by manipulation of control rods, to minimum levels of the reactor control range, and then the reactor is placed on automatic.

j) Actual power operation consists of a program of tests at reduced and rated pressure and at intermediate power levels up to full power. Progress from one step to the next depends upon successful completion of tests at each level. Appropriate tests determine core flow characteristics, power distribution, integrated operational characteristics of reactor and turbine generator units, operation of safety and protective system for demonstration and proving design.

\section{Normal Reactor Operation}

a. Preparation and Startup

In a normal plant startup the reactor and both heat transfer loops are full of coolant and all reactor and turbine systems are available. Electric power for initial startup requirements is provided from temporary tie-ins to dock-side facilities, or from the emergency diesel generator if dock-side power is not available. All machinery and control circuitry, interlocks and control valves are checked prior to startup to insure that the plant is in proper condition for operation. The status of all equipment necessary for startup is indicated in the control room and a detailed check list is used.

The auxiliary boiler feedwater system is placed in service and the auxiliary boiler put in operation. Steam tracer heat is supplied to the process systems, and ample time allowed to preheat the piping and equipment. The turbine-generator set is then placed in service and operated at the necessary power level to meet the requirements of the plant auxiliary systems, following which the dock-side power can be cut off. (Note - In general, when the reactor is shut down in a normal manner, the auxiliary boiler can be placed in service in a scheduled manner to simplify the startup requirements.) The steam generator feedwater system and turbine lube oil systems are then placed in service. The main coolant pumps are then started and coolant is circulated through the heat transfer loops in the normal manner. 
The reactor control rods are raised and power is brought up through the counting and period ranges to a low thermal power level. Steam flow is hand controlled through the dump lines to the condenser as pressure rises. When full steam pressure is obtained, the ships auxiliary systems are placed on line and control is shifted from manual to automatic at $10 \%$ of nominal power.

b. Normal Operation

The control system automatically adjusts plant power in response to propulsion or auxiliary steam demand under normal operating conditions.

Propulsive power is normally furnished on automatic control only. The separate turbine control system accepts the power demand signals and valves the turbine steam through an interlock with the reactor control system. If steam conditions cannot meet the turbine requirements, the turbine steam valves will follow the available power and prevent low steam pressure and excessive moisture in the turbine. In this way, maximum power may be demanded even though the reactor plant is capable of producing only partial power because of a possible difficulty such as stuck rods or reduced coolant flow.

During automatic operation the main function of the plant operators is surveillance of all plant equipment and systems for proper operation and making necessary adjustments. These functions include stream sampling, observing and recording of information provided by plant instrumentation, evaluation of abnormal conditions and taking action as required to minimize the effects of equipment difficulties. Besides routine preventive and corrective maintenance, the coolant processing and radiation monitoring of the plant is carried out routinely by the members of the crew.

\section{c. Shutdown}

A normal shutdown is accomplished by gradually reducing the auxiliary load on automatic control down to $10 \%$ power and changing to manual control. The remaining auxiliary loads are tripped out until the steam is entirely bypassed to the condenser. After providing full organic flow to the steam generators, the rods are driven in and the organic pumps stopped. Decay heat is removed by natural convection with appropriate manual adjustments of steam bypass to the condenser while bringing the system to an equilibrium temperature. 


\section{STEADY STATE AND TRANSIENT OPERATION}

The steady state reactor plant operating characteristics with the specified control system are shown in Figure 31 and 32 for partial power conditions from 10 to $120 \%$ of nominal power. The reactor outlet coolant temperature is constant at $675^{\circ} \mathrm{F}$ while the inlet temperature decreases from $671^{\circ} \mathrm{F}$ at $10 \%$ of nominal power to $620^{\circ} \mathrm{F}$ at $120 \%$. The steam generator organic outlet temperature is a minimum of $527^{\circ} \mathrm{F}$ at $20 \%$ power and increases to $620^{\circ} \mathrm{F}$ at $120 \%$. The superheated steam temperature is over $670^{\circ} \mathrm{F}$ from 30 to $60 \%$ power but drops to $654^{\circ} \mathrm{F}$ at $20 \%$ and at $120 \%$.

The reactor coolant flow rate is a maximum at about $50 \%$ power because of the minimum pressure drop configuration of the organic loops at this point. At 10 to $120 \%$ of nominal power the reactor flow is minimized because of maximum pressure drop in the bypass and steam generator loops, respectively. Throttling of the organic in the steam generator loop is required below about $60 \%$ power to maintain flow control. The decreasing average reactor coolant temperature with increasing power provides a load following reactivity increase with the negative fuel and coolant temperature coefficients. As a result, the required regulating rod withdrawal rate for the maximum increasing load swing is small.

The transient plant performance is shown in Figure 33 for an increasing load change from 20 to $80 \%$ of nominal power at a rate of $6 \%$ per second.

A moderate maximum steam generator coolant flow rate change of $63 \mathrm{lb} / \mathrm{sec}^{2}$ is specified in each loop to accommodate this maximum load swing. With these conditions, the steam pressure drop is about 15 psi and pressure recovery is achieved in 15 to 20 seconds. The reactor responds at a later time because of the flow delay (about 7 seconds) between the mixing point of the bypass and steam generator coolant, and the reactor inlet. The reactor power increases directly with the decreasing inlet temperature, with slight anticipation, and very little disturbance of the reactor outlet temperature is experienced.

\section{AUXILIARY POWER}

The auxiliary power requirements are tabulated in Table XVI. Under normal operating conditions, this power will be supplied by one of two $2000 \mathrm{kw}$ auxiliary 


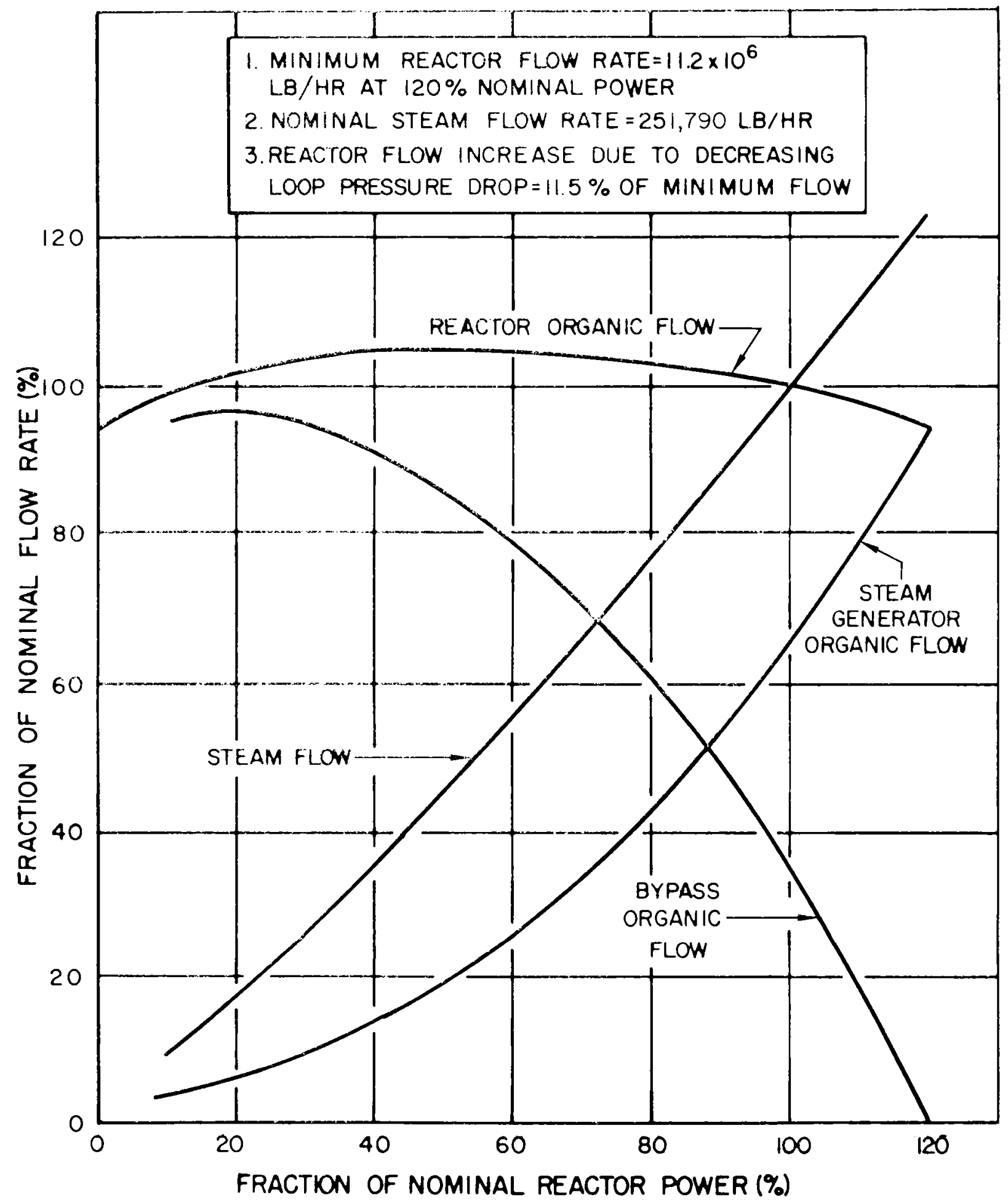

Figure 31. Steam and Organic Coolant Flow Program 


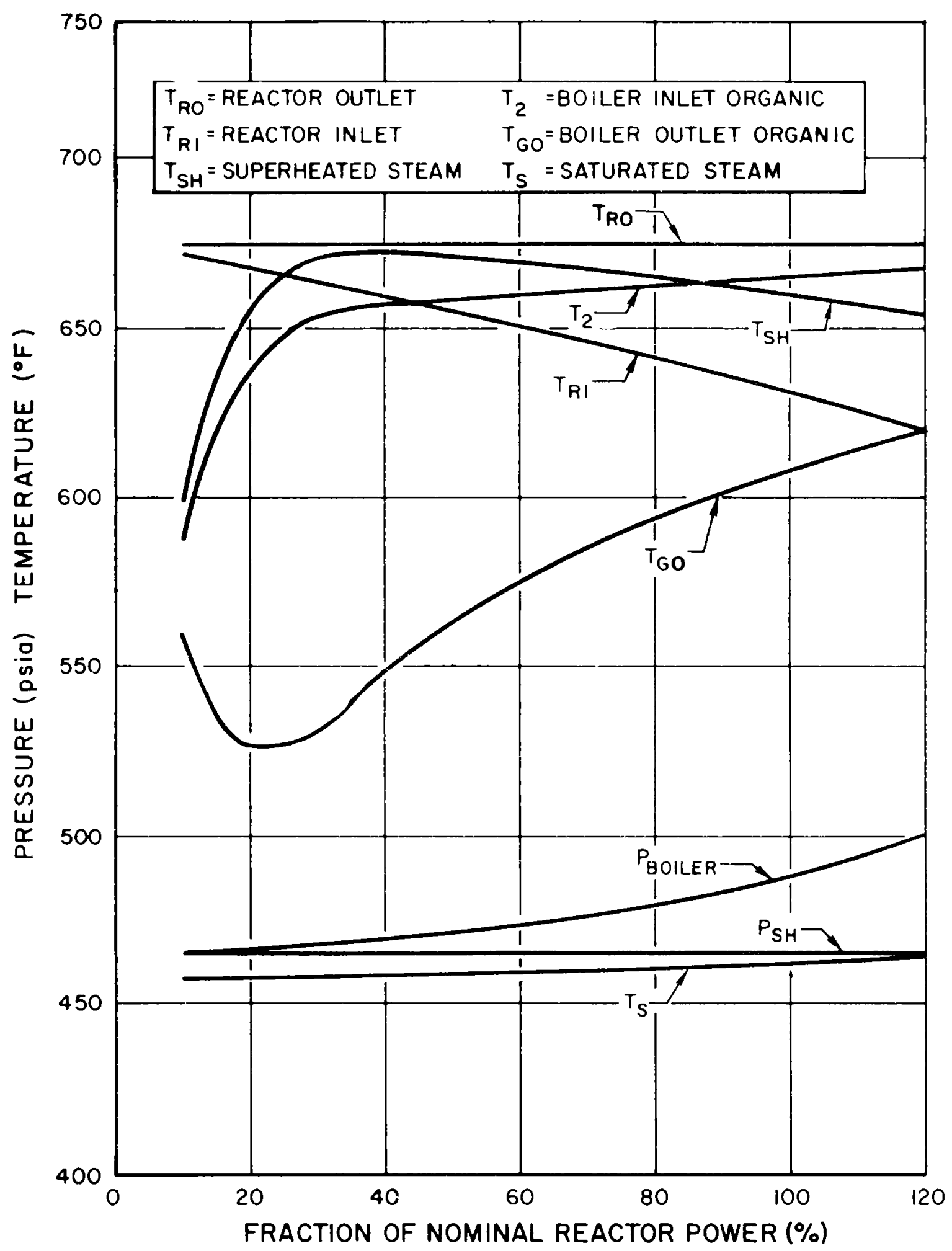

Figure 32. Steam and Organic Temperature Program

VII -32 

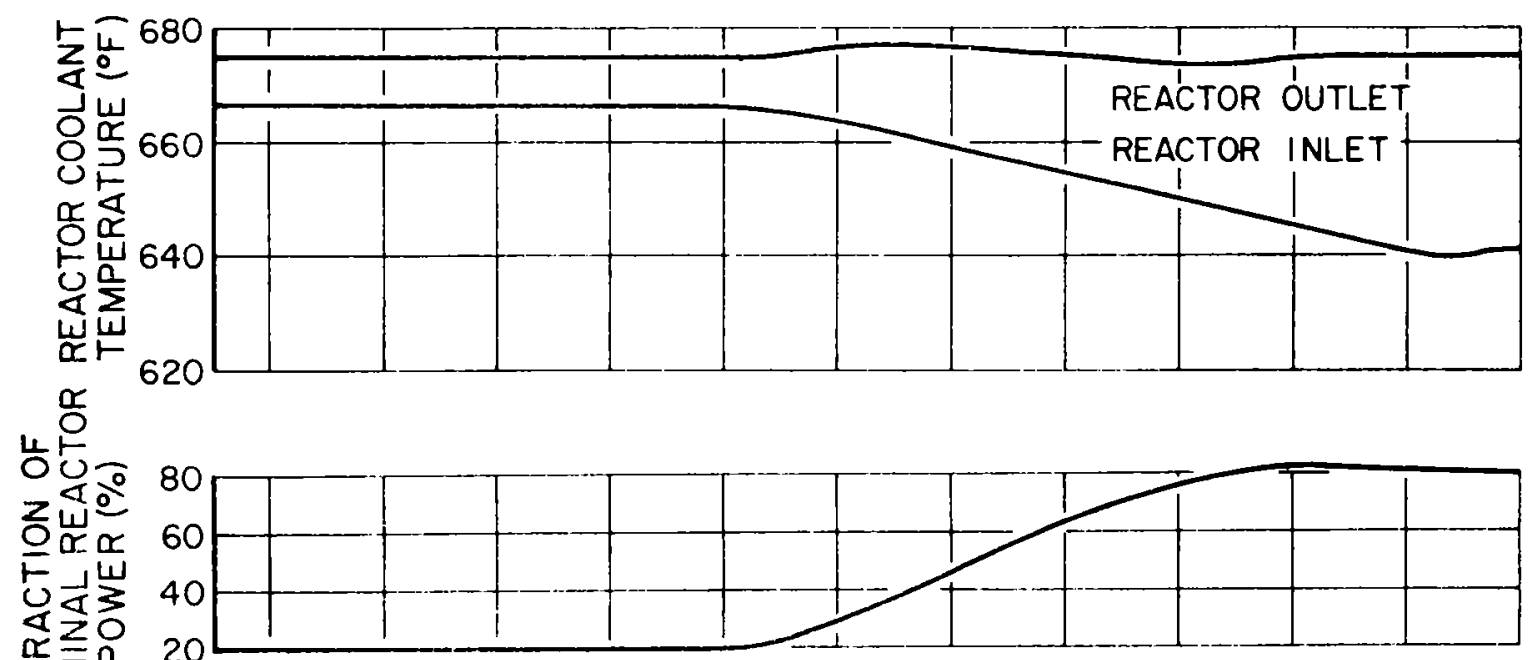

노
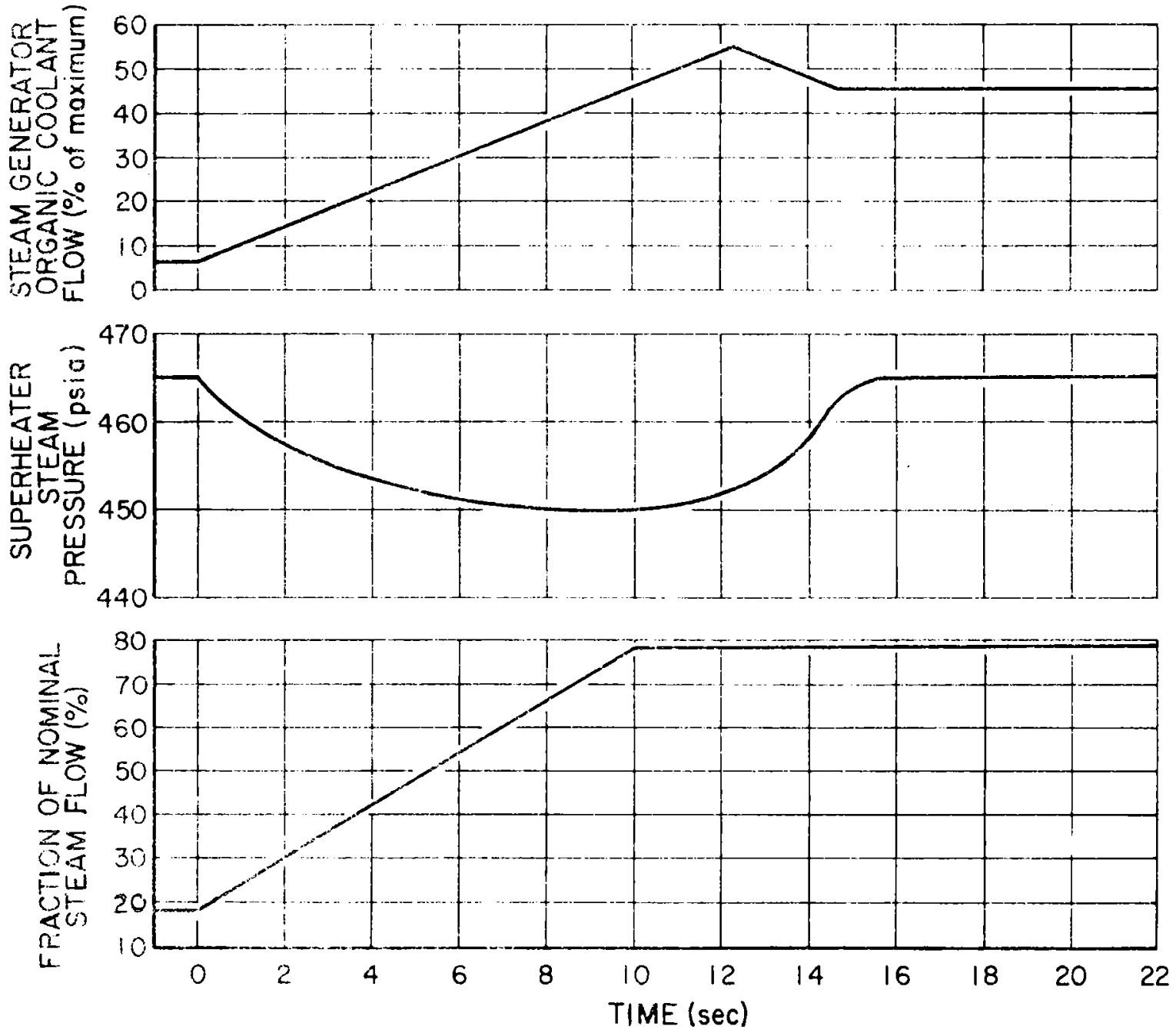

Figure 33. Plant Response to Load Increase 
turbine generators using steam from the nuclear steam generators. The auxiliary turbine generators have their own independent condensing, circulating and condensate pumping systems up to the inlet of the low pressure heater of the main feed system. Downstream of this junction, the main feed and auxiliary feed systems are common. One of the auxiliary turbine generator systems acts as a spare.

During an emergency situation when the reactor is not operating, or while in port, steam for the auxiliary turbine generator is supplied by the auxiliary oil fired steam generator. This steam generator is sized to supply steam for the auxiliary turbine generator to meet electrical requirements and the main propulsion turbines for emergency take-home power. The auxiliary steam generator is connected in parallel with the nuclear steam generating system. The feedwater junction is downstream of the high pressure heater and the steam junction is in the main steam line down stream of the non-return valves.

Another source of auxiliary power is the battery-diesel generator system. This system is an emergency backup power system for the reactor and miscellaneous emergency circuits. In the event that the reactor and both turbine generator units are incapacitated, the diesel generator is capable of supplying the minimum auxiliary systems and reactor protective system electrical requirements to bring the ship to port. The main propulsion steam would be supplied by the auxiliary steam generator.

The auxiliary power requirements as presented in summary form in Table XVI, are continuous loads after allowance for load factors is made. In determining the capacity of the auxiliary turbine-generators the following estimated load factors were applied:

$\begin{array}{ll}\text { Turbine Plant } & 90 \% \\ \text { Reactor Plant } & 80 \% \\ \text { Ships Services } & 60 \%\end{array}$

The sizing of the emergency diesel generator was based on the minimum electrical load requirements to maintain the safety of the ship.

The major electrical machinery components in the turbine plant includes the main and auxiliary circulating pumps, main and auxiliary condensate pumps, L.P. drain pump, port feed pump and lube oil service pump.

VII-34 
The major electrical equipment in the reactor plant includes the primary coolant pumps, $\mathrm{H} \& \mathrm{~V}$ blowers, air conditioning, centrifuge, pressurizing pump, air compressor, purification feed heater, reboiler heater, gas scrubber pump, shield cooling pumps, and reactor instrumentation.

The major electrical requirements for ships services includes ventilation, deck machinery, galley and pantry, lighting, tankcaire equipment, distilling equipment and instrumentation. Ships services include all of the electrical requirements for the ship except the turbine and reactor plants.

The minimum electrical load requirements which will be supplied by the emergency diesel generator includes the main circulating pony motors, L. P. heater drain pump, reactor decay heat removal pump, gas scrubber pump, shield cooling pump, canned blowers, H \& V blowers, nuclear instrumentation, ships instrumentation, ships lighting and radio and radar.

TABLE XVI

ELECTRICAL LOAD ANALYSIS

\begin{tabular}{|c|c|c|c|c|}
\hline \multicolumn{5}{|c|}{ LOAD SUMMARY, NORMAL } \\
\hline \multirow[t]{2}{*}{ LOAD } & \multicolumn{2}{|c|}{ NORMAL SEA LOAD } & \multicolumn{2}{|c|}{ NORMAL DOCKSIDE LOAI } \\
\hline & $\begin{array}{c}\text { Total } \\
\text { Connected } \\
\mathrm{kw}\end{array}$ & $\begin{array}{c}\text { Continuous } \\
\mathrm{kw}\end{array}$ & $\begin{array}{c}\text { Total } \\
\text { Connected } \\
\text { kw }\end{array}$ & $\begin{array}{c}\text { Continuous } \\
\mathrm{kw}\end{array}$ \\
\hline Turbine Plant & 359 & 323 & 67 & 60 \\
\hline Reactor Plant & 1,120 & 895 & 1,120 & 895 \\
\hline Ships Services & 637 & 382 & 333 & 200 \\
\hline Totals & 2,116 & 1,600 & 1,520 & 1,155 \\
\hline
\end{tabular}

LOAD SUMMARY, EMERGENCY

DIESEL GENERATOR

$500 \mathrm{kw}$

\begin{tabular}{c|c|c}
\hline & $\begin{array}{c}\text { EMERGENCY SEA LOAD } \\
\text { CONTINUOUS kw }\end{array}$ & $\begin{array}{c}\text { EMERGENCY DOCKSIDE LOAD } \\
\text { CONTINUOUS kw }\end{array}$ \\
\hline Turbine Plant & 155 & - \\
Reactor Plant & 175 & 175 \\
Ships Service & 18 & $\frac{16}{191}$ \\
\hline
\end{tabular}




\section{E. REFUELING}

The purpose of the fuel handling system is to provide a safe effective means for the removal and loading of fuel elements in the reactor core. The major components of the fuel handling system are a fuel handling cask assembly, a rotating type top shield assembly, and an indexing cover plate assembly which is interchangeable with the operating cover of the core tank.

The main body of the fuel handling cask is composed of lead and steel and is 42 inches in diameter by 10 -feet high. A hydraulic cylinder is centrally mounted above the cask, and the cylinder rod extends downward through the center of the cask. The grapple for the fuel element is mounted directly on the end of the cylinder rod and is designed to reach into the core tank to engage a fuel element. A rotating lead plug is eccentrically located at the bottom of the cask to provide an opening into the cask and to serve as shielding during the removal of the cask.

Directly above the rotating plug, a hand operated gate valve is provided to seal the organic coolant in the fuel element receiving chamber of the cask. Pool organic is drawn into the cask by vacuum prior to the removal of an element from the core. Thus, the spent fuel element is constantly immersed in organic coolant during fuel handling operations. The contained organic in the fuel handling cask is circulated through coils which are cooled by forced air convection.

An extended steel sleeve is provided at the bottom of the cask to insure sealing during the movement of the spent fuel element into the cask.

The fuel handling cask is transported by the shore side or barge crane. Pneumatic, hydraulic and electrical service lines are attached to the crane and utilize Appleton-type hose reels.

The top shield assembly consists of a 9-1/2 feet diameter plug of iron. Within this large plug is an eccentrically located secondary plug. A third plug is located within the secondary plug, and it is removed from the shield assembly during refueling operations to provide direct access into the core tank. Proper indexing of the large plug and the secondary plug permits accurate positioning of the access port over any fuel element location.

VII-36 
The indexing cover plate assembly is designed to replace the operating cover of the core tank and to support the rotating top shield assembly. The outer cover plate is 10-1/2 feet in diameter and is supported at its outer periphery on a 2 -inch ball bearing assembly mounted directly on the core tank flange. The plate is indexed to the upper race by means of indexing pins. An inner cover plate is supported on ball bearings mounted on the outer cover plate and is free to rotate independently. The inner cover plate is furnished with a power operated sliding cover which closes off the access port during absence of the cask. The weight of the top shield as sembly is transmitted to the two cover plates by means of the shield lifting studs. When the shield is lifted from its seating ledge, it is free to rotate with the cover plates. Indexing is done by manual operation of the indexing handwheels.

After the reactor has been shut down and the organic coolant temperature has decreased to approximately $350^{\circ} \mathrm{F}$, the system is depressurized, the core tank ventilation system is put into operation, and the organic liquid level in the core tank is maintained at approximately 6 -inches below the top shield. Flange bolts are then removed and all process lines on the cover plate are disconnected and removed to permit removal and stowing of the cover. The indexing cover plate assembly is brought in by the shore side or barge crane and lowered into position on the ball bearing races. Proper adjustments are made to lift the top shield from its rest position into its free rotating position. The small plug over the access hole of the top shield is removed, the sliding cover on the inner plate is closed over the access hole, and the small plug is then stowed in a recess provided for it in the shielded deck. The fuel handling cask is lowered in through the deck hatches by the barge or shore side crane to a position over the reactor cover assembly. As the bottom of the cask reaches the access port, the sliding cover is opened, and the bottom sleeve of the cask is received into the access port. With the bottom plug of the cask rotated to the open position and the valve open, the hydraulic cylinder on top of the cask is actuated, and the grapple extends into the core tank to engage the fuel element. After the grapple has secured a lock on the fuel element, a column of organic is drawn into the fuel element chamber of the cask by vacuum. After the element is brought up into position in the cask, the gate valve is closed and the bottom plug is rotated shut. 
The coolant pump and air fan provide adequate cooling. The fuel handling cask is then raised from the core tank, the access port closed, and the fuel is transported to the barge or shore side receiving facility.

After the spent fuel elements have been removed from the core, new fuel is brought into the core from the barge. The reverse process of unloading fuel elements is followed except that provisions for cooling the new fuel element are not required. Since the fuel element orificing will vary for different locations in the core, each element will be coded and placed in a specific location in the core. Loading charts will be provided showing fuel element locations and the loading sequence.

After the core has been reloaded, the cask is re moved to the barge or shore side storage facility and the access port plug is replaced in the top shield. The shield plugs are returned to their rest positions on the core tank, and the indexing cover plate assembly is removed by the barge or shore side crane storage facilities. The operating cover plate over the core tank is replaced and bolted down, and process lines are connected. The core tank ventilation system is shut off and the organic coolant level is returned to normal. After the seals, connections, and valves have been checked for leaks, the reactor is ready for normal startup procedure.

\section{F. OPERATING PERSONNEL}

The complement of an OMR-propelled marine tanker is similar to that for a conventional tanker with an increase of only seven men over the total number in the regular crew. Table XVII is a manning table of the estimated crew with a total of 53 personnel.

\section{TABLE XVII}

\section{SHIPS COMPLEMENT}

\section{Summary:}

Deck Department

Engine Department

Stewards Department 
Deck Department:

Master

First Officer

Second Officer

Third Officer

Jr. Third Officer

Radio Officer

Health Physicist

Boatswain

A. B. Seamen

Ordinary Seamen

Deck Maintenance Men

\section{Engine Department:}

Chief Engineer

First Assistant Engineer

Second Assistant Engineer

Third Assistant Engineer

Jr. Third Assistant Engineer

Jr. Engineers

Reactor Operators

Electronics Technician

Chemistry Technician

Electrician

Chief Pumpman

Pumpman-Machinist

Oilers

1

Wipers

Total 
TABLE XVII (continued)

\section{Stewards Department:}

Steward 1

Chief Cook 1

Second Cook 1

Assistant Cook 1

Utility Man 1

Messmen

Total

As only a few of the crew have duties that differ from those of a crew on a conventional tanker, this section is limited to the engine department with the exception of the health physicist.

It is estimated that 25 men will be necessary to operate and maintain the OMCR shipboard propulsion system. Table XVIII is an organization chart for the Engine Department. Three operating crews, each comprised of five men, will be required to operate the reactor and engine compartment. Standard maritime practice of four hours on watch and eight hours off will be followed. The maintenance and handling crew of nine men would normally work a day shift only with the exception of fuel oil transfer, emergencies, and reactor refueling operations.

No relief crew as such is provided and hence all members of the maintenance crew should be familiar with the reactor and ultimately trained in its operation. As it is anticipated that any radioactive repair and maintenance work will either be of a minor nature or accomplished in dry dock, a watch health physicist has not been provided. The ship's health physicist assigned to the deck department will always be on call and together with the chemistry technician, will be able to handle routine and emergency monitoring.

The eight technically trained members of the engine department should have the regular training and experience required by the Maritime Administration 
for crew members on a typical tanker of this size. In addition, the engineers would receive a series of lectures, observation periods, and on-the-job training programs in order to adequately supervise and operate the reactor system.

\section{TABLE XVIII}

ORGANIZATION CHART FOR AN OMCR SHIPBOARD PROPULSION SYSTEM ENGINE DEPARTMENT

Engine Department (25)

Chief Engineer

Operating Crew A (5)

2nd Asst. Engineer

Jr. Engineer

Reactor Operators

Oiler

Operating Crew B (5)

3rd Asst. Engineer

Jr. Engineer

Reactor Operators

Oiler
1

1

2

1

1

1

2

1

Operating Crew C (5)

Jr. Asst. Engineer 1

Jr. Engineer 1

Reactor Operators 2

Oiler

Maintenance and Handling Crew

lst Asst. Engineer 1

Electronics Tech. 1

Electrician $\quad 1$

Chemistry Tech. 1

Chief Pumpman 1

Pumpman Machinist 1

Wipers

3

The reactor operators probably will not be maritime personnel, but will be recruited from existing land-based reactor installations. Their normal duties will be to operate the reactor controls from the controls from the main console panel in the reactor control room and operate the reactor auxiliary equipment, such as the moderator-coolant purification unit. They should have a minimum of a high school education and several years experience in the operation of nuclear reactors and related equipment. 
The electronics technician will have the duties of routine preventive and corrective maintenance, trouble shooting, and calibration of equipment such as the nuclear reactor power control system, nuclear instrumentation, process instrumentation, potentiometer and null balance type recorders and indicators, and radiation measuring instruments. His qualifications include a thorough knowledge of electronics from such sources as electronic institutes, military, maritime, or navy schools, college or university, or on-the-job training. In addition to this training, the job would require about three years experience at nuclear installations, process plant, refineries, naval-military, or electronics. The ability to evaluate schematic network diagrams is important.

The chemistry technician will be required to perform water and certain hydrocarbon analyses, various chemical analyses, and to assist the health physicist in routine radiation monitoring techniques. His qualifications would probably be a bachelor's degree in chemical engineering with little or no experience.

The chief pumpman, pumpman-machinist, oilers, and wipers will have the same basic qualifications as required in normal maritime practice, and their duties would be very similar to those on a conventional tanker.

The health physicist, nominally a member of the deck department, will have the duties of making radiation measurements prior to and during work by operations or maintenance personnel, routine radiation surveys, radiological safety surveys, personnel monitoring program, radiation instrument standardization and calibration, routine and emergency radiation procedures, and special radiation measurements during reactor critical assembly and trial runs. His qualifications will be a bachelor's or master's degree in engineering or physical sciences with mathematics through differential equations and some nuclear physics. At least two years experience is required as a health physicist at an installation that uses a large amount of radioactive material. If special postgraduate health physics training has been received the experience requirements may be reduced to one year.

VII -42 


\section{SAFETY AND CONTAINMENT}

\section{A. INTRODUCTION AND SUMMARY}

This section presents a summary of the potential hazards in the Maritime OMCR plant and describes the controlling safeguards provided. Also included is a discus sion of the radiation protection provided various plant accident situations, and a discussion of the criteria and provisions for containment of the plant.

Radiation protection is specified on the basis of dose rates of $1.5 \mathrm{mrem} / \mathrm{hr}$ for uncontrolled and routinely occupied areas with a maximum annual dose of 5 rem. Shielding provided on the plant is designed to meet these requirements. The radiation monitoring equipment for the plant is discussed in terms of its functional requirements.

Plant accident analyses are based upon a set of hypothetical failure conditions which are considered to have some degree of credibility. Considered are: 1) uncontrolled continuous rod withdrawal during startup of the reactor, 2) introduction of cold coolant into the core, 3) loss of coolant flow, 4) loss of coolant pressure, 5) leakage of boiler water into the coolant, 6) fires and coolant leaks in the reactor compartment, 7) collisions, 8) grounding and, 9) sinking. Compounding of unrelated accident situations is considered incredible.

For all accident situations considered, proper action of the plant protective system will result in immediate shutdown of the reactor with no severe pressure or temperature transients within the reactor compartment and no uncontrolled release of radioactivity to the seawater or atmosphere.

Containment is provided by the reactor compartment, and is based on complete and absolute control of the release of radioactivity under all normal and emergency conditions. When the ship is at sea, gaseous activity may be released through the stack at concentrations equal to or less than the maximum permissable concentrations established by the AEC. There is no release of activity to the seawater at anytime and no release of gaseous activity in restricted waters or at the dock.

\section{B. RADIATION MONITORING}

The safe operation of a nuclear power plant requires that information be available at all time regarding the levels of radioactivity throughout the plant 
and the surrounding areas. The function of the Radiation Monitoring System is to provide an unattended automatic data collection and recording system to accomplish this purpose. A secondary function of the system is to provide signals to operate dampers in the ventilation system when radioactivity levels in certain areas exceed safe limits. The Radiation Monitoring System proposed for this design is shown in Figure 30 and described in detail in section VII.

\section{SHIELDING}

The shielding of the plant has been designed to limit the maximum annual dose received by the crew to $5 \mathrm{rem}$. A portion of this $5 \mathrm{rem}$ per year is reserved in order to provide unforeseen or infrequent maintenance in limited access areas. With a forty hour work week and a maximum dose rate of 1.5 millirem per hour the crew has an available reserve dose of $1.88 \mathrm{rem}$. For these reasons the shielding design dose rate in unlimited access areas is 1.5 millirem per hour. The detailed shielding design for the Maritime OMCR is presented in Section VI.

\section{CONT AINMENT}

Containment of radioactive fission products is provided by three successive enclosures. These three enclosures include the fuel cladding, the primary system and the reactor compartment. The primary purpose of the containment is to provide complete and absolute control of the release of radioactive substances under all normal and emergency conditions.

The design criteria for the containment of the Maritime OMCR are:

1) At sea there shall be no release of radioactivity to the seawater.

2) At sea the release of gaseous activity during normal operation shall be equal to or less than the maximum permissible concentrations established by the $A E C$ for continuous exposure of personnel aboard the ship.

3) At dockside or in restricted waters there shall be no release of radioactivity.

The containment is described in the order in which it is necessary for failures to occur in order to release radioactive fission products.

VIII - 2 
1) The cladding is the first barrier which the fission products must violate in order to be released. The cladding is APM (Aluminum Powder Metal) with welded end closures. During the life of a core a few pinhole failures of the cladding can be tolerated, resulting in the release to the primary system of some of the gaseous fission products within the fuel rod. These fission products will be removed from the primary system by the degasifier and the vacuum still. The activity contained in the primary system will always be less than $10 \mu \mathrm{c} / \mathrm{cc}$ due to this continuous reprocessing.

2) The second barrier to the fission products is the primary system. The operating pressure of the primary system is 34 psia. The entire system will be designed for 300 psia and tested to a pressure of 450 psia. Derangemert of equipment in the primary system due to excessive shock loadings is minimized by providing adequate holding down arrangements and the use of convertional rolling and collision checks.

3) The third containment is the reactor compartment. This compartment is designed to be collision resistant and will withstand an internal pressure of at least $15 \mathrm{psig.} \mathrm{An} \mathrm{excessive} \mathrm{external} \mathrm{hydrostatic}$ pressure will open spring loaded one-way valves in this containment and allow sea water to flood the compartment. This flooding of the compartment will provide a means of removing the reactor decay heat if the ship is sunk regardless of the final position. It is assumed that the integrity of this compartment is maintained under all accident conditions.

\section{E. NUCLEAR INCIDENTS}

Nuclear incidents are those accidents which are considered to have an effect on the reactivity of the core. The incidents classified as nuclear incidents are:

1) Control rod withdrawal accidents

2) Cold inlet coolant accidents

3) Loss of flow accidents

4) Loss of reactor vessel pressure. 
These accidents have not been analyzed in detail for the core described in this report but due to the similarity of this core and other cores which have been analyzed in detail* the results of such a study can be anticipated.

In all cases wherein the reactor protective system is operable, there will be no mechanical damage to the core or the primary loop. The outlet coolant temperature of the hottest channel at full power is less than the boiling point of Santowax $R$ at atmospheric pressure. A complete loss of system pressure would therefore only result in a larger area of subcooled nucleate boiling. A loss of reactor vessel pressure will not cause fuel melting even without protective system action. The other accidents, listed above in which the protective system is inoperable, result in bulk boiling at the outlet of the hottest channels. This bulk boiling may cause channel blocking and subsequent fuel meltdown. Void formation and a change in geometry due to fuel melting are the ultimate shutdown mechanisms. The primary system is not violated during any accidents in which bulk boiling occurs at the outlet of the hottest channels and the fission products are not released to the reactor compartment.

\section{Control Rod Withdrawal Accidents}

One of the more severe potential hazards associated with the operation of a nuclear reactor is the so-called startup accident. This accident occurs when the control rods are withdrawn continuously from a shutdown condition. It results in a very rapid increase in power level as the reactor approaches full power and an increase in power level beyond the protective system setpoint due to the time-lag in the response of the protective system. The extent of the power overshoot is a function of several core parameters such as neutron source level, effective fraction of delayed neutrons, neutron lifetime, reactivity insertion rate, full power rating of the reactor core, protective system setpoints, etc.

As discussed in Section VII the temperature coefficients associated with the core are all negative. These coefficients act to limit the reactor power during a transient of this nature.

In addition the reactivity insertion rate is limited to a value which will not cause damage to the core should a startup accident occur. The startup

*BCPI - Vol II

\section{VIII - 4}


accident study merely placed an upper limit on the insertion rate which may be used. If the rate required to change power level for a specified load change is less than the maximum permissible insertion rate as determined from a startup accident study then the lower value would be used. The maximum reactivity insertion rate, required for the desired load following characteristics, has been determined as $0.035 \%$ sec.

Finally, many precautions have been taken to ersure that the reactor protective system will protect the reactor against this type of accidert. For the accident to occur, the operator must continue to withdraw the rods, or the control circuit must malfunction so that the rods continue to receive the electrical power necessary to withdraw anc the following alarms, setbacks and scrams in the protective system must fail to function:

1) Low level Period Computer Channels 1 ard 2
a) Alarm

2) Period Computer Channels 3 and 4
a) Alarm
b) Power Setback
c) Scram

3) High Neutron Power (Coincidence Circuitry)
a) Alarm
b) Power Setback

With protective system action, the startup excursions produce no radiation hazard nor in any way cause mechanical damage to the core. Without protective system action, melting of some fuel cladding and fuel may occur during the accident, but the integrity of the main coolant system will be maintained, and the entire accident will be contained within the coolant system.

Another possible reactivity insertion accident is control rod withdrawal from the core during operation in the power range. Should this accident occur with no protective system action, some melting of the core will occur. This accident, however, is less severe than transients occurring during startup accidents. The reactivity insertion rate used for power level control is the 
same as that used for startup purposes. In the case of rod withdrawal from full power, the temperatures in the core rise immediately and the temperature coefficients tend to return the reactor to a critical condition; whereas, in a startup accident, a large amount of reactivity can be inserted into the core before the power reaches a level which will introduce substantial temperature coefficient effects. For these reasons, the maximum power attained during a startup accident will be higher and the results more severe than the case of a rod withdrawal accident from an operating power level.

\section{Cold Inlet Coolant Accident}

In any reactor having a negative coolant temperature coefficient of reactivity, the introduction of cold coolant into the core or an increase in flow rate through the core will cause a reactivity excursion and produce temperature transients in the system. The loop which is suddenly turned on is interlocked such that the blocking valves cannot be opened unless the pumps are in operation. This interlocking together with mixing in the lower plenum limits the rate at which cold coolant may be introduced to the core. This loop is also interlocked to prevent opening of the blocking valve if the loop temperature is more than $100^{\circ} \mathrm{F}$ less than the lower plenum temperature.

Without the protective system and without the loop interlocks some damage to the core may result with the shutdown mechanism being void formation and fuel melting. The entire accident will be contained in the primary system. With either protective system action or with interlock action there is no damage to the core or the primary system.

\section{Loss of Flow Accident}

Complete loss of flow in the reactor system represents no hazard with protective system action provided there is sufficient inertia in the flow system to prevent the flow from decaying too rapidly. Due to the relatively low thermal conductivity of $\mathrm{UO}_{2}$, a considerable quantity of heat is stored in the fuel. During a loss-of-flow transient, this heat is released to the coolant over a relatively long ( $\sim 10$ seconds) period of time. If the flow decay following pump failure is rapid, the heat is not completely released until a relatively low flow rate is attained.

VIII - 6 
Temperatures in the core following such an accident may become excessively high and cause melting or damage to the core structure. To minimize the effect of this accident fly wheels have been added to the pumps specified for the plant. Without protective system action bulk boiling in the hot channels and subsequent fuel melting will occur. The entire accident will be contained in the primary system.

A loss of flow in one of the two loops will cause a reactor setback and the plant continues to operate on one loop without a scram. Quick closing blocking valves are installed in main loops to prevent flow reversal in the affected loop during a one loop loss of flow.

4. Loss of Reactor Vessel Pressure

Loss of reactor vessel pressure represents little or no hazard to the Maritime OMCR. The maximum hot channel outlet coolant temperature is less than the boiling point at atmospheric pressure and therefore a complete loss of pressure will simply increase the subcooled nucleate boiling area in the core. No fuel melting or fission product release occurs during this accident.

F. INCIDENTS RESULTING FROM FAILURES IN THE PRIMARY SYSTEM AND AUXILIARY SYSTEMS

1. Introduction and Summary

Since the primary coolant is designed to contain as much as $10 \mu \mathrm{c} / \mathrm{cc}$ of fission product activity, incidents resulting from failures in the primary system can release the fission products in the coolant to the reactor compartment. However, these fission products will be contained in the reactor compartment since the compartment has been designed to withstand an internal pressure of 15 psi as discussed in Section $D$, above. The pressure rise in the containment has been minimized by maintaining large heat sinks in the compartment consisting of pressurized tanks of relatively cold water which are equipped with fog nozzles. The release of this water is controlled by pressure and temperature within the reactor compartment. These tanks also serve as biological shields before use and therefore represent little or no loss of cargo carrying capacity.

The transfer of fuel elements from the ship to the refueling barge is accomplished by a fuel handling cask. A loss of cooling to this cask could 
cause excessive temperatures and pressures in the cask. The cask has been so designed to serve as a pressure vessel and remove decay heat by radiation and natural convection at the surface of the cask should this accident occur. The elements in the cask may melt but no fission products will be released. A discussion of the accidents considered in this section follows.

\section{Water Leak into the Main Coolant System from the Steam Generators}

Since the operating pressure of the Maritime OMCR is less than the pressure of the steam being generated, a leak in a steam generator could introduce water into the coolant system. High system pressures would result from this water being flashed to steam by the higher-temperature coolant. The pressure relief system has been designed to prevent damage to the reactor or the coolant system in the event an accident of this nature should occur.

The steam pressure in the boilers during plant operation is $\sim 500$ psia. The coolant pressure in the boilers is about 50 psia. Thus, a pressure differential exists which would allow water to enter the main coolant system in the event of a leak or failure of a boiler tube. Since the coolant temperature in the boiler is about $670^{\circ} \mathrm{F}$, water entering from a leak will be vaporized to steam with a consequent buildup of pressure in the main coolant system.

The following design features have been incorporated into the plant to minimize the effects of this accident:

a) The design pressure of the main coolant system is 300 psia.

b) Four pressure-relief valves have been included in the main coolant system, two in each loop.

c) A reactor scram circuit is provided for emergency shutdown due to high-pressure in the reactor coolant system.

d) Steam dump valves are provided on the steam generators to rapidly lower the steam pressure in the event of a leak and thus reduce the flow of water into the coolant system. These valves are of the quick-operating type and are actuated automatically by a high-pressure signal from the coolant system.

e) A main coolant loop will be isolated from the rest of the plant in the event of a water leak by closing the blocking valves in the loop. 
Provision of four relief valves is adequate to handle pressure buildup due to a water leak. The pressure relief system is discussed in Section IV.

\section{Large Coolant Leak Accident}

The severity of a large coolant leak is strongly dependent on the location of the break in the primary system. If the break occurs on the suction side of the main coolant pump, the pressure and static head within the reactor will force the coolant out of the broken line. If the rupture occurs on the discharge of the pump the coolant will be discharged at a rate which is a function of the pressure and static head within the reactor and the pump pressure drop. A major break in any of the primary loops will be sensed by instrumentation and the blocking valves on the affected loop will be closed. The valves are located as close to the core tank as practicable. The reactor is, of course, scrammed with a major rupture of a primary loop. The core itself is not damaged by a major rupture in the piping, since the reactor is scrammed and the main loop blocking valves are closed. Flow can be maintained in the decay heat removal system and the transients in the core are similar to those of an accidental scram from power with $100 \%$ of full flow.

The activity released from a coolant spill will be contained in the reactor compartment. The pressure buildup due the expansion of the air in the compartment is minimized by storing large energy sinks in the reactor compartment. These energy sinks consist of large pressurized tanks of relatively cool water located above the piping and process equipment. This water is released through fog nozzles which are mechanically actuated and are temperature and pressure sensitive. The amount of water stored in these tanks is sufficient to absorb the required amount of energy to prevent excessive pressures in the reactor compartment if all of the organic coolant, saturated water and steam were released to the compartment simultaneously.

The decay heat will be removed through the decay heat removal system if the coolant level in the reactor is still above the decay heat removal system coolant outlet nozzle. If it were impossible to remove the decay heat by the decay heat removal system the coolant in the core would be boiled off and the core would be exposed. In this case the core would most probably melt down and settle in the bottom of the reactor pressure vessel. The bottom and sides of the pressure vessel will be cooled 
by the water and organic coolant surrounding the vessel. Any vapors produced by the decay heat will not cause further pressure buildup but will be condensed on the surfaces in the reactor compartment. Gaseous fission products will be released to the reactor compartment but will not be released to the sea or the atmosphere.

\section{Rupture of the Steam Generators}

A rupture of the steam system within the reactor compartment could result in the release of significant quantities of steam. If the leak is small, no problem exists since the ventilation system can quite adequately exhaust the steam to the atmosphere.

Any leak of appreciable size in either boiler will cause immediate isolation of the coolant loop and loss of feedwater to the steam system involved. If the leak is large the pressures inside the compartment will not increase beyond the design pressure of the compartment due to the condensation of this steam by water released through the fog nozzles. Containment by the reactor compartment will not be violated even with a simultaneous rupture of both steam generators.

5. Chemical Compatibility in the Core

Experimental information on chemical reactions between $\mathrm{UO}_{2}$ fuel and aluminum indicates formation of an intermetallic compound between aluminum and uranium when intimately mixed in a dispersion type matrix, at temperatures above $900^{\circ} \mathrm{F}$. Initial tests conducted at Atomics International in which $\mathrm{UO}_{2}$ pellets were sealed in a APM tube and held at $900^{\circ} \mathrm{F}$ for approximately 30 days indicate no reaction. While further tests will be conducted it is presently believed that no chemical instability exists. The maximum surface temperature of the cladding in the reactor is designed for $825^{\circ} \mathrm{F}$. This temperature should never be exceeded due to the characteristics of sub-cooled nucleate boiling.

Corrosion tests of APM material in organic coolants at reactor operating conditions have indicated excellent corrosion resistance. APM corrosion tests have been run in circulating diphenyl at $800^{\circ} \mathrm{F}$ and coolant velocities ranging from 0 to $30 \mathrm{feet} / \mathrm{second}$ for periods up to 3 months. Weight changes observed during these tests have varied from $0.96 \mathrm{mg} / \mathrm{cm}^{2}-\mathrm{mo}$ weight gain at zero 
velocity to $0.3 \mathrm{mg} / \mathrm{cm}^{2}$-mo weight los $\mathrm{s}$ at the higher velocities. In addition APM material has been exposed under static conditions to monoisopropyl diphenyl containing $0.3 \mathrm{wt} \%$ water, for 1,000 hours at a temperature of $750^{\circ} \mathrm{F}$. Weight gains of the order of $0.5 \mathrm{mg} / \mathrm{cm}^{2}$-mo have been observed on the se tests.

Since the corrosion rates observed for APM in organic coolants have been essentially negligible, the combination of APM cladding with coolant may be considered non-reactive.

No problems of incompatibility between $\mathrm{UO}_{2}$ fuel and organic coolant have been uncovered and none appear to exist. Corrosion tests of $\mathrm{UO}_{2}$ in Santowax $R$ at $750^{\circ} \mathrm{F}$ indicate no significant weight changes in the fuel.

6. Loss of Cooling to the Fuel Handling Cask

The fuel handling cask is designed to transfer elements from the ship to the refueling barge. During this transfer operation, the element is cooled by circulating organic fluid in the cask. The organic fluid is in turn cooled by air circulated through the cask. A loss of this cooling air could cause relatively high pressures and temperatures within the cask, but no melting of the element should occur. The fuel handling cask is designed to serve as a pressure vessel and contain this element and its associated fission products even if the element melts. The surface area on the fuel handling cask is sufficient to remove the decay heat of the element without violating the containment of the fuel handling cask.

\section{G. COLLISIONS, GROUNDING, AND SINKING}

1. Introduction and Summary

In this section consideration is given to those accidents which are peculiar to shipboard applications of an OMCR. The area of the ship which contains the reactor compartment has been designed to be collision resistant. A collision in this area with another ship should not violate the containment provided by the reactor compartment. The cases considered are collisions, grounding, and sinking. In no case considered is radioactivity released to the atmosphere or the seawater in an uncontrolled manner. 


\section{Collisions}

The hazards associated with a collision are very dependent on the severity of the collision with results ranging from little or no release of radioactivity to complete release of all of gaseous fission product activity to the reactor compartment. To minimize the effects of a collision, all components in the reactor compartment are provided with adequate holding-down arrangements and conventional rolling and collision checks. The reactor is, of course, scrammed during any collision in which the "G" loading in the reactor compartment exceeds the design limitations.

A collision in which there is no derangement of equipment, and emergency power is available, results in no release of radioactivity to the reactor compartment. Decay heat removal is accomplished regardless of ship position by the decay heat removal system.

A collision in which there is no derangement of equipment and emergency power is not available results in no release of radioactivity to the reactor compartment provided the ship has a permanent list of less than $90^{\circ}$. If the ship lists more than $90^{\circ}$ the decay heat removal systems cannot operate on natural convection and the pressure inside the primary system will increase and release organic through the primary loop relief system. The organic liquid and vapors released will condense and be cooled in the reactor compartment resulting in essentially no pressure rise in the reactor compartment. The pressurized water tanks in the reactor compartment ensure the maintenance of a low pressure in the reactor compartment.

A collision in which there is derangement of equipment and no emergency power could possibly result in the release of all gaseous fission products to the reactor compartment simultaneously with all of the energy stored in the primary coolant and the steam system. This could possible result in pressures exceeding the design pressure of the reactor compartment and the release of this activity to the atmosphere if there were no energy sinks provided to absorb the energy release. The pressurizing tanks of relatively cool water which release a fog spray to the reactor compartment have been sized for just such an accident. This release of the fog spray is controlled by temperature and pressure sensitive valves which do not require emergency power and will therefore operate under

VIII -12 
any conceivable conditions. This large energy sink precludes the possibility of a large pressure surge in the reactor compartment and therefore the fission products released to the reactor compartment are contained. Decay heat removal is accomplished by radiation, condensation and natural convection to the compartment surfaces.

3. Grounding

All of the situations discussed under collisions are applicable to groundings and therefore the discussion will not be repeated.

\section{Sinking}

Sinking of the ship can occur either in shallow waters or in deep waters and it is necessary to remove the decay heat of the reactor regardless of its final resting position. In either case the integrity of the reactor compartment is maintained. The reactor compartment will remain intact if the ship sinks in shallow waters. If the ship sinks in such a position that the decay heat removal system will not remove the decay heat by natural convection then the primary loop will build up pressure and release Santowax $\mathrm{R}$ liquid and vapor through the pressure relief system. The organic liquid spilled will be cooled and there will be no pressure buildup. If there was a pressure buildup the stored tanks of water would again serve as energy sinks. The exposed surfaces of the reactor compartment are sufficient to remove the decay heat by radiation, condensation and natural convection. The time interval before the reactor compartment walls will be corroded through in salt water is long enough to allow planned removal of the sunken hall by salvage operators before any contamination takes place in the restricted surrounding waters.

A flooding arrangement is provided to equalize pressure and prevent the collapse of the reactor compartment if the ship should sink in deep waters. This flooding arrangement provides flow of water one way only. Decay heat removal is accomplished by natural convection to the exposed surfaces. The reactor is sub-critical even if the organic is displaced by seawater. There is no uncontrolled release of radioactivity to the seawater regardless of the position in which the ship sinks or finally settles. 


\section{H. RADIOLOGICAL HAZARDS}

A design objective for the Maritime OMCR is continued operation with failed fuel pins in the reactor core. This means that it will not be necessary to shut down the plant in the event a small portion of the fuel pins within the core develops weld failures or pinhole leaks which release fission products into the coolant. Operation will continue up to a maximum level of activity at which point the plant will be shut down for removal of the fuel elements containing the failed pins.

During operation, the core will be monitored for failed fuel pins by the fuel element failure detection system and the coolant will be periodically sampled for determination of fission product concentration. This information together with a realistically established maximum value for specific coolant activity will permit removal of failed elements during regularly scheduled shutdowns in port.

Since the core is designed to operate without fuel centerline melting under normal operating conditions, fission product release has been determined for the case of continued operation with cladding failures, pinholes, or "leaky" fuel pins. Under these circumstances a conservative approach is to consider release of $0.5 \%$ of the volatile (i.e., $\mathrm{Xe}, \mathrm{Dr}$, and I) fission product isotopes to the coolant. Evaluation of fabrication procedures, operating experience, and experimental tests of fuel pins reveals that 0.05 to $0.1 \%$ can be taken as an upper limit estimate of the expected failure of the fuel pins during operation. In order to develop a consistent plant design, a maximum equilibrium specific coolant activity has been established on the basis of $0.1 \%$ failure of fuel pins in the core. This activity is $10 \mu \mathrm{c} / \mathrm{cc}$ of coolant if $0.5 \%$ of the gaseous activity produced is released. The gamma radiation associated with this coolant activity is $1.7 \mathrm{R} / \mathrm{hr}$ during plant operation at the one-foot distance from 18 -inch-diameter piping.

When the ship is at sea the waste gases will be passed through an AMSCO scrubber to remove radioactive gases and discharged to the atmosphere through the stack. The radioactive gases released through this system are in "trace" quantities and represent no hazard. The radioactive gases and hydrocarbons are retained in the fluid in the AMSCO scrubber. If this fluid becomes saturated with gases it is replaced with fresh scrubbing fluid and the saturated fluid is stored on the ship. The gases released from the scrubber are held-up in a waste gas storage tank when the ship is in restricted waters or at the dock. The used

VIII -14 
scrubbing fluid is removed in shielded casks when the ship is in its home port and burned after the radioactive isotopes have decayed to a tolerable level.

Due to the fact that operation with pinhole failures in the cladding of the fuel elements is a design criterion, the HBC is stored in shielded tanks or incinerated when the vessel is at sea. Stored HBC is pumped to dockside decay storage tanks when the vessel is in its home port.

Radioactive solid and aqueous waste products are also held-up in storage facilities at sea and removed when the ship returrs to its home port. 



\section{RESEARCH AND DEVELOPMENT}

\section{A. INTRODUCTION}

The Research and Development Program outlined in this section has been developed with the objective in mind of satisfying the specific engineering requirements necessary to complete the design and construction of the reactor system for the 30,000 SHP tanker described in this report. These projects are directed toward the development of the specific components or sub-systems planned for the Maritime OMCR. It is assumed the basic general OMR Design information will be available from the Advanced OMR Program supported by the AEC under Budget Activity 4107. This includes determination of basic heat transfer, physical and chemical properties data for organic coolants.

\section{B. OMCR DEVELOPMENT PROJECTS}

The organic moderated and cooled reactor concept as proposed in this report represents a significant advance over other OMR designs. As such, several well defined basic areas require an extension of present development effort. These areas are: (1) a complete experimental investigation of nucleate boiling heat transfer with organics, including fouling and burnout studies; (2) fuel element materials and design studies, irradiation and post-irradiation evaluation of materials, and the investigation and development of fabrication techniques, specifically for APM and similar fuel element cladding materials; (3) the investigation of the physics of a power flattened core; and (4) determination of pressure buildup characteristics during the suppression of organic fires in contained areas. Component development work deemed necessary includes prototype control rod testing, testing of the failed fuel element detecting system, testing of the incore power mapping system, and development of absolute seals for organic coolants.

Specific development programs essential to the Maritime OMCR Program are:

1. Fuel Element Heat Transfer and Hydraulic Studies

OMCR elements will be studied at OMCR operating conditions; specific information required consists of: 
a) determination of nucleate boiling heat transfer parameters

b) determination of burnout heat flux limitations for the OMCR fuel element configuration

c) determination of the fouling characteristics and limitations of the OMCR coolant, and fuel element configuration

d) determination of the hydraulic performance of the OMCR fuel element including pressure drop and pin vibration under hydraulic loading

e) determination of flow characteristics during nucleate and bulk boiling, including instabilities associated with reactor transients

f) determine the effect of pitch and roll conditions on heat flux limitations.

Preliminary studies conducted at Atomics International have established the technical feasibility of utilizing nucleate boiling with organic fluids as a means of heat transfer. The studies outlined above are necessary to define the limits of nucleate boiling, to enable some of the present design conservatism to be eliminated, and to specifically investigate the applicable OMCR components under conditions simulating the OMCR core.

2. Fuel Element Development and Evaluation

The Research and Development Project set forth here is scheduled to include the following:

a) fuel element materials and design studies

b) irradiation and post-irradiation evaluation of materials

c) development of fabrication and assembly techniques for the fuel element box and end connectors

d) development of production jigs and fixtures

e) development of tests and procedures for quality control of finishing fuel element components.

Preliminary development work at Atomics International under the Advanced OMR program has demonstrated, on a laboratory scale, the feasibility of using APM as a cladding material for $\mathrm{UO}_{2}$. The work outlined above will

IX -2 
augment the present effort. In addition, this phase of the R\&D program will furnish sufficient fuel elements required for other test purposes.

3. Organic Fire Control and Containment Evaluation

The effort under this phase of the development program will determine optimum methods of quenching organic fires within contained areas. It is expected that the information gained in this effort will permit the use of the ships structure for containment and minimize containment weight.

4. Core Power Mapping System

Effort under this project will be devoted to testing of individual components and the complete core power mapping system. Since the majority of these components are co:nmercially available primary emphasis will be placed on system reliability. Specific equipment to be tested includes:
a) The thermo-pile and drive system and the positioning accuracy
b) The data logging system
c) Electrical noise problems associated with incore instru- mentation.

The successful completion of the work undertaken under this project will allow semi-continuous monitoring of the power distribution in the OMCR core. It is expected that the information gained therefrom will improve the control rod programming and assist in securing higher core performance.

\section{Control Rod Development}

Specific information to be secured under this phase of the R\&D program is the testing under simulated operating conditions of the control rod and drive system proposed for the OMCR. Specific information to be obtained includes:
a) Operating characteristics of the drive
b) Reliability of the drive
c) Performance characteristics of the rod snubber system.
d) Structural behavior of the rod and follower
e) Wear rates of the various components
f) Reliability and operating characteristics of the complete control rod and drive assembly under roll and pitch conditions. 
A full size mockup of the bottom mounted control rod assembly proposed for the OMCR core will be required.

\section{Incore Failed Fuel Detection System}

Specific work included under this project will be the optimization and development of a fuel element monitoring system capable of detecting minor cladding failures within the fuel elements. The development work will emphasize environmental factors peculiar to an organic cooled reactor.

\section{Development of Absolute Seals for Organic Coolants}

While the pumps, valves and other components utilized in the OMCR main heat transfer loops and process systems a re commercially available, additional emphasis is required to develop techniques for effecting leak tight seals requiring a minimum of maintenance. Various mechanical seal designs will be developed and tested under this program.

8. Fission Product Removal

Because of the large core and number of fuel elements with their associated end closures it is anticipated there may be some fission product leakage to the organic primary system. The plant is being designed to operate with a certain leakage rate. It will be necessary to have a processing system to continuously remove fission products from the coolant. A study will be made under this project to determine the best methods for removing fission products from the degasification system. The plant is presently designed so that fission products removed from the organic system are stored for an appropriate decay time before release.

\section{Critical Experiment}

A full-scale critical experiment is suggested for this project. The critical experiment would be used to minimize the many uncertainties that exist in the core physics data. This data will give information on the effects of various control rod poisons, power flattening of the core and control rod programming, the temperature and void coefficient of reactivity, shielding parameters, and will establish criteria for orificing the core coolant channels to maintain the required bulk outlet temperature. A critical experiment is necessary in order that the 
full-scale plant will require only a minimum time for check-out before going into full power commercial operation.

\section{ESTIMATE OF FUNDING REQUIREMENTS FOR OMCR DEVELOPMENT PROGRAM}

Table XIX provides estimates for each of the above projects for fiscal years 1960 and 1961. The total estimate for FY 1960, exclusive of the critical experiment, is $\$ 1,645,000$ and for FY 1961, $\$ 950,000$. The total cost of the critical experiment is estimated to be $\$ 1,070,000$. This total amount includes $\$ 275,000$ for pelletizing $\mathrm{UO}_{2}$. The pelletizing costs are recoverable since the $\mathrm{UO}_{2}$ can be utilized and fabricated into the fuel for the first core loading.

TABLE XIX

SCHEDULE AND FUNDING - OMCR R\&D

Thousands of Dollars

$\underline{\text { Title }}$

$\underline{\text { FY } 1960 \quad \underline{\text { FY } 1961} \text { Total }}$

1. Fuel Element Heat Transfer and

Hydraulic Studies

600

325

925

2. Fuel Element Development and Evaluation

250

60

310

3. Organic Fire Control and Containment Evaluation

4. Power Mapping Monitor

120

-

120

5. Control Rod Development

55

140

195

6. Fuel Element Failure Detection System

270

195

465

7. Development of Absolute Seals

95

40

135

8. Fission Product Removal

SUB-TOTAL

140

15

155

115

175

290

$\overline{1,645}$

950

2,595

9. Critical Experiment (unrecoverable costs)*

$\frac{505}{2,150} \quad \frac{290}{1,240} \quad \frac{795}{3,390}$

* Not including $\$ 275,000$ for $\mathrm{UO}_{2}$ pelleting since these costs are recoverable by utilizing this fuel in the first core loading. 
Due to the similarity of design features between the 75 and 300 electrical Mw OCR power plants* and the Maritime OMCR described in this report, there is a certain amount of duplication in the $R \& D$ programs required for these plants. For this reason, it should be stressed that the prosecution of either the 75 or 300 electrical MW OCR R\&D programs would satisfy the bulk of the needs for the Maritime OMCR. The exceptions are Project 3, Organic Fire Control and Containment Evaluation, in its entirety and those portions of Project 1, Fuel Element Heat Transfer and Hydraulic Studies, and of Project 5, Control Rod Development, which are directed toward the investigation of the effects of ship pitch and roll on the performance of these components.

It is to be noted that the OMCR R\&D Program must be increased in the event the Advanced OMR Program being performed at Atomics International is not supported at a minimum level of $\$ 4,800,000$ (including about $\$ 1,000,000$ for fuel development) in FY 1960 and at a comparable level in FY 1961.

*BCPI-1 Vol. I, II, III, IV

IX -6 


\section{ECONOMICS}

\section{A. CAPITAL COSTS}

Atomics International has accumulated considerable cost information which has been utilized to estimate the cost of the OMCR tanker. All costs are based upon a four year construction schedule assuming an initial design study contract, including research and development, is signed July 1, 1959 and the ship is accepted by about July 1, 1963.

Estimated costs for the major items of equipment in the reactor and steam systems are evaluations based upon quotations or estimates from manufacturers to supply such equipment according to the descriptions and specifications furnished them. The DeLaval Steam Turbine Co. (under contract to Atomics International) furnished preliminary quotations on the conventional propulsion equipment. Items not included in the capital cost summary are those pieces of equipment which are not normally associated with the power plant system. A complete list of equipment that is furnished is presented in Section XI.

Equipment prices are estimated F.O.B. Philadelphia, Pa. The estimated costs include escalation but do not include interest during construction.

The engineering, design, and startup cost applies to the reactor and propulsion machinery only. It includes preliminary engineering, final engineering, field engineering, operator training, startup, and initial operation (including consumable materials but excluding fuel), and the charge for manuals. Engineering of the ship is not included in this charge.

The cost of the initial core loading (plus 9 spares) including escalation, packaging and shipping is $\$ 905,600$. This cost is not capitalized as part of the construction cost of the plant.

The capital cost summary for the reactor and propulsion system is presented in Table XX. All costs are contingent upon the research and development program, presented in Section IX, being approved. 


\begin{tabular}{lr}
\hline \hline Engineering, Design and Startup, including & \\
Operator Training, Manuals and Initial Operation & \\
Reactor Equipment & $3,491,900$ \\
Installation & $3,762,700$ \\
$\begin{array}{l}\text { Propulsion Machinery Equipment } \\
\text { Installation }\end{array}$ & $1,795,800$ \\
$\begin{array}{l}\text { Refueling Barge Equipment } \\
\text { Installation }\end{array}$ & $2,938,900$ \\
& $1,469,500$ \\
Total Capital Cost of OMCR Power Plant & 72,400 \\
without contingency & \\
Contingency & $\$ 13,682,800$ \\
& 500,000 \\
\hline
\end{tabular}

\section{B. FUEL COSTS}

For the first core, it has been calculated that an enrichment of $3.7 \%$ will give a reactivity life sufficient to achieve an average exposure of $10,000 \mathrm{MWD} /$ MTU. Because the flux is somewhat higher in the center of the core at the end of core life, the central third of the core is exposed to an average burnup higher than 10,000 MWD/MTU upon removal. By shifting the remaining fuel toward the center and inserting a fresh batch of fuel on the periphery, additional energy can be extracted from the remaining two-thirds of the original charge. Similarly after further exposure, the high burnup elements are removed and fresh fuel is loaded as the fuel-cycle approaches a steady state condition.

The fabrication charge for the first set of fuel elements is estimated to be approximately $\$ 118.10$ per $\mathrm{kg}$ of contained uranium. This figure includes all handling charges, material losses, escalation, packaging, and shipping to an East Coast site but it does not include the cost of working capital. Fabrication of the first core costs $\$ 905,600$ for 88 elements (plus 9 spares). This amount is not capitalized as part of the construction cost of the plant.

$x-2$ 
Burnup charges are based upon the price schedule for partially enriched uranium published by the AEC. Plutonium contained in the spent fuel is credited toward the uranium burnup cost in the amount of $\$ 12 / \mathrm{gm}$ of plutonium (all isotopes) minus $\$ 1.50 / \mathrm{gm}$ for reducing plutonium nitrate to metal. During steady state operations the average exposure of the fuel removed from the reactor is estimated to be 14,000 MWD/MTU. At this exposure, the uranium enrichment has dropped to $2.36 \%$ and the fuel contains $6.77 \mathrm{gm}$ of total plutonium per kilogram of uranium.

Spent fuel is held in storage 6 months for cooling before being shipped to Hanford, Washington for reprocessing. Shipping charges are estimated at $\$ 5 / \mathrm{kg} \mathrm{U}$. Total insurance charges are estimated to be about $1 / 2 \%$ of the value of the fuel shipped each way.

Charges for processing the spent fuel to nitrates are based upon the hypothetical processing plant specified by the AEC. Each batch of spent fuel elements requires one day of plant operation per thousand kilograms of uranium plus 3 days for plant cleanup. The charge for each day of operation is $\$ 15,300$. Approximately one-third of the core is reprocessed every 16 months assuming a plant utilization factor of $85 \%$. Reclaimed uranium nitrate is converted to UF 6 at the standard charge of $\$ 5.60 / \mathrm{kg} \mathrm{U}$.

The following material losses are included in the processing charges:

1. $1 \%$ U loss in processing to nitrate.

2. $1 \% \mathrm{Pu}$ loss in processing to nitrate.

3. $0.3 \% \mathrm{U}$ loss in conversion to $\mathrm{UF}_{6}$.

4. $1 \% \mathrm{Pu}$ loss in conversion to metal.

Inventory charges are calculated with a $4 \%$ per annum assessment on the value of the uranium at its initial enrichment.

The residence times for estimating fuel-cycle costs assuming one-third of the core is refueled every 16 months are:

\begin{tabular}{lcc} 
Item & Time $(\mathrm{yr})$ & Quantity (cores) \\
\cline { 2 - 3 } Fabrication & $1 / 2$ & $1 / 3$ \\
Spares & $1-1 / 3$ & $1 / 10$ \\
Reactor & $1-1 / 3$ & 1 \\
Cooling & $1 / 2$ & $1 / 3$ \\
Reprocessing & $1 / 4$ & $1 / 3$
\end{tabular}


The net fuel cost is the sum of costs for fuel preparation and fabrication, net fuel burnup, shipping, reprocessing, insurance, and a use-charge for the entire period that the uranium is not in AEC possession.

The fuel charges corresponding to a 16 month operating fuel cycle are:

\begin{tabular}{|c|c|}
\hline Fuel element fabrication & $\$ 270,000$ \\
\hline Uranium burnup & 484,000 \\
\hline Shipping charges & 11,400 \\
\hline Insurance & 10,800 \\
\hline Reprocessing & 88,650 \\
\hline Chemical conversion & 16,240 \\
\hline Uranium inventory & 248,300 \\
\hline Total & $\$ 1,129,390$ \\
\hline Plutonium credit & 162,000 \\
\hline Net fuel cost & $\$ 967,390$ \\
\hline
\end{tabular}

Annual net fuel cycle charges are $\$ 725,000$ per year which corresponds to 3.57 mills/SHP-hr based upon a fabrication cost for the first core. No charges have been included for amortizing the cost of fabricating the first core. This charge can be retired in the first few years of reactor operation and should not influence the steady-state, fuel-cycle costs. Neither are charges included for working capital. In the steady state, fuel burnup charges may be deferred until spent fuel is returned to the AEC for credit. This deferred payment offsets the advanced payments for new fuel elements permitting the plant operator to pay fabrication charges out of operating revenue. The fuel cycle costs corresponding to the first core will be slightly higher than for the steady state condition because the first charge of fuel elements removed from the core will not achieve a burnup of 14,000 MWD/MTU and the inventory charges will increase due to the preoperational testing period.

Optimization of the plant steam cycle and the turbine plant equipment could conceivably result in a $4 \%$ reduction in plant heat rate (Section V - Turbine Plant). The steady state fuel cycle cost for this improved cycle condition is estimated to 
be about $3.43 \mathrm{mills} / \mathrm{SHP}-\mathrm{hr}$. Also, the OMCR fuel costs are expected to decrease significantly during the first ten years of reactor operation due to technological developments combined with the advantages of mass production techniques. Fuel element fabrication charges should decrease approximately $40 \%$ during the first five years of plant operation. This reduction in fabrication cost should reduce fuel costs to approximately 3.07 mills $/$ SHP-hr. During the second five years of plant operation, technological developments should permit burnups of at least $20,000 \mathrm{MWD} / \mathrm{MTU}$. Increasing the burnup to this value would further reduce the fuel cycle costs to 2.73 mills/SHP-hr.

A summary of the steady state fuel cycle costs for varying operating conditions are tabulated in Table XXI.

TABLE XXI

STEADY STATE FUEL CYCLE COSTS

\begin{tabular}{llc}
\hline Operating Conditions & $\begin{array}{c}\text { Fuel Cost } \\
\text { (mills/SHP-hr) }\end{array}$ \\
\hline 1. $\begin{array}{l}\text { Utilizing } 450 \text { psig }-650^{\circ} \mathrm{F} \\
\text { steam cycle and fabrication } \\
\text { cost corresponding to initial } \\
\text { core. }\end{array}$ & 3.57 \\
2. $\begin{array}{l}\text { Utilizing an improved steam } \\
\text { cycle and fabrication costs } \\
\text { corresponding to initial core. }\end{array}$ & 3.43 \\
3. Utilizing improved steam cycle \\
and $40 \%$ reduction in fabrication \\
costs. \\
$\begin{array}{l}\text { Utilizing improved steam cycle, } \\
\text { 40\% reduction in fabrication } \\
\text { costs and increased burnup to } \\
\text { 20,000 MWD/MTU. }\end{array}$
\end{tabular}

\section{OPERATING COSTS}

The major effort has been directed toward developing the conceptual design of the organic moderated and cooled reactor and propulsion system for the class 
T-7 tanker. Although little attention was given to the design of the ship, its characteristics and capital costs, this section reviews the operating costs of the OMCR tanker and compares these costs with the operating cost of a conventional tanker for the same service. A comparison of the cargo capacity of the OMCR tanker and a conventional tanker are presented in Table XXII. Load line regulations were not taken into account in this analysis.

TABLE XXII

CARGO CAPACITY COMPARISON OMCR AND CONVENTIONAL TANKER (Long Tons)

\begin{tabular}{lrr}
\hline & OMCR & Conventional*s \\
\hline Displacement & 77,100 & 77,100 \\
Light Ship & 16,260 & 15,390 \\
Deadweight & 60,840 & 61,710 \\
Take-home Boiler Oil (15 day) & 250 & - \\
Fuel Oil Allowance (Kuwait to Phila.) & - & 5,180 \\
Misc. Fluids, Consumables and Crew & 280 & 280 \\
Total Misc. Deadweight & 530 & 560 \\
Cargo Capacity & 60,310 & 56,250 \\
Total Cargo per Year (6.4 trips/year) & 386,000 & 360,000 \\
\hline
\end{tabular}

*"Engineering Economy in Tanker Design" by H. Benford. Paper presented December 1956, Northern California Section, S. N. A. M. E. Cargo weights, capital and operating costs for the conventional tanker were estimated from this source.

The capital cost of the complete OMCR tanker was estimated by adding the cost of the OMCR reactor and propulsion system to the estimated cost of steel and outfit for a conventional tanker. Steel and outfit costs for the conventional ship were estimated by subtracting the cost of the boiler and propulsion machinery from the cost of a completed vessel escalated to the mid construction date of about November 1961. The capital cost summary of the OMCR tanker is presented in Table XXIII. 
CAPITAL COST SUMMARY OMCR TANKER

\begin{tabular}{lr}
\hline Conventional Tanker Capital Cost & $\$ 19,200,000$ \\
Boiler and Propulsion Machinery & $5,083,400$ \\
Conventional Tanker Steel and Outfit & $14,116,600$ \\
Reactor and Propulsion Machinery including & $14,182,800$ \\
$\quad \begin{array}{l}\text { engineering design, barge equipment } \\
\text { and supplies (not incl. initial core loading) }\end{array}$ & \\
$\begin{array}{l}\text { Secondary Shield and Containment } \\
\text { OMCR Tanker Capital Cost }\end{array}$ & $\mathbf{2 0 3 , 0 0 0}$ \\
\hline
\end{tabular}

Depreciation and interest of the capital cost of both vessels was evaluated at $8.02 \%$ per year. Fuel oil cost for the conventional tanker was assumed to be $\$ 2.70$ per bbl. Nuclear fuel costs were estimated at 3.57 mills $/ S H P-h r$. The yearly operating cost summary is presented in Table XXIV.

TABLE XXIV

YEARLY OPERATING COST SUMMARY

\begin{tabular}{lrr}
\hline \hline & OMCR Tanker & Conventional Tanker \\
\hline Crews Wages & $\$ 500,000$ & $\$ 435,000$ \\
Subsistence & 47,000 & 40,800 \\
Stores and Supplies & 134,000 & 30,000 \\
Maintenance, Repair and Refueling & 215,000 & 180,000 \\
Insurance (not inc. nuclear liability) & 360,000 & 230,000 \\
Port Expenses & 45,000 & 45,000 \\
Overhead and Misc. & 53,500 & 53,500 \\
Canal Tolls & 7,700 & 7,700 \\
Interest and Depreciation & $2,285,000$ & $1,540,000$ \\
Total Cost Excluding Fuel & $3,647,200$ & $2,562,000$ \\
Fuel Cost & 725,000 & 876,000 \\
Total Annual Operating Cost & $4,372,200$ & $3,438,000$ \\
Long Tons of Cargo per Year & 386,000 & 360,000 \\
Cost per Ton of Cargo & 11.30 & 9.55 \\
\hline
\end{tabular}


Table XXIV illustrates that the cost of hauling oil from Kuwait to Philadelphia with the first 60,000 DW T OMCR tanker is approximately $18.4 \%$ greater than a conventional tanker for the same service.

Many cost savings can be anticipated in future OMCR tankers. The second OMCR tanker should be approximately $\$ 5,000,000$ cheaper than the first tanker. This cost reduction is estimated by assuming:

1. The cost of engineering and design is reduced by $67 \%$

2. Charge for manuals is eliminated

3. Barge costs are eliminated

4. Service reserve is reduced by $80 \%$

5. Equipment and installation costs of the steel, outfit and machinery are reduced $10 \%$.

Fuel costs should reduce significantly for subsequent cores. Assuming a $40 \%$ reduction in fuel element fabrication cost, the fuel costs should reduce from $3.57 \mathrm{mills} / \mathrm{SHP}-\mathrm{hr}$ to $3.07 \mathrm{mills} / \mathrm{SHP}-\mathrm{hr}$. This reduced fuel cost, combined with the lower capital cost, should reduce the cost of hauling cargo in the second OMCR tanker to $\$ 10.00$ per ton. This operating cost is only $5.8 \%$ greater than for the conventional tanker which consumes fuel oil worth $\$ 2.70$ per bbl. Fuel oil cost must increase to $\$ 3.20$ per bbl. before the second OMCR tanker becomes competitive. 


\section{EQUIPMENT LISTS AND WEIGHTS}

\section{A. REACTOR SYSTEM}

1. Reactor Vessel

\begin{tabular}{|c|c|c|c|}
\hline Quantity & Service & $\begin{array}{l}\text { Preliminary } \\
\text { Specifications }\end{array}$ & Weight \\
\hline 1 & Core Tank & $\begin{array}{l}\text { ASTM A-204 Gr B } 350 \text { psig } \\
\text { @750 F; 21'-1' O.A. x } 9^{\prime}-3^{\prime \prime} \\
\text { l.D. } \times 1-1 / 2^{\prime \prime} \text { thick }\end{array}$ & \\
\hline 1 & $\begin{array}{l}\text { Outer Thermal } \\
\text { Shield }\end{array}$ & $\begin{array}{l}\text { ASTM A-204 Gr B 8'-0"' } \\
\text { O.A. X 8'-1" I.D. x 6" total } \\
\text { thickness }\end{array}$ & \\
\hline 1 & $\begin{array}{l}\text { Core Support } \\
\text { Structure }\end{array}$ & $\begin{array}{l}\text { ASTM A-204 Gr B } 13^{\prime}-6^{\prime \prime} \\
\text { O.A. } \times 7^{\prime}-9^{\prime \prime} \text { I.D. (Upper) } \\
\times 6^{\prime}-6^{\prime \prime} \text { I.D. (Lower) } \\
\text { thick }\end{array}$ & \\
\hline 1 & $\begin{array}{l}\text { Inner Thermal } \\
\text { Shield }\end{array}$ & $\begin{array}{l}\text { ASTM A-204 Gr B 5'-11" O.A. } \\
\times \text { 6'." I.D. } 1-1 / 2^{\prime \prime} \text { thick }\end{array}$ & \\
\hline 1 & $\begin{array}{l}\text { Upper Grid Plate } \\
\text { and Control Rod } \\
\text { Guide Assembly }\end{array}$ & $\begin{array}{l}\text { ASTM A-204 Gr B 6'-4"' Dia. } \\
\text { x 1/4" thick. 6" Grid Plate } \\
\text { Web Depth; 4'-2" Control Rod } \\
\text { Guide Assembly Web Depth }\end{array}$ & \\
\hline 1 & Lower Grid Plate & $\begin{array}{l}\text { ASTM A-204 Gr B 6'-5-1/2"' } \\
\text { Dia. } x 3^{\prime \prime} \text { thick }\end{array}$ & \\
\hline 88 & Fuel Elements & & \\
\hline 7 & Dummy Elements & & \\
\hline 1 & Source Element & & \\
\hline \multirow[t]{2}{*}{21} & Control Rods & 1-hp Drive Motors ea. & \\
\hline & & $\begin{array}{l}\text { Total } \\
\text { (empty) }\end{array}$ & $\overline{281,000}$ \\
\hline
\end{tabular}


2. Vessels

\begin{tabular}{|c|c|c|c|}
\hline Quantity & Service & $\begin{array}{l}\text { Preliminary } \\
\text { Specifications }\end{array}$ & Weight \\
\hline 1 & Surge Tank & $\begin{array}{l}2,000 \mathrm{gal}, 5^{\prime} \times 14^{\prime}, 750^{\circ} \mathrm{F}, \\
300 \mathrm{psig}\end{array}$ & 9,020 \\
\hline 1 & Drain Tank & $\begin{array}{l}10,000 \text { gal, } 8^{\prime} \times 26^{\prime}, 750^{\circ} \mathrm{F}, \\
100 \mathrm{psig}\end{array}$ & 16,200 \\
\hline 1 & Gas Scrubber & $\begin{array}{l}500 \mathrm{gal}, 4^{\prime} \times 5^{\prime}, 200^{\circ} \mathrm{F}, \\
100 \mathrm{psig}\end{array}$ & 1,100 \\
\hline 1 & Degasifier & $\begin{array}{l}1,000 \text { gal, } 5^{\prime} \times 7^{\prime}, 750^{\circ} \mathrm{F} \\
300 \text { psig }\end{array}$ & 5,940 \\
\hline 1 & Suction Tank & $\begin{array}{l}10 \mathrm{cu} \mathrm{ft}, 2^{\prime} \times 3-1 / 2^{\prime}, 200^{\circ} \mathrm{F} \\
50 \mathrm{psig}\end{array}$ & 266 \\
\hline 1 & $\begin{array}{l}\text { Product Receiver } \\
\text { Tank }\end{array}$ & $\begin{array}{l}5,500 \mathrm{gal}, 4^{\prime} \times 5^{\prime}, 650^{\circ} \mathrm{F}, \\
\text { vacuum to } 100 \mathrm{psig}\end{array}$ & 1,100 \\
\hline 1 & $\begin{array}{l}\text { New Coolant Storage } \\
\text { Tank }\end{array}$ & $\begin{array}{l}18,000 \text { gal, } 12^{\prime} \times 21^{\prime}, 400^{\circ} \mathrm{F}, \\
50^{\mathrm{psig}}\end{array}$ & 16,700 \\
\hline 1 & $\begin{array}{l}\text { Relief System } \\
\text { Condenser }\end{array}$ & $\begin{array}{l}2,500 \text { gal, } 7^{\prime} \times 9^{\prime}, 200^{\circ} \mathrm{F}, \\
100 \text { psig }\end{array}$ & 5,320 \\
\hline 1 & $\begin{array}{l}\text { Residue Storage } \\
\text { Tank }\end{array}$ & $\begin{array}{l}15,000 \text { gal, } 12^{\prime} \times 18^{\prime}, 600^{\circ} \mathrm{F} \text {, } \\
50^{\mathrm{psig}}\end{array}$ & 15,150 \\
\hline 1 & $\begin{array}{l}\text { Back-wash } \\
\text { Receiver Tank }\end{array}$ & $\begin{array}{l}500 \text { gal, } 4^{\prime} \times 5^{\prime}, 400^{\circ} \mathrm{F} \\
300 \text { psig }\end{array}$ & 2,940 \\
\hline 1 & $\begin{array}{l}\text { Aqueous Waste } \\
\text { Monitoring Tank }\end{array}$ & $\begin{array}{l}2,500 \text { gal, } 7^{\prime} \times 9^{\prime}, 200^{\circ} \mathrm{F}, \\
50 \text { psig }\end{array}$ & 2,700 \\
\hline 1 & $\begin{array}{l}\text { Waste Gas Storage } \\
\text { Tank }\end{array}$ & $\begin{array}{l}50 \mathrm{cu} \mathrm{ft}, 3^{\prime} \times 7^{\prime}, 150^{\circ} \mathrm{F} \\
100 \mathrm{psig}\end{array}$ & 660 \\
\hline 1 & $\begin{array}{l}\text { Amsco Makeup } \\
\text { Tank }\end{array}$ & $\begin{array}{l}500 \text { gal, } 4^{\prime} \times 5^{\prime}, 100^{\circ} \mathrm{F}, \\
50 \text { psig }\end{array}$ & 736 \\
\hline 1 & $\begin{array}{l}\text { Amsco Decay } \\
\text { Tank }\end{array}$ & $\begin{array}{l}500 \text { gal, } 4^{\prime} \times 5^{\prime}, 150^{\circ} \mathrm{F}, \\
50 \text { psig }\end{array}$ & 736 \\
\hline 1 & Expansion Tank & $\begin{array}{l}100 \text { gal, } 2^{\prime} \times 4^{\prime}, 100^{\circ} \mathrm{F} \text {, } \\
50 \text { psig }\end{array}$ & 170 \\
\hline 2 & Air Receiver Tank & $\begin{array}{l}10 \mathrm{cuft}, 2^{\prime} \times 3-1 / 2^{\prime}, 100^{\circ} \mathrm{F}, \\
200 \mathrm{psig}\end{array}$ & 200 \\
\hline
\end{tabular}


3. Heat Exchangers

\begin{tabular}{|c|c|c|c|}
\hline Quantity & Service & $\begin{array}{l}\text { Preliminary } \\
\text { Specifications }\end{array}$ & Weight \\
\hline 2 & Main Boiler & $\begin{array}{l}\text { U-tube, } 135.5 \times 10^{6} \mathrm{Btu} \\
3,835 \mathrm{ft}^{2} \text {, Shell } 550 \mathrm{psig}, \\
\text { Tubes } 300 \mathrm{psig}\end{array}$ & 35,000 \\
\hline 2 & Superheater & $\begin{array}{l}\text { U-tube, } 19.6 \times 10^{6} \mathrm{Btu} \\
2,215 \mathrm{ft}^{2} \text {, Shell } 300 \mathrm{psig}, \\
\text { Tubes } 550 \text { psig }\end{array}$ & 12,000 \\
\hline 1 & $\begin{array}{l}\text { Decay Heat } \\
\text { Exchanger }\end{array}$ & $\begin{array}{l}\text { U-tube, } 5.12 \times 10^{6} \mathrm{Btu}, \\
127 \mathrm{ft}^{2}, \text { Shell } 300 \mathrm{psig}, \\
\text { Tubes } 200 \mathrm{psig}\end{array}$ & 1,200 \\
\hline 1 & $\begin{array}{l}\text { Air-Fin Condenser } \\
\text { (decay heat) }\end{array}$ & $\begin{array}{l}\text { Finned tube (water to air) } \\
5.12 \times 10^{6} \mathrm{Btu}, 12,300 \mathrm{ft}^{2}\end{array}$ & 1,000 \\
\hline 1 & $\begin{array}{l}\text { Purification Still } \\
\text { Condenser }\end{array}$ & $\begin{array}{l}\text { U-tube, } 35,000 \mathrm{Btu}, 2 \mathrm{ft}^{2} \\
\text { Shell vacuum to } 100 \mathrm{psig} \\
\text { Tubes } 300 \mathrm{psig}\end{array}$ & 100 \\
\hline 2 & $\begin{array}{l}\text { Purification Still } \\
\text { Freeze Traps }\end{array}$ & $\begin{array}{l}\text { Finned tube, } 1,000 \mathrm{Btu} \\
3.2 \mathrm{ft}^{2} \text {, Shell vacuum to } \\
100 \mathrm{psig} \text {, Tubes } 100 \mathrm{psig}\end{array}$ & 150 \\
\hline 1 & $\begin{array}{l}\text { Purification Water } \\
\text { Condenser }\end{array}$ & $\begin{array}{l}\mathrm{U} \text {-tube, } 40,000 \mathrm{Btu}, 3.8 \mathrm{ft}^{2} \\
\text { Shell vacuum to } 100 \mathrm{psig}, \\
\text { Tubes } 100 \mathrm{psig}\end{array}$ & 150 \\
\hline 2 & $\begin{array}{l}\text { Instr. Air Compr. } \\
\text { Aftercooler }\end{array}$ & $\begin{array}{l}\text { Straight Tube, } 1,500 \text { Btu, } \\
4 \mathrm{ft}^{2} \text {, Shell } 100 \text { psig, } \\
\text { Tubes } 200 \text { psig }\end{array}$ & 150 \\
\hline 1 & $\begin{array}{l}\text { Degasification } \\
\text { Water Condenser }\end{array}$ & $\begin{array}{l}\mathrm{U} \text {-tube, } 30,000 \mathrm{Btu}, 2.8 \mathrm{ft}^{2} \\
\text { Shell vacuum to } 100 \mathrm{psig}, \\
\text { Tubes } 100 \mathrm{psig}\end{array}$ & 150 \\
\hline 1 & $\begin{array}{l}\text { Degasifier } \\
\text { Condenser }\end{array}$ & $\begin{array}{l}\text { U-tube, } 215,000 \mathrm{Btu}, 5.23 \mathrm{ft}^{2} \text {, } \\
\text { Shell vacuum to } 100 \mathrm{psig}, \\
\text { Tubes } 300 \mathrm{psig}\end{array}$ & 250 \\
\hline 1 & $\begin{array}{l}\text { Degasifier After } \\
\text { Condenser }\end{array}$ & $\begin{array}{l}\mathrm{U} \text {-tube, } 7,600 \mathrm{Btu}, 0.76 \mathrm{ft}^{2} \\
\text { Shell vacuum to } 100 \mathrm{psig}, \\
\text { Tubes } 300 \mathrm{psig}\end{array}$ & 100 \\
\hline 2 & $\begin{array}{l}\text { Degasifier Freeze } \\
\text { Traps }\end{array}$ & $\begin{array}{l}\text { Finned tube, } 3,000 \mathrm{Btu} \\
8.5 \mathrm{ft}^{2} \text {, Shell vacuum to } 100 \mathrm{psig}, \\
\text { Tubes } 100 \mathrm{psig}\end{array}$ & 350 \\
\hline
\end{tabular}




\begin{tabular}{clll} 
Quantity & \multicolumn{1}{c}{ Service } & \multicolumn{1}{c}{$\begin{array}{c}\text { Preliminary } \\
\text { Specifications }\end{array}$} & Weight \\
\hline 1 & Amsco Cooler & $\begin{array}{l}\text { Straight tube, 10,000 Btu, } \\
4.6 \mathrm{ft}^{2}, \text { Shell 100 psig, } \\
\text { Tubes } 100 \mathrm{psig}\end{array}$ & 300 \\
1 & $\begin{array}{l}\text { Shield Coolant Heat } \\
\text { Exchanger }\end{array}$ & $\begin{array}{l}\text { Straight tube, 600,000 Btu, } \\
117 \mathrm{ft}^{2}, \text { Shell 100 psig, } \\
\text { Tubes 100 psig }\end{array}$
\end{tabular}


4. Pumps

\begin{tabular}{|c|c|c|c|}
\hline Quantity & Service & $\begin{array}{l}\text { Preliminary } \\
\text { Specifications }\end{array}$ & Weight \\
\hline 2 & $\begin{array}{l}\text { Primary Coolant } \\
\text { Pump }\end{array}$ & $\begin{array}{l}\text { Vertical turbine, } 12,900 \mathrm{gpm} \text {, } \\
\text { Head } 42.5 \mathrm{psi} \text {, Motor } 500 \mathrm{hp}\end{array}$ & \\
\hline 2 & Decay Pumps & $\begin{array}{l}\text { Horizontal Centrifugal, } 220 \\
\text { gpm, Head } 50 \text { psi, Motor } 10 \mathrm{hp}\end{array}$ & 2,000 \\
\hline 2 & $\begin{array}{l}\text { Drain and Transfer } \\
\text { Pumps }\end{array}$ & $\begin{array}{l}\text { Horizontal Centrifugal, } 50 \mathrm{gpm} \text {, } \\
\text { Head } 50 \mathrm{psi} \text {, Motor } 2 \mathrm{hp}\end{array}$ & 450 \\
\hline 1 & $\begin{array}{l}\text { Gas Scrubber } \\
\text { Circulating Pump }\end{array}$ & $\begin{array}{l}\text { Horizontal Centrifugal, } 20 \mathrm{gpm} \text {, } \\
\text { Head } 40 \text { psi, Motor } 1 \mathrm{hp}\end{array}$ & 380 \\
\hline 2 & $\begin{array}{l}\text { Coolant Makeup } \\
\text { Pump }\end{array}$ & $\begin{array}{l}\text { Horizontal Centrifugal, } 5 \mathrm{gpm} \text {, } \\
\text { Head } 20 \text { psi, Motor } 1 / 4 \mathrm{hp}\end{array}$ & 600 \\
\hline 2 & Residue Pump & $\begin{array}{l}\text { Rotary Gear, } 125 \mathrm{gpm} \text {, Head } \\
50 \mathrm{psi} \text {, Motor } 5 \mathrm{hp}\end{array}$ & 800 \\
\hline 1 & $\begin{array}{l}\text { New Coolant } \\
\text { Controlled Volume }\end{array}$ & $\begin{array}{l}\text { Controlled Volume, } 0.167 \mathrm{gpm} \text {, } \\
\text { Head } 25 \text { psi, Motor } 1 / 4 \mathrm{hp}\end{array}$ & 200 \\
\hline 2 & $\begin{array}{l}\text { Purification Vacuum } \\
\text { Pump }\end{array}$ & $2 \mathrm{cfm}$, Motor $1 / 2 \mathrm{hp}$ & 100 \\
\hline 2 & $\begin{array}{l}\text { Degasifier Vacuum } \\
\text { Pump }\end{array}$ & $10 \mathrm{cfm}$, Motor $2 \mathrm{hp}$ & 250 \\
\hline 2 & Pressurizing Pump & $\begin{array}{l}\text { Horizontal Centrifugal, } 222 \mathrm{gpm} \text {, } \\
\text { Head } 50 \mathrm{psi} \text {, Motor } 10 \mathrm{hp}\end{array}$ & 2,000 \\
\hline 2 & $\begin{array}{l}\text { Amsco Circulation } \\
\text { Pump }\end{array}$ & $\begin{array}{l}\text { Horizontal Centrifugal, } 5 \mathrm{gpm} \text {, } \\
\text { Head } 25 \mathrm{psi} \text {, Motor } 1 / 4 \mathrm{hp}\end{array}$ & 810 \\
\hline 2 & $\begin{array}{l}\text { Water Circulation } \\
\text { Pump }\end{array}$ & $\begin{array}{l}\text { Horizontal Centrifugal, } 50 \mathrm{gpm} \text {, } \\
\text { Head } 20 \mathrm{psi} \text {, Motor } 1 \mathrm{hp}\end{array}$ & 400 \\
\hline 2 & Waste Amsco Pump & $\begin{array}{l}\text { Horizontal Centrifugal, } 10 \mathrm{gpm} \text {, } \\
\text { Head } 50 \mathrm{psi} \text {, Motor } 1 / 2 \mathrm{hp}\end{array}$ & 400 \\
\hline 2 & $\begin{array}{l}\text { Aqueous Waste } \\
\text { Pump }\end{array}$ & $\begin{array}{l}\text { Horizontal Centrifugal, } 15 \mathrm{gpm} \text {, } \\
\text { Head } 50 \mathrm{psi} \text {, Motor } 1 \mathrm{hp}\end{array}$ & 400 \\
\hline
\end{tabular}


5. Compressors and Blowers

\begin{tabular}{|c|c|c|c|}
\hline Quantity & Service & $\begin{array}{c}\text { Preliminary } \\
\text { Specifications }\end{array}$ & Weight \\
\hline 2 & $\begin{array}{l}\text { Waste Gas Com- } \\
\text { pressors, Water } \\
\text { Cooled }\end{array}$ & $\begin{array}{l}\text { Canned, } 0.25 \text { scfm, Head } 55 \text { psia, } \\
\text { Motor } 100 \mathrm{hp}\end{array}$ & \\
\hline 1 & $\begin{array}{l}\text { Instrument Air } \\
\text { Compressor }\end{array}$ & $\begin{array}{l}100 \mathrm{scfm}, \text { Head } 135 \text { psia, Motor } \\
3,000 \mathrm{hp}\end{array}$ & \\
\hline 1 & $\begin{array}{l}\text { Utility Air } \\
\text { Compressor }\end{array}$ & $\begin{array}{l}100 \text { scfm, Head } 135 \text { psia, Motor } \\
3,000 \mathrm{hp}\end{array}$ & \\
\hline \multicolumn{4}{|c|}{6 Primary Loop Piping } \\
\hline Quantity & Service & $\begin{array}{c}\text { Preliminary } \\
\text { Specifications }\end{array}$ & Weight \\
\hline & Straight pipe (18") & & 11,400 \\
\hline 18 & $18^{\prime \prime} \mathrm{e} 11 / 100 \mathrm{p}$ & & 6,750 \\
\hline 3 & $16^{\prime \prime}$ valves/loop & & 9,750 \\
\hline \multirow[t]{2}{*}{1} & $12 "$ valves/loop & & 1,860 \\
\hline & 14" pipe straight/loop & & 2,700 \\
\hline 3 & $14^{\prime \prime}$ ell/loop & & 675 \\
\hline \multirow[t]{2}{*}{2} & $R$ valves/loop & & 2,000 \\
\hline & $12 "$ relief piping/loop & & 3,850 \\
\hline \multirow[t]{3}{*}{6} & $12 "$ el1/loop & & 1,080 \\
\hline & & Total/loop & 40,065 \\
\hline & & $\begin{array}{l}\text { Total piping weight } \\
\text { (two loops) }=\end{array}$ & 80,130 \\
\hline
\end{tabular}

XI-6 
7. Instrumentation Equipment List

\begin{tabular}{|c|c|c|}
\hline Quantity & $\begin{array}{c}\text { Preliminary } \\
\text { Specifications }\end{array}$ & Weight \\
\hline & $\begin{array}{l}\text { Fuel element failure } \\
\text { detection and location } \\
\text { system }\end{array}$ & \\
\hline & Radiation monitoring system & \\
\hline & Health physics equipment & \\
\hline & Core power mapping system & \\
\hline & Nuclear instrumentation system & \\
\hline & Reactor plant protective system & \\
\hline & Core instrumentation & \\
\hline & Process system instrumentation & \\
\hline & Control rod controllers & 10,000 \\
\hline
\end{tabular}

\section{Organic Inventory}

The total volume of Santowax $R$ in the reactor vessel and primary loops is 18,000 gallons or 123,300 pounds. 
9. Miscellaneous Equipment

\begin{tabular}{|c|c|c|c|}
\hline Quantity & Service & $\begin{array}{r}\text { Preliminary } \\
\text { Specifications }\end{array}$ & Weight \\
\hline 1 & Organic filter & $\begin{array}{l}\text { Removable cartridge, } \\
50 \mathrm{gpm}\end{array}$ & 75 \\
\hline 1 & Flash feed heater & Electrical, $5 \mathrm{kw}$ & 200 \\
\hline 1 & Still bottom heater & Electrical, $5 \mathrm{kw}$ & 25 \\
\hline 1 & Distillation column & $\begin{array}{l}\text { Packed column, } 24 " 1 \times 3{ }^{\prime \prime} \\
\text { flash section- } 10^{\prime \prime} \phi \times 8^{\prime} \\
\text { stripping }\end{array}$ & 1,100 \\
\hline 1 & Degasifier filter & $\begin{array}{l}\text { Removable cartridge, } \\
220 \mathrm{gpm}\end{array}$ & 150 \\
\hline 1 & Centrifuge & Continuous & 600 \\
\hline 1 & Amsco scrubber & Packed column & 700 \\
\hline 1 & $\mathrm{HBC}$ incinerator & & 4,000 \\
\hline 1 & Control rod system & $\begin{array}{l}2 \text { I rods, drives, and } \\
\text { lead out cables }\end{array}$ & \\
\hline 1 & Neutron source & & \\
\hline \multirow[t]{8}{*}{1} & Nitrogen system & manifolds and racks & \\
\hline & $\begin{array}{l}\text { Chemical lab } \\
\text { equipment }\end{array}$ & & \\
\hline & $\begin{array}{l}\text { Laundry and change } \\
\text { room equipment }\end{array}$ & & \\
\hline & \multicolumn{2}{|l|}{$\begin{array}{l}\text { Decontamination room } \\
\text { equipment }\end{array}$} & \\
\hline & \multicolumn{2}{|c|}{$\begin{array}{l}\text { Heating, ventilating, and } \\
\text { air conditioning }\end{array}$} & \\
\hline & \multicolumn{2}{|c|}{$\begin{array}{l}\text { Conventional fire protec- } \\
\text { tion system }\end{array}$} & \\
\hline & \multicolumn{2}{|c|}{$\begin{array}{l}\text { Emergency fire protec- } \\
\text { tion system, reactor } \\
\text { room only }\end{array}$} & \\
\hline & $\begin{array}{l}\text { Reactor primary } \\
\text { shield }\end{array}$ & Lead, Iron and water & 806,000 \\
\hline$X I-8$ & \multicolumn{2}{|l|}{ Spare parts } & \\
\hline
\end{tabular}


B. TURBINE SYSTEM

\begin{tabular}{|c|c|c|c|}
\hline Quantity & Service & $\begin{array}{c}\text { Preliminary } \\
\text { Specifications }\end{array}$ & Weight \\
\hline 1 & $\begin{array}{l}\text { Main turbine and } \\
\text { reduction gears }\end{array}$ & $\begin{array}{l}\text { DeLaval two-cylinder, series } \\
\text { flow, impulse type. Astern } \\
\text { turbine in low pres sure tur- } \\
\text { bine, impulse type } 27,250 \\
\text { normal Shp, } 30,000 \text { max. Shp } \\
109 \text { normal rpm, } 113 \text { max. } \\
\text { rpm. Normal steam conditions } \\
\text { Pressure,psi } 4425 \\
\text { Temperature, }{ }^{\circ} \mathrm{F} \quad 650 \\
\text { Vacuum, in. Hg } 28.0 \\
\text { Reduction gears, DeLaval } \\
\text { double reduction, double } \\
\text { helical type }\end{array}$ & 429,500 \\
\hline 2 & $\begin{array}{l}\text { Auxiliary tur- } \\
\text { bine generators, } \\
\text { regulators and } \\
\text { accessories }\end{array}$ & $\begin{array}{l}\text { Turbine-DeLaval, marine, } \\
\text { multistage, impulse type } \\
\text { including planetary, double } \\
\text { helical type gear and flexible } \\
\text { couplings. Oil relay type, } \\
\text { constant speed governor with } \\
\text { motor operated speed changer, } \\
\text { voltage regulator, and low } \\
\text { lubricating oil pressure cir- } \\
\text { cuit breakers. Normal steam } \\
\text { conditions. } \\
\text { Pressure, psi } \\
\text { Temperature, }{ }^{\circ} \mathrm{F} \quad 650 \\
\text { Vacuum, in. Hg } 28.0 \\
\text { Generators, } 2000 \mathrm{kw}, 450 \text { volt, } \\
60 \text { cycle, } 3 \text { phase A.C. } 1200 \\
\text { rpm. Power factor } 0.8 \text {; insula- } \\
\text { tion, class B, temperature rise, } \\
\text { windings, } 60^{\circ} \mathrm{C}\end{array}$ & 90,000 \\
\hline 1 & $\begin{array}{l}\text { Main condenser } \\
\text { and air ejector }\end{array}$ & $\begin{array}{l}\text { Horizontal, single pass, reheat- } \\
\text { ing surface type. } 18,500 \mathrm{sq} \text {. ft. } \\
\text { Tube material } 90 / 10 \mathrm{Cu}-\mathrm{Ni}, 3 / 4^{\prime \prime}- \\
18 \mathrm{BWG} \text {. } \\
\text { Air ejector, twin element, two } \\
\text { stage, inter, after and gland } \\
\text { steam condenser }\end{array}$ & 100,000 \\
\hline 2 & $\begin{array}{l}\text { Auxiliary con- } \\
\text { densers and air } \\
\text { ejectors }\end{array}$ & $\begin{array}{l}\text { Horizontal, two pass, reheating } \\
\text { surface type. } 2400 \mathrm{sq} / \mathrm{ft} \text {. Tube } \\
\text { material } 90 / 10 \mathrm{Cu}-\mathrm{Ni}, 3 / 4 "- \\
18 \mathrm{BWG} \text {. Air ejectors, twin } \\
\text { element, two stage, inter, after } \\
\text { and gland steam condenser }\end{array}$ & 40,000 \\
\hline
\end{tabular}




\begin{tabular}{|c|c|c|c|}
\hline Quantity & Service & $\begin{array}{c}\text { Preliminary } \\
\text { Specifications }\end{array}$ & Weight \\
\hline 3 & $\begin{array}{l}\text { Gland leak-off ex- } \\
\text { hausters }\end{array}$ & $\begin{array}{l}\text { Main exhauster, } 300 \mathrm{cfm} \text {, } \\
12^{\prime \prime} \text { water, } 1-1 / 2 \mathrm{hp} \text { motor. } \\
\text { Auxiliary exhausters, } 150 \\
\text { cfm, } 14 \text { " water, } 1-1 / 2 \mathrm{hp} \\
\text { motors. }\end{array}$ & 150 \\
\hline 1 & $\begin{array}{l}\text { Low pressure feed- } \\
\text { water heater }\end{array}$ & $\begin{array}{l}\text { Horizontal, multi pass, } \\
\text { shell and tube, complete } \\
\text { with hotwell, gauge glasses, } \\
\text { spare parts and tools. Con- } \\
\text { densate, } 195,000 \mathrm{lb} / \mathrm{hr} \\
\text { normal. } \\
\text { Steam supply, psia, } 12.5 \text {. } \\
\text { Condensate in, }{ }^{\circ} \mathrm{F} 100 \\
\text { Condensate, out }{ }^{\circ} \mathrm{F} 200\end{array}$ & 11,000 \\
\hline 1 & $\begin{array}{l}\text { Generating feed- } \\
\text { water heater }\end{array}$ & $\begin{array}{l}\text { Direct contact, deaerating, } \\
\text { vertical marine type with } \\
\text { vent condenser. Condensate } \\
\text { flow } 215,000 \mathrm{lb} / \mathrm{hr} \text { normal } \\
\text { Storage capacity, } 5000 \text { gal } \\
\text { Oxygen content, } 0.01 \mathrm{ml} / \text { liter }\end{array}$ & 58,000 \\
\hline 1 & $\begin{array}{l}\text { High pressure } \\
\text { feedwater heater }\end{array}$ & $\begin{array}{l}\text { Horizontal, straight tube, } \\
\text { closed type. Condensate, } \\
250,000 \mathrm{lb} / \mathrm{hr} \text { normal } \\
\text { Condensate in, }{ }^{\circ} \mathrm{F} 282 \\
\text { Condensate out, 'F } 325\end{array}$ & 13,000 \\
\hline 2 & $\begin{array}{l}\text { Main feedwater } \\
\text { pumps and tur- } \\
\text { bine drives }\end{array}$ & $\begin{array}{l}\text { Horizontal, multistage, } \\
\text { centrifugal, turbine driven. } \\
\text { Rating, gpm } 735 \text {. Suction } \\
\text { pressure, psig } 35 \text {. Discharge } \\
\text { pressure, psig } 750 \text {. Steam } \\
\text { pressure, psig } 425 \text {. Tem- } \\
\text { perature, } \text { F } 650 \text {. Exhaust } \\
\text { pressure, psig } 35\end{array}$ & 9,140 \\
\hline 1 & $\begin{array}{l}\text { Port feedwater } \\
\text { pump and motor }\end{array}$ & $\begin{array}{l}\text { Vertical, multistage, cen- } \\
\text { trifugal, driven by a constant } \\
\text { speed motor. Rating, gpm } 125 \\
\text { Suction pressure, psig } 35 \\
\text { Discharge pressure, psig } 750 \\
\text { Motor, rpm } 3600 \text {, Motor hp } \\
100\end{array}$ & 3,570 \\
\hline
\end{tabular}




\begin{tabular}{|c|c|c|c|}
\hline Quantity & Service & $\begin{array}{l}\text { Preliminary } \\
\text { Specifications }\end{array}$ & Weight \\
\hline 1 & $\begin{array}{l}\text { Main circulating } \\
\text { pump and motor }\end{array}$ & $\begin{array}{l}\text { Vertical, single stage, } \\
\text { centrifugal. Rating, gpm } \\
20,000 \text {. Total head, ft } 7 . \\
\text { Motor, rpm } 700, \text { hp } 150\end{array}$ & 7,500 \\
\hline 2 & $\begin{array}{l}\text { Auxiliary circula- } \\
\text { ting pumps and } \\
\text { motors }\end{array}$ & $\begin{array}{l}\text { Vertical, single stage, } \\
\text { centrifugal. Rating, gpm } \\
3300 \text {. Total head, ft } 27 \text {. } \\
\text { Motor, rpm } 1200, \mathrm{hp} \\
35\end{array}$ & 6,500 \\
\hline 2 & Main condensate & $\begin{array}{l}\text { Vertical, two stage, cen- } \\
\text { trifugal. Rating, gpm } 490 \text {. } \\
\text { Total head, ft } 290 \text {. Motor, } \\
\text { rpm } 1800 \text {, hp } 75\end{array}$ & 5,000 \\
\hline 2 & $\begin{array}{l}\text { Auxiliary condensate } \\
\text { pumps and motors }\end{array}$ & $\begin{array}{l}\text { Horizontal, two stage, close } \\
\text { coupled, centrifugal. Rating, } \\
\text { gpm 62. Total head, ft } 290 \text {. } \\
\text { Motor, rpm } 3500 \text {, hp } 20\end{array}$ & 2,100 \\
\hline 2 & $\begin{array}{l}\text { Low pressure } \\
\text { heater drain pumps } \\
\text { and motors }\end{array}$ & $\begin{array}{l}\text { Horizontal, close coupled } \\
\text { Rating, gpm } 50 \text {. Total head, } \\
\text { ft } 200 \text {. Motor, rpm } 3500 \text {, } \\
\text { hp } 7.5\end{array}$ & 500 \\
\hline 2 & $\begin{array}{l}\text { Lubricating oil } \\
\text { service pumps and } \\
\text { motors }\end{array}$ & $\begin{array}{l}\text { DeLaval - IMO Pump, rotary } \\
\text { type. Rating, gpm } 600 . \\
\text { Discharge pressure, psig } 55 \text {. } \\
\text { Viscosity, } 150-500 \text { SSU. } \\
\text { Suction lift, Hg max. I5 } \\
\text { Motor, rpm 1750, hp } 50\end{array}$ & 5,200 \\
\hline 2 & $\begin{array}{l}\text { Lubricating oil } \\
\text { coolers }\end{array}$ & 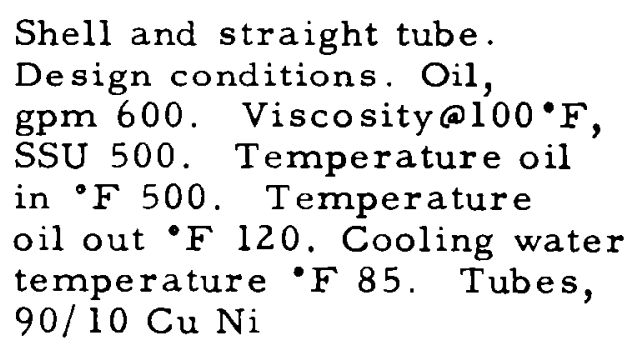 & 20,000 \\
\hline 1 & $\begin{array}{l}\text { Auxiliary steam } \\
\text { generator }\end{array}$ & $\begin{array}{l}\text { Oil fired steam generator } \\
\text { generating the following: } \\
\text { Steam flow, lb/hr } 70,000 \text {. } \\
\text { Pressure, psig } 425 \text {. Tem- } \\
\text { perature, } \mathrm{F} 650\end{array}$ & 150,000 \\
\hline
\end{tabular}




\begin{tabular}{clll} 
Quantity & \multicolumn{1}{c}{ Service } & \multicolumn{1}{c}{$\begin{array}{c}\text { Preliminary } \\
\text { Specifications }\end{array}$} & Weight \\
\hline 1 & $\begin{array}{l}\text { Emergency diesel } \\
\text { generator }\end{array}$ & $\begin{array}{l}500 \mathrm{kw}, 450 \text { volt, } 60 \mathrm{cycle} \\
3 \text { phase, A.C. }\end{array}$ & 5,000 \\
1 & $\begin{array}{l}\text { Emergency battery- } \\
\text { motor generator } \\
\text { system }\end{array}$ & $\begin{array}{l}300 \mathrm{volt}, 1315 \text { ampere- } \\
\text { hours }\end{array}$ &
\end{tabular}


Items not concerned directly with the reactor propulsion system will not be supplied. The following are examples:

Cargo pumps and their associated auxiliaries

Evaporators and their associated auxiliaries

Salt water service pumps

Atmospheric drain pumps

Fire pumps

Bilge pumps

Fire and Butterworth pumps

Fresh water pumps

Sanitary pumps

Fuel oil transfer pumps

Air compressors and as sociated equipment

Butterworth heater and drain cooler

Fresh water heaters

Ventilating and exhaust fans

Grease extractors, if any

Propellers

Shafting

Line shaft and propeller shaft bearings

Work shop machinery

Standard tools

Feedwater testing equipment

Drain cooler, de-oiler and inspection tank

Storage and service tanks

Piping, valves and fittings not specifically indicated as supplied

Machinery foundations

Insulation except as noted as furnished

Control panel boards except as noted as furnished

Pressure gauges, level gauges, thermometers and gauge boards, except as noted as furnished

Engine order telegraph

Salinity indicators for various systems 
Secondary shielding

Shadow shielding (exclusive of reactor primary shield)

All other equipment not specifically listed as furnished

Any omissions in the list should not be construed to indicate that it will be supplied.

$\mathrm{XI}-14$ 


\section{BARGE REFUELING EQUIPMENT}

The following equipment is provided on the refueling barge. Since this barge has been built for another nuclear application, other refueling equipment which is not specifically related to the OMCR is assumed furnished.

\begin{tabular}{|c|c|c|c|}
\hline Quantity & Service & $\begin{array}{c}\text { Preliminary } \\
\text { Specifications }\end{array}$ & Weight \\
\hline & \multicolumn{2}{|l|}{$\begin{array}{l}\text { Fuel handling and } \\
\text { operating tools }\end{array}$} & 1,500 \\
\hline & \multicolumn{2}{|l|}{ Cask Assembly } & 56,000 \\
\hline & Shell & Steel $42 "$ Dia $\times 10^{\prime}-0^{\prime \prime}$ & 7,000 \\
\hline & $\begin{array}{l}\text { Hydraulic } \\
\text { Cylinder }\end{array}$ & $\begin{array}{l}\text { Steel } 20^{\prime}-0^{\prime \prime} \text { stroke } \mathbf{x} \\
1 \text { ton cap }\end{array}$ & \\
\hline & $\begin{array}{l}\text { Upper Support } \\
\text { Structure }\end{array}$ & Steel & 1,000 \\
\hline & \multicolumn{2}{|c|}{ Pump (hydraulic) Steel } & 100 \\
\hline & \multicolumn{2}{|l|}{$\begin{array}{l}\text { Induced Draft } \\
\text { Fan }\end{array}$} & 100 \\
\hline & $\begin{array}{l}\text { Indexing Cover } \\
\text { Assembly } \\
\text { Outer rotating } \\
\text { plate }\end{array}$ & Steel 11'-0" Dia x 3" & 10,000 \\
\hline & $\begin{array}{l}\text { Inner rotating } \\
\text { plate }\end{array}$ & Steel $5^{\prime}-6^{\prime \prime}$ Dia $\times 6^{\prime \prime}$ & 6,000 \\
\hline & \multicolumn{2}{|l|}{ Fuel wash cell } & 1,000 \\
\hline & \multicolumn{2}{|c|}{$\begin{array}{l}\text { Organic residue disposal } \\
\text { system }\end{array}$} & 15,000 \\
\hline & \multicolumn{2}{|l|}{ Organic makeup facility } & 15,000 \\
\hline
\end{tabular}




\section{SUMMARY TABLE OF WEIGHTS}

The weights of the items of equipment tabulated in the equipment lists are summarized below:

Item

Reactor, primary loops and drain tank

Purification system, degasification system and miscellaneous process equipment

Turbine, reduction gear, steam system and auxiliary power

Miscellaneous auxiliary equipment

Total Machinery Weight
Long Tons

303

612

$\frac{50}{1,010}$

Estimates of the steel weight and outfitting " have been obtained to evaluate the light ship weight and deadweight. A summary of the se weights including the shielding weights are:

Item

Displacement

Light ship

Machinery

Steel weight

Outfit

Primary and secondary shielding
Long Tons

77,100

$$
\begin{array}{r}
1,010 \\
12,300 \\
1,750
\end{array}
$$

1,200

$\begin{array}{ll}\text { Total } & \frac{16,260}{60,840}\end{array}$

* "Engineering Economy in Tanker Design" by H. Benford presented December 1956, Northern California Section, S. N. A.M.E. 
The weight of the fluids associated with the reactor and propulsion system are:

Item

Organic in reactor and primary system

New coolant inventory and HBC storage

Water in steam system

Other process fluids

Take-home boiler oil storage (15 days)
Long Tons

55

55

50

20

Total $\quad \frac{250}{430}$

Subtracting the weight of the working fluids from the deadweight and making allowances for additional consumable items, the cargo capacity of a T-7 tanker propelled with an organic moderated and cooled reactor should be approximately 60,000 long tons. 



\title{
XII. ENGINEERING DRAWINGS
}

\author{
I. 30,000 SHP Maritime OMCR Heat Balance \\ II. 30,000 SHP Maritime OMCR General Arrangement \\ III. Reactor Equipment Arrangement \\ IV. Turbine Equipment Arrangement \\ V. Reactor and Turbine Area Deck Plan \\ VI. Reactor Vessel and Assembly \\ VII. Fuel Element Sections and Elevation \\ VIII. Control Rod Drives \\ IX. Heat Transfer, Drain and Vent System \\ X. New Coolant and Coolant Purification System \\ XI. Degasification and Pressurization System \\ XII. Radioactive Gas, Aqueous Waste and Shield Cooling Systems \\ XIII. Fuel Transfer Equipment
}





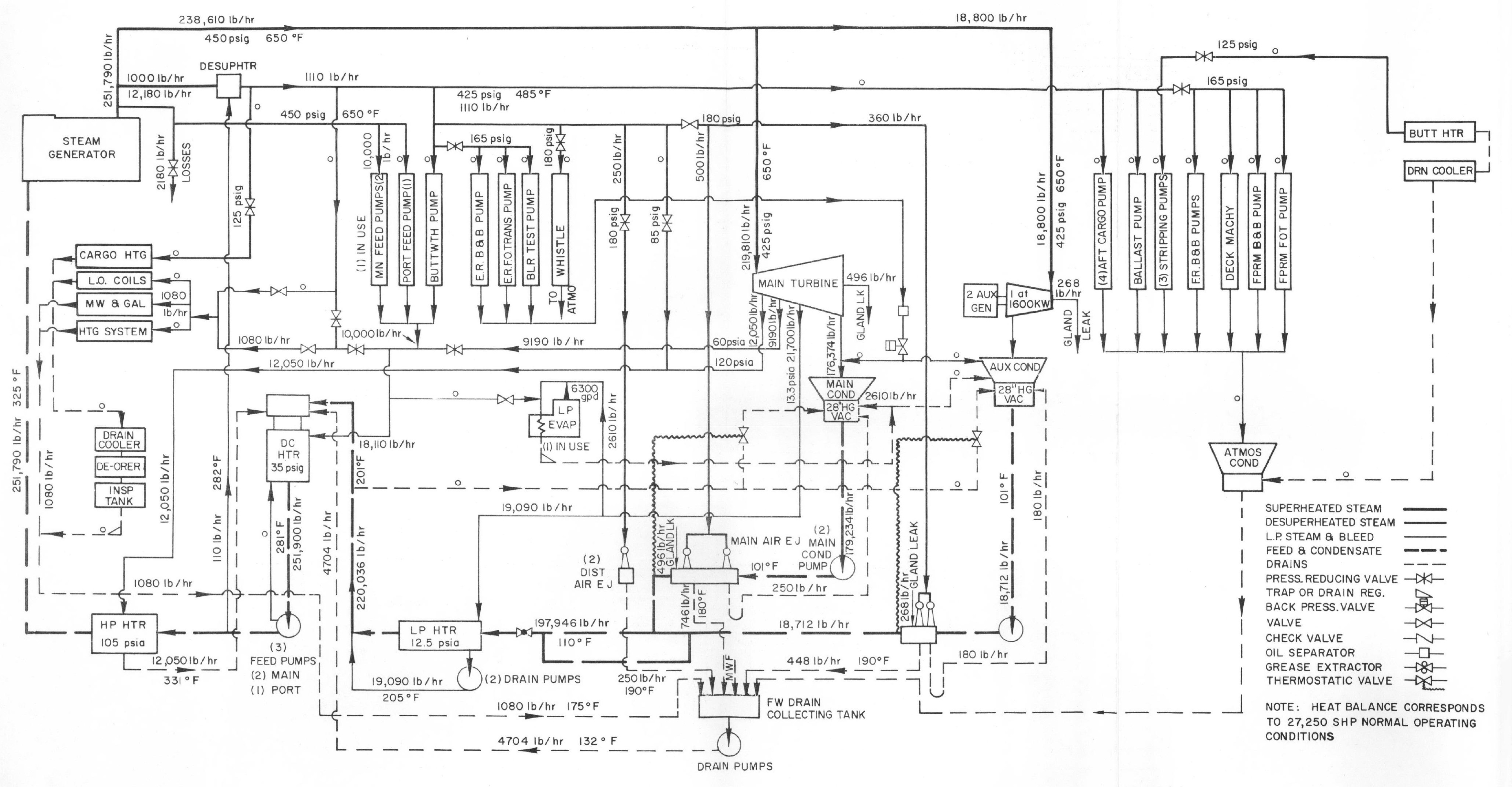

Plate I. 30, 000 SHP Maritime OMCR Heat Balance 


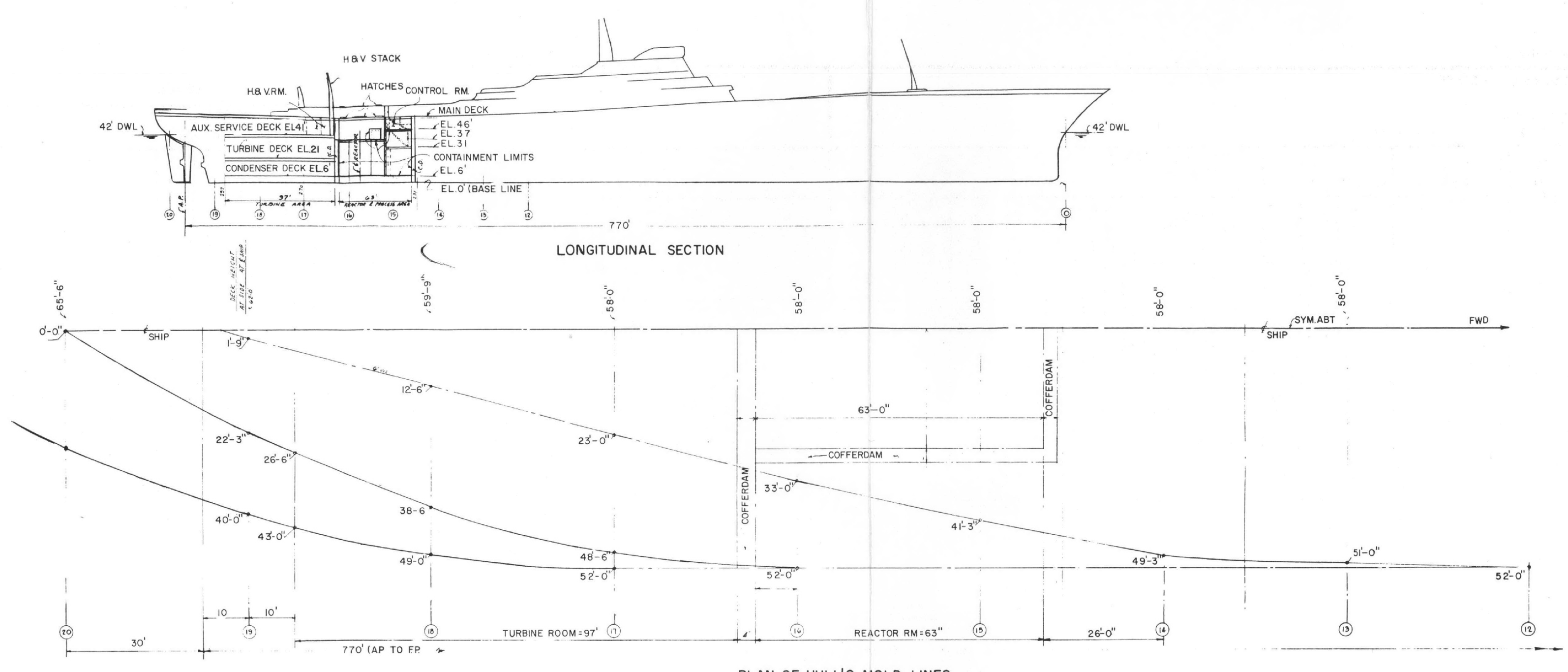

PLAN OF HULL'S MOLD LINES

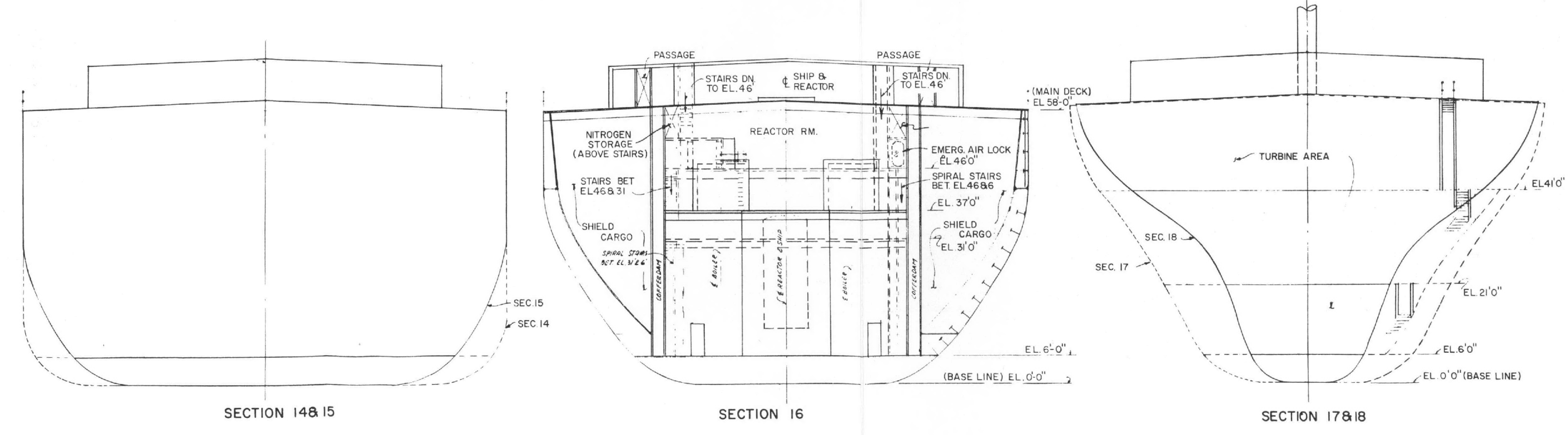

Plate II. 30,000 SHP Maritime OMCR General Arrangement 

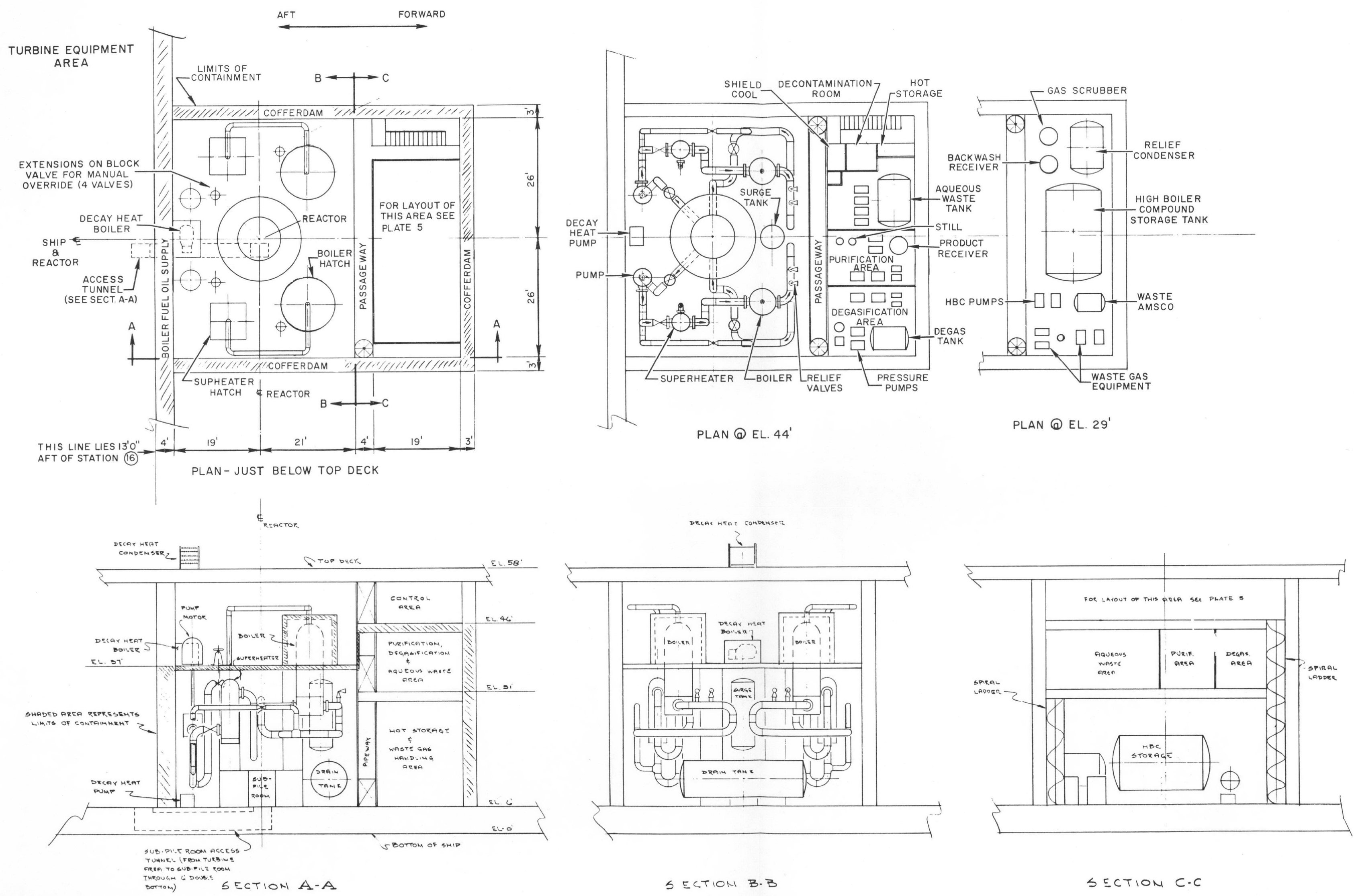

SECTIOH B.B

SECTION C.C 


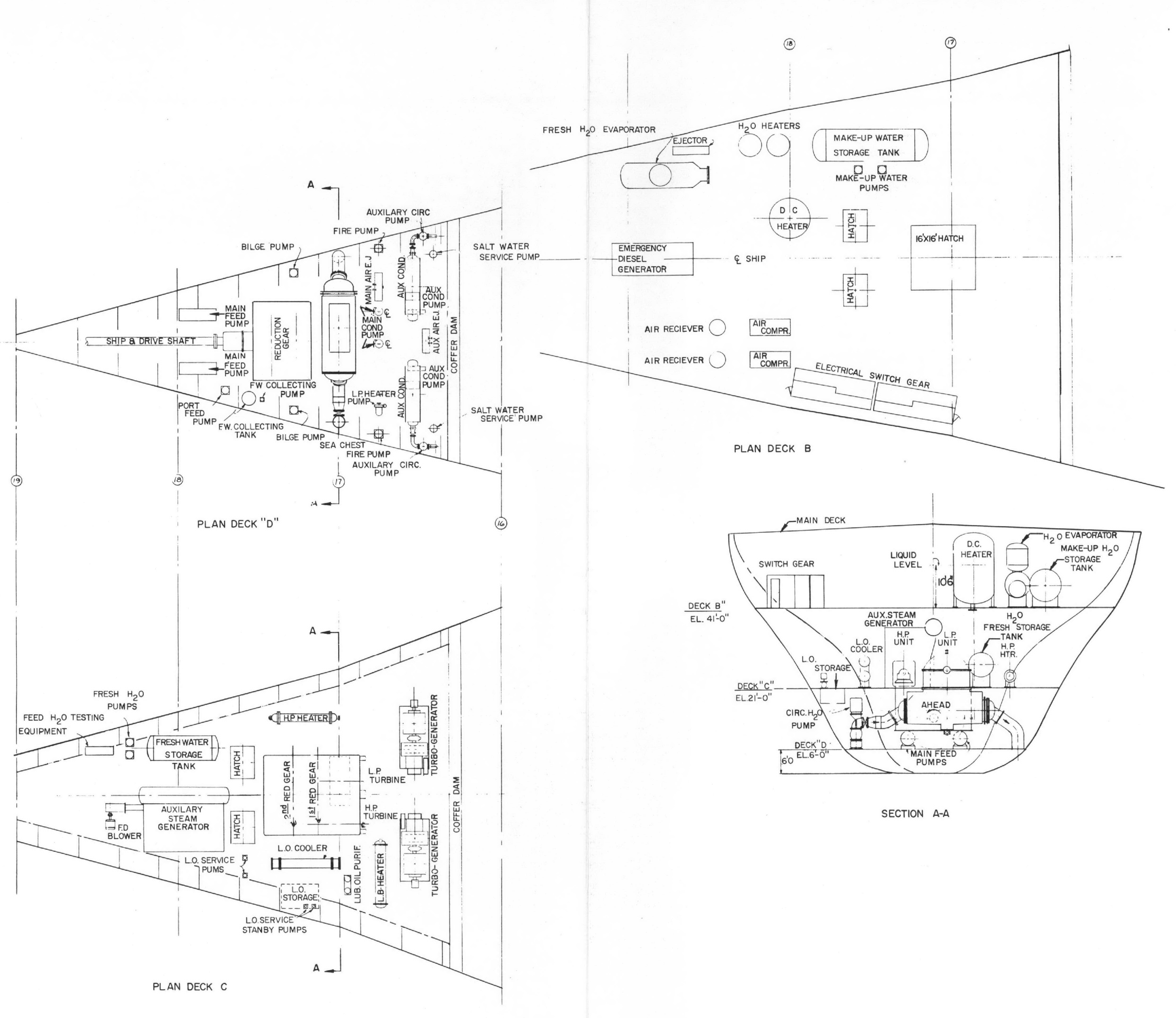




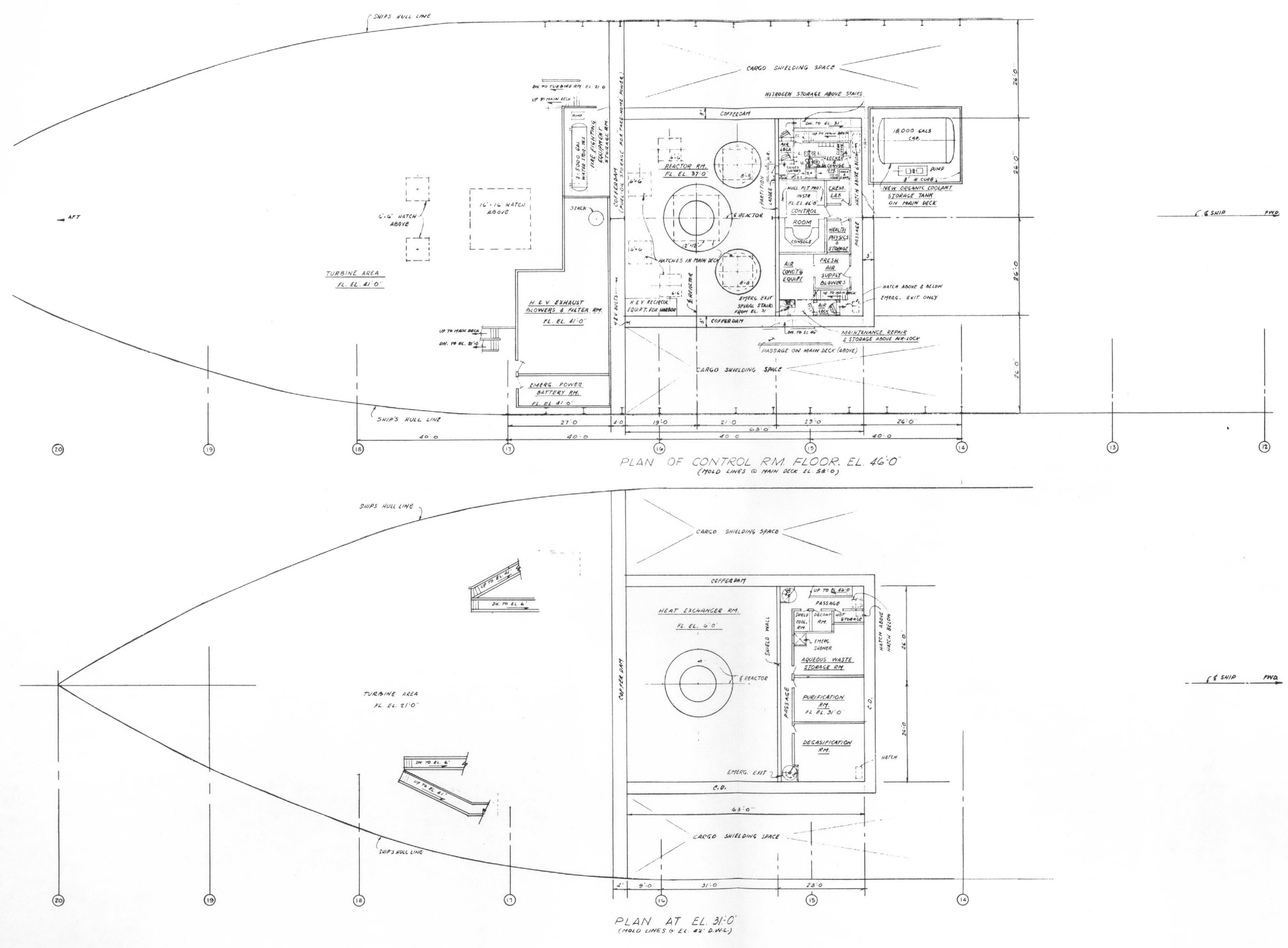

Plate V. Reactor and Turbine Area Deck Plan 


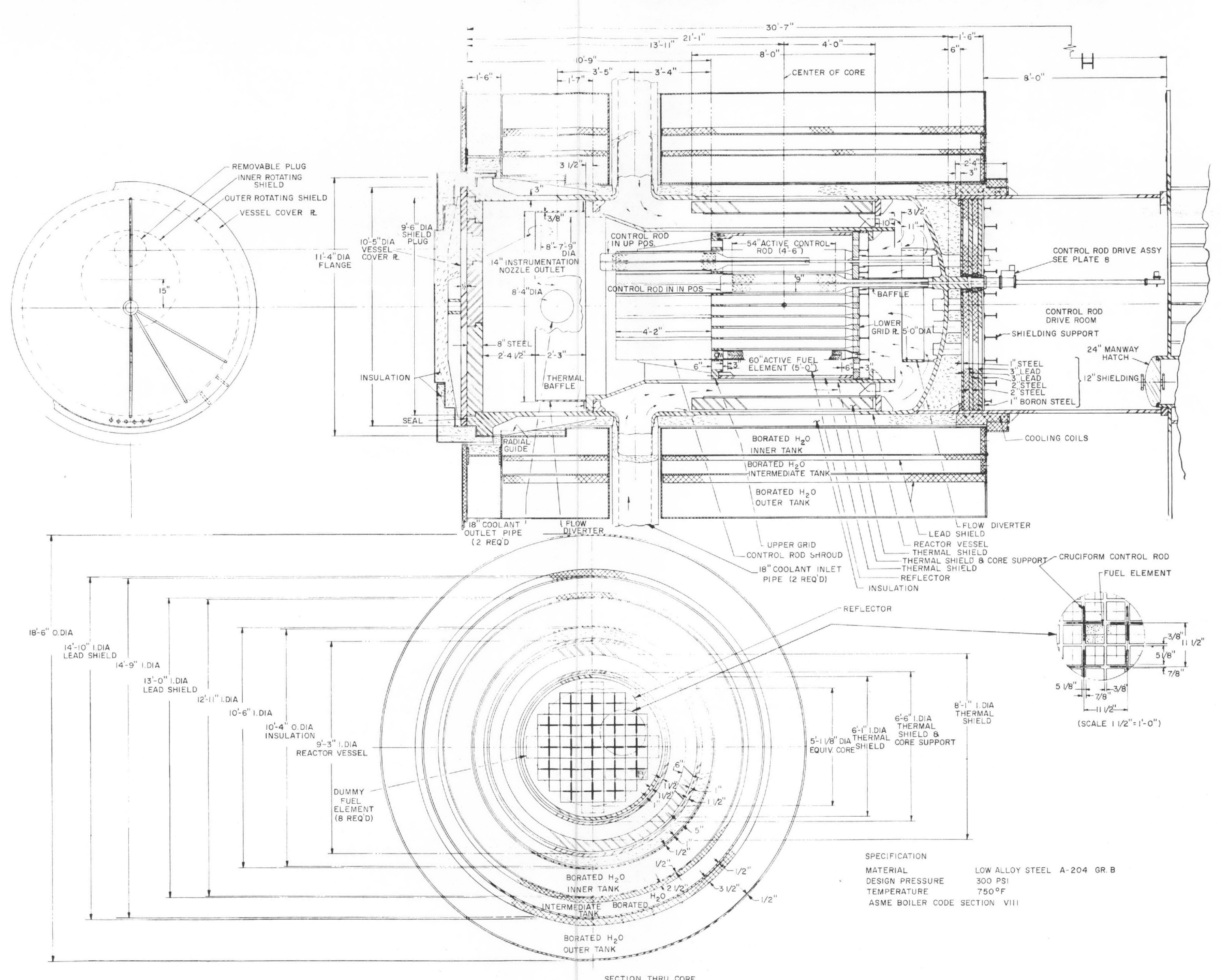

Plate VI. Reactor Vessel and Assembly 


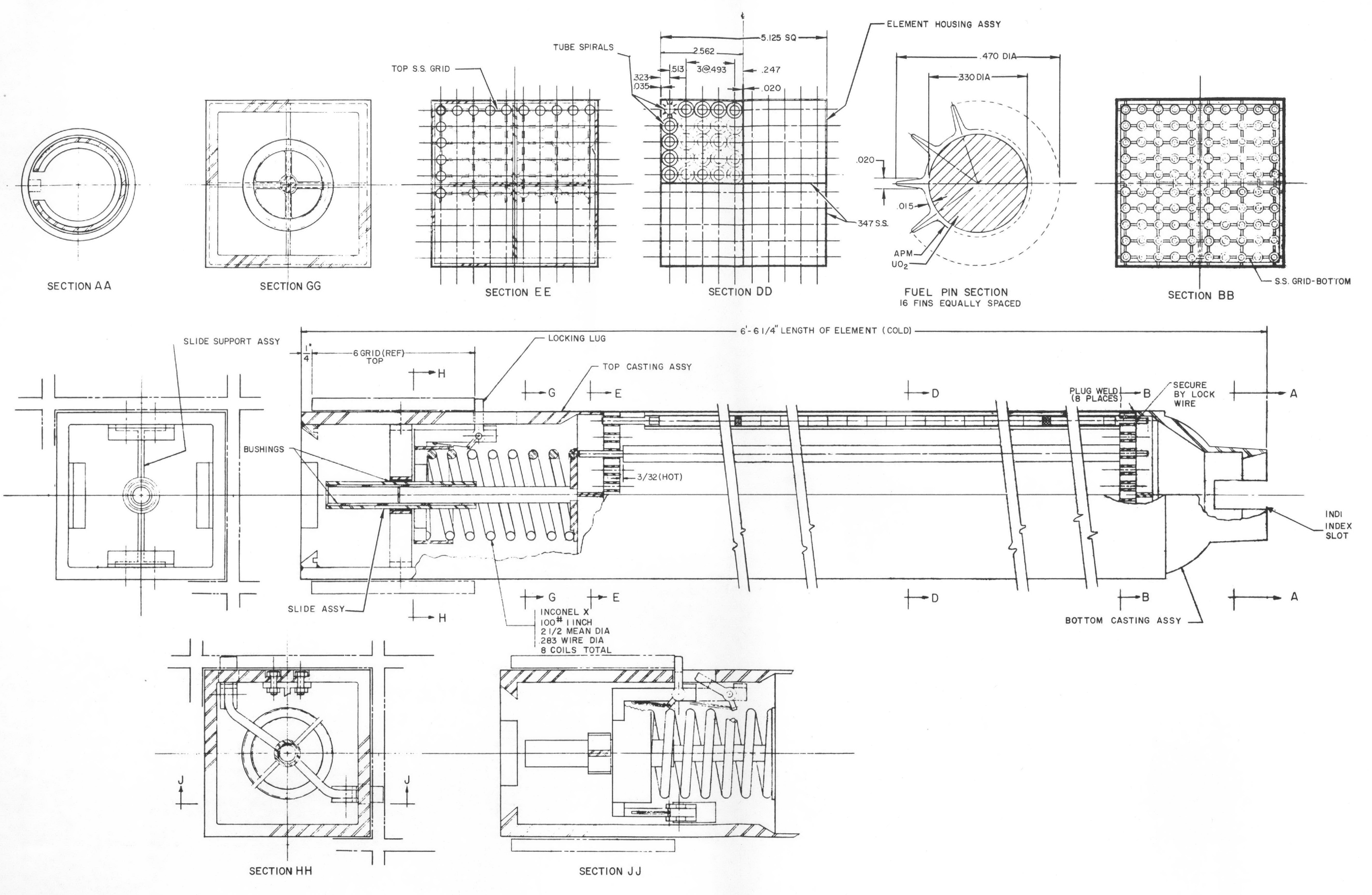




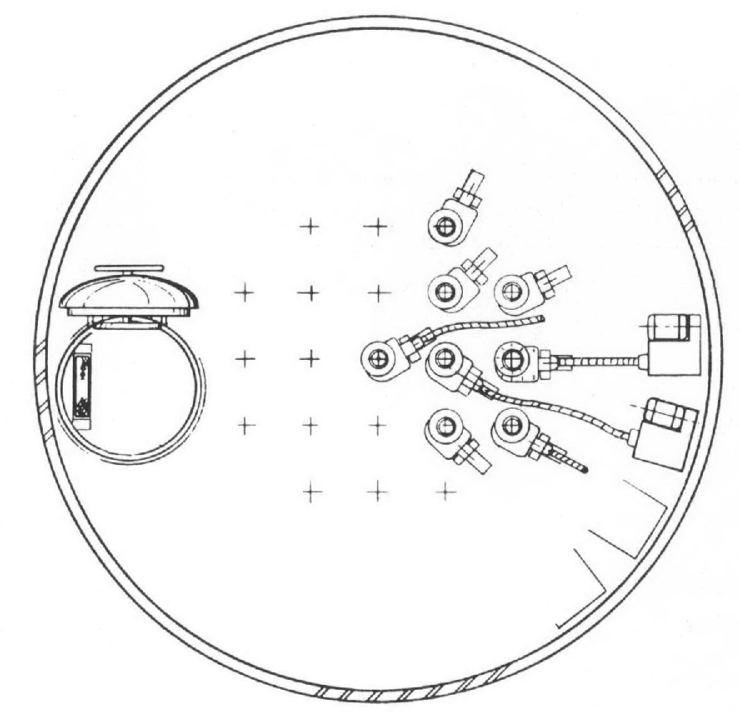

SECTION A-A
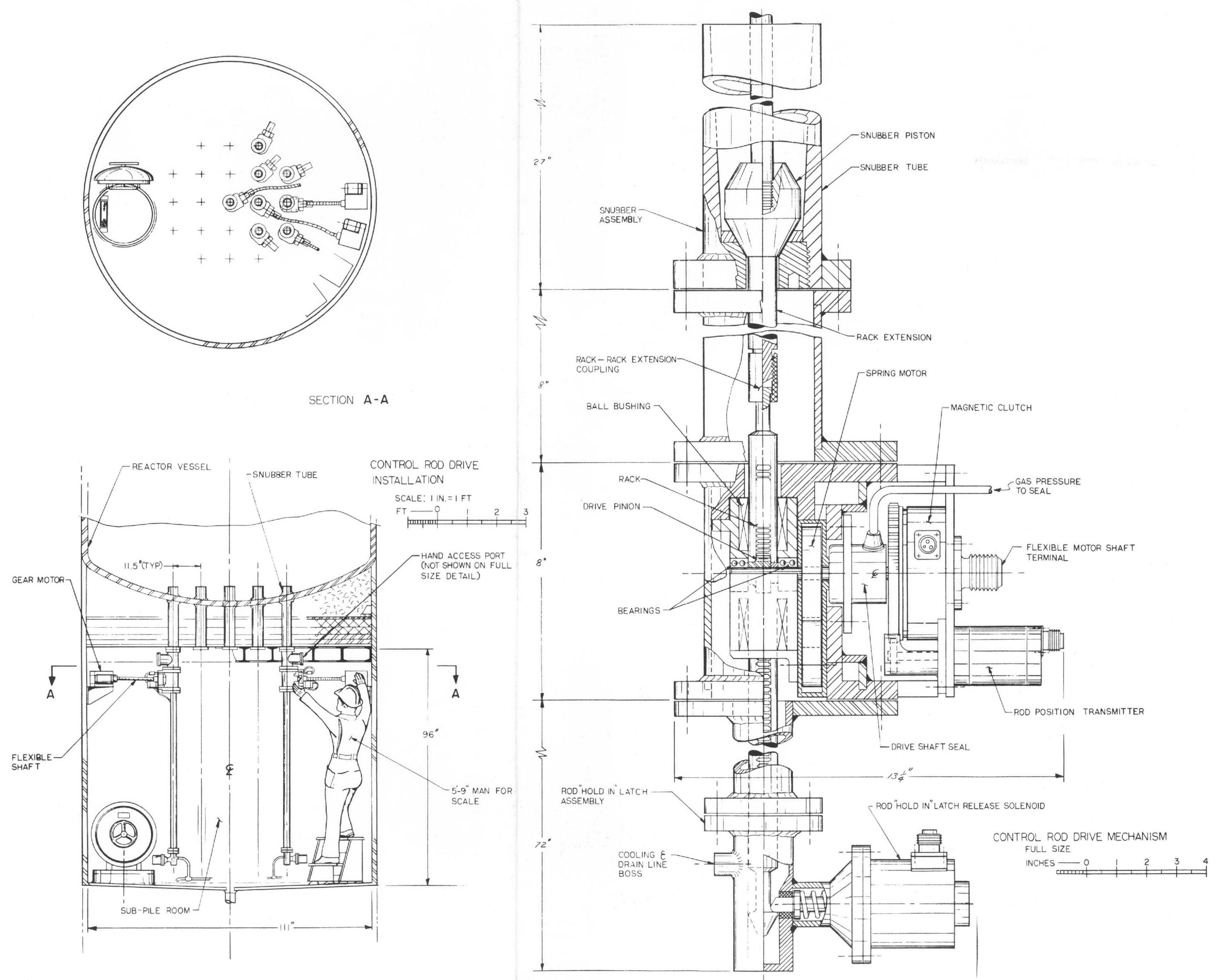

Plate VIII. Control Rod Drives 


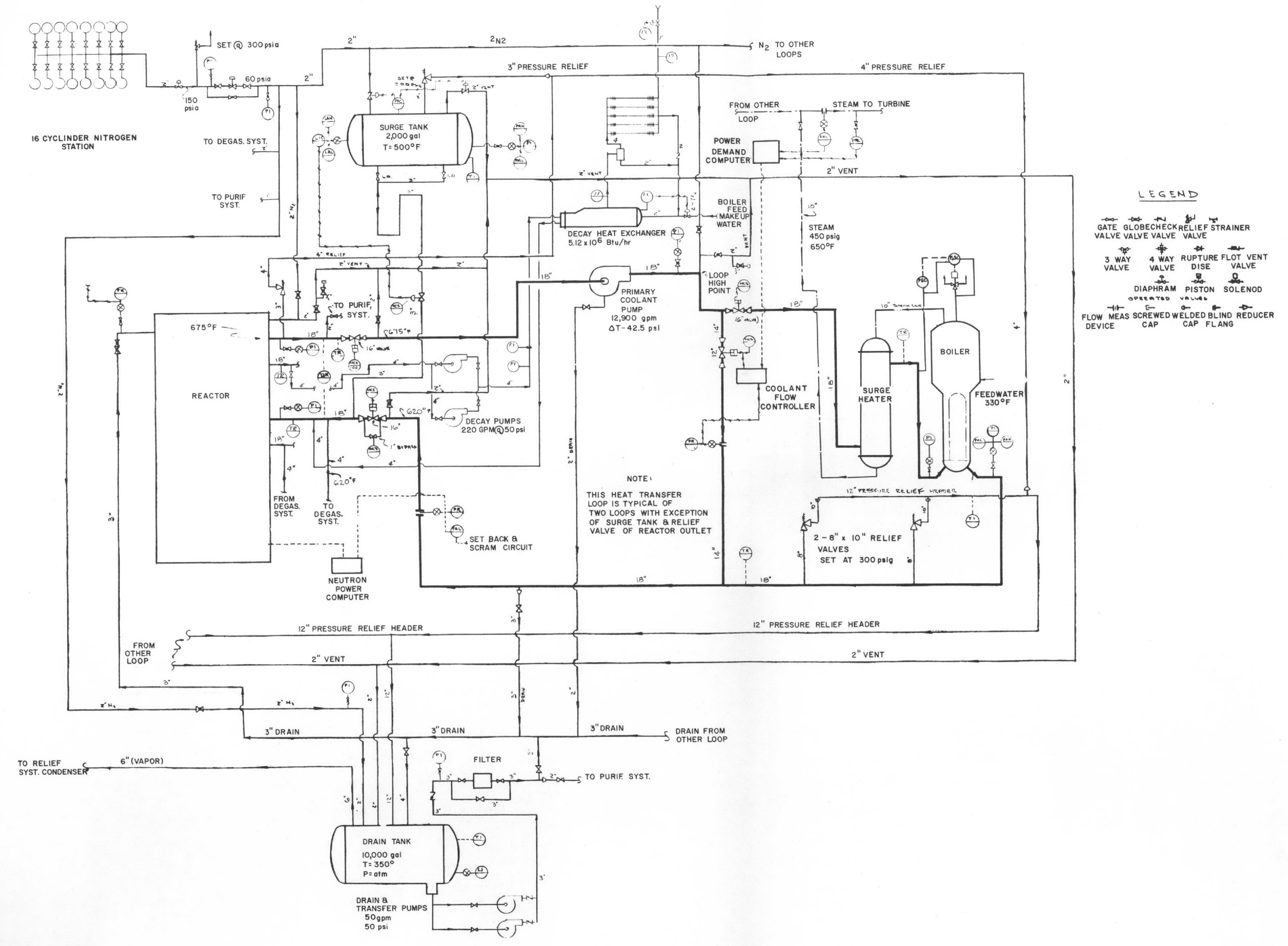

Plate IX. Heat Transfer, Drain and Vent System 


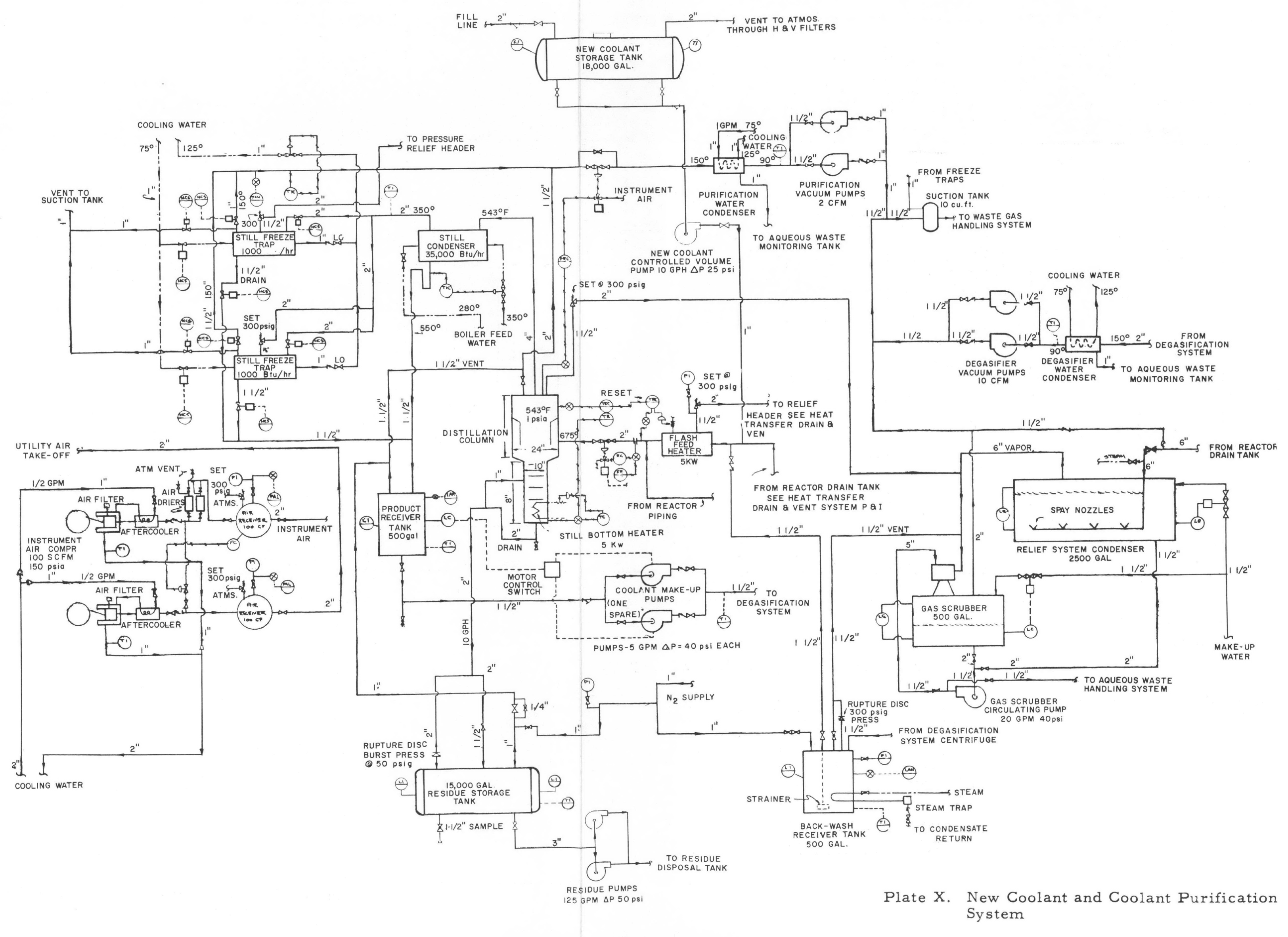




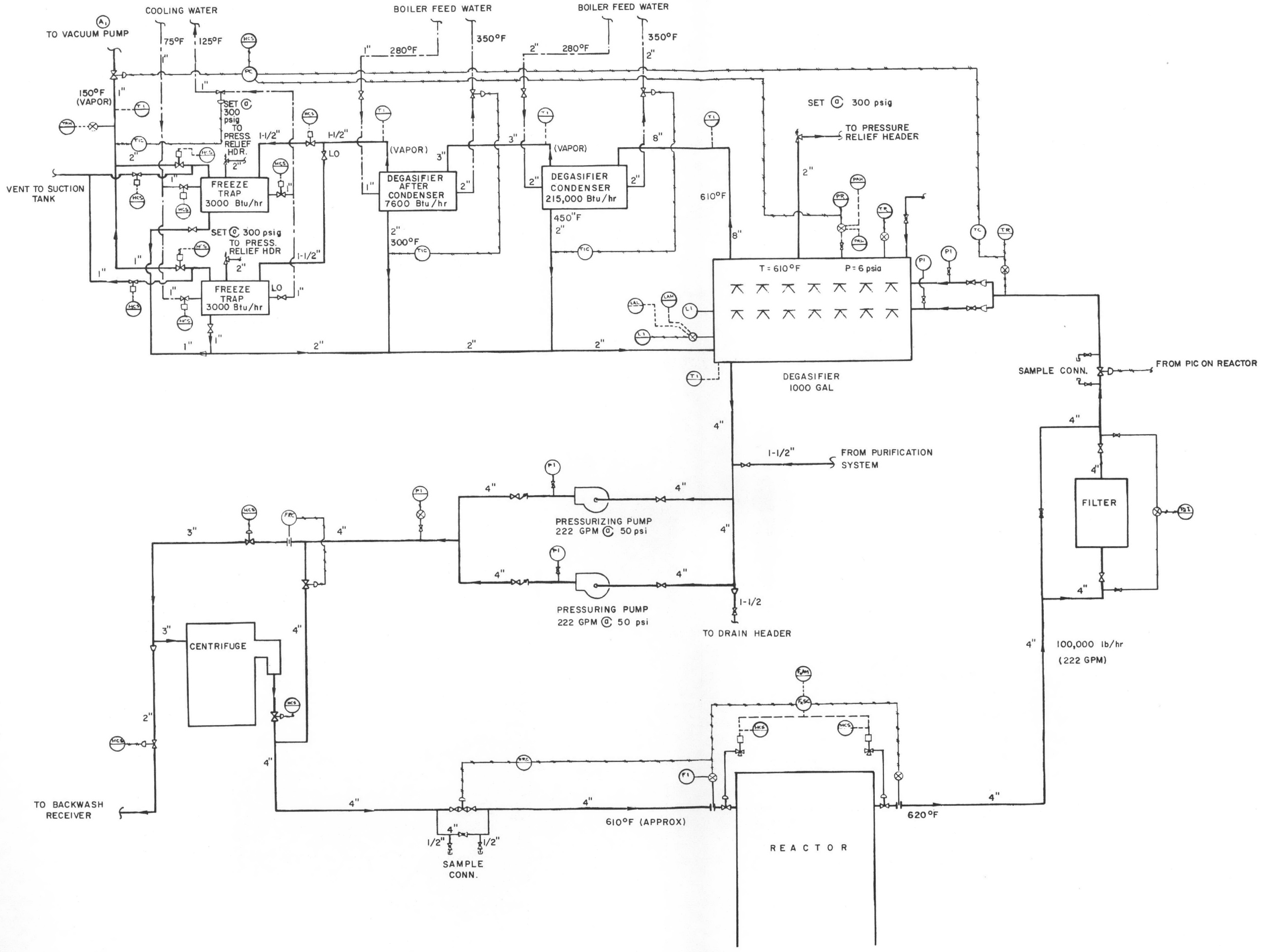

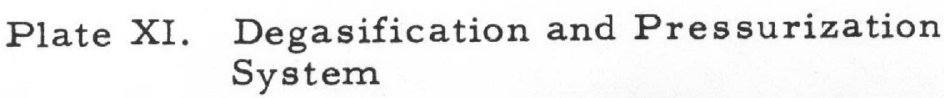




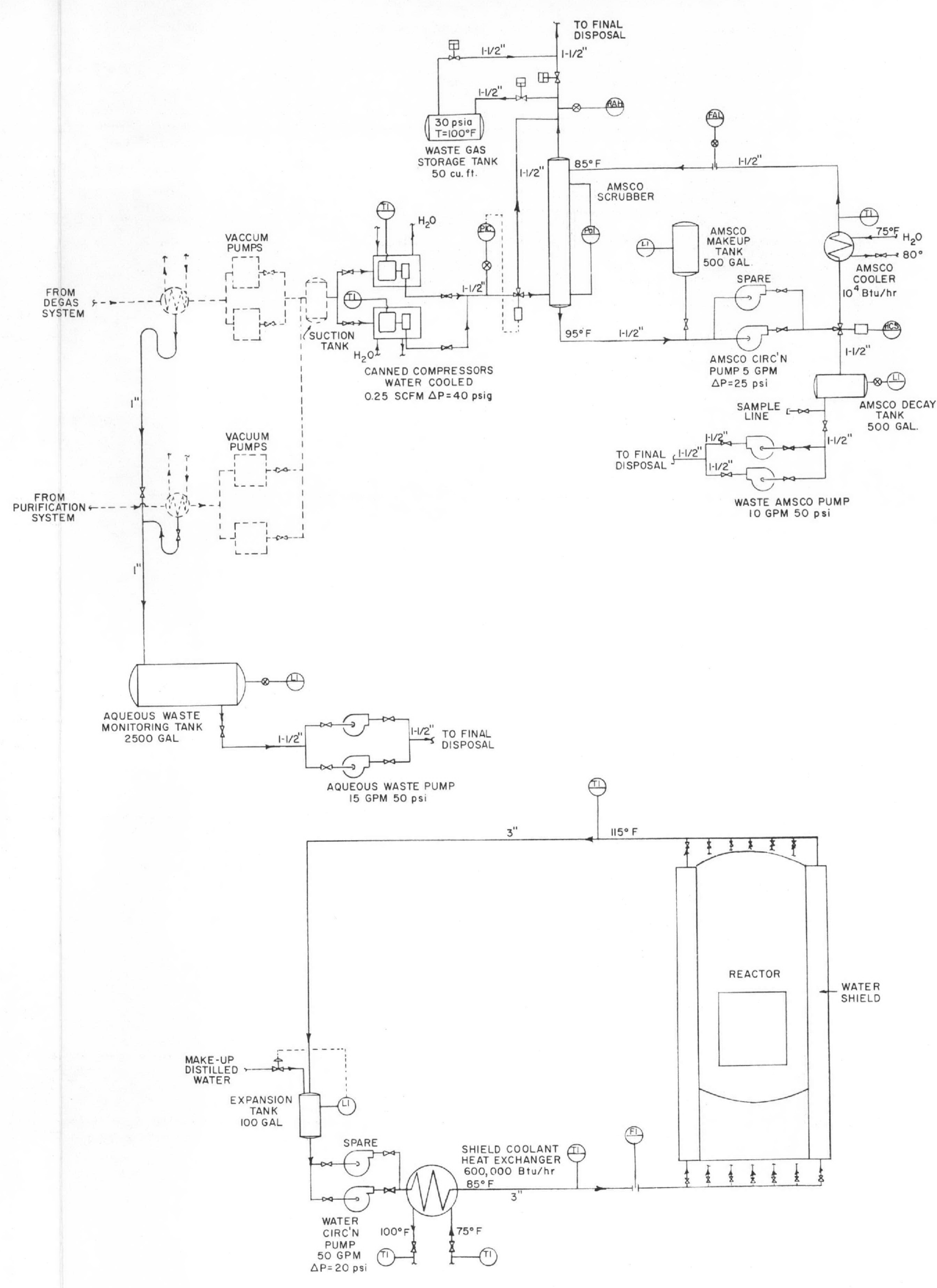

SHIELD COOLANT SYSTEM

Plate XII. Radioactive Gas, Aqueous Waste and Shield Cooling Systems 


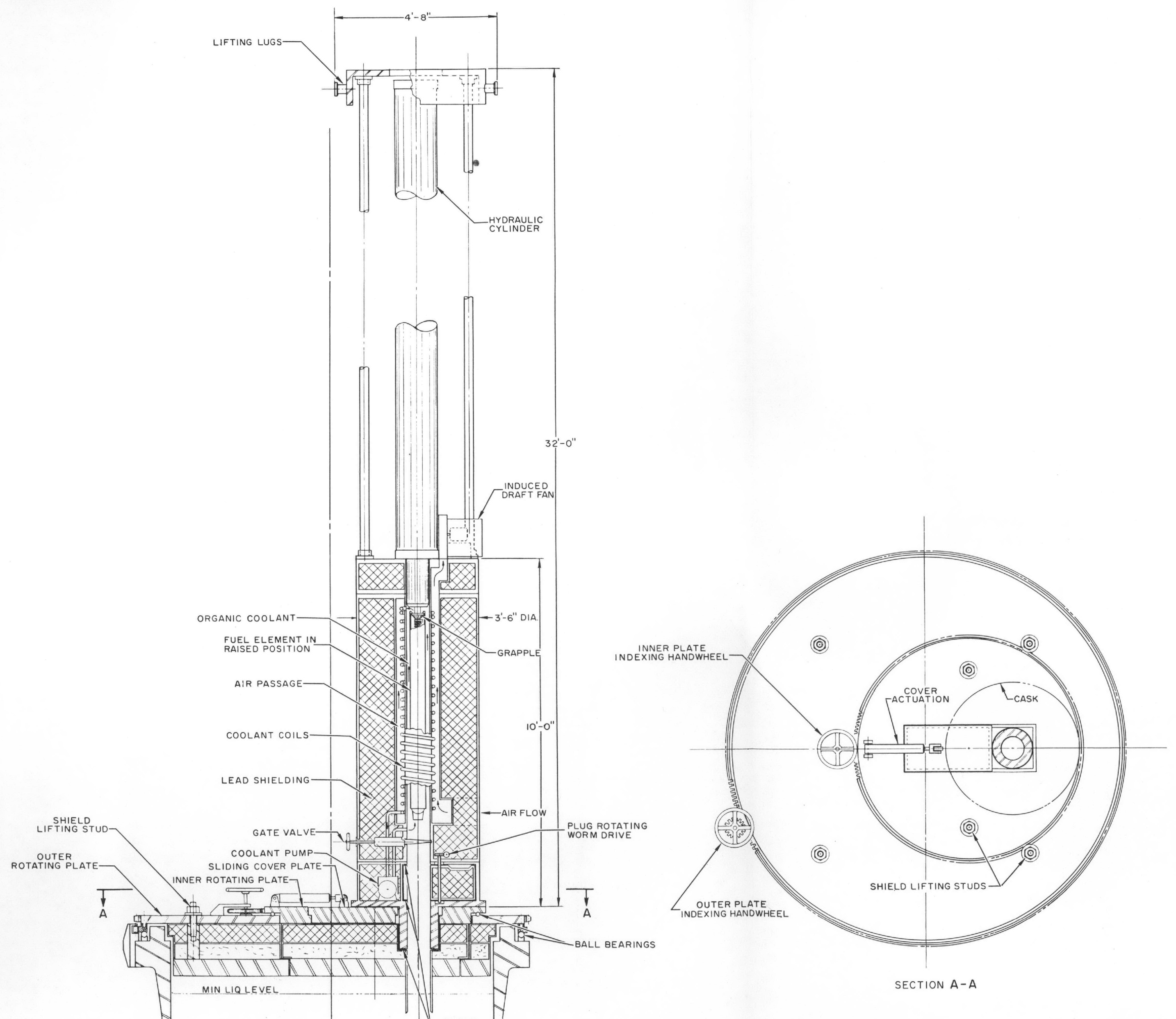

Plate XIII. Fuel Transfer Equipment 

